\title{
AT THE SERVICE OF THE UNUSUAL: WAYS TO WRITE THE BUILT ENVIRONMENT
}

\author{
BY
}

\section{PHILIPA ADAM}

A thesis submitted to the Victoria University of Wellington in fulfilment of the requirements for the degree of Doctor of Philosophy

Victoria University of Wellington

2012 


\section{ABSTRACT}

This thesis asks the question: in what ways can the language of structural engineering inform, alter and enlarge the language of fiction? My aim is to write our relationship with the built environment in ways that highlight the strangeness of surroundings that we normally take for granted in order to amplify what might usually be a muted aspect of fiction. I argue that 'strangeness' is a useful term since it suggests something of the paradox of a large built form, that it is both manifestly solid and still but also basically a machine for balancing forces that are constantly in motion.

The thesis is in two parts: a critical essay followed by a work of fiction. I use a Translation Studies framework to identify characteristics of structural engineering language. The findings of this research inform my creative work.

My research essay starts by investigating imaginative literature that expresses the built form as symbol or surface. I conclude from this review that one way of highlighting the strangeness of our built environment is to express the hidden, inner world of the built form. Structural engineers have a unique understanding of this inner world which resists the type of symbolism used in imaginative literature.

After exploring research which investigates pathways between rational and imaginative literature, I propose an analysis of the language of structural engineering to uncover characteristics which might inform my creative project. I use a Translation Studies framework, based on Gideon Toury's Descriptive Translation Studies (DTS) and Hans J. Vermeer's skopos theory, to analyse a variety of texts written by engineers. This methodology allows me to identify choices and problems engineers face in 'translating' built forms into written and oral communication. Current Translation Studies theory recognises the importance of context; therefore the discussion of my findings begins by summarising perceptions of the engineering culture, paying particular attention to writing by engineers about the engineering profession. The following three chapters deal in turn with how engineers translate features of the built form associated with: Action and Event, the Relationship between the Human and the Built, and Aesthetics or Felt Response.

I conclude my essay with a chapter which introduces my creative work, a novel called I'm Working on a Building, in which I attempt to use characteristics from the language of structural engineering to restore some of the strangeness of these structures, and to promote into view aspects of the physical world which might ordinarily figure as 
background or veiled symbol. My aim is that the fiction plays with and tests some of the ideas in the research essay rather than illustrating or enacting them. In some ways, the fiction might also contradict the theoretical observations. For example, to what extent was I able to free my work from symbolism? Is the act of writing figuratively and indeed reading a reflexive one? These and other questions raised may generate further discussion. 


\section{ACKNOWLEDGEMENTS}

Above all, this work would not have been possible without the thoughtful and generous supervision of Damien Wilkins and Andrew Charleson. Andrew's engineering knowledge and experience were vital to this project. I benefitted greatly from Damien's skill as a writer and teacher. Damien and Andrew's willingness and skill in sharing their knowledge meant this project extended far further than I could have taken it alone.

This project would not have been possible without the Victoria Doctoral Scholarship I received and the support of Victoria University of Wellington.

Many busy engineers have given time to this project and have worked hard to explain complex technologies to an extreme novice. I am particularly indebted to: Alistair Cattanach, Sean Gledhill, Chris Speed, Hendry Sutjiadi and Peter Johnstone. I am also grateful to have taken part in events organised by the Institute for Professional Engineers of New Zealand and New Zealand Society of Earthquake Engineering.

For a large part of this project, I had two groups of fellow students: my $\mathrm{PhD}$ Creative Writing cohort at the Institute of Modern Letters and the architecture and building science students at Victoria University of Wellington Architecture School. I am indebted to both. I have also had much support from my writing community who never fail to inspire me.

I would like also to thank the Institute of Modern Letters, especially Bill Manhire, the PhD Co-ordinator who was an astute and generous reader of this project, and the office administrators Katie Hardwick-Smith and Clare Moleta.

My husband Brent McIntyre was tirelessly supportive and proof-read this project. My daughter Tallulah was patient and interested.

This project started in earnest with a story about an earthquake and I cannot read any part of it now without remembering what a foreign thing such a huge event seemed less than a year and half ago. My thoughts are never far from Christchurch and my friends and family who have endured much while I worked on this project. 


\section{TABLE OF CONTENTS}

ABSTRACT

The Built Form in Imaginative Literature ..........................................................

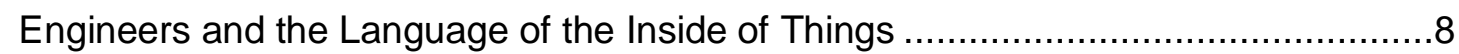

Pathways between Scientific and Imaginative Language .....................................11

Pathways between Engineering and Imaginative Language ................................13

Applying Translation Studies Theory................................................................14

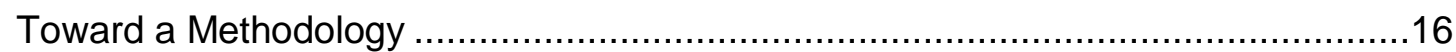

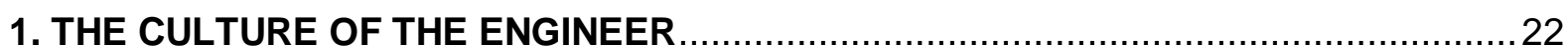

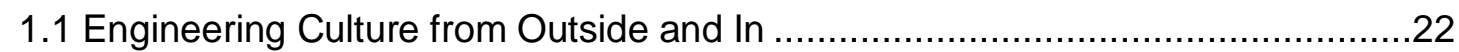

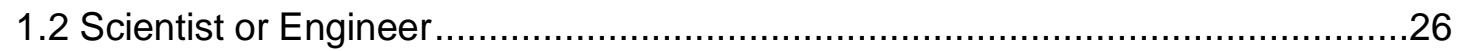

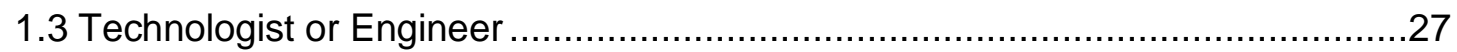

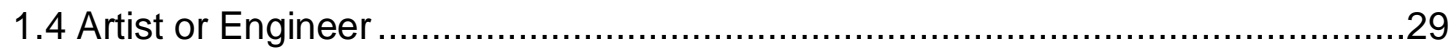

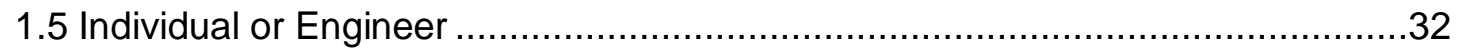

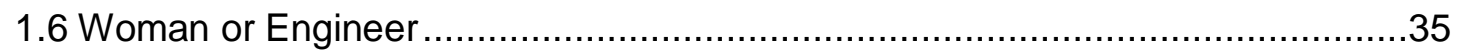

2. ALL AT ONCE AND MAYBE NEVER: SOLVING LANGUAGE PROBLEMS OF ACTION AND EVENT IN ENGINEERING WRITING

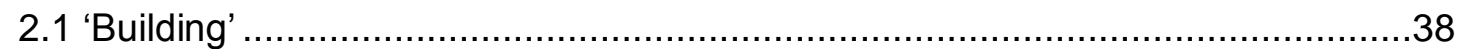

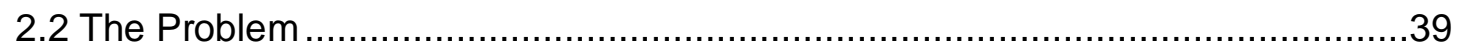

2.3 Te Puni Village Student Accommodation ......................................................40

2.4 All at Once: The Language Problem of Simultaneous Action in Te Puni Village .40

2.5 Maybe Never: Contingency in Te Puni Village ............................................43

3. NOT US BUT BECAUSE OF US: SOLVING LANGUAGE PROBLEMS OF THE RELATIONSHIP BETWEEN THE HUMAN AND THE BUILT.

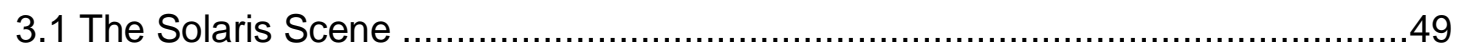

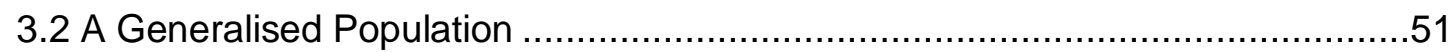

4. FELT RESPONSE: SOLVING LANGUAGE PROBLEMS OF AESTHETICS IN ENGINEERING WRITING.

4.1 Delight

4.2 Centre Georges Pompidou / Beaubourg .......................................................68 
4.3 Dà kùchă (大裤衩) Big Boxer Shorts China Central Television Centre (CCTV)

Building / 中央电视台总部大楼....

5. HOW MIGHT ENGINEERING LANGUAGE INFORM, ALTER AND ENLARGE THE LANGUAGE OF FICTION?

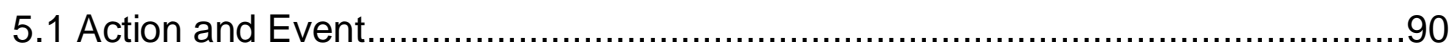

5.2 The Relationship between the Built and the Human .......................................94

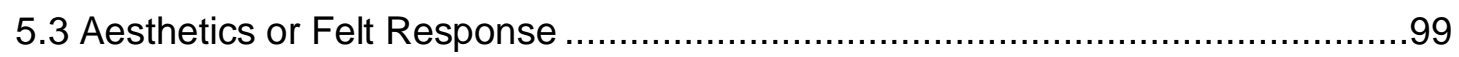

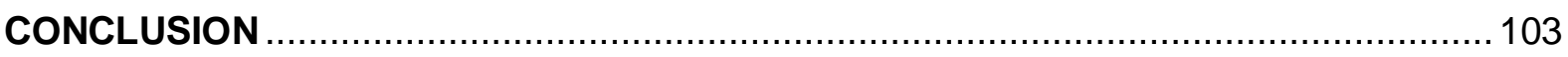

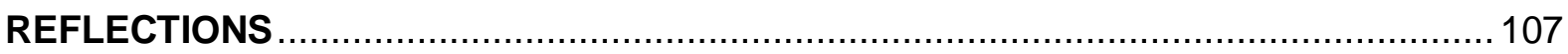

Opportunities for further study............................................................... 108

Reflections on the creative component ..........................................................109

Appendix 1: TABLES SHOWING ANALYSIS OF ASSUMED TRANSLATIONS ...........112

Appendix 2: RATIONALISED WORD LISTS FROM PRELIMINARY CONTENT

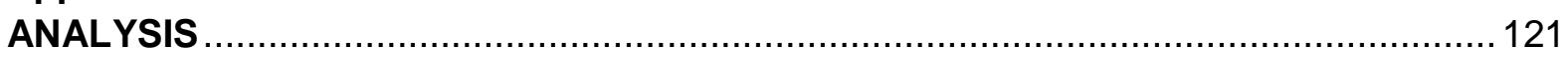

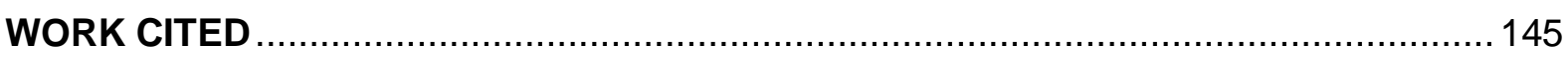

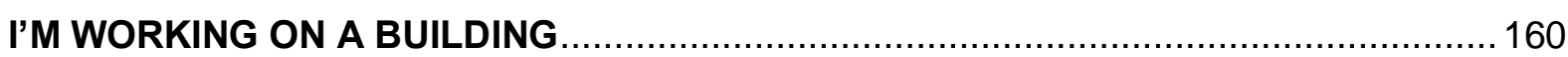




\section{TABLE OF FIGURES}

Figure 1: Image showing my notes from a lecture on soil mechanics and retaining walls and the creative work which resulted from this class (Adam Notes from Soil Mechanics

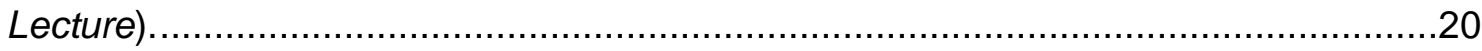

Figure 2: Creative Professions (Holtzapple and Reece 26) ......................................

Figure 3: Te Puni Student Accommodation (CISabroad) ...........................................40

Figure 4: Failure modes in cantilever walls (Johnstone and Alcantara 4) ....................51

Figure 5: Useful relationships for estimation purposes (Holtzapple and Reece 72).....53

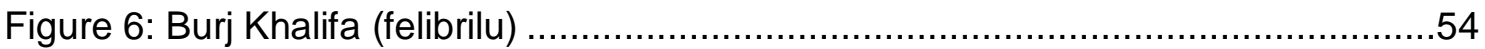

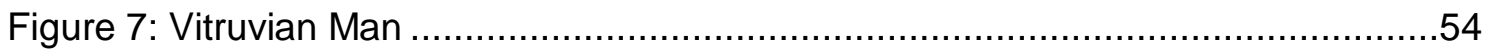

Figure 8: Typical Floor Plan (Baker, Pawlikowski and Young "The Challenges in Designing the World's Tallest Structure: The Burj Dubai Tower" 1473) ........................55

Figure 9: Comparison of Burj with other tall buildings (Baker, Pawlikowski and Young "The Challenges in Designing the World's Tallest Structure: The Burj Dubai Tower"

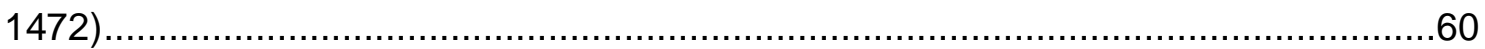

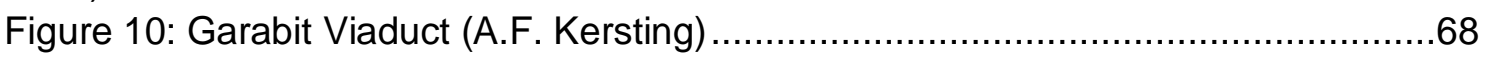

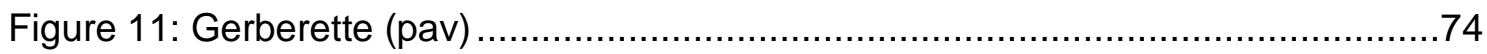

Figure 12: CCTV Building (Picture of the Day: Beijing Building) .................................77

Figure 13: Indeterminate facade building, Houston, TX - 1974 (SITE) .........................79

Figure 14: Peeling Project, Richmond, VA - 1971 (SITE) .......................................... 79

Figure 15: Notch Showroom, Sacramento, CA (SITE) .......................................... 80

Figure 16: Corner of Colombo and Tuam Streets, Christchurch (Channel New Asia) ..80

Figure 17: Best Store Sacramento ("Best Store in Sacramento, California When It Is

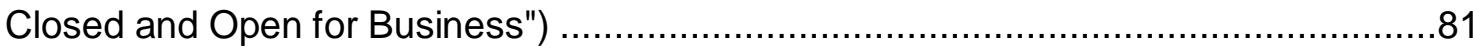

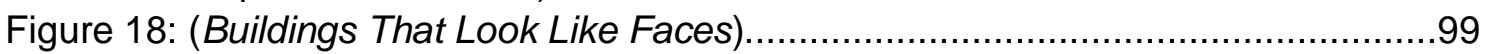

Figure 19: City Scape, San Francisco (Hirschberg) ............................................. 161

Figure 20: Centre Pompidou (Orlyg) ............................................................. 164

Figure 21: New Zealand Stock Market, Auckland (Grant) ...................................172

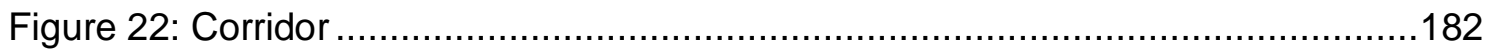

Figure 23: Auckland University Library (itsabitblurry) ......................................... 182

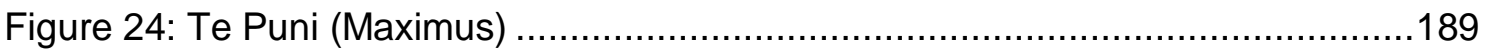

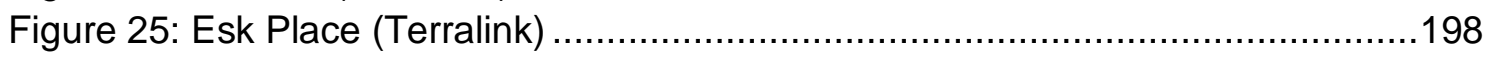

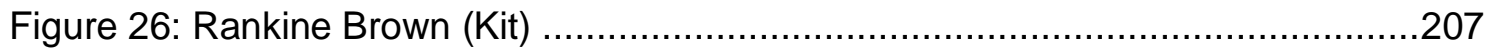

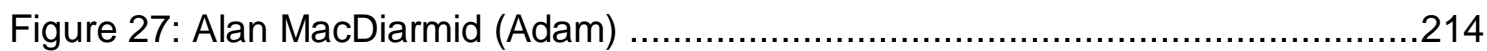

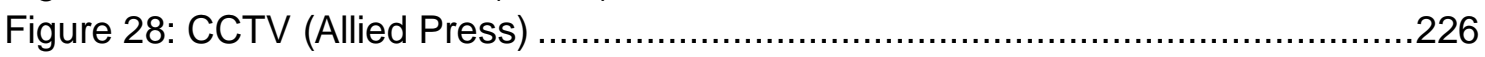

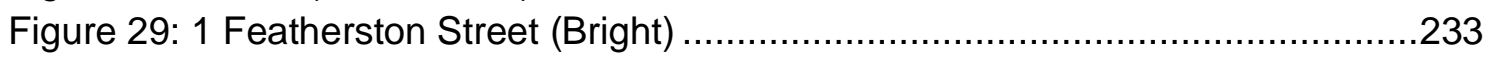

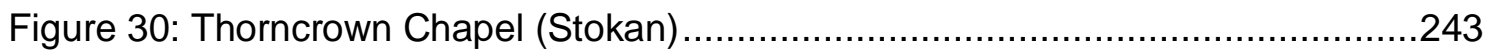

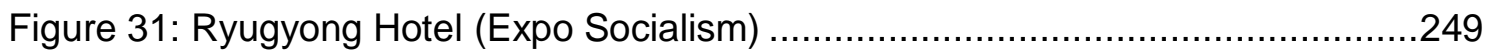

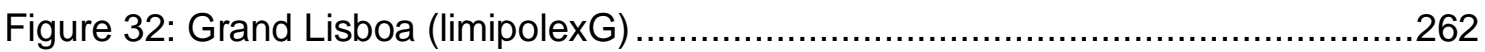

Figure 33: Soil Water Exposed Soil Substrate (Hallett, Palmer) ..............................269

Figure 34: Plattenbauten (Poikonen) ............................................................. 274

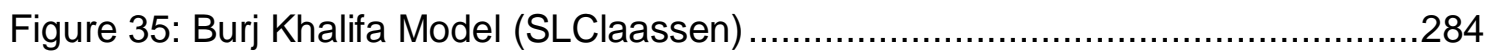




\section{INTRODUCTION}

'Architecture has always offered the prototype of an artwork that is received in a state of distraction and through the collective.' - The Work of Art in the Age of Its Technological Reproducibility. Walter Benjamin, 1935.

In 2007 I participated in the MA Creative Writing workshop at the International Institute of Modern Letters at Victoria University of Wellington. The manuscript I submitted for the completion of this degree was a collection of short stories, most of them autobiographical.

I had spent the year in a process of ordering up events and people from my past and writing down what I remembered. I quickly realised I had control over these stories. Writing fiction, my stories didn't need to be recounted exactly as they had played out. I began to change things, sometimes to protect people, often to make myself look better but always to avoid writing confessional or sentimental stories which could be read as memoir. My concentration and control was very firmly on the people and events. Oddly, the physical spaces in which these dissembled projections of my life actually took place remained largely intact. When I revised the stories, I knew the shape of things exactly. In houses, I knew just where to find a butter knife or a fresh tea towel. In restaurants, I felt the shape of the bathroom key and heard the noise of the traffic outside. When I completed the manuscript, every character sat and moved and lived in places I had; places that came to me fully-formed and complete as I re-read the work.

One of the examiners of the thesis commented, 'Smaller settings are not really elaborated on - people work in featureless offices or salons, they live in houses made up of blank rooms and fences and gardens, they drive nondescript cars'.

I read the manuscript again and the examiner was right. Because I knew the settings so completely, was so familiar with them, I had put very little effort into portraying them in my stories. They were represented in scant, heartless detail and then only when that detail would help amplify something about the people or the events I created. Of course, I reassured myself, this is where the story is - with the people. But I took cursory heed and while revising the manuscript looked around the rooms and added just enough 
detail to ensure reality and avoid abstraction.

I spent eight months revising my MA manuscript. During this time I mainly worked in the Victoria University Central Library which is located in the Rankine Brown building on the Kelburn Campus above the Wellington central business district. A couple of mornings each week I would walk up Adams Terrace, climb the steps past the University Crèche and along Fairlie Terrace. In 2008, there was a building site on Fairlie Terrace. I had a vague idea that the building was for student accommodation. I took very little notice of the actual construction but I loved the cranes.

I would try to walk as slowly as I could along Fairlie Terrace so I could see the cranes. They seemed precarious; sometimes the long arm of one would swing round in the wind. One day I saw a man climbing down from the crane. I'd seen the cabs of the cranes empty and I'd seen drivers in them but I'd never seen someone climbing down the ladder inside the tower of the crane. Even though it was the cranes that had caught my attention, I only recognised the potential for a story when I saw the driver taking this brave action. My friend Shaun had driven cranes. He had developed vertigo but continued working on high structures for a couple of years. I started to write a story about a crane driver who was scared of heights. I mentioned it to Shaun and he suggested we meet for lunch and talk about what his job was like. He was an architect now and I met him in a small park, beside a church, opposite a row of multi-storey apartment block. I sat with my back to the apartments so I could enjoy the space and the quaintness of the historic church.

The last crane-driving job Shaun had was during the construction of the Otira Viaduct in Arthur's Pass. He brought photographs of himself, the men he worked with and the bridge they were building. I looked at the men, assuming they were the heart of my story. Shaun explained what it was like, how frightening and cold. He told me men left in the middle of the night rather than work another day. I asked why it was frightening and he said how the work was high, but it was also low, they had to dig deep before they could build high and the viaduct was very high. He paused, trying to think of a way to explain it. Then he said he needed to tell me a bit about how the viaduct was built in the snow in a tiny valley bordered by huge leans of unstable schist, how they ran formwork out over nothing, cantilevered it off what they had finished only days before. I understood only a few of the words and none of the concepts, so I fell back on what I did know - poetics. When he said 'tensile strength', I listened to the music of the sibilance; 'tensile' summoned up images of flexed muscles and sweat. Shaun talked about piers, and I thought he'd said, 
'pears' or 'pairs' so I made sense of it in an image of two Victorian women eating fruit off a silver tray. I repeated the word back to him, trying to make it my own. Playing with the way it felt in my mouth. Trying to make it serve my literary aim. Then he talked about concrete: aggregate, fly-ash, slag, cement. I snatched the words as Shaun said them, thinking about all the ways I could break them and put them to work in my story. As I listened, I turned everything he said into material for my work. I nodded and took notes, hiding them so that Shaun wouldn't stop to correct me or explain further. All I wanted was the words and then only the words as I made sense of them in the context of writing.

Shaun stopped and asked if I understood. I was a shocked at the question. I felt like telling him it didn't matter whether I understood or not. My plan was to transform everything he said to suit my work; the truth behind it was his job, he was the architect not me. He had caught me off guard, though, so I said, no, I didn't understand. I knew Shaun well, and I knew he would explain again and if I wanted him to keep talking about Otira and cranes, that next time I needed to be able to give him answer which showed I was beginning to understand. So I tried to listen differently.

Shaun went back a step, did I understand about physics? Did I understand about how objects resist force? He pointed to the office blocks across the road, and explained how they stand up. He talked about the relationship concrete and steel have to gravity and ground. I looked at the buildings with an attention I'd never given any built form before. As Shaun talked and I began to understand what he was saying in his terms, I recognised the buildings as I'd never seen them before. They became odd to me. Buildings were objects for my use and when they were of no direct use to me I viewed them as shade, or obstruction, beautiful or ugly. As I listened to what Shaun was saying, everything I knew about them was being undone. Buildings became unusual to me and I realised this oddness was a lot more interesting to me than the things I'd thought about buildings before.

Throughout our discussion Shaun kept talking about engineers. At the time I had very little idea what an engineer did but it was their language Shaun was using. Instead of adapting Shaun's words into something I understood, something familiar, I wondered what would happen if I put my work at the service of the unusual. If I let the ideas and words of engineering rule my work rather than trying to force them into the shape of conventional fiction. Would I be able to recreate the odd way I had perceived those buildings on that day? 


\title{
The Built Form in Imaginative Literature
}

\author{
'Ceci tuera cela (This will kill that)' - Notre Dame de \\ Paris, Victor Hugo, 1831.
}

In the early evening of August 291907 the partially completed Quebec Bridge collapsed across the banks and into the water of the St Lawrence River. Eighty-four men working on the bridge were killed. The following morning, news of the collapse hit the front pages in New York where Willa Cather was working as a journalist and editor at McClure's, the magazine which would serialise her first novel Alexander's Bridge the following year. Since John P. Hinz's 1950 essay 'The Real Alexander's Bridge' there has been critical agreement that the collapse in Cather's novel of the fictional Moorlock Bridge, Alexander's Bridge, is based on the actual collapse of the Quebec Bridge (Quirk 155-56).

In his 1986 article, 'A Disaster in the Making', John Tarkov details the final collapse of the Quebec Bridge:

Two compression chords in the south anchor arm of the bridge had failed, either by the rupture of their latticing or by the shearing of their lattice rivets, and as the distress of mortally tortured steel spread through the entire superstructure, the nineteen thousand tons of the south anchor and cantilever arms and the partially completed centre span thundered down onto the banks of the St Lawrence River and into the water the bridge had been designed to cross (307-08).

In the same article, Tarkov writes, 'no bridge collapses quickly', presenting a number of factors which accumulated over time leading to the failure of the Quebec bridge. In the simplest terms, the Quebec Bridge finally fell because at one precise moment, $5.30 \mathrm{pm}$ on that day, it could no longer sustain the forces acting on it.

It wasn't this moment or the action of load on material which interested the novelist Cather, for despite its title Alexander's Bridge is a book about Bartley Alexander, not his bridge. Moorlock Bridge is presented as a symbol of Bartley Alexander projected into 
the physical world of the novel. As Alexander's story evolves, his bridge is transformed from a symbol of promise and victory to one of failure and demise until. Finally, the bridge collapses with him. In the world of Cather's novel, Moorlock Bridge doesn't collapse because of physics but to complete its job as metaphor for the failings of a character. Alexander's inner world transforms all his bridges, including the first he built:

The bridge seemed longer than it had ever seemed before, and he was glad when he felt the beat of the wheels on the solid rail road again. He did not like coming and going across that bridge, or remembering the man who built it. And was he, indeed, the same man who used to walk that bridge at night, promising such things to himself and the stars? (Cather 149).

This simple railway bridge made of timber and steel serves as a symbol of a promising young man's ruin. Nothing of its true nature remains in the novel. Instead it is transformed into an object which stands for the familiar human state of loss.

The powerful symbolic appeal of built forms has produced a range of literary works which use bridges, buildings, tunnels and dams to describe in material terms the inner world of human characters. The tunnel in Michael Ondaatje's 1987 novel In the Skin of the Lion alludes to repression, the hidden experiences. The bridge of Rudyard Kipling's 1920 short story, 'The Bridge Builders' suggests the difficulties of joining distinct cultures. In his epic poem The Bridge (1930) Hart Crane attempts to present the Brooklyn Bridge as a symbol of hope in the face of modernity's despair. Charles Ryder's final thoughts in Evelyn Waugh's 1945 Brideshead Revisited rest on the chapel lamp 'burning anew among the old stones' of the estate just as his new faith burns inside him (315). The symbolic power of the built form is so strong that readers and writers find it irresistible to project human experience onto these structures.

In hindsight, it's easy to see the Quebec Bridge collapse coming. The combination of human failing and cost-cutting culminated to produce an impossible structure. But on that afternoon in August, 1907 the final collapse took the people working on the bridge by surprise. Despite the visible deflection of several of the lower chords under the weight of the cantilever, work forged ahead. The people designing and building the bridge expected 
it to act the way they had calculated - the way it acted on paper. Yet deep inside the bridge it was acting in totally different ways; it was weak where they thought it strong, flexible where they thought it rigid. The Quebec bridge was anything but a projection of their thoughts or beliefs; acting of itself despite their hopes for it. Cather's novel approaches this inner world when she describes the moment of collapse but it seems the only inner world she can imagine for the bridge is a personified one. The bridge 'shrieks' and 'roars' and 'screams' so that finally no longer a symbol of Alexander it becomes Alexander himself. It is as Jean Paul Sartre describes literature's portrayal of objects, 'less a matter of observing a pebble than of installing oneself in its heart and seeing the world with its eyes ...' (From Sartre "L’Homme et les choses" quoted in Archer 9; Robbe-Grillet "Nature, Humanism, Tragedy" 68). Human experience is elevated over all others. We seem unable in fiction to present an inner world for the object which is separate or distinct from our own.

The critical and creative work of French writer and filmmaker Alain Robbe-Grillet challenges this type of representation. Robbe-Grillet articulates a distinction between human and object through an approach to imaginative expression which rejects the humanisation of objects. In his 1958 essay 'Nature, Humanism, Tragedy’ Robbe-Grillet describes this new approach as one that writes about objects rather than with them (68). He wants to escape a literature in which, 'Drowned in the depth of things, man no longer even perceives them: his role is soon limited to experience, in their name, totally bumanised impressions and desires' (Robbe-Grillet "Nature, Humanism, Tragedy" 68). He proposes an expression of objects that involves description of only what we see and can be sure of, their surface and position:

To describe things, as a matter of fact, is deliberately to place oneself outside them, confronting them. It is no longer a matter of appropriating them to oneself, of projecting anything onto them. Posited from the start, as not being man, they remain constantly out of reach and are, ultimately, neither comprehended in a natural alliance nor recovered by suffering. To limit oneself to description is obviously to reject all the other modes of approaching the object: sympathy as unrealistic, tragedy as alienating, comprehension as answerable 
to the realm of science exclusively (Robbe-Grillet "Nature, Humanism, Tragedy" 70).

Robbe-Grillet argues that only through this kind of portrayal is a realism of individual human experience possible.

This portrayal of objects which uses only geometry - outlines and distances privileges sight above the other senses. Detractors of Robbe-Grillet's work complain of the subjectivity of this approach. Robbe-Grillet counters that the subjectivity of sight, this point of view, is a powerful tool enabling him to express an individual's position in the world (Robbe-Grillet "Nature, Humanism, Tragedy" 74). In his 1957 novel Jealousy, written from the isolated point of view of jealousy, Robbe-Grillet uses the emotion to control what is seen and how, in order to tell a story through sight and no other sense.

At the centre of Jealousy is a plantation residence. Instead of using this built structure as symbol, Robbe-Grillet expresses only what can be seen. The book begins with a floor-plan of the residence and because of his externalised style the building maintains its abstraction throughout the book. In this way Robbe-Grillet breaks the symbolic bond with human experience. This break with conventional representation creates a home that is unusual enough to be noticed differently. Because of its oddness we pay it particular attention and in this attentive state we notice the clues which make it possible to read the plot and characters:

Now the shadow of the column - the column which supports the south-west corner of the roof - divides the corresponding corner of the veranda into two equal parts. This veranda is a wide, covered gallery surrounding the house on three sides, the line of shadow cast by the column extends precisely to the corner of the house; but it stops there, for only the veranda flagstones are reached by the sun, which is still high in the sky (Robbe-Grillet Jealousy: A Novel 9).

This unusual, almost mathematical language and the complete subversion of traditional tropes of narrative and character make Jealousy a powerful book. It illustrates as RobbeGrillet argues, the freedom a writer can find by refusing to take refuge in objects and 
instead shows that "To measure the distances - without futile regret, without hatred, without despair - between what is separated will permit us to identify what is not separated, what is one, since it is false that everything is double - false, or at least provisional' (Robbe-Grillet "Nature, Humanism, Tragedy” 74).

By emphasising the distinction between human and non-human, Robbe-Grillet subverts our everyday understanding of the objects we live in and around. His depersonalised approach breaks the symbolic relationship between people and things, yet gives deep insight into the human experience. But what of the inner world of the built form? Robbe-Grillet said, 'Only science can claim to know the inside of things' (RobbeGrillet "Nature, Humanism, Tragedy" 71). So what does science understand about the inner world of the built form and what part can this understanding play in fiction that aims to represent the built form in unusual ways?

\section{Engineers and the Language of the Inside of Things}

In the stories that have grown around the Quebec Bridge engineers are blamed for its collapse, and one in particular. The bridge was supposed to be the jewel in the crown of American bridge-building superstar Theodore Cooper, an elaborate and elegant legacy boasting the longest span in the world at the time. But Cooper made mistakes, grossly underestimating the dead weight of the bridge itself in his calculations. The final weeks of the bridge are remembered through historic accounts in almost epic tone. Historians recount critical and fatal misjudgements so they appear like the hand of fate frustrating any hope of success. Letters arrive late, errors go unnoticed. Even in these historical accounts the Quebec Bridge becomes a symbol of hubris. Although we can all take something from this symbolic representation, the lessons of the Quebec Bridge must be even more acute to the engineer who must ensure that what stands, stays standing.

One of the first architect-engineers was the Roman Marcus Vitruvius Pollio who wrote De Architectura around 25 BCE. Known today as The Ten Books on Architecture, Vitruvius' treatise, intended as a guide for building projects, is the only surviving book on the architecture of classical Roman antiquity. In the third book of De Architectura Vitruvius asserts that a built form must exhibit three qualities: it must be strong, useful and beautiful. Centuries later, the architect Forrest Wilson explains in his 1971 book Structure: The Essence 
of Architecture that the purpose of structure, in its simplest terms, 'is to hold the building up' (24), suggesting that if a building is not strong in its structure it is neither useful nor beautiful. This sentiment is reinforced outside engineering by German architect, Heinrich Engel, in his 1967 book Structural Systems, 'Of all component elements contributing to the existence of rigid material form - house, machine, tree or animate being - structure is the most essential. Without structure material form cannot be preserved and without preservance [sic] of form the inner organism cannot function' (15). The fundamental qualities of a large built form, which reveal its inner world are located in its ability to resist forces imposed on it in order to make it useful in a way that is, ideally, aesthetically pleasing. The structural engineer's work is inextricably connected to these characteristics.

The responsibility to keep buildings standing and the devastating consequences of failing to do so require an intense relationship with empirical rules. In the shadow of disasters attributed to human failing, engineers must be committed to producing forms sound in science rather than symbol. To succeed, they cannot be concerned with projecting themselves but must instead create a projection of those things which have been proven outside of individual experience: those repeatable laws that govern force, load and movement. The engineer needs the certainty to predict the reaction an action will create. This necessarily unsentimental, un-symbolic approach affords engineers a window on the inner world of the built form distinct from fiction's attempts to humanise or symbolise. The engineer depersonalises the bridge and instead aims to understand it in terms of science. In this way, she expresses an inner world for the built form in rational terms.

When the site engineer explained the Quebec Bridge's deflecting beams to Theodore Cooper there was a series of fatal miscommunication. Cooper assumed that work on the bridge had ceased two days before, but this was not the case. Under this assumption, Cooper wired orders that no more weight be added to the bridge presuming he was directing a continuation to the stay in construction. But the wire never reached the site (Tarkov 314) and work continued. If work had ceased 84 men would have survived.

The stakes are high when engineers talk to each other about what they build. It is a large part of their work; surveys show an engineering professional will spend 58\% of her working year communicating (Tenopir and King 158). This communication involves explaining structural form and performance under load to a range of audiences. To communicate these complex, and often counter-intuitive, ideas and forms engineers must 
capture the fundamental features of built forms in a variety of written, oral and visual languages. Engineers are constantly called upon to express in words, numbers and diagrams their unique experience with the fundamental and empirical nature of a variety of built forms.

Research into engineering discourse falls into two main categories: the first, and most prolific, investigates the processes of engineering communication, more specifically the life-cycle of information through the engineering community (Tenopir and King 7). These studies look at how information is produced, shared and retrieved. The second type of research investigates the resources produced by this communication activity and has largely been undertaken by researchers from the linguistic and rhetoric disciplines (Cheng and Mok; Makropoulos, Butler and Maksimovic; Haldar and Reddy).

Implicit in both these categories of research is an understanding of the vital role oral and written communication plays for practicing engineers, and a concern over the quality of this communication (Tenopir and King 183-84; Collins, Li and Cheung 32). Most studies conclude low quality engineering communication is a result of poor communication skills in engineers and aim to offer systems and tools to improve engineers' written and oral communication skills.

Some researchers, however, challenge the dominant idea that engineers are ineffective communicators. They suggest engineering communication is ineffective not because engineers are poor communicators but because engineering, as a language, has been captured by the characteristics of scientific discourse (Johnston, Lee and McGregor; Ahearn; Bryce, Johnston and Yasukawa). In a 1999 article presenting the results of her study into engineers' communication, A. L. Ahearn suggests that the 'sterilised, unemotional objectivity' used as persuasive device by science discourse makes engineers unable to 'demonstrate the creative thinking required in engineering in all its forms' (Ahearn 156). Researchers, arguing that engineering is a captured discourse, call for a 'broader, more discursive framework' to give engineering the 'linguistic tools' to carry out the 'self-evaluation needed for renewal and regeneration of the profession' (Johnston, Lee and McGregor 3). Johnston et al. conducted their studies in the late 1990s, and although they failed to obtain much traction, as late as 2004 researchers have called for the introduction of frameworks other than scientific to help engineers communicate their ideas more widely and effectively (Bryce, Johnston and Yasukawa). This research suggests 
pathways may be built between the rational language of engineering and diverse, possibly non-rational, language frameworks.

\section{Pathways between Scientific and Imaginative Language}

There has long been academic interest in how scientific discourse might affect creative literature and vice versa. To date, research concerning the relationship between scientific and creative discourse has focussed on the natural sciences. In his 2006 review of Noah Heringman's book, Romantic Rocks, Aesthetic Geology, about geologist Charles Lyell, Jack Morrell identifies the two main approaches research into the relationship between science and creative literature has taken:

The first and more popular examines in literary texts the uses of science and the ways in which in creative literature scientific representations of the natural world were transfigured [...] A second and less popular approach is to study science and literature side-by-side by focusing on 'interrelations' and crosscurrents between them and their common denominators and 'correlations'. This approach is called the inter-change model by Gillian Beer (614).

Examples of the first approach can be seen widely in contemporary research, including recent literary studies investigating how quantum and Newtonian physics might be used to analyse imaginative literature (Schaible; Banfield; Kinch). This type of research, where science is used as analytical tool or gateway, has been used to analyse the work of authors as diverse as Gerard Manley Hopkins, Walt Whitman, David Foster Wallace, John Updike, William Gaddis and John Fowles (Banfield; Schaible; Kinch).

The second main approach, as Morrell explains, was pioneered by Gillian Beer and the clearest examples of her inter-change model can be found in her 2000 work Darwin's Plots: Evolutionary Narrative in Darwin, George Eliot and Nineteenth-Century Fiction. Beer points out that the nineteenth century was a time when science still shared 'a literary, nonmathematical discourse which was readily available to readers without a scientific training' (Beer 4). Nineteenth century writers whose disciplines were as rational as physiology, 
mathematics and physics produced writing which could be 'read very much as literary texts' (Beer 4). Beer identifies and analyses instances where 'not only ideas but metaphors, myths and narrative patterns could move rapidly and freely to and fro, between, scientists and non-scientists' (Beer 5). She explores how Charles Darwin's wide reading of poetry and prose affected his scientific writing and identifies how the major Victorian imaginative theme of 'the grotesque, the beautiful and the wonderful' (Beer 81) can be seen in The Origin of Species by Darwin's regular intensification of the word 'fact' as 'a truly wonderful fact' or 'this great fact' or 'such a wonderful and well-established fact' (Beer 81). On the flip-side of the inter-change model, Beer examines how the imaginative writing of Thomas Hardy and George Eliot were affected by Darwin's work. She cites both authors' emphasis on the 'discordances between a woman's individuality and her progenerative role' as examples of how Darwin's theory of natural selection prompted them to re-read and rewrite 'traditional fictional topics' (Beer 213). Beer's work highlights the shift from a shared language between science and literature to a time when complexity and specialisation of science made such a shared language impossible. This split between science and humanities forms the basis of some of scholarship's most vital debates.

Starting with Matthew Arnold's 1882 speech 'Literature and Science', academics placed the humanities and sciences in opposition to one another. Academics have argued over this divide for the supremacy of one of the schools as the 'right' education for the betterment of humanity. In a 1989 essay Arthur Stinner says the best illustration of this confrontation can be seen in the Snow-Leavis controversy of the mid-twentieth century ${ }^{1}$. One commentator close to the controversy was Aldous Huxley, who, in his 1963 book Literature and Science responds, 'Snow or Leavis? The bland scientism of The Two Cultures or, violent and ill-mannered, the one-track, moralistic literalism of the Richmond Lecture? If there were no other choice we should indeed be badly off (5). Huxley rejects the view that pits science against creative literature. Instead, he sets out to explain the differences between the two disciplines and how they relate to one another.

Huxley contemplates 'what might be done by men of letters in a scientific age' (49). One of his conclusions is a call for a creative writing which embraces technological thought and language. He identifies a struggle between rendering 'theory and life, concepts

\footnotetext{
${ }^{1}$ Scientist and novelist C.P. Snow's 1959 Rede Lecture 'The Two Cultures' argued that the intellectual life of western society was split into two titular cultures: sciences and humanities. Literary critic F.R. Leavis attacked Snow's theories and Snow himself in his February 1962 Richmond Lecture 'Two Cultures? The significance of C.P. Snow'. In this lecture Leavis argues that there is no need for scientific and humanist disciplines to understand each other.
} 
and immediate experience' and advocates for a creative literature that can accommodate these two ways of seeing the world:

My own belief is that he [the imaginative writer] should try to make the best of all the world in which, willy-nilly, he has to live - the world of stars and the world of astro-physics, the world of crowded halls and the world of silence, the worlds of grey theory, green life and many-coloured poetry (Huxley 48).

Huxley states that 'For some people the contemplation of scientific theories is an experience hardly less golden than the experience of being in love or looking at a sunset' (47). These statements suggest that Huxley believes science has an aesthetic which is available to the imaginative writer for exploration and experimentation.

Few academics today argue for the dominance of art over science, or vice versa. There is more concern with how one discipline might be used to investigate the other (Schaible; Kinch; Linsey, Wood and Markman; Pluciennik; Matsuda and Tardy "Voice in Academic Writing: The Rhetorical Construction of Author Identity in Blind Manuscript Review"; Matsuda and Tardy "Continuing the Conversation on Voice in Academic Writing"; Allchin; Banfield). There seems increasing interest in the pathways between science and imaginative literature which leads to the question of whether similar interest can be seen in the pathways between engineering and imaginative literature.

\section{Pathways between Engineering and Imaginative Language}

There has been limited research into the relationship between engineering and imaginative language. Most discussion of the applied sciences falls under the heading of technology and deals with the effect of technology itself on imaginative literature, rather than the writing of technologists. Two studies do stand out in their investigation of the pathways between engineering and the humanities.

Kelly Hamilton's 2001 article investigates how Ludwig Wittgenstein's engineering training affects his later philosophical work. She argues that some of the principles and processes of aeronautic engineering practice are reflected in the philosophical doctrines of Wittgenstein's Tractatus Logico-Philosophicus (Hamilton 1). Hamilton expands and deepens 
ideas she outlined in an article published earlier in 2001, 'Wittgenstein and the Mind's Eye'. In both these articles, Hamilton suggests that the problems faced by the engineer Wittgenstein, concerning visualisation and the translation of scale model to full-scale object, influenced the philosopher Wittgenstein's Bild theory and theory of projection (Hamilton 2-3). Hamilton's research aims to identify pathways between Wittgenstein's aeronautic research and his philosophical writing.

The second study which explores directly the pathways between engineering and the humanities is outlined in Tom Moran's 2008 IEEE International Professional Communication Conference paper, 'Strong Words: The Creative Writing of Engineers'. Moran begins his conference paper by listing literary writers who have trained and worked as engineers including: Fyodor Dostoevsky, Nevil Shute, Robert Musil, L. Sprague de Camp, Robert Louis Stevenson, Kurt Vonnegut and Norman Mailer (Moran 1-2). Moran interviews contemporary engineers who have authored books of poetry, award-winning short fiction, highly acclaimed creative non-fiction and best-selling novels. He investigates their engineering education, the engineering workplace, and technical and creative writing. During the interviews authors discuss how engineering knowledge and experience translates to their creative practice and work. Moran discusses several implications of his research relevant to engineering education, including further investigation into the paths that 'connect creativity, engineering, and the written word' (9).

The pathways described in these research examples suggest a journey - a movement of 'metaphors, myths and narrative patterns' (Beer 5) between cultures. One of the key creative aims of this thesis requires movement of content and style from the language of engineering to that of imaginative prose, a project which shares many of the characteristics of translation. This prompts me to investigate current ideas in translation theory.

\section{Applying Translation Studies Theory}

Translation is usually seen as a process of replicating an original text in a second language. A translation acts as a replacement for people who cannot read the original text, as it is considered equivalent to the source. Current Translation Studies theory broadens what has been considered the 'proper' job of translation theorists and practitioners. In particular, the 'translational turn' explores the idea of translation across cultures as well as languages. This 
has led to other disciplines within the humanities adopting translation theory. Translation Studies theory is now applied to areas of enquiry as diverse as the translation of religious into secular language, migration as translational action, violence and translation, translating terror, and translation and conflict (Bachmann-Medick). Disciplines including sociology, ethnology, philosophy and cultural studies use the concepts and methods of translation studies as a framework for research. This move 'beyond the transfer of language and texts' (Snell-Hornby qtd. in Bachmann-Medick 5) which began in the 1980s has seen an increased research interest in descriptive rather than prescriptive rule-based study. This new focus moves translation studies from a search for universal rules for absolute equivalence to a concern with choices made by individual translators in particular situations to produce texts which are not subservient to their originals but works in their own right.

In the climate of the 'translational turn', research is conducted into the relationship of science and translation. Sundar Sarukkai trained in physics and philosophy and his research interests straddle the philosophies of science, mathematics and art, postmodernism and phenomenology and draws on Western and Indian traditions. The majority of his scholarship explores the pathways between the humanities and science. This research focus is explored in one of his earliest articles, 'Mathematisation of Human Sciences Epistemological Sanskritisation?', published in 1995 which explores what he calls the 'mathematisation' of humanities research'. Sarukkai investigates what he sees as the humanities' attempt to gain legitimacy by using the tropes of mathematical language in largely ritualised ways (Sarukkai "Mathematisation of Human Sciences - Epistemological Sanskritisation?" 3357). Sarukkai's research since 1995 continues to focus on how the philosophy and frameworks of science, mathematics and the arts are expressed through the languages of these disciplines.

Sarukkai's work into the relationship of science and translation culminates in two articles published in 2001. In the first of these articles he describes the connection between science and the various conceptual ideas of translation (Sarukkai "Translation and Science" 646). He describes the translation process of scientists as two-fold. First, scientists use multi-semiotic languages, such as diagrams, graphs and mathematics, to describe scientific concepts. Secondly, science is only possible because it sees the world as an original text. He

2 This concern with the relationship of science and humanities is evident in Sarukkai's 2004 Leonardo editorial about technology in art and his 2009 Leonardo editorial which argues an exploration into the relationship of art and the social sciences may offer insight into the art/science discourse. 
argues that science's response to the original-world shares common features with the concerns of translation (Sarukkai "Translation and Science" 646). The second of Sarukkai's seminal articles deals more specifically with mathematics as language and argues that applied mathematics, particularly physics, constantly shifts from one language (and culture) to another and, therefore, is best understood within the ambit of translation studies (Sarukkai "Mathematic, Language and Translation" 664). Sarukkai's ideas concerning the exchange of meaning from mathematics to language serve as the foundation for his 2003 book Translating the World: Science and Language (St Amant). His research is pertinent to my project, particularly his argument that scientific discourse reflects an attitude which places the world as an original or source document which is translated into scientific theory and writing.

At the root of engineering communication is an attempt to translate a built form into language so others can share an agreed vision of what that built form is. As structural engineering becomes more and more specialised, this agreed vision is more important, as is adherence to an agreed cultural language. The characteristics of the agreed language of engineering offer insights to the distinct inner world of the built environment. To identify these characteristics I turn to the work of Gideon Toury who attempts, through his framework Descriptive Translation Theory (DTS), to identify choices made by individual translators when approaching individual texts. Toury claims these choices can best be seen through the solutions a translator finds to problems apparent in the source text. He suggests that these solutions can be described as norms which he defines as 'regularities of translation behaviour' (Toury 206).

Toury's work prompts me to explore the possibility of using DTS to identify norms in engineering texts.

\section{Toward a Methodology}

Descriptive Translations Studies (DTS) is the branch of translation studies used to test, refute, modify and amend the theory of translation (Toury 1). DTS involves the study of corpuses, or sets of translation problems, in order to explain and predict choices made during the process of the translation. James S. Holmes first identified DTS in 1972 as a means to analyse existing translated texts in order to explore retrospectively the processes used by translators (Toury 7). In his seminal work Descriptive Translation Studies and Beyond 
Toury develops Holmes' idea by proposing a systematic methodology for DTS to ensure that individual studies could be subjectively tested, compared and repeated (Toury 70-86). Toury proposes a process for conducting DTS research. The steps of this process follow:

\section{Identify assumed translation texts}

Toury advocates identifying assumed translations as the first step in a descriptive study. $\mathrm{He}$ identifies criteria for judging a text's status as an assumed translation, including: the text's presentation as a translation, its exhibition of characteristics associated with translation, and the knowledge of a text in another language which the translation has replaced (70).

\section{Explore assumed translations in terms of their acceptability}

Toury recommends the assumed translation be analysed in terms of its acceptability in the system of which it forms a part (71). This is a measure of how well the translated text sits in the context of the receiving culture and how it is accepted by that culture.

\section{Compare assumed translation with various parallel texts}

Toury suggests 'several types of comparative work, which may add a dimension to the account of the texts' [assumed translation's] acceptability' (72). Toury recommends two types of comparison:

Comparison of various parallel, or similar texts in one language, e.g., A German translation of Shakespeare is compared with other German translations of Shakespeare. Comparison of various parallel texts in other languages, e.g., A German translation of Shakespeare is compared with a French translation of Shakespeare.

\section{Identify appropriate source text}

Toury states that the identification of a source text is often problematic and in some cases a multitude of candidates for a source text may exist (74). He suggests that it is up to the researcher to justify her selection and that this justification may form part of the comparative analysis itself (Toury 74).

\section{Compare segments of target text with segments of source text}

The main purpose of this step is to identify and describe solutions used in the assumed translation to problems apparent in the source text. In this way it is possible to investigate 
the translation relationship between the two texts and to identify norms used to make it possible to represent the source text in the translated text's language. Toury explains that the translation relationship can best be analysed at the level of textual segments (77-78). These segments are corresponding sections which demonstrate a particular translation problem and its solution in the assumed translation.

DTS has been criticised for its rigidity and it has almost exclusively been applied to analysis of literary translations. Both these factors became issues when I conducted a pilot test. While imaginative literature may be produced by an individual writer in isolation from other activity, engineering texts are usually created as by-products of engineering work. To analyse engineering communication as a translation activity I require a methodology which recognises that 'the linguistic form of the target text is determined by the purpose it is meant to fulfil' (Schaffner 115). While DTS is helpful as a framework to analyse language traits, I needed to temper it with a methodology which takes into account the real-world activities surrounding and producing the engineering texts.

Hans J. Vermeer's skopos theory offers a framework based in function and action and is well suited for non-literary text types. The word skopos is used for the 'purpose, aim, goal or objective of a translation' (Schaffner 117). Vermeer suggests that generally, 'it must be the intended purpose of the target text that determines translation methods and strategies' (Schaffner 117). Once identified, the skopos of a text can be used first, to gauge the acceptability of engineering texts in the culture they are presented to and secondly, to explore reasons for the expressive choices made by engineers when creating these translations.

Using this adapted methodology, I identified a selection of engineering texts as assumed translations by evaluating them against the criteria outlined by Toury. Next, I explored these assumed translations in terms of the degree to which they are acceptable to the audience they were written for. As part of this process I identified the skopos or purpose of each assumed translation which enabled me to evaluate the translation's acceptability in the context of the activity or event which surrounded it. I compared each assumed translations with various parallel texts. These parallel texts included texts produced about the same building as the assumed translation for a variety of purposes by engineers and non-engineers.

It was then necessary to identify an appropriate source for the assumed translation. 
As Toury states, even in literary texts source is often problematic and in some cases a multitude of candidates for a source text may exist (74). When an engineer designs structure for a building this design is based on architectural drawings or sketches, so the immediate source text appeared to be these drawings. However, in all cases but one ${ }^{3}$ the assumed translations replace or stand in for built structure which exists physically in the world ${ }^{4}$. Therefore, I identify the building itself as the source document. I justify this choice by asserting that although drawings and other documents produced as part of the design process could be partial sources, the building itself is a consolidation of these other texts and therefore the most complete and extant source to the translations. In all cases the source is a physical object which is translated into written and spoken English.

Once I identified a source for the assumed translations I was able to compare segments of the source with corresponding segments of the translations. The main purpose of this process was to identify characteristics of the source which were not easily translatable. Toury identifies these characteristics as 'problems apparent in the source' (Toury 74). He suggests that a translator will make a choice when faced with these problems which the translator believes will be the most acceptable to the culture $\mathrm{s} /$ he is presenting the translation to. I believe that by uncovering the problems engineers face when translating built form to written and spoken language I am able to analyse the language choices they make in order to solve these problems. These solutions give me insight to the characteristics of engineering language. I am then able to assess the ways these characteristics might inform, alter and enlarge the language of fiction. To make an accurate assessment it is necessary for me to continue to write works of imaginative fiction to experiment with the features of engineering discourse I am uncovering in my analysis ${ }^{5}$. Therefore, a degree of reciprocity will exist between my creative and critical work; my creative work often as much an engine for my crtical as vice versa.

\footnotetext{
${ }^{3}$ Johnstone, Peter, and Pablo R. Alcantara. No. 1 Featherston St. Building 05-294. Wellington: Romulus Consulting Group, 2007. Print.

${ }^{4}$ In some cases the building was not complete at the time the assumed translation was published. In these cases I have concentrated on the sections of the texts which translate the structure complete at the time of publication and identify this as the source.

${ }^{5}$ I tested the standard of this work by submitting it to literary journals for publication.
} 

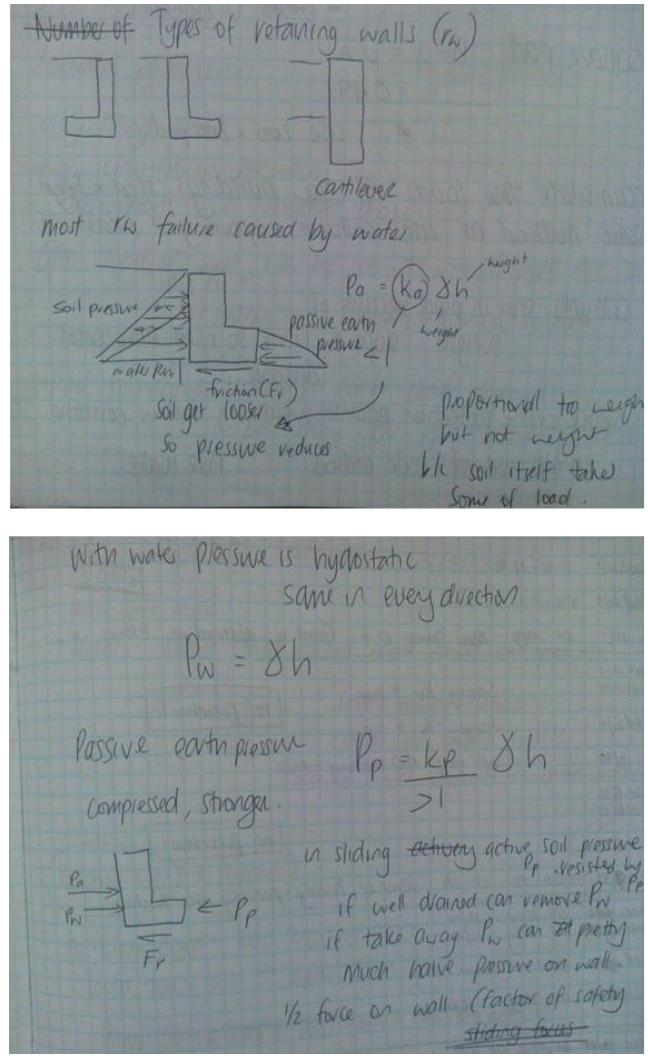

Figure 1: Image showing my notes from a lecture on soil mechanics and retaining walls and the creative work which resulted from this class (Adam Notes from Soil Mechanics Lecture).

My aim is not to redefine translation studies. I am using this framework as a tool to explore the nature of engineering language. I am aware that when I talk about the act of translation in this study I am referring to what would normally be called engineers writing and speaking about buildings but I believe that the broadening application of translation studies makes it possible for me to use this methodology to achieve the aims of this project. Further, I believe the results this process has produced suggests it is an appropriate model for the analysis of non-literary language.

Using this methodology I identified and analysed 63 texts written by engineers about eight buildings $^{6}$. My essay deals with the three features of built forms which are difficult to translate to written and spoken language. These are the problems associated with: Action and Event, the Relationship between the Human and the Built, and Aesthetics or Felt

\footnotetext{
${ }^{6}$ For a summary of how this methodology was applied please see Appendix 1: Tables Showing Analysis of Assumed Translations.
} 
Response. Although I identified other problems I believe these three are the most useful to my aim of discovering ways that engineering language might alter, inform and enlarge the language of fiction and offer the most scope for my fiction which aims to highlight the strangeness of surroundings we normally take for granted.My essay dedicates a chapter to each of these. In each chapter I identify and discuss the problem as it presents itself in the built form and the solutions chosen by engineers to make translation possible. I follow these chapters with a discussion of my findings in the context of fiction. My conclusion includes opportunities for further study and reflections which I hope will act as a bridge to my creative work, I'm Working on a Building, a novel which follows.

Both Toury and Vermeer recommend exploring a translated text in terms of its acceptability to a receiving culture. Most of my selected texts are written by engineers for engineers. Therefore I begin this essay with an investigation of the culture of engineering. I present this investigation through a discussion on perceptions of the engineering culture expressed in writing from outside and inside the engineering profession. 


\section{THE CULTURE OF THE ENGINEER}

The machinery was always pounding away in this man, and Wilson preferred companions of a more reflective habit of mind. He could not help feeling that there were unreasoning and unreasonable activities going on in Alexander all the while; that even after dinner, when most men achieve a decent impersonality, Bartley had merely closed the door of the engine-room and come up for an airing. The machinery itself was still pounding on - Alexander's Bridge, Willa Cather, 1911.

To analyse the language of engineering in a Translation Theory framework, it is necessary to explore the culture this language is created in and for. This chapter outlines the results of my research into the engineering culture and shows the assumptions I used when judging the acceptability of the texts selected for my study. I begin by discussing perceptions of engineers found in writing outside the engineering community. Then I focus on writing by engineers about their profession. Particularly, I discuss how these engineer writers attempt to define their identity in comparison with other professions.

\subsection{Engineering Culture from Outside and In}

My discussion of popular images of the engineer begins in Hollywood. The 1974 film Towering Inferno is perhaps the quintessential disaster movie. It tells the story of an imagined tallest building in the world that, through cost cutting, has become a burning death trap. Steve McQueen plays the hard-talking and courageous Fire Chief Michael O'Hallorhan, and Paul Newman the talented and highly-principled architect, Doug Roberts. Roberts is paired with the elegant and sexy Sarah (Faye Dunnaway). As well as being stylish and attractive he is also strong and brave. The movie includes two engineers.

The electrical engineer, Roger Simmons, played by Richard Chamberlain, is the villain of the film. It is his shifty cost cutting on the wiring of the tower which has caused the fire and the malfunction of the emergency services. Simmons is an unrepentant coward. He spends most of the fire drinking. When he acts it is to push people off a breeches buoy attempting to ensure his safe escape. Instead of safety he plummets to his 
just demise. The other engineer appears toward the end of the film, when all attempts by O'Hallorhan and Roberts to contain the fire or rescue the hundreds of people trapped in the building have failed. Someone important-looking approaches O'Hallorhan in the foyer of the building saying they have a plan. O'Hallorhan, sooted and rugged, walks to a desk where a man in glasses and a clean white shirt and tie, despite the late hour, sits in front of large sheets of paper. One of the men explains to O'Hallorhan that the engineer believes there is only one way out and they proceed to explain the plan. All the while, the engineer flicks and shifts the pieces of paper in front of him:

\section{BOSS}

Johnson's a structural engineer. Tell the chief your calculations.

\section{JOHNSON}

The structural strength of the joists in that room could definitely withstand the explosion.

\section{O'HALLORHAN}

What explosion?

\section{FIREFIGHTER}

Chief, we've got the copter ready.

\section{O'HALLORHAN}

Wait a minute. We'll handle that.

Just get back to your job.

\section{FIREFIGHTER}

Yes, sir.

$$
\text { O'HALLORHAN }
$$

What explosion?

\section{JOHNSON}

We can blow the tanks two floors above the Promenade Room. They hold gallons of water. That's enough to drown the fire.

\section{O'HALLORHAN}

You're crazy. 
Mike, it's the only way.

O'HALLORHAN

You could kill everybody up there.

JOHNSON

I don't think so.

\section{O'HALLORHAN}

You don't think?

$$
\text { JOHNSON }
$$

When you take into account the stress factors, the design...

\section{O'HALLORHAN}

Wait a minute. Just hold it.

$$
\text { BOSS }
$$

We've already made the decision.

\section{JOHNSON}

Someone has got to go up there, rig the charges and blow them.

\section{BOSS}

There's only two people qualified for that. You and Conners. They just brought Conners down. He's on his way to the burn centre. Under the circumstances, we can't order you to go up there. I'm just laying it out for you.

\section{O'HALLORHAN}

But you...

\section{BOSS}

You see how it is, don't you?

O'HALLORHAN

How do I get back down? Oh, shit!

(Silliphant)

And so O'Hallorhan embarks on a suicide mission to do dirty work for a fastidious paperpusher in order to put right the work of an evil technologist. 
In 1968, Samuel C. Florman, published Engineering and the Liberal Arts: A Technologist's Guide to History, Literature, Philosophy, Art and Music. Florman, a civil engineer, advocates for the liberal arts education of engineers. He offers several 'bridges' over which the engineer might enter the liberal arts. One is the 'Bridge to Literature'. Florman suggests that engineers might be interested in, 'seeing where our own profession appears in the literature of our age? How are we engineers depicted by our literary contemporaries? What image do we project?' (Engineering and the Liberal Arts 74). He offers a thorough survey of engineers in literature. Beginning with the work of Rudyard Kipling and Harold Bell Wright, he uses a Wright quote as an example of the representation of engineers by this school of writer:

All were strong, clean-cut, vigorous specimens of intelligent, healthy manhood, for in all the professions, not excepting the army and navy there can be found no finer body of men than our civil engineers (Harold Bell Wright quoted in Florman, Engineering and the Liberal Arts 77).

Florman turns to contemporary writing, where engineers appear infrequently and when they do it is 'as a symbol of all that seems to have gone wrong with the world in this age of technological splendour and spiritual decay' (Engineering and the Liberal Arts 77). Florman's survey of literature shows again and again the engineer as either hero or villain. He is writing as an engineer for engineers and encourages his audience to consciously build an identity for the profession which is distinct and notable.

In many texts the engineer aims to find his place by comparing and contrasting his profession with fields better defined in the public mind. The motivation for this seems two-fold: the engineer compares in an attempt to associate engineering with the authority and public understanding of other professions but she also contrasts in an attempt to distinguish engineering.

In this chapter I present part of the story of the culture of engineering in this way, exploring in turn: Scientist or Engineer, Technologist or Engineer, and Artist or Engineer. I follow this with an investigation of the place of the individual in the engineering profession.

Any discussion of engineering culture is incomplete without mentioning the female engineer. Women are conspicuous by their absence in the engineering professions. I 
conclude this chapter with a discussion of women in engineering, a topic which has been researched extensively by others yet still offers areas for further investigation. I discuss this topic with reference to the decision to place a female engineer at the centre of my creative work.

In discussing the culture of engineering I limit myself to texts written by engineers, in order to present a survey of how engineers see themselves. I think the discussion shows stereotypes about engineering culture are complicated by close reading of work written by engineers about their community. Texts from inside the engineering profession present a more nuanced cultural identity than those written from outside.

\subsection{Scientist or Engineer}

Engineering is generally recognised as an applied science and this link to science can be seen in the language of structural engineering.

In his 2009 rhetorical analysis of engineering texts, Louis L. Bucciarelli, Emeritus Professor of Engineering and Technology Studies, Massachusetts Institute of Technology, identifies several traits of scientific language present in engineering texts:

Like science, engineering texts are written as if they were timeless and untainted by socio-cultural features. However, a technical treatise is not devoid of metaphor or creative rendering of events; there is always a narrative within which worldly data and instrumental logic is embedded - but it is a story in which the passive voice prevails, history is irrelevant, and the human actor or agent is painted in quantitative parameters fitting the occasion. (333).

It has been argued that engineering uses traits of science discourse as a persuasive tool to give authority to what engineers have to say (Ahearn 156) and, as Florman points out, the application of scientific principles and alignment with the natural sciences was instrumental in the birth of engineering as a profession (The Existential Pleasures of Engineering, $\mathrm{x}$ ). But engineers also want to differentiate themselves from scientists. The research conducted by technical communication scholars which challenges the reliance on scientific rhetoric calls 
for a wider discursive framework in engineering communication (Johnston, Lee and McGregor; Bryce, Johnston and Yasukawa; Ahearn). Bucciarelli challenges the monopoly science discourse has in engineering by stating, 'Whether this rhetoric [scientific] can be sustained in the face of challenges to traditional ways of doing engineering is an open question' (333).

Desire to differentiate engineering from science is not limited to conversations about the language of engineering. Henry Petroski, the engineer and writer, addresses the distinction between engineers and scientists in his 2009 Washington Post article 'Want to Engineer Real Change? Don't Ask a Scientist'. Petroski responds to U.S. President Barak Obama's inaugural speech statement that science was the tool for environmental and economic change (Obama). Petroski says the President's misconception that science and engineering are the same is a common one. He points out the difference, 'Science seeks to understand the world as it is; only engineering can change it' (Petroski). He gives several examples of science standing in the way of technology; of engineering moving ahead and in spite of science.

The problematic relationship between science and engineering can be seen from these examples. Aligning itself with science has increased the authority of the engineering culture. However, engineers also demonstrate a desire to differentiate themselves from scientists in order to better describe what they do.

\subsection{Technologist or Engineer}

Technology has many definitions but one of its most common is, 'the systematic application of scientific or other organised knowledge to practical tasks' (Walker and Addis 27). This makes technology synonymous with engineering. The action of applying science brings risks that merely thinking, observing or writing about science does not. How much better would Dr Frankenstein's lot have been if he had written a research paper concerning his theories on reanimation, rather than creating a monster? As early as 1976 Florman identifies a growing intellectual movement of 'antitechnology' which directs 'hostility against the engineer as the archetypical technologist' (The Existential Pleasures of Engineering, $\mathrm{x})$. Unlike its reaction to science, engineering culture does not appear to distance itself from technology but instead aims to improve the technologist's image by advocating the ideal of technology used for good. 
Today technology seems to be in the uncomfortable position of being, as Homer Simpson says of alcohol, '... the cause of and solution to all of life's problems' (Groening). On their webpage 'About climate change' the Ministry for the Environment states that increasing industrialisation over the last 150 years has led to increasing greenhouse gas emissions and global warming (Ministry for the Environment). Industrialisation is driven by technology, largely designed and implemented by engineers. Yet in an era where there is agreement that technology has intensified global warming there is also growing hope that technology can save the planet. From catalytic clothing to artificial volcanoes to machines that suck carbon out of the air, the media reports every technology developed in the hope it will counteract global warming (Collins; Internationa Business Times Staff Reporter; Harris). Colin Brown's September 2011 opinion piece for the New Scientist states that, 'While the world's politicians have been locked in predominately fruitless talks, engineers have been developing the technologies we need to bring down emissions and help create a more stable future' (Brown). This sentiment is echoed by science blogger Joe Romm in his article, 'World Engineers: Technology we need already exists!' (Romm). In this way engineers as technologists exist in the present culture simultaneously as hero and villain.

As mentioned, Florman recognises this dichotomy early and his project is to lead the engineer at the intersection of good and evil back to the light, so to speak. Florman's theory is that if engineers would study and appreciate the liberal arts they would: improve their intellect and imagination, develop leadership qualities, enrich their personal lives with a better appreciation of beauty, increase the esteem of the profession and contribute to the public good (Engineering and the Liberal Arts 13). He is advocating for what another structural engineer, Ted Happold, identifies as the 'civilising counterbalance' art might have on technological advances (Happold "A Personal Perception of Engineering" 27). Florman and Happold point to the humanities to provide a counter to the image of the singleminded technologist concerned only with progress at all costs.

It appears many engineers are not afraid to align themselves with technology provided that this alignment is tempered with humanitarian awareness. Advocacy for the 'right' kind of technology can be seen today in the growing movement of sustainability engineering. Formed in 2003, The Sustainability Society is an active technical interest group of the Institute of Professional Engineers New Zealand (IPENZ). The Society aims to provide training and foster dialogue which ensures development 'meets the needs of the 
present without compromising the ability of future generations to meet their own needs ${ }^{7}$ (Sustainability Society). The growing worldwide interest in sustainability engineering is an example of engineers tempering technology with humanitarian concerns.

\subsection{Artist or Engineer}

Florman and Happold's call for the 'civilising counterbalance' of art on technology signals a complicated relationship between art and engineering which can be seen in examples from engineering writing.

Peter Rice, the engineer who designed, among other structures, the Sydney Opera House, Paris' Pompidou Centre and Lloyd's of London Building notes that people often call him an 'architect engineer' (An Engineer Imagines 71). He says it's a compliment. That people are trying to single him out as 'a quality of engineer who is more imaginative and design-orientated than a normal engineer' (Rice An Engineer Imagines 71). In the building world the artist is the architect and as Rice says, in the dialogue between architecture and engineering, the engineer is the voice of rationality and reason' (An Engineer Imagines 76). He explains that the engineer is expected to play Iago to architecture's Othello, to use 'sound, sensible arguments throughout to destroy the romantic idyll of Othello's existence' (Rice An Engineer Imagines, 76). Is there any escape, Rice asks, for the engineer from the Iago role? His answer is to reassess the engineer's task. He says, 'They [Engineers] work with materials. They can work with light. They can work with air. They work with the basic and fundamental elements of construction. They work with the content, not the image' (Rice An Engineer Imagines, 76). Rice suggests a type of engineering which makes real the 'presence of the material' of a building. Engineering which gives people a sense of the material itself and the human hands behind its design and manufacture. In this way Rice suggests that the engineer can be incredibly creative and can alter the entire sense of a building.

Happold goes even further to champion the creative capabilities of engineering, suggesting engineering is freer and less bound by convention than art and can therefore

\footnotetext{
${ }^{7}$ The Sustainability Society adopts the Brundtland Report definition of sustainability as its core belief. The Brundtland Commission was established by the United Nations General Assembly to address growing concern over environmental issues. The Report of the Brundtland Commission, Our Common Future, was published by Oxford University Press in 1987.
} 
take the lead in innovation and creativity. This stance can be seen in 'A Personal Perception of Engineering', a piece Happold writes in 1987 as part of a publication for the Great Engineers Exhibition celebrating the 150th anniversary of the foundation of the Royal College of Arts. He writes:

... a world which sees art and engineering as divided is not seeing the world as a whole. These days often only those people with an arts training are said to be creative. But, if the truth is told, it is technology that is creative because it gives new opportunities. Historic ideas of art and culture can entrap. It is technology that frees the scene (Happold "A Personal Perception of Engineering" 27).

This representation of engineering seems far more inventive or synthesising than merely problem-solving; it seems generative in a way more usually attached to art practice. There are examples of engineers supporting the idea of engineering as a creative profession, and several of these encourage engineers to be more creative. Mark T. Holtzapple and W. Dan Reece's 2003 textbook Foundations of Engineering includes a chapter on creativity. They suggest engineering education, while not directly addressing creativity, does focus on problem-solving, and engineers get frequent opportunities to flex their 'analysis muscles' but less chance to develop their 'synthesis muscles' (26). They suggest both types of thinking are important for creativity and engineers may need to venture into activities outside the engineering classroom to improve their synthesis skills (Holtzapple and Reece 26). They offer a table comparing the creative professions: 
TABLE 1.3

Creative professions

\begin{tabular}{|c|c|c|}
\hline Profession & Goals & Constraints \\
\hline Author & $\begin{array}{l}\text { Communication, exploration of emotions, } \\
\text { development of characters }\end{array}$ & Language \\
\hline Artist & $\begin{array}{l}\text { Communication, creation of beauty, experimentation } \\
\text { with different media }\end{array}$ & Visual form \\
\hline Composer & $\begin{array}{l}\text { Communication, creation of new sounds, } \\
\text { exploration of potential of each instrument }\end{array}$ & Musical form \\
\hline Engineer & $\begin{array}{l}\text { Simplicity, increased reliability, improved efficiency, } \\
\text { reduced cost, better performance, smaller size, } \\
\text { lighter weight, etc. }\end{array}$ & $\begin{array}{l}\text { Physical laws and } \\
\text { economics }\end{array}$ \\
\hline
\end{tabular}

Figure 2: Creative Professions (Holtzapple and Reece 26)

Engineers don't often use the word 'artistic' to describe their work but here, in a textbook, two engineers group artists, composers and engineers under the same heading of 'Creative Professions'. Holtzapple and Reece identify the main goals of artists, composers and writers as communication and it could be argued this simplification of aim moves art to the problem-solving or craft end of the creative spectrum. Rather than clarifying engineering's relationship to art and creativity, I believe the table represents the complication of this relationship, and signals the tension between art and rationality. This tension is discussed later in this essay in the chapter concerning aesthetics and also in my creative project.

Engineers do think and write about creativity and art and some see themselves very much involved in these pursuits. One characteristic of engineering culture which is different from professions traditionally recognised as artistic is the tendency to attribute acts of creativity to groups rather than individuals. One of the ways this is achieved is by the loss of author, commonplace in the day-to-day work of engineering and the writing that surrounds it. It is interesting to explore, through the writing of engineers, how they consider their place as author, creator and individual. 


\subsection{Individual or Engineer}

In their technical writing, engineers, like scientists, make extensive use of the passive voice to create object-focused texts. In his rhetorical analysis of engineer writing, Bucciarelli looks at the description of a diode in which the diode is the only active agent:

The reader need worry little about where the author is coming from (as long as the English is well written); they need only sit back and observe the diode's action unfold - as it would any place in the world or the universe (Bucciarelli 342).

The absence of the author in technical writing is used by the engineering community to give the impression of universal rather than subjective truth or opinion. Most engineering papers are published as the work of multiple authors, reinforcing a collaborative, corporate authorship.

This non-individualistic representation matches the collaborative process that takes place when a building is designed and constructed, and is used in several different types of engineering communication. Analysing the writing surrounding the construction and opening of the Te Puni accommodation building at Victoria University of Wellington uncovers several rhetorical devices used to reflect the collaborative process ${ }^{8}$. In the body of a 2008 paper written by contributing engineers Sean Gledhill, Geoff Sidwell and Darren Bell, they refer to themselves not by name but as company 'Connell Wagner developed and has refined a new system ...' (8). The same technique is used in newspapers and trade magazines (Butterworth, Clifton and MacRae; “Aurecon Recognised for Seismic World First”; “A World First for a Multi-Storey Steel-Framed Building”). When the individual is announced, he is defined by the company he works for: 'Connell Wagner's Sean Gledhill' (“A World First for a Multi-Storey Steel-Framed Building" 3). In my interview with Gledhill about the Te Puni complex he names all the individuals involved in the invention of the new seismic systems used in the building. He also puts this invention in context, explaining there was 'someone in the 1990s who did some research on rocking systems'. Instead of promoting his own work, Gledhill pulls himself back into a crowd of other

\footnotetext{
${ }^{8}$ Completed in 2009, Te Puni Village is located at the Southern end of Victoria University of Wellington's Kelburn Campus and consists of three buildings which house 348 dormitory rooms, 298 studio rooms and three two-bed apartments.
} 
engineers, making it clear that any success is very much shared. For the rest of the interview he uses the collective pronoun 'we' when discussing the design and construction of the buildings.

There is a sense in the texts I analysed of collaboration and team work. However, when engineers write outside of their work, in memoirs or opinion essays, they often explore the place of the individual, revealing a less clear-cut position than the more conventional texts demonstrate.

Peter Rice's book An Engineer Imagines, written at the end of his life, is a remarkable blend of memoir and essay. It is a valuable insight into Rice, who is described in one obituary as 'fond of poetry, philosophy, mathematics, racing, football (he was an avid QPR supporter), wild flowers, wine (which he collected), and whiskey (Scotch before Irish), Rice was, perhaps, the James Joyce of structural engineering' (Glancey).

In An Engineer Imagines Rice explores the identity of the engineer through his personal experience and opinions. He challenges stereotypes and suggests a shape for a future ideal:

Grey people, you say, working in teams, not great individuals placing their personal authority on the line in what they design. But is that true? Of course not. Every team has a leader, one who is ultimately responsible for the work the team does $[\ldots]$ The problem, then and today, is that the name and role of the engineer are not known to the public. Engineers work incognito. Unlike their predecessors, today's engineers work behind a screen of other egos (Rice $A n$ Engineer Imagines, 73).

Rice compares this current situation with the great engineers of the nineteenth century:

Telford, Stephenson, Brunel father and son, Eiffel, these are names of pride and achievement, [...] Indeed in their time they outshone architects and other designers and their achievements are still spoken of with awe (An Engineer Imagines, 73). 
Rice makes it clear that engineers today do the same work those of the nineteenth century but the problem is one of identity, 'Engineers need to be known as individuals responsible for the artefacts they have designed' (An Engineer Imagines, 74). But how does this declaration for the promotion of individuals fit with the collaborative nature of the engineering task?

Ted Happold and Peter Rice worked together at Ove Arup. They were on the team which designed and built the Pompidou Centre in Beaubourg, Paris. In An Engineer Imagines Rice dedicates a whole chapter to Beaubourg, describing the set of events behind the decision to cast the steel for the structure rather than use more conventional rolled steel. Rice describes a trip he took to Japan, after the team had won the competition to design Beaubourg. Rice visited the surviving buildings from the 1970 World Fair in Osaka, and from these he claims he got the idea to use cast steel instead of rolled or extruded steel sections (An Engineer Imagines, 29-30). Happold reviewed Rice's book in a 1995 issue of the Royal Society of Arts Journal. He refutes Rice's description of events, maintaining that he Happold - had been discussing cast steel with another engineer for a long time before the Beaubourg competition and that the Ove Arup entry included the use of this material, so there was no way that Rice could have come up with the idea after the competition had been won. Happold goes so far as to say there are others who worked on the entry who could verify his memory of events. Happold follows this stinging revelation with the following statement, in summation of the book:

It is a worthy memorial to a very gifted man who died far too young. Engineers are, I suspect for business reasons, far too modest about their contribution to the advancement of the art of building and architecture. Here is one writing about it and in the context of his life ("Essential Engineer" 86).

Happold's concluding comments and their context act as a warning to the engineer who would step forward and be counted as an individual. They suggest that the individual engineer is a problematic identity in the engineering community. Happold's comments act as a sobering reminder that the true nature of engineering work is collaborative and an individual's assertion of ownership over particular ideas can become contentious and difficult in this co-operative environment. 


\subsection{Woman or Engineer}

More men than women are engineers. It's estimated that $9 \%$ of engineers in the United States of America are women (Burke, "Women and Monirities in Stem: A Primer" 6). In Britain, estimates suggest $6 \%$ of engineers are women (Powell, Bagilhole and Dainty 48). In New Zealand, women add up to only $7 \%$ of the engineering workforce (Buchanan). Throughout the 21st century there has been growing awareness of the importance of Science, Technology, Engineering, Mathematics (STEM) professions to economic performance and an equal awareness that many developed countries are facing a potential shortage of skilled STEM workers (Burke, "Women and Monirities in Stem: A Primer" 34). These dual drivers have seen a number of initiatives to encourage female participation in engineering courses and careers.

Many scholars try to pinpoint what it is about engineering education and business that leads to low female participation. There seems general agreement that women 'can cope with the engineering work, but not with the engineering culture' (Burke, 'Women and Monirities in Stem: A Primer" 9). Powell et al. explain in their 2007 chapter 'The Good, the Bad and the Ugly: Women Engineering Students' that although the general public don't understand much about the role of an engineer, when asked to describe it, they consider the profession as a 'somewhat dull, uncreative activity, associated with the so-called "old economy" (51). It is seen as a 'tough, heavy and dirty' job which has a lot to do with machinery and is very much a 'masculine profession' (Powell, Bagilhole and Dainty 51). Cultural barriers to women's advancement in engineering education and careers have been identified and include: isolation and exclusion; credibility issues; stereotyping and downplaying of women's abilities; lack of role models; work-family balance; sexual or other forms of harassment; relocation difficulties; lack of development plans for their growth and advancement; companies more focused on recruiting women than developing and retaining them (Burke, "Women and Monirities in Stem: A Primer" 10). Despite these barriers, some women gain engineering qualifications and work and progress in the engineering profession.

In 1997, Temple University Press published the book Journeys of Women in Science and Engineering : No Universal Constraints. The books seeks to 'illustrate the countless ways in which individuals - some with exceptional talents and some with ordinary ones - have forged useful and rewarding lives in science' (Hornig xiii). The book includes eighty-eight 
first-person profiles of women in the STEM field including three by female civil engineers. There are differences in the engineers' profiles also similarities. All three women are successful in their chosen positions within the field of civil engineering. All three mention an early role model, usually male, who suggested engineering as a career. All profiles include sections in which the women describe their work, and when it comes to the 'work' of engineering their language and description is very similar, if not the same, as a male engineer. All three talk about work-life balance and make special mention of the issues connected with working in a male-dominated field. Two conclude with a series of anecdotes about the difficulties of being female engineers, concluding with the aspiration that one day it won't be so unusual (Colmenares; McNeil; Washington). Unfortunately these aspirations seem not to have come to fruition. Between 1994 and 2005 women's participation in engineering increased only 1\% (Burke, "Women and Minorities in Stem: A Primer" 6).

The Society for Women Engineers (SWE) is an organisation which 'empowers women to succeed and advance in the field of engineering, and to be recognized for their life-changing contributions as engineers and leaders' (Society of Women Engineers). The 2010 Conference edition of SWE magazine shows an interesting representation of the female engineer. The magazine is full of images of women standing in front of symbols of engineering technology: aircraft, space ships, mathematical equations. However, the written content of the magazine gives very little clue that it is a magazine for and about female engineers. One article concerning President Obama's 'Change the Equation' initiative, takes three paragraphs before identifying one of the prime aims of the initiative is to 'broaden participation of women' in STEM education and careers (Guy 20). The first two paragraphs deal with initiatives which do not relate directly to female students. When the initiative to broaden female participation is mentioned, it is as part of a wider initiative to increase participation by under-represented minorities. In this way, the article's focus is far wider than issues directly relating to female participation in STEM careers. However, the image accompanying the article shows a young woman sitting at a desk with a pencil in hand. The magazine is definitely a female-orientated publication and it includes articles of interest to female engineers, but the emphasis of the written texts is very much on the role, not the gender, the 'student engineer' not the 'female student engineer', the 'engineer' not the 'female engineer'. This focus shows a deliberate and quite successful philosophical strategy for the problems associated with working in a male-dominated field. This 
approach reflects research which concludes that female engineers have little difficulty with the work (engineering) part of the culture but do encounter difficulties with the gender (woman) part of the culture (Burke, "Women and Minorities in Stem: A Primer" 9).

These examples from the writing of engineers suggest engineering culture is masculine but that a minority, less than $10 \%$ in most western countries, are female. This makes for an odd disruption to what is a predominantly homosocial culture. To minimise this disruption and perhaps in order to maintain the collaborative nature of engineering work, one strategy women have undertaken is to identify themselves strongly as engineers, diverting emphasis from their gender.

Thorough analysis of gendered language and culture in engineering is outside the scope of this essay. However, I believe it is important to offer this brief survey as background to my decision to place a female engineer at the centre of my creative work. My decision is largely based on my own gender, but it is also an opportunity to present a different, minority experience of a community which has largely been represented in imaginative literature as male and heroic. My aim is to present the surroundings we take for granted as unusual. My research identifies several problematic or complicated factors in the engineering culture which disrupt perceived stereotypes. It is useful to my creative aim to highlight where possible the unusual or complicated. My central female engineer is an example of my decision to move toward the unusual rather than the conventional.

This chapter has outlined some of the characteristics of the engineering culture by focussing on representations of the engineer in the writing of engineers. I have shown that when these texts are consulted many of the generally-held views of what it is to be engineer are interrupted or complicated. This complication of stereotypes is useful for my creative aim because it suggests ways that the engineering culture is not what most of us expect or take for granted.

What follows are three chapters which investigate the findings from an analysis of texts written for and by members of the engineering culture. Each chapter deals with a problem inherent in the built form which must be solved to translate buildings to written and oral language. The first chapter deals with the problem of action and event, particularly, the expression of simultaneous and contingent events. After an explanation of the problem, I explore the solutions used by engineers when translating built forms as written and oral language. 


\section{ALL AT ONCE AND MAYBE NEVER: SOLVING LANGUAGE PROBLEMS OF ACTION AND EVENT IN ENGINEERING WRITING}

\section{1 'Building'}

In 2009 I attended lectures about building structure at the Victoria University of Wellington School of Architecture and Design. The papers offered an introduction to the basic structural principals and material properties that underpin the fabric of natural and constructed environments' (“ARC222: Structural Systems”). They covered, 'the basic requirements for structural systems; structural form and proportion; equilibrium; strength of materials; bending and shear; combined stresses; elasticity, plasticity and ductility; elastic deformation; buckling; structural design principles; and, elementary soil mechanics” (“ARC222: Structural Systems”).

As I attended the lectures I found myself more and more troubled by the word 'building'.

Hearing the word over and over made it strange. I had an idea that the office blocks and apartments we studied in class were permanent, finished, solid and it troubled me that we gave them a name that although obviously a noun, is also a present progressive verb - a continuous activity, a never completed action. It confused my sense of time. The building is here, finished, still, and also in process. The word seemed to carry on some act started by construction workers well after they had left.

To add to this trick of language, I learned that concrete doesn't reach its maximum strength until many days after being poured; how it is impossible to know whether concrete is as strong as it should be for almost a month after it has been cast, in which time several new storeys may have been built. Even more disturbing to my sense of linear time and what I knew about deterioration, I found out good concrete gets stronger as it gets older. This strengthening happens rapidly to begin with then slows down but, unlike us, concrete's strength increases with age.

It seemed the more I learned, the more distorted space and material became. Everything in my experience to that point suggested that the natural state of an object, like a building, was stillness. The lectures, however, explained that the natural state of an object in the absence of applied force is a maintained velocity or motion over time 
(Holtzapple \& Reece 268). Built forms stand still because they are designed so that all forces are held in equilibrium within the elements. I found myself experiencing buildings in a different way. They are alive, in action, a complex relationship of force and reaction to that force happening all at once. I began to see that buildings are built based on how they will be in the future, at another time, when the weight of the building is finished, when the concrete has strengthened, when the full force of the function of the building is imposed and none of this seems fixed, or finished. These future selves are anticipated in the design and so are future events - earthquakes, fire, flood - events out of anyone's hands and completely contingent. So my strange hearing of 'building' begins to fit more and more. The progressive present verb acting as a noun, the most solid part of speech; it is a clever trick which describes exactly what these things are that we live and work in - at once still and moving, here and at another time, finished and finishing. All at once and maybe never.

\subsection{The Problem}

In relation to action and event, built forms display complex and often anti-intuitive characteristics which the engineer must translate into written and oral language.

As explained previously, the reason a built form stands still is because all forces acting on it are held in equilibrium. This means that at any one time, a built form is reacting to many forces acting constantly and simultaneously.

Engineers design buildings to stand over time. In order to do this they must consider unusual events which may or may not happen in the future, including high wind, fire, flood and earthquake. Even in normal conditions, built forms change through their lifetime. From construction to completion and beyond, a built form appears and acts quite differently; changing function, changing structural action, even changing shape. Engineers are asked to write about built forms at different stages of a building's life-cycle. Often, it is necessary for them to capture anticipated change in language before that change has happened.

Conventional language is linear, it needs a beginning, middle and end, preferably just one at a time. So how does the engineer translate the numerous simultaneous actions of a built form into linear language? And how do they translate contingency into language which conventionally works toward one certain outcome? 
I explore these questions in this chapter through an investigation of writing by engineers concerning the Te Puni Village Student Accommodation complex.

\subsection{Te Puni Village Student Accommodation}

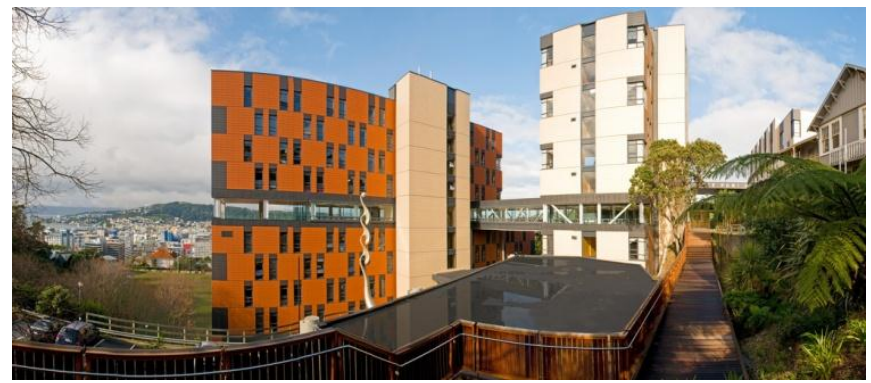

Figure 3: Te Puni Student Accommodation (ClSabroad)

Completed in 2009, Te Puni Village is located on an elevated site at the southern end of Victoria University of Wellington's Kelburn Campus. Te Puni Village is made up of three buildings: The Terrace, The Edge and The Tower which house 348 dormitory rooms, 298 studio rooms and three two-bed apartments.

As well as acting as accommodation for the growing student roll, Victoria University's post-large-earthquake scenario requires that, in the event of an earthquake, these buildings remain essentially undamaged to serve as an administration centre while other university buildings are repaired (Butterworth, Clifton and MacRae 21).

To meet these requirements, engineers Connell Wagner (now Aurecon) implemented a Damage Avoidance system which, in simple terms, allows the building to lift off the ground and rock in a controlled way during an earthquake. The system incorporates several elements which work together to ensure the buildings can 'withstand a major seismic event with minimal and repairable damage' (Gledhill, Sidwell and Bell xxx).

\subsection{All at Once: The Language Problem of Simultaneous Action in Te Puni Village}

In 2010 I interviewed Sean Gledhill about the structural performance of the Te Puni Student Accommodation buildings. During the interview Gledhill pauses in his explanation to say, 'This is all happening dynamically i.e. very quickly' (Gledhill). It may 
be closer to the truth to say it is all happening at once.

Isaac Newton's first law of motion states that, 'Every body remains in a state of constant velocity unless acted upon by an external unbalanced force' (Browne 9). In order for an object to stay at rest, equilibrium is required. To achieve equilibrium, the sum of all forces in each orthogonal direction $-\mathrm{x}, \mathrm{y}, \mathrm{z}$ - must be zero. In this condition an object cannot move up or down, side to side, back or forth, or rotate in any direction. The engineers M.G. Salvadori and R. Heller, stated in their 1986 book, Structure in Engineering that:

The fundamental requirement of equilibrium is concerned with the guarantee that a building, or any of its parts, will not move. Obviously, this requirement cannot be interpreted strictly since motion is both unavoidable and necessary, but the displacements allowable in a building are usually so small compared to its dimensions that to the naked eye the building appears immovable and undeformed $(62-63)$

When understood in this way, any stillness a building displays is hard-won and achieved only through constant and simultaneous resistance to forces. Salvadori and Heller make it clear this resistance will often require motion to maintain perceived stillness and integrity.

At any one time, under earthquake or normal conditions, Te Puni Village is resisting different forces in order to fulfil the use it was designed for. The action of any one element is affecting other elements instantaneously. The selected texts written by Gledhill and his associates which I analyse, demonstrate solutions to translating this simultaneous action into language?

\footnotetext{
${ }^{9}$ The texts met the test for acceptability by the engineering culture since all were peer-reviewed or edited by other engineers before publication. Therefore it seems reasonable to suggest that the language solutions I identify in the texts by Gledhill et al are acceptable to the engineering culture and do not represent a disruption or distinction in the language of engineers.
} 
Gledhill explains the action of the building under earthquake attack as follows:

Talking in a little bit more detail about the transverse frame, so what it does is, in an earthquake the tension forces due to overtuning $[\ldots]$ build up and keep building up [...] and so the initial thing is that the joint has to overcome the friction, the friction joint on the outside of the column, and then it needs to overcome the gravity in the column $[\ldots]$ and then the tensions needs to overcome the pre-stress in the Ringfeder axial spring and then once the pre-stress is overcome the frame is free to rock and lift off its foundations (Gledhill).

Gledhill's description here is typical of others throughout the interview. His descriptions are characterised by the isolation of the story of one force as it travels through one structural system, in this case the transverse frames. To explain the action of the structure Gledhill describes a steadily increasing force which overcomes elements one by one. He isolates his description, artificially, to one system in the building. Both these decisions allow him to use a progressing, linear 'and then' syntax which artificially lays a narrative onto the action in order to best explain it. In the event of an earthquake this action would be violent, random and involve other systems in the building but Gledhill controls this chaos into a conventional 'beginning, middle and end' narrative form by moving a steady force through a distinct structural system.

Although not a pure example ${ }^{10}$, the strategy Gledhill uses is similar to another accepted explanation technique used by engineers, which incorporates the concept of the 'force-path'. Using this concept engineers visualise the 'path' a force takes as it 'travels from the applied force to the foundations and into the ground below'(Charleson 29). This is an imagined path, as Andrew Charleson explains in his 2008 book Seismic Design for Architects:

The term 'force path' is metaphorical because forces don't actually move. Rather they exist within structural members in a state of action and reaction in such a way that every structural element and connection remains in equilibrium (29).

\footnotetext{
${ }^{10}$ Gledhill's description is of seismic force, which is from the ground and rapidly changing and cycling.
} 
The metaphorical solution of the 'force path' offers engineers a way to give beginning, middle and end to continuous and simultaneous action in built forms. Gledhill uses the key characteristics of this concept - isolation and a linear narrative - to describe the action of Te Puni Village under the randomness and immediacy of an earthquake attack.

\subsection{Maybe Never: Contingency in Te Puni Village}

Wellington City sits on a seismically active part of New Zealand, 'within the earthquakegenerating collision zone between two of the Earth's great tectonic plates' and on top of the Wellington Fault (GNS Science). Due to this risk, seismic forces are one of the main contingent events considered for buildings designed and constructed in the Wellington region. Seismic resistance design has two objectives: to protect human lives, and limit building damage (Charleson 39). Engineers work toward these two objectives by designing buildings that will resist what building codes call a 'design-level earthquake' which is defined as an earthquake 'with an average reoccurrence interval of approximately 500 years' (Charleson 39). To protect lives, buildings are designed so they will not collapse during a design-level earthquake, however, 'considerable structural and non-structural damage is usually considered acceptable' (Charleson 39). Most earthquakes are caused by continental drift or tectonic plate movement. The earth's crust is made up of deep continental and shallower oceanic plates, which drift slightly above the molten rock which forms the layer beneath them. The plates 'move relative to each other approximately $50 \mathrm{~mm}$ per year; apparently about as fast as our fingernails grow' (Charleson 4). In some places, this slight movement is smooth, tectonic plates slip horizontally past each other, but in some places due to friction and the angle of contact, plates become locked up. So instead of sliding easily past each other 'the rock in a plate boundary (say along a fault line) absorbs greater and greater compression and shear strains until it suddenly ruptures' (Charleson 39). Charleson likens the mechanical process of an earthquake to the way we snap our fingers:

We press finger against thumb to generate friction, then also using our finger muscles we apply a sideways force at the interface between the surfaces. If the initial pressure is low, they slide past each other without snapping. Increasing the pressure and the sideways force distorts the flesh. When 
the sliding force exceeds the friction between thumb and finger, the finger suddenly snaps past the thumb and strikes the wrist as the pent-up strain converts to kinetic energy (39).

Although a reasonably consistent pattern of earthquake occurrences has emerged over the 100 years that scientists have understood the implications of tectonic plate movement, they are not able to predict with any certainty the precise location, time and magnitude of the next earthquake.

Because of the nature of seismic events engineers design buildings for a devastating and unexpected event, one that may not occur over the life of the building. The technology they design to resist an earthquake is largely unused during the life of the building. But in the event of an earthquake that technology must work well to save lives, so a seismically resistant building is two buildings at once: one acting under normal forces and a second, latent but always alive in the first, ready to resist an earthquake attack. Both these states and their relationship to each other have to be fully described by the engineer writing or speaking about the building.

Returning to the previously quoted description of Te Puni Village by Gledhill we can see that one of the main features setting it apart from a conventional description of 'force path' is the contingency in the language needed to explain that this particular action will only take place in certain conditions: 'the joint has to overcome the friction', it "needs to overcome the gravity" (Gledhill, Sidwell and Bell; Gledhill). The use of these modals reminds us this action is latent in the building and not normal. This echo of the latent in descriptions of seismically-designed buildings is a feature of the language used to describe them. Other examples of this echo of latency are the names engineers use for the elements they design.

Due to the complexity and specificity of the objects and concepts of engineering, engineers rely on agreed terms to ensure correct information is communicated. One group of agreed terms is the word compounds used as nouns to name specific elements in building structure. Many of these terms can be found in a conference paper about Te Puni Village written by S. Gledhill, G. K Sidwell and D. K Bell for the $2008 \mathrm{New}$ Zealand Society of Earthquake Engineering (NZSEE) Conference. The paper uses many nominal word compounds, including the following terms:

\footnotetext{
${ }^{11}$ My emphasis.
} 
- Coupled concentrically braced frames

- Prestressed Ringfeder friction springs

- Moment resisting steel frame

- Vertically orientated column flange mounted sliding joint

- Fixed-head bored concrete piles

- Vertically orientated hinge joint friction plates

- Rigid concrete diaphragms

- Steel collector beam

The way the element will move in an earthquake is alive in many of these terms. While word compounds have a practical nominal use in accurately identifying an element, they also suggest the latent action present in the building's structure. In some compounds the element is braced, or prestressed; they are ready and waiting. One innovative seismic element is called a 'sliding joint', emphasising the movement latent in the object; the joint will only slide in the event of a large enough earthquake, but this joint is not called a 'will-slide' joint or a 'slideable joint', it uses a progressive verb to name it in the action it will take up in the event of an earthquake.

These word compounds also help solve the problems associated with expressing simultaneous and continuing action. The compounding of multiple adjectives with nouns, the piling up of words, gives a sense of lots of things happening at the same time, while the choice of adjectives adds acknowledgement to the action always present in the building but not always seen. For example the moment frame is 'resisting' in the present progressive tense, reminding us that it is always acting in order to appear at rest. These word compounds act as an elegant solution to the language problems of action and event apparent in the source text.

Engineers need to design for seismic forces to set their buildings in motion so to speak, to place them under an imagined earthquake attack. They use agreed mathematical and physics formulae and modelling conducted virtually on computers or actually using sized-down models on shake tables. Because of modelling engineers have a very clear idea how a building will perform in an actual earthquake attack. Engineers have to translate this action into language. This necessitates the description of a contingent event. 
The Gledhill et al. paper is written to share knowledge of a seismic system being implemented in New Zealand for the first time. At the time of publication, this system had never been tested in a real earthquake but had been tested and peer-reviewed thoroughly. To fulfil the purpose of the paper it is necessary for the writers to describe an imagined event and the effect it has on the structural system they have designed.

The section of the Gledhill et al. paper titled Transverse Bracing - Tension Limited Rocking Steel Shear Walls - Basic Concepts begins with an explanation of the elements which make up the structural system and how they relate to each other. In the fifth paragraph of the section the Victoria University of Wellington Student Accommodation Project (later renamed Te Puni Village) is set in motion with the words 'Under seismic lateral loads'. The paragraph continues to describe the action as follows:

Under seismic lateral loads the CBF's [Concentrically Braced Frames] are designed to uplift at the tension column. At the internal column, uplift is limited by coupling beams, hence less spring compression force (to resist column tension) is required resulting in less friction spring elements. Uplift occurs after the coupling beam overstrengths, gravity and the sliding hinge resistance is overcome (Gledhill, Sidwell and Bell 9).

This paragraph exemplifies the way the effect of the earthquake is described throughout the paper. Conditional or modifying phrases, such as 'Under seismic lateral loads', are used to maintain the contingency of the event but also simplify the tense of the action. The writers use these conditional phrases so that the action can be described in present tense. The earthquake as an event is not mentioned. Instead 'seismic lateral forces', which can be scaled up and down, act on isolated elements of the building. The buildings are un-peopled, unused - un-accommodated accommodation buildings. Using these language strategies, the future/possible earthquake is presented in theory thus maintaining its contingence but also making it possible to present its effect on Te Puni Village in a rational way

In the absence of unusual events, it is still anticipated Te Puni Village will change over time. As mentioned, the Gledhill et al. paper was presented to the 2008 NZSEE 
Conference. The buildings were not completed until January 2009 (Aurecon 5). So, at the time of the paper's publication they were still under construction. Gledhill et al. refer to the built forms described in the paper as either, Fairlie Terrace Student Accommodation Project or Victoria University of Wellington Student Accommodation Project. The name Te Puni Village is not used as it had not yet been assigned. The multiple names for Te Puni Village are an example of the changes over the life of a built form which engineers must reconcile in written and oral texts.

One way of accommodating this change of identity over time is demonstrated in the section Fairlie Terrace Student Accommodation Project for the Victoria University of Wellington which provides a description of the project. The second paragraph of this section begins, 'The buildings are situated ...' (Gledhill, Sidwell and Bell 3). At the time of writing, the Te Puni Village buildings were not complete. Therefore, the present tense must refer to the structure that has been built so far. Two paragraphs later the text states, also in present tense that, 'The proposed buildings extend up to 11 storeys or $37 \mathrm{~m}$ to roof level' (Gledhill, Sidwell and Bell 3). Engineers use present tense for clarity but there is a secondary effect which Bucciarelli identifies, 'In the use of the present tense throughout the narrative, it proclaims the eternal nature of this knowledge, of this text, this figure, this device' (341). In this way the present tense has the habit of collapsing what has been built and what will be built into an artificial present.

The strategy of presenting the different identities of Te Puni Village in an eternal present can also be seen in the section of the paper which presents the 'possible damage avoidance design solutions considered for this project' (Gledhill, Sidwell and Bell xxx). This section explains the design process which considered a number of current design technologies. It describes each possible structural solution in turn. These design technologies are then either discounted or adapted for the Te Puni Village. This section, like most of the article, is written in present tense giving the impression of several versions of Te Puni Village existing at the same time. This reflects the design process which includes testing and evaluation of possible design technologies. It could be argued each of the possibilities is present in the final built form because Te Puni Village is a synthesis of the design technologies which were considered. However, the main motivation seems to be to collapse Te Puni Village, in all its iterations, into one timeless building.

In his 2009 book The Secret Lives of Buildings Edward Hollis describes Ithiel Town's painting The Architect's Dream, 'It is a timeless vision because timeless is just what 
we expect great architecture to be' (6). Architectural criticism of Te Puni Village has been harsh. Tommy Honey titles his review for ArchitectureNZ 'Uphill Battle for Commanding Heights'. Honey blames what he sees as the many failings of the complex on the commissioning model which saw 'lots of cooks in the Te Puni village' (86). He feels that the architects were forced to compromise on the design to meet the needs of other stakeholders. He judges the greatest failing of the design as the external articulation of K-braces on the Sky Lounge floor. However, the engineers who write about the structure of Te Puni still attempt to place it in a state of timelessness through the use of the present tense. It is unlikely this is being done to make any claim for the structural design's place as 'great architecture' however it does bolster the image of the complex as complete or finished, in a state where nothing can be added, nothing taken away. All the various states of Te Puni through the design and construction process or after, in use, are collapsed and accounted for in the description of the complex in present tense.

My analysis identifies features associated with action and event apparent in built forms which are difficult to translate to written and spoken language. Engineers choose a variety of solutions to overcome these problems. The problem of expressing simultaneous action in linear language is solved by enforcing conventional narratives and using word compounds to maintain a sense of concurrent activity. The problem of expressing contingency is solved by the use of an 'if ... then' syntax and modifying and conditional phrases which allows the contingent action to be described in present tense. This, along with the use of names which include adjectives describing the action of elements under the contingent event, gives a sense of the latent capability of the building.

The following chapter investigates how the relationship between the human and the built is managed in selected texts written by engineers about Burj Khalifa, One Featherston Street and the Owen G. Glenn Auckland University Business School. 


\section{NOT US BUT BECAUSE OF US: SOLVING LANGUAGE PROBLEMS OF THE RELATIONSHIP BETWEEN THE HUMAN AND THE BUILT}

The problem of the engineer is the problem of anyone who attempts to write the conversation between the built and the human. The built is not like us. Although we dream it, design it, construct it, live and work in it, the built is cold and dead and lasts well beyond us. So how are we to relate to it? How can we fit ourselves to the built environment and it to us? While the creative writer may personify the built to fit it to a human story and the architect may conceptualise a vision which brings it closer to us and the things we understand, the engineer must maintain a detached, rational distance from the built. Theirs is the world of objective truth, of laws proven outside subjective human opinion or feeling. So how do engineers write the relationship of the human and the built? How do they maintain the balance between a vision of a building's inner world which is based on objective truth and the subjective experience of the people it is built for?

This chapter investigates the solutions engineers choose to express the features of the relationship between people and the built environment which are difficult to translate. The investigation is presented as a discussion of the analysis I completed on texts written by engineers about three very different buildings: the Burj Khalifa, 1 Featherston Street and the Owen Glenn Auckland University School of Business.

\subsection{The Solaris Scene}

In 2001, Richard Lowenstein directed a film adapted from John Birmingham's cult novel He Died with a Felafel in His Hand. Birmingham's novel consists of a series of anecdotes about shared living in Brisbane and other Australian cities, as does Lowenstein's film.

Toward the end of the film, in what has become known as 'the Solaris scene' Danny (Noah Taylor) sits against a wall outside a bathroom in which Anya (Romane Bohringer) is sitting against the same wall. After passing a cigarette to Danny under the locked bathroom door, Anya, tells him a story:

There is a man in a space ship floating above a planet which is like a brain that can read from his mind. The planet 
recreated his dead wife from his memory but she wasn't exactly the same she was like a photocopy so he hates her. He locks her in a room to be rid of her but she tears through the door like if it was paper just to be with him. She loves him but he hates her. So she tries to kill herself but she can't die so she comes back to life, like the resurrection. It's only when he sees the pain she's going through that he's able to love her for what she is. You understand? (Lowenstein).

Anya's story is a re-telling of Solaris, a novel written by Stanislaw Lem in 1961 which was adapted into a film by Andrei Tarkovsky in 1972. Lowenstein's film credits Tarkovsky but doesn't mention Lem. So I assume, Anya's retelling is of 'Tarkovsky's re-telling of Lem's novel, which until 2011 has only ever been translated into English from a French translation of the original Polish. A year after He Died with a Felafel in his Hand American director Steven Soderbergh released a film called Solaris, which Lem calls 'a remake of the Tarkovsky film' (Lem).

Lem's novel is an exploration of man's anthropomorphic limitations. The planet Solaris is sentient but so perfectly non-human that attempts to understand it from a human consciousness are futile. The book hints that the replicants the planet produces are an effort to communicate with the humans orbiting its atmosphere but by the end of the book any attempt to translate this communication into meaning which we humans could understand seems ridiculous. Lem creates a series of ever-decreasing circles of ununderstanding which eventually deliver the reader to a place strangely spacious, strangely cramped. After seeing the premiere of Soderbergh's Solaris Lem complains it reduces the planet's sentient ocean to a 'mirror' of humanity, saying:

As Solaris author I shall allow myself to repeat that I only wanted to create a vision of a human encounter with something that certainly exists, in a mighty manner perhaps, but cannot be reduced to human concepts, ideas or images. This is why the book was titled 'Solaris' and not 'Love in Outer Space' (Lem). 
The problem of our anthropomorphic limitations in relation to the built form is nowhere near as pure or clean as the Solaris problem but in my mind they are linked.

About six months into my research it occurred to me that it had been a long time since I'd seen an image of a person. As my classes travelled further and further into the intricacies of structural design we talked more and more about things we couldn't see and 'people' became an increasingly abstract idea. We aimed to abstract elements and materials in order to rationalise these into features that are repeatable and objective. A beam becomes a set of equations and arrows and a long way from something that supports people as they work. Yet in tandem with this re-learning there was an awareness, an unspoken agreement perhaps, that buildings are designed and built by people for the ultimate use of people and that here we are, people inside buildings.

Buildings are created by us, lived in by us, touched by us; they echo our voices and can reflect our deepest aspirations, but to build them we must concentrate on how they are 'not us'. An engineer cannot treat concrete and steel like flesh and bone any more than she can imagine a building hopes to stand up. So how does the engineer/writer translate this relationship between buildings and humans?

\subsection{A Generalised Population}

The problem of where and how to place people in relation to buildings in engineering writing has been solved by replacing the concept of a group of individual people with an abstracted and generalised population of identical form. At its simplest this solution can be seen in the following figure from a 2007 structural design report compiled by Romulus Consulting Group about the 1 Featherston Street building in Wellington, New Zealand.

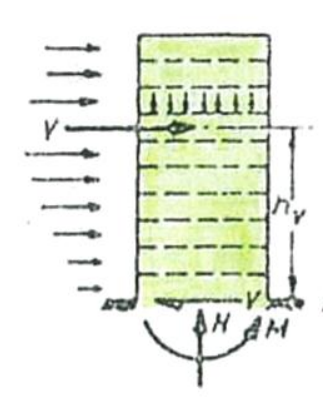

(a)

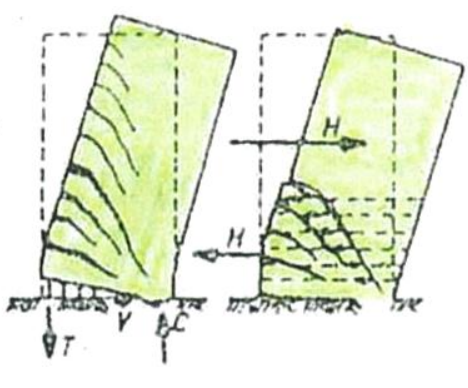

(b) (c)
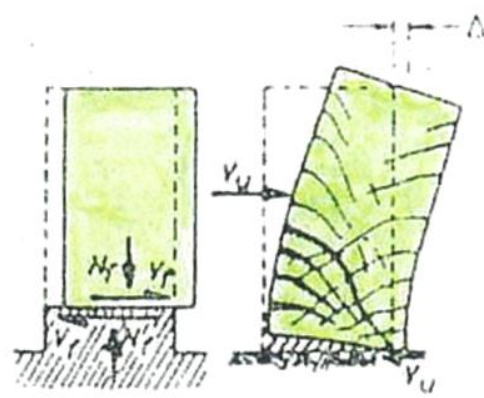

(d) (c) 
The figure is designed to express the failure modes of typical cantilever walls. The first image (a) explains how the wall behaves in equilibrium. On the $7^{\text {th }}$ floor of this image a line of seven figures stand. The remaining four images show the building with the walls up so the figures don't appear again explicitly. However, due to their inclusion in the first image they can be imagined behind the walls during failure. It is as if their appearance in the first image is enough to make them implicit in the other four and perhaps, that the appearance of the figures on the $7^{\text {th }}$ floor suggests there are more on the other floors. The figures are rendered abstractly, uniformly, they are designed to be typical, average, not in any way unique or individual. They are easily generalised or multiplied to populate other images and other floors. They are like mathematical symbols which, in the language of the engineering text, they are. From the writing of Rice and others it is clear that engineers think about individual human experience. However, engineers also have a responsibility to keep a building standing so it is safe for people. To do this they must de-humanise people into force and weight.

This idea of people as physical value is demonstrated again in the table below. It comes from Holtzapple and Reece's 2003 textbook Foundations of Engineering and is designed to help student engineers use estimation as a way to check their answers to questions like: 'How many pillows can fit in the back of a tractor trailer? How much fuel is burned by Texas A\&M students for the Thanksgiving visit home?' (73). The introduction proceeding this table explains that experienced engineers "can "feel" if the answer is in the right ballpark' but beginner engineers can use the table until they have learned the 'rules of thumb' (Holtzapple and Reece 71). 
TABLE 3.2

Useful relationships for estimation purposes

\begin{tabular}{|c|c|c|c|}
\hline \multicolumn{2}{|c|}{ Conversion Factors } & \multicolumn{2}{|c|}{ Physical Constants } \\
\hline $1 \mathrm{ft}=12 \mathrm{in}$ & $1 \mathrm{~atm}=760 \mathrm{~mm} \mathrm{Hg}$ & \multicolumn{2}{|c|}{ Speed of light $\approx 3 \times 10^{8} \mathrm{~m} / \mathrm{s}$} \\
\hline $1 \mathrm{in}=2.54 \mathrm{~cm}$ & $1 \mathrm{~atm} \approx 34 \mathrm{ft} \mathrm{H}_{2} \mathrm{O}$ & \multicolumn{2}{|c|}{ Speed of sound (air, $\left.20^{\circ} \mathrm{C}, 1 \mathrm{~atm}\right) \approx 770 \mathrm{mph}$} \\
\hline $1 \mathrm{mi}=5280 \mathrm{ft}$ & $1 \mathrm{~min}=60 \mathrm{~s}$ & \multicolumn{2}{|c|}{ Avogadro's number $\approx 6 \times 10^{23}$} \\
\hline $1 \mathrm{~km} \approx 0.6 \mathrm{mi}$ & $1 \mathrm{~h}=60 \mathrm{~min}$ & \multicolumn{2}{|c|}{ Acceleration from gravity $\approx 9.8 \mathrm{~m} / \mathrm{s}^{2} \approx 32.2 \mathrm{ft} / \mathrm{s}^{2}$} \\
\hline $1 \mathrm{ft}^{3}=7.48 \mathrm{gal}$ & $1 \mathrm{~d}=24 \mathrm{~h}$ & \multicolumn{2}{|c|}{ Mathematical Constants } \\
\hline $1 \mathrm{gal}=3.78 \mathrm{~L}$ & 1 year $=365 \frac{1}{4} d$ & $e \approx 2.718$ & $\pi \approx 3.14159$ \\
\hline $\begin{array}{l}1 \mathrm{bbl}=42 \mathrm{gal} \\
1 \mathrm{mi}^{2}=640 \text { acre }\end{array}$ & $\begin{array}{l}1 \mathrm{Btu} \cong 1000 \mathrm{~J} \\
1 \mathrm{Btu} \cong \frac{1}{4} \mathrm{kcal}\end{array}$ & \multirow{3}{*}{\multicolumn{2}{|c|}{$\begin{array}{l}\text { Density }=1 \mathrm{~g} / \mathrm{cm}^{3}=62.4 \mathrm{lb}_{\mathrm{m}} / \mathrm{ft}^{3}=8.34 \mathrm{lb} / \mathrm{g} / \mathrm{gal} \\
\text { Latent heat of vaporization } \approx 1000 \mathrm{Btu} / \mathrm{lb}_{\mathrm{m}} \\
\text { Latent heat of fusion } \approx 140 \mathrm{Btu} / \mathrm{lb}_{\mathrm{m}} \\
\text { Heat capacity }=1 \mathrm{Btu} /\left(\mathrm{lb}_{\mathrm{m}} \cdot{ }^{\circ} \mathrm{F}\right)=1 \mathrm{kcal} /\left(\mathrm{kg} \cdot{ }^{\circ} \mathrm{C}\right)\end{array}$}} \\
\hline $\begin{array}{l}1 \mathrm{~kg} \approx 2.2 \mathrm{lb}_{\mathrm{m}} \\
1 \mathrm{~atm}=14.7 \mathrm{psi}\end{array}$ & $1 \mathrm{hp}=550 \mathrm{ft} \cdot \mathrm{lb}_{\mathrm{f}} / \mathrm{s}$ & & \\
\hline $\begin{array}{l}1 \mathrm{~atm}=14.7 \mathrm{psi} \\
1 \mathrm{~atm} \approx 1 \times 10^{5} \mathrm{~N} / \mathrm{m}^{2}\end{array}$ & $1 \mathrm{hp} \approx 0.75 \mathrm{~kW}$ & & \\
\hline \multicolumn{2}{|c|}{ Temperature Conversions } & \multicolumn{2}{|c|}{ Melting point $=0^{\circ} \mathrm{C}$} \\
\hline$[\mathrm{K}]=\left[{ }^{\circ} \mathrm{C}\right]+273.15^{\text {Ten }}$ & {$\left[{ }^{\circ} \mathrm{R}\right]=\left[{ }^{\circ} \mathrm{F}\right]+459.67$} & \multicolumn{2}{|l|}{ Boiling point $=100^{\circ} \mathrm{C}$} \\
\hline$\left[{ }^{\circ} \mathrm{F}\right]=1.8\left[{ }^{\circ} \mathrm{C}\right]+32$ & {$\left[{ }^{\circ} \mathrm{C}\right]=\left(\left[{ }^{\circ} \mathrm{F}\right]-32\right) / 1.8$} & \multicolumn{2}{|r|}{ Densities } \\
\hline \multicolumn{2}{|c|}{ Ideal Gas } & Air $\left(0^{\circ} \mathrm{C}, 1 \mathrm{~atm}\right)=1.3 \mathrm{~g} / \mathrm{L}$ & Aluminum $=2.6 \mathrm{~g} / \mathrm{cm}^{3}$ \\
\hline Standard temperature & & Wood $\approx 0.5 \mathrm{~g} / \mathrm{cm}^{3}$ & Steel $=7.9 \mathrm{~g} / \mathrm{cm}^{3}$ \\
\hline Standard pressure $=1$ & & Gasoline $=0.67 \mathrm{~g} / \mathrm{cm}^{3}$ & Lead $=11.3 \mathrm{~g} / \mathrm{cm}^{3}$ \\
\hline Molar volume (@STP) & & Oil $=0.88 \mathrm{~g} / \mathrm{cm}^{3}$ & Mercury $=13.6 \mathrm{~g} / \mathrm{cm}^{3}$ \\
\hline \multirow{2}{*}{\multicolumn{2}{|c|}{$\begin{array}{r}\text { Molar volume (@ } 3 / P)=359 \mathrm{ft} / \mathrm{Ibmole} \\
\text { Molecular Weights }\end{array}$}} & \multicolumn{2}{|l|}{ Concrete $=2.3 \mathrm{~g} / \mathrm{cm}^{3}$} \\
\hline & & \multicolumn{2}{|l|}{ Cireumforence $\mathrm{m}$ in $000 \mathrm{~km}$} \\
\hline$H=1$ & $N=14$ & \multirow{2}{*}{\multicolumn{2}{|c|}{$\begin{array}{l}\text { Circumference } \approx 40,000 \mathrm{~km} \\
\text { Mass } \approx 6 \times 10^{24} \mathrm{~kg}\end{array}$}} \\
\hline$C=12$ & $\mathrm{O}=16$ & \multirow{2}{*}{\multicolumn{2}{|c|}{$\begin{array}{l}\text { Mass } \approx 6 \times 10^{24} \mathrm{~kg} \\
\text { Male }\end{array} \begin{array}{c}\text { People } \\
\text { Female }\end{array}$}} \\
\hline \multicolumn{2}{|c|}{ Air $=29\left(21 \mathrm{~mol} \% \mathrm{O}_{2}, 79 \mathrm{~mol} \% \mathrm{~N}_{2}\right)$} & & \\
\hline \multicolumn{2}{|c|}{ Geometry Formulas } & \multirow{4}{*}{\multicolumn{2}{|c|}{$\begin{array}{l}\text { Avg mass }=168 \mathrm{lb}_{\mathrm{m}} \quad \text { Avg mass }=139 \mathrm{lb}_{\mathrm{m}} \\
\text { Avg height }=68 \mathrm{in} \quad \text { Avg height }=63 \mathrm{in} \\
\text { Sustained work output of man }=0.1 \mathrm{hp}\end{array}$}} \\
\hline \multirow{2}{*}{\multicolumn{2}{|c|}{$\begin{array}{l}\text { Circle area }=\pi r^{2} \\
\text { Circle circumference }=2 \pi r\end{array}$}} & & \\
\hline & & & \\
\hline \multicolumn{2}{|c|}{ Cylinder volume $=\pi r^{2} L$} & & \\
\hline Cylinder area (without & $2 \pi r L$ & \multirow{3}{*}{\multicolumn{2}{|c|}{$\begin{array}{l}\text { Energy } \\
\text { Natural gas: } 1000 \text { standard } \mathrm{ft}^{3} \approx 10^{6} \mathrm{Btu} \\
\text { Crude oil: } 1 \mathrm{bbl} \approx 6 \times 10^{6} \mathrm{Btu}\end{array}$}} \\
\hline Sphere area $=4 \pi r^{2}$ & & & \\
\hline Cnhore unlume $=\frac{4}{2} \pi r^{3}$ & & & \\
\hline
\end{tabular}

Figure 5: Useful relationships for estimation purposes (Holtzapple and Reece 72)

The table shows people abstracted into a typical value of weight and force: an automobile, the earth, a fluorescent lamp, a person, a male, a female. This rationalisation of the individual form into standardised unit can be seen in the way engineers communicate size. 
This is the Burj Khalifa خد خد يـ فة in Dubai

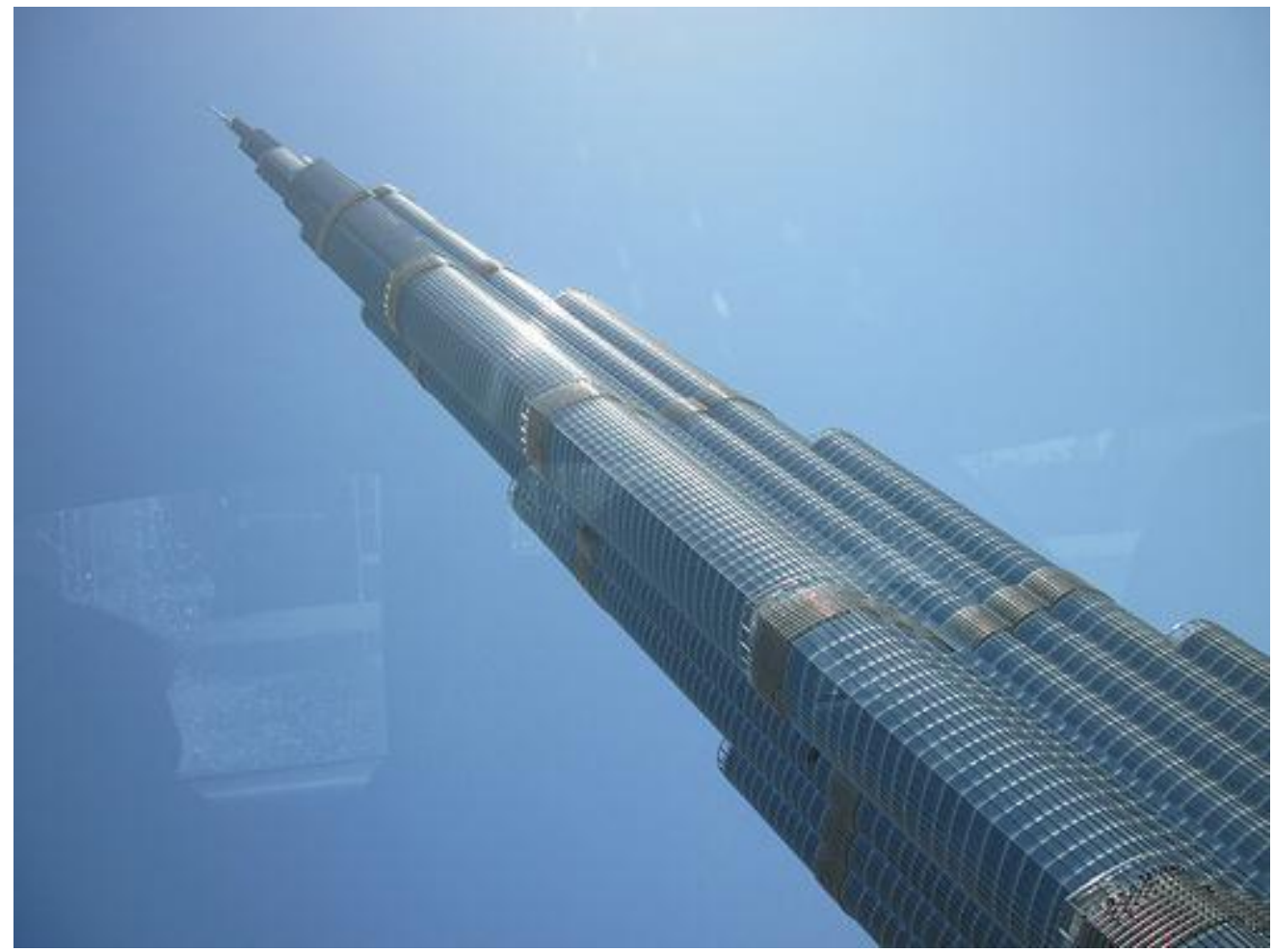

Figure 6: Burj Khalifa (felibrilu)

It is 828 metres high, the tallest building in the world, which you can't really tell from this picture. In fact, very few pictures capture the size of it, and if pictures fail to capture the scale of this building how can it be rendered in written language?

One of the main reasons these pictures fail to capture a sense of scale is they don't include a human being. The engineer and architect Forrest Wilson explains, in his 1971 book Structure: The Essence of Architecture, how the further away from human scale something gets the harder it is to conceive of (Wilson). We can feel the shape of a door knob in our hand and walk through a door in our mind's eye but once an object gets as far away from the size of us as the Burj, it's very hard to comprehend. We measure the world against ourselves in it.

Measurement against individual shape and size is difficult to repeat and therefore prove, so mathematics and physics seek to standardise physical form.

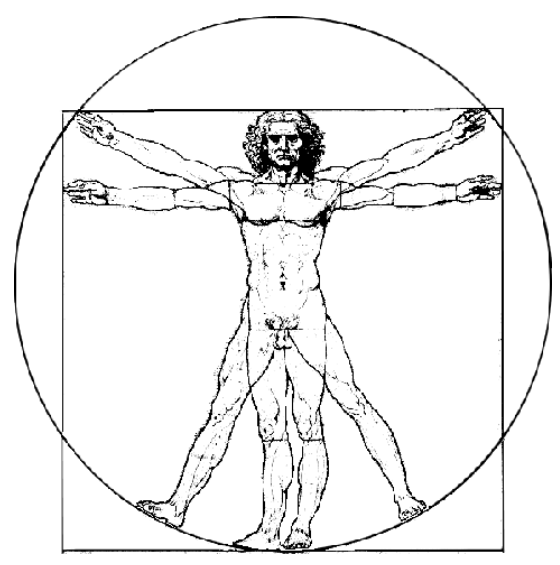

Figure 7: Vitruvian Man

One example of an attempt to standardise human form can be seen in Leonardo da Vinci's Vitruvian Man. Surrounding da Vinci's sketch are notes from Vitruvius' 
architectural treatise De Architectura. These notes describe 'the human figure as principal source of proportion among the Classical orders of architecture' (Pollio). However, Vitruvius has in mind a particular human figure. He asserts that the symmetry of two eyes, two arms, two legs should be mimicked in the design of buildings. Da Vinci's sketch and the notes are also known as the Canon of Proportions and illustrate the ideal human figure Vitruvius has in mind. By supplying architecture with a standardised man to measure its work by, a design can be tested against a constant ideal which does not alter from design to design or designer to designer.

One of the language solutions engineers use to translate built forms is to break the complete form into sections which are simple enough to comprehend. These sections often represent parts of the structure which are repeated. So once understood in their isolated form, a reader is able to multiply these sections and build them into the complete structure. Articles written about the Burj Khalifa by engineers working on the project often include a diagram of a Typical Floor Plan.

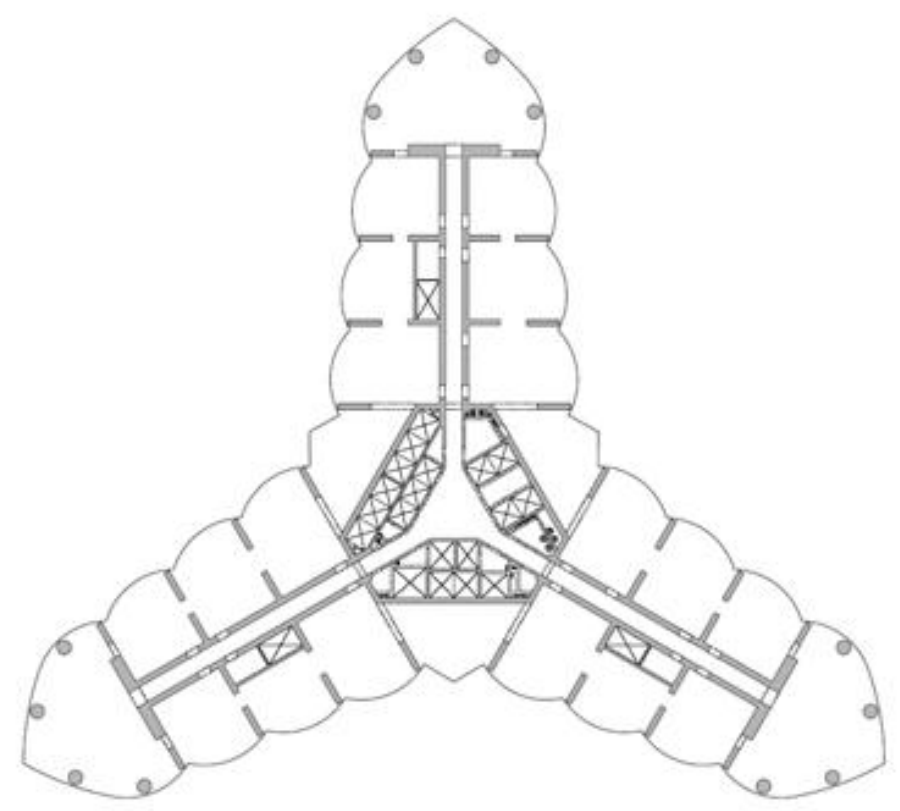

Figure 8: Typical Floor Plan (Baker, Pawlikowski and Young "The Challenges in Designing the World's Tallest Structure: The Burj Dubai Tower” 1473) 
This diagram includes no detail which distinguishes it as a specific storey, unlike other floor-plans which are used to communicate the layout of an office or hotel storey. The image is accompanied by writing which helps the reader build the whole Burj Khalifa from this simplified floor-plan ${ }^{12}$ :

As such, the floor plan of the Tower consists of a tri-axial, "Y" shaped plan, formed by having three separate wings connected to a central core. As the Tower rises, one wing at each tier sets back in a spiralling patter, further emphasising its height (Baker, Pawlikowski and Young "The Challenges in Designing the World's Tallest Structure: The Burj Dubai Tower" 1473).

Engineers apply a similar strategy to the problem of expressing size. By using agreed measurement systems to break whole size into consistently proportioned smaller parts engineers can communicate an agreed perception of built forms. All systems of measurement use a base unit similar to human size which can be multiplied or divided to give a sense of an object's size in comparison to that base unit. The unit of a 'foot' is the end result of the standardisation of the act of measuring objects against parts of the body. The fathom, an imperial unit used to measure depth of water, was originally the distance between the fingertips of a man's outstretched arms. This distance would inevitably vary so to meet the need for greater consistency it was standardised against an inch: one fathom equals 72 inches.

Abstraction of the human form is necessary to develop and repeat the complex equations forming the basis for the structural design of a building. The building is measured against the ideal foot and is built to support the standard man as he walks at a standard pace to sit in a standard way. Individuals who will populate the building on completion are largely an abstract concept. At the point of design the building is also abstracted into force and weight but as construction begins it becomes a tangible and individual object during construction. The building is populated with construction

\footnotetext{
${ }^{12}$ The Burj Khalifa's architecture and engineering were performed by Skidmore, Owings and Merrill of Chicago, with Adrian Smith as chief architect, and Bill Baker as chief structural engineer. During the construction of the tower Baker presents talks and publishes papers. All the texts are peer-reviewed and so accepted by the receiving culture of engineering suggesting that the solutions Baker et al found were acceptable in the context of engineering language.
} 
workers and although the anticipated population comes into focus through the activity of these workers, the final population and their activities remain largely conceptual. At this stage of completion, there are often attempts to re-people the building using language - to give an individual and actual human shape to the anticipated population.

These attempts to humanise the building are often made by architects and developers, usually in order to market what is ostensibly concrete and steel. The simplest strategy is to name the building after someone whose characteristics they want to associate with it. An example is the Victoria University of Wellington Teaching, Learning and Research Building which became, toward the end of its construction, the Alan MacDiarmid Building. MacDairmid is a Victoria alumnus and Nobel Prize winner who symbolises the aspiration made by Deputy Vice-Chancellor, Professor Neil Quigley, that the building 'will ensure we continue our world-class work in science' ("Doors Open at Alan MacDiarmid Building"). A similar strategy was used when the University of Auckland Business School was named after Owen G. Glenn, a benefactor of the school and one of New Zealand's most successful businesspeople. Glenn's name is synonymous with prosperity and inspiration, words used by the school's website to describe the building ("Owen G Glenn Building: Facilities and Resources"). The major financial contributor to the building is the New Zealand Government but Glenn's name adds more weight to its aspirations. Through naming and promotional writing the abstract version of the building, expressed in the technical language used to construct it, is transformed into an architecture which embodies positive individual human characteristics. It is instructive to analyse if engineers make a similar attempt to re-people and personalise these buildings in their texts.

In 2009 engineering consultants Beca Group Limited enter their work on the Owen G. Glenn Building to the Association of Consulting Engineers New Zealand (ACENZ) Annual Awards of Excellence. In line with requirements Beca enter a written submission which includes a descriptive technical report, an entry form and images. The entry requirements state that the submission will be distributed to a panel of judges and should include information 'adequate for them to assess your project by reading this submission alone' (Association of Consulting Engineers New Zealand 1). In this way the submission acts as a surrogate or translation of the building. Although the front page of the submission identifies the building as, 'Owen G. Glenn Building - University of Auckland New Business School', the rest of the submission refers to the building as the 'University of Auckland Business School', or 'the building'. In general the building is 
referred to by way of its parts; it is only in the introductory chapters that it is referred to as a whole. There is a diagram on page six which includes abstract human forms. Most of the images of the building in the appendix are taken at night and contain no people. One shows people in the background and another the building under construction and populated by building contractors.

The executive summary of the submission says Beca aims to complement the 'architectural vision for an iconic form' $(1)^{13}$ and describes the people who inhabit the building as: 'students totalling 6000 in the building at any one time, in addition to the $300+\operatorname{staff}(1)$.

Beca's entry in 2009 is successful and they are awarded the 2009 Gold Award by the ACENZ. A link to this award, pictures and description of the Owen G. Glenn building can be found on Beca's website except, again, the name Owen G. Glenn does not appear, the building is called the University of Auckland Business School. The pictures available on the website all show an empty building with no people.

The representation of the completed building in Beca's ACENZ entry and website maintains the abstraction and de-peopling norms used in the language of physics, mathematics and diagram which describe the building before it is begun. This representation elevates the building above the people associated with it, giving the building's structure primacy over human characteristics. The engineering texts display a different relationship between humans and buildings to that projected by architects and developers. Where architects and marketers will isolate and promote what is unique and individual about people, engineers represent an abstract, generalised population in their texts. The people engineers choose to associate in their texts with the buildings they design do not distinguish themselves as 'prosperous' or 'inspirational' but are instead '6000 students' or ' $300+$ staff. It could be argued that the architect attempts to make the building more human while the engineer seeks to make the human more building. A full exploration of this idea would require research outside of the scope of this project. However, it is relevant to explore further the extent to which engineers standardise human form and experience to translate buildings. The following example investigates the communication techniques one set of engineers choose when they are unable to express a building's height in units of standard measure.

\footnotetext{
${ }^{13}$ This follows the general norm of representing any conceptual feature of the building as belonging to the architect (See also: Gledhill in interview, and others).
} 
On January 4, 2010, as the world's tallest building was opened, its height was revealed as $828 \mathrm{~m}$ (2717 ft.) and it was renamed Burj Khalifa after Sheikh Khalifa bin Zayed Al Nahyan - the president of the United Arab Emirates and the ruler of the neighbouring emirate of Abu Dhabi (Arnold). Until this time, the height of the Burj Khalifa was a 'well-guarded secret' (Baker, Korista and Novak 361). On 20 March, 2009, Baker makes a speech as part of the Lehigh Lecture Series in which he jokes, 'How tall will it be? - I can't tell you' (Baker). Before its completion Bill Baker and members of his staff had spoken and written many times about what would be the tallest synthetic structure in the world without mentioning the measurement they were working toward. Instead Baker et al. employ other communication techniques to express the building's height. Many of the articles written by Baker and his team start with this, or a similar, sentence:

The goal of the Burj Dubai Tower is not simply to be the world's highest building; it's to embody the world's highest aspirations (Baker, Korista and Novak 361).

The concept of the superlative makes the translation of Burj Khalifa's height relatively straightforward. Most people understand the concept of the 'highest' but it is interesting that Baker and his company choose to compare the physical height of the tower with the emotive concept of aspiration. Perhaps this is another way to measure something so far from human size against something we can hold in our mind. Everyone has felt hope, or recognised it in others, and this experience might be extended by the imagination to an image of the 'highest aspirations'. The solution employed by these engineers is similar to those used by architects and marketers previously mentioned. Baker et al. do not refer to an individual's highest aspirations, though, but 'the world's'. This gives an odd sense of a communal highest hope set above the hopes of any one individual.

In the absence of standard units of measure Baker et al. also employ other solutions to the problem of expressing the final height of the Burj Khalifa. They usually follow a comment about confidentiality with an assurance that the Burj will 'comfortably exceed the current record holder of the 509 m (1671 ft.) tall Taipei 101' (Baker, Korista and Novak 361). Baker and his co-authors often use comparison to other buildings to express the height of the Burj. In his Lehigh speech, given to a largely American audience Baker superimposes a drawing of the Burj onto the Manhattan skyline and compares it to the Sears Tower. In written texts a diagram is sometimes used which 
compares the Burj with several other super tall buildings (Baker, Pawlikowski and Young "The Challenges in Designing the World's Tallest Structure: The Burj Dubai Tower" 1472).

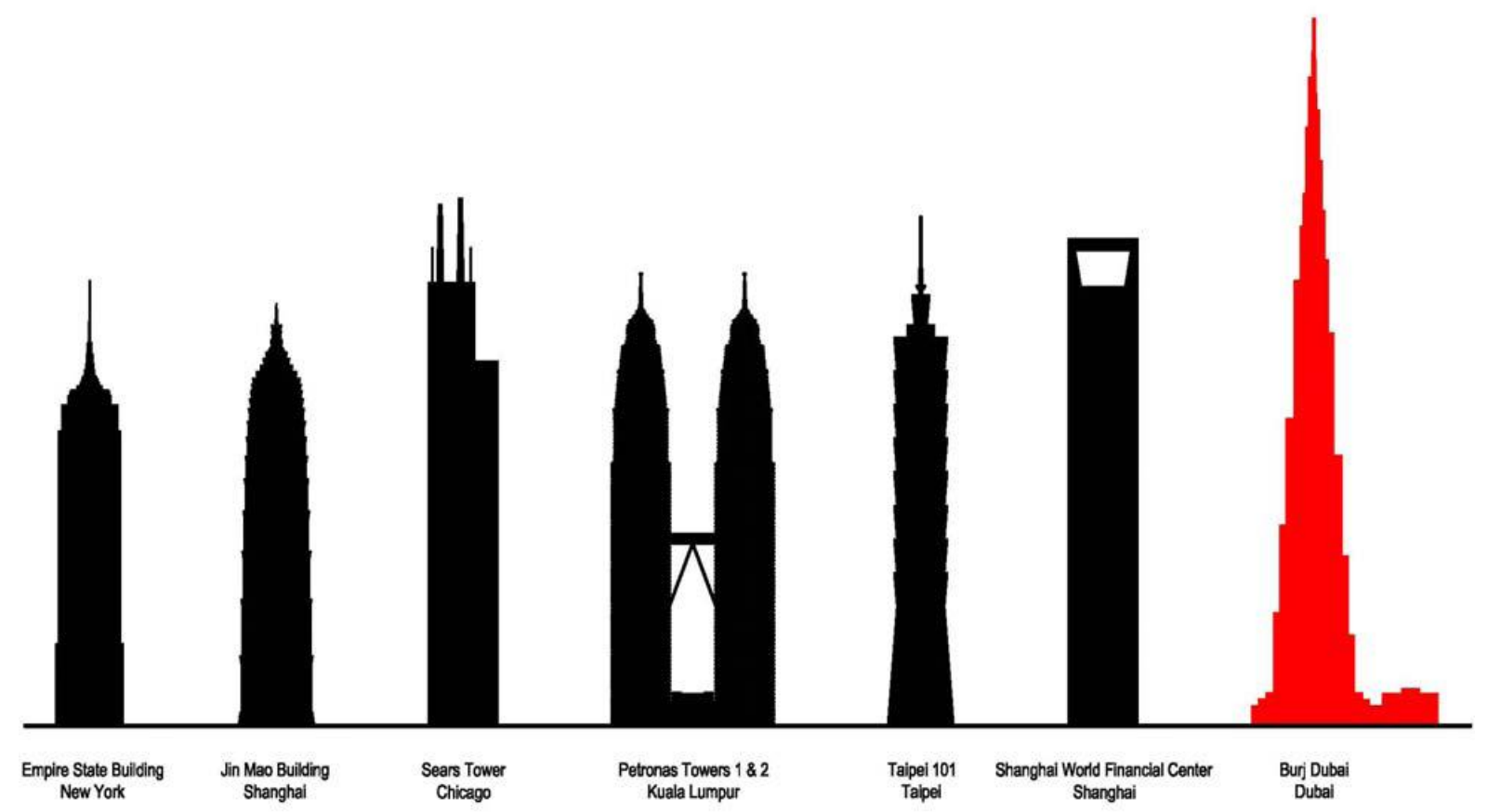

Figure 9: Comparison of Burj with other tall buildings (Baker, Pawlikowski and Young "The Challenges in Designing the World's Tallest Structure: The Burj Dubai Tower" 1472)

Baker et al. put the Burj Khalifa in context with other buildings rather than a human form. As previously mentioned, the place of the individual in engineering culture is a complicated one and when exploring the relationship between the human and the built it can be seen that there is a writing away from individual experience and form. It could be argued that the buildings alone are able to be individual or eminent but even this seems erroneous when the writing of engineers is analysed.

The Council of Tall Buildings and Urban Habitat (CTBUH) is the official arbiter of the criteria upon which tall buildings are measured and confers the title of 'World's Tallest Building' (Council on Tall Buildings and Urban Habitat). On completion, the CTBUH declare that Burj Khalifa as not only the tallest building in the word but the tallest man-made structure, a title it takes from the KVLY-TV mast in North Dakota. At the time of writing, it is taller than any other man-made structure in the world. In a 2007 
paper Peter A. Wesmantle, Gregory L. Smith and Mohamed Sheriff, of Skidmore, Owings \& Merrill, state:

Burj Dubai is termed a 'super-tall' building, but, because of its significant increase in height over any existing structure, it could also be termed the world's first 'mega-high-rise' (340).

This call for a new term coined especially for the Burj sets it off as one-of-a-kind. While many of the language strategies surrounding Burj Khalifa aim to pull it out from the crowd, whether visually in a diagram or verbally by inventing new terms to describe it, there is also language surrounding the Burj Khalifa which aims to put it in context. In an interview with Sky News, Baker says engineers could 'easily' go to a one kilometre high building with a 'fairly economical design' (SkyNews). However, he explains that Frank Lloyd Wright's mile high tower ${ }^{14}$ would be a bit of a reach as engineers are largely limited by the mechanics of the human middle ear and the decompression that happens in an elevator travelling to such great heights (SkyNews). By placing Burj Khalifa on a continuum starting with Wright's 1956 design and looking ahead to the next tallest building, Baker pulls Burj Khalifa back into the context of engineering achievement. By alluding to Burj Khalifa in context, Baker highlights the combined progress the engineering profession has had and will have in the future. In a way he ensures progress through language by presenting Burj Khalifa not as distinct or peculiar but as part of a tradition which can extend into the future.

The engineer must chose ways of writing and speaking features associated with the relationship between the built and the human which are difficult to translate. The key language problem is that in order to build, engineers must standardise human form to a general or ideal condition. However, as buildings are designed and populated by diverse individuals it is necessary also to reflect this in their writing. Architects and developers reflect this varied population by associating individual character traits with the building. From the example of the Burj Khalifa it can be seen that engineers also associate buildings with human character traits but their writing displays a tendency to emphasise continuity and context rather than individuality. It is the 'world's aspirations' that Burj

\footnotetext{
${ }^{14}$ Baker is referring to the Illinois Tower which was designed by Wright but never built.
} 
Khalifa will embody, not those of the King it is named after. Engineering writing contains examples of expression that pull the individual back into a continuum. My previous chapter on engineering culture shows how the individual engineer is a complicated figure, while the community of engineers is better established. This chapter shows the individual occupant is standardised into a generalised population when engineers write about people. My final example of this chapter shows that even when writing about the tallest built structure in the world, engineers temper superlatives with talk of context and continuity.

The following chapter explores ideas of aesthetics. In particular it seeks to identify the features of a built form an engineer might find beautiful or pleasing, features which are often difficult to translate into written and spoken language. Through analysis of the writing surrounding Centre Pompidou and the China Central Television (CCTV) building I investigate how engineers translate these features and the felt response they provoke. 


\section{FELT RESPONSE: SOLVING LANGUAGE PROBLEMS OF AESTHETICS IN ENGINEERING WRITING}

This chapter explores the features apparent in a built form which are designed to create response and how engineers translate these into written language. Largely, it deals with delight and I explore texts in an attempt to uncover what engineers find beautiful or pleasing. Particularly, I investigate how engineers attempt to standardise delight and beauty in order to solve the problem of translating subjective felt response. I explore what my analysis of Peter Rice's texts on Centre Pompidou reveals about the application of these standards of beauty. Finally, through an analysis of texts written about the China Central Television (CCTV) complex, I explore how these standards of beauty relate to a building designed to elicit less conventional responses.

\subsection{Delight}

In his 1951 lecture 'The Interrelation of Engineering Design and Architecture', the architect Frederick Newman points to the Oxford Dictionary entry for the word 'Aesthetic' to identify a misapplication of the word. Newman explains that a note in this entry states the word aesthetic 'is an adaptation of a Greek word and means of, or pertaining to “aisteta” (feeling) as opposed to "noeta” (mind)' (45-46). Newman argues that aesthetics has become synonymous with analysis which centres in the mind when in fact what it originally stood for was something associated with synthesis and feeling. Newman gives an example which articulates the felt response he associates with aesthetics:

When we admire bridges of Telford, Rennie and Harrison or Michelangelo's cupola of St. Peter's in Rome, we are completely satisfied. One of the reasons for this happiness is most definitely that we are confronted with strong conceptions or creations which convey to us - among many other feelings - a perfect engineering solution. The same can be said about much of the Roman engineer-architects which culminated in such buildings as the Pantheon in Rome 
If we look, on the other hand, on structures like the bridge over the River Indus at Sukkur, or the office buildings erected recently under the 'Lessor Scheme' in London, we cannot maintain that they communicate similar feelings to us as the buildings mentioned before (47)

Vitruvius uses the word 'venustas' in his three commodities and it is generally translated as 'beauty'. However, it has also been translated as 'delight'. The effect of using 'delight' instead of 'beauty' is to move the quality from the object to the observer or occupant. This shift from objective to subjective experience complicates the translation of built forms into written and spoken language. However, Newman's suggestion that felt response is generated by the very rational event of a 'perfect engineering solution' begs the question, do engineers agree on this perfect solution? If they do, does this point to an agreed language and measurement of delight? Is it possible to identify what engineers find beautiful and apply this standardised view of beauty applied to the problem of translation into written and spoken language the delight expressed by built forms?

In his 1985 article 'Aesthetics of Wood Structure', the engineer Stefan J. Medwadowski conducts an exploratory enquiry that considers 'those characteristics of wood structures which are thought to endow them with beauty' (31). He sees the two pertinent concepts which must be investigated before examining the constructional characteristics of wood structures as 'the source of delight as a human response to a work of architecture, and the questions of simplicity and rationality in design' (Medwadowski 31). This pairing of response and rationality seems characteristic of writing by engineers about aesthetics.

Medwadowski states that an observer or occupant of a built form experiences delight in three ways: intellectually, morally and sensually. Intellectual delight is experienced through an understanding of 'the manner in which the structure transfers forces, the manner in which it was fabricated and erected or, more generally in understanding the manner in which the structure fulfils its role in the project as a whole' (Medwadowski 34). Moral delight is experienced when 'the structure may satisfy the observer's sense of [the] "fitness" of things - he deems it the right structure for the task it is to perform' (Medwadowski 34). Sensual delight, for Medwadowski, comes primarily through sight, 'Through it, information is received about the form of the structure in the large, about its internal make-up (the structure in the small), and about the nature of its 
material, its connections and its relation to the surroundings' (34). The sense of vision also provides information about colour and texture. Information about texture may also be provided by the sense of touch. The sense of hearing provides information about acoustics. It is through this information that an observer may experience sensual delight. Medwadowski's description of how an observer or occupant might experience delight seems far more prescriptive and precise than Newman's elusive ideas of happiness or satisfaction.

After his explanation of how delight might be experienced, Medwadowski suggests two characteristics of structure which are generally considered aesthetically pleasing: simplicity and rationality. He explains that although easier, perhaps, to 'recognise than to define' (Medwadowski 34), objects that display simplicity share a common attribute:

they perform their function, or capture the essence of an entity, of an event, or of an idea with the greatest possible economy of expression while using a minimum of material appropriate to the task at hand (Medwadowski 35-36).

He explains further:

Rationality is, possibly, easier to grasp. A structure may be considered rational if it conforms to the general constructional characteristics of the material of which it is built. As an example, light material such as fibreglass should not be used in the construction of counterweights in a bascule bridge, or a material weak in tension and available only in small blocks, such as stone, should not be used as longspan beams (Medwadowski 36)

This idea of a general agreement and definition of what is delightful seems to echo earlier discussions in the engineering community about aesthetics.

In 1944, the Institute of Civil Engineers, presents a lecture series called 'The Aesthetic Aspect of Civil Engineering Design' in which engineers and a handful of 
architects are invited to speak on the topic ${ }^{15}$. By and large, the speakers agree that there are measures of beauty. One speaker, Charles Edward Inglis, explains, 'I believe that what is pleasing and the reverse is fundamentally a matter of human psychology and certain normal mental reactions common to all' (43). There is emphasis on order as part of beauty, defined by Charles Holden as, 'the condition in which every part or unit is in its right place; tidiness; normal or healthy or efficient state' (28). This definition is similar to Medwadowski's simplicity. What is apparent in many of the speeches is the engineer's moral duty to design built forms which meet these agreed measures of beauty. Holden states:

It is right and proper that any person, be he engineer or architect, who designs for any specific purpose should wish, in the first place, that his plan should have the highest possible efficiency for the purpose it has to fulfil. In the second place, it must be constructed to fulfil its purpose with reasonable economy having regard to the client's interest in respect to length of life and low maintenance costs. In the third place, the finished structure must be seemly in whole and in part, because we have no right to inflict upon our clients or upon the public a structure which offends the eye or which ignores the desirable qualities of neighbourliness, good form, good material and good execution. Our own pride in our work must guide us in the direction of beauty. I use the word 'pride' as meaning the feeling of elation and pleasure in work, and not in the sense of overweening opinion or arrogance (26).

Holden's comments and the certainty with which he makes them are exemplary of the attitude of all other speakers, with the exception of one. Only architect and town planner, Patrick Abercrombie suggests the ambiguity of aesthetics cannot be fully resolved. Abercrombie finds it necessary to adapt the title of his talk to 'Some Aesthetic

\footnotetext{
${ }^{15}$ In his 1951 lecture, Newman suggests that this series often applies the word 'aesthetic' instead of the word 'art' but I believe this criticism of the lectures doesn't discount them as demonstrations of the standardised measures of beauty apparent in engineering writing. See Newman, Frederick H. "The Interrelation of Engineering Design and Architecture," Frederick H. Newman: Lectures on Architecture, ed. Andrew Leach (Gent: A \& S Books, 1951) 46.
} 
Aspects of Civil Engineering' (71). He apologises for the unmethodical and vague nature of his talk, following this with another apology for his dogmatic defence of his definite opinions. The first of Abercrombie's opinions mirror the Platonic belief that beauty is a thing in itself, that it is not tied to utility but is instead abstract and absolute, 'a beautiful thing may be unfit for a practical purpose, and something fit for its purpose may not be beautiful' (71). Abercrombie's talk stands in contrast to those of the engineers and even the other architects. He seems less than convinced of absolute measures for beauty, especially over time. His talk contains several references to the expansion of the canon of beauty which over time has allowed more and more objects in. Abercrombie's speech stands alone and in contrast to the others presented in the series, all arguing for the existence of an agreed engineering aesthetic.

The concept of an engineering aesthetic may arise out of the industrial revolution - a time of accelerated change. In the building industry this was characterised by factory-produced new materials, new construction methods and their application to new building projects including railways and in turn bridges and tunnels. In their 2009 paper 'The Engineer's Aesthetics - Interrelations between Structural Engineering, Architecture and Art', architect Jutta Weber and structural engineer Viktor Sigrist identify industrialisation as the shift from 'traditional architectural concepts toward a new socalled engineer's aesthetic - which was first critically discussed, but soon celebrated as the only acceptable aesthetic of modern times' (1494). This aesthetic grows out of economic and technologic demands and is best expressed as a 'truth to the material and the embodiment of the flow of forces' (Weber and Sigrist 1497). Weber and Sigrist use Gustave Eiffel's Garabit Viaduct to demonstrate:

The construction shows a new space-mass-relationship: The massive body of a stone bridge resolves into an 'air framing' steel skeleton, which rises above the riverbeds in an almost immaterial way. The technical character of the structure, thus, predominates the building both in respect to its construction and its aesthetic appearance 
The engineering aesthetic is reflected in the Modernist movement in art and architecture. In his manifesto Towards a New Architecture, Modernist architect and writer, Le Corbusier states, 'The engineer, inspired by law of economy and governed by mathematical calculations, puts us in accord with universal law. He achieves harmony' (7). When Le Corbusier turns to the engineer for art, he adopts the standards placed on beauty by the

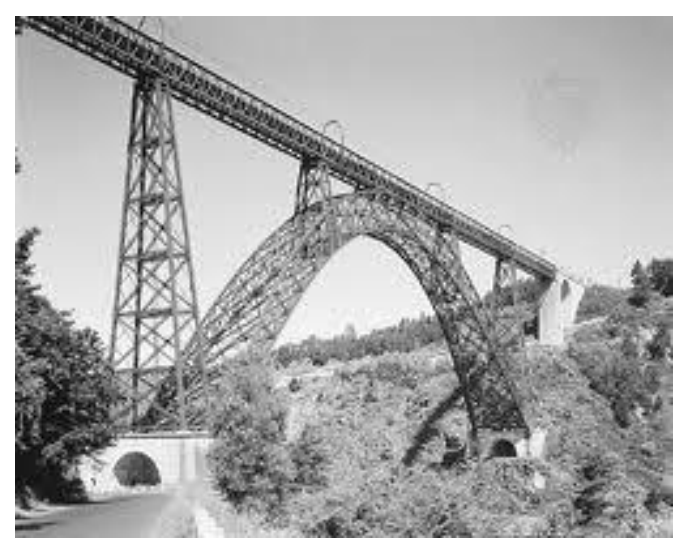

Figure 10: Garabit Viaduct (A.F. Kersting) engineering culture - harmony through design which reflects empirical truth.

Having an agreed language of beauty which includes measures for order, proportion and expression of material and force goes some way to answering the problems of how to express subjective responses like delight and joy. To identify how engineers use these principles when translating built forms I have chosen texts concerning the Centre Georges Pompidou, also known as Beaubourg, in Paris and the Central Television Centre (CCTV) building in Beijing. I have chosen these buildings because neither has an uncomplicated relationship to beauty and delight. Beaubourg represents something of an inversion in architecture, exposing all structure and utilities, as if the building had been turned inside out. CCTV expresses the concept of interconnectivity and synergy in a literal loop, putting all its structural engineering at the service of shape. Both buildings are controversial because they show such strong commitment to the principles of their different aesthetics. I am interested in how engineers approach questions of felt response in their writing about Beaubourg and CCTV.

\subsection{Centre Georges Pompidou / Beaubourg}

In 1971 the French government sent out a competition brief for the design of a 'Centre erected in the heart of Paris, not far from Les Halles, devoted to the contemporary arts, which would include a public library of all-encompassing scope' (Competition Brief cited in Colquhoun). There were 681 entries. The winning entry was submitted by a group from Ove Arup \& Partners in collaboration with the architects Renzo Piano and Richard Rogers. Their design was praised by the president of the judging panel for its 'striking 
simplicity' (Levy). In a 2001 interview for the documentary series Architects 1 Richard Rogers still stands by the building's simplicity of vision:

The structure is simple and repetitive but dressed to shock. All the functional parts are on the outside. Walkways for each floor between facade and tie rods, outside the frame, a huge escalator to the fifth level. These two superimposed layers on the frame of the building give it its industrial image. Transparent tube - a fairground ride. Facing the forecourt is the fair, facing the centre is the factory. The Eastern facade is made of building entrails - cables. Proud and playful - displayed. Blue for water, green for air, yellow for electricity, red for transport. White mushrooms, red boxes, everything contained within space between steel columns and tie rods (Copans et al.).

As previously stated, the lectures from 1944 and Medwadowski's 1985 article emphasise again and again the importance of simplicity and rationality to aesthetic delight.

However, when Beaubourg was opened in 1977, many people were less than delighted ${ }^{16}$. Criticism of the Pompidou Centre was strong. In her 2007 review of The SoCalled Utopia of the Centre Beaubourg Elizabeth Schambelan summarises the criticism as follows:

Henri Lefebvre called it an 'immense boutique', the 'Palm Beach of the poor' and a 'complete failure'; Gordon MattaClark dubbed it a 'brave-new cobweb'; and Jean Baudrillard, in a single short paragraph, likened it to a 'carcass', an 'incinerator', a 'black monolith', and a 'mad convention current' (Schambelan).

\footnotetext{
${ }^{16}$ Weber and Sigrist explain the Modernist engineering aesthetic was not universally popular and that from its earliest applications critics, including Karl Bötticher, Gottfried Semper, and later Eugene Viollet-le-Duc complained 'the new structures appeared too technical, too cold, crude and quasi dead' (1495).
} 
The criticism went on for years - 'oil refinery', 'hanger', 'scrap metal monstrosity', 'insult to good taste' (Copans et al.). Copans and Neumann suggest in their 2001 documentary that the young architects and engineers did not set out to provoke. The design was light and playful and embodied a desire to 'carry on the British tradition of building in steel only in France, where concrete is king' (Copans et al.). The concrete in the Pompidou Centre is underground, three storeys deep below the whole centre, enclosing a concert hall and carpark. This burying of concrete in favour of culturally British steel seems to have an interesting manifestation in the book The So-Called Utopia of the Centre Beaubourg which appeared in 1976 to coincide with the opening of Pompidou, under the pseudonym Gustave Affeulpin. The So-Called Utopia of the Centre Beaubourg imagines an alternative Centre Pompidou built in concrete under the official building. The unofficial Beaubourg is established to be the antithesis of the state-sanctioned cultural vision of its upstairs neighbour. In Affeulpin's Beaubourg, everything will be included, nothing excluded but first the subversive-curators need a meeting to organise some chairs ${ }^{17}$.

On the subject of the delightfulness, or not, of the Centre Pompidou, Renzo Piano's comments embody the Modernist aesthetic of building as machine. In the Architects 1 documentary he describes the Pompidou Centre as process rather than object:

Like a machine the centre produces and like a machine the finished goods are more beautiful than the centre itself. The Pompidou machine produces space - naked space (Copans et al.).

Piano's comments on Pompidou's aesthetic borrow heavily from the language of manufacture; yet they are articulated in the culture of architecture - concept expressed through material into form. It is interesting to examine how engineers articulate the delight of this very engineered of buildings.

In 1971, when the competition brief for Beaubourg arrived, Peter Rice was working in the Structures 3 group of Over Arup \& Partners in London, a group run by Ted Happold. Rice dedicates an entire chapter to Beaubourg in his book An Engineer Imagines.

\footnotetext{
${ }^{17}$ Affeulpin plays the pragmatics and bureaucracy necessary for the subversive and revolutionary project of the New Beaubourg for comic effect. The crowd of curators decide they need a meeting but they have no chairs. So they decide they need a meeting to decide how to have some chairs.
} 
Rice does not represent the beauty of Beaubourg the same way as the architects. Instead of describing it as a playful machine, in Rice's writing the Centre becomes earnest and honest.

The purpose of Rice's Beaubourg chapter must be considered. Rice is not writing a technical paper purely for use in an engineering office. His family explain in the Preface to An Engineer Imagines that:

He [Rice] always had a specific idea about what sort of book he wanted to create - not a textbook about how to solve technical problems but a personal account of the joy and enthusiasm he took from his profession. More than anything Peter wanted to communicate the limitless potential of the engineer's role in pushing back the frontiers of the built environment. Consequently, it was very important to him that An Engineer Imagines should be accessible to all and not just to an architectural or engineering elite (Rice, An Engineer Imagines 19) ${ }^{18}$.

An analysis of Rice's chapter on Beaubourg shows another way engineers translate the beauty of a building through their writing and it is interesting to note how this interpretation fits within the conventional concept of the engineering aesthetic of simplicity and rationality.

Rice begins his chapter with a description of the people he worked with on Beaubourg and the establishment of the office in Paris. He includes an amusing comment about the advantages of not speaking French:

From time to time members of our team who spoke French would interrupt the dream, and tell us how sceptical and

\footnotetext{
${ }^{18}$ This is not what would be considered conventional engineering writing, however, there is evidence that it has been accepted into the engineering culture. The book was recommended to me by several engineers I talked to about my project and I found few who hadn't heard of or read it. It also gained positive reviews in architectural, scientific and engineering publications: Ian Ritchie, 'An Engineer Imagines' by Peter Rice, 1994, Ian Ritchie Architects, Available: http://www.ianritchiearchitects.co.uk/literature/an-engineer-imagines/, 25 August 2011 2011, Ritchie, 'An Engineer Imagines' by Peter Rice, Mark Whitby, An Engineer Imagines, 1994, The Architectural Review, Available: http://findarticles.com/p/articles/mi_m3575/is_n1174_v196/ai_16561938/, 25 August 2011 2011, Ted Happold, "Beaubourg: Architecture or Engineering?," Centre Pompidou (New York: Rizzoli International Publications, 1977).
} 
unhappy the French officials were, how unreal they considered our presumption, particularly the British engineers' presumption: 'We have some great engineers in France you know ...' But we continued to smile and believed somehow we were different' (Rice, An Engineer Imagines 28)

After describing the team and their situation, Rice describes the problems posed by their design for Beaubourg. This statement of problems is a vital component in engineering's standardised concept of beauty. Traditionally, the engineer aims for an elegant construction which solves the problems of strength and utility using the least amount of money.

After expressing the problems posed by the design, Rice explains the trip he took to Japan, his observation of the cast steel nodes and the idea this prompted ${ }^{19}$. Rice explains that he had wondered for some time about which features of the large engineering structures of the nineteenth century gave them their 'special appeal' ( $A n$ Engineer Imagines 29). His use of the word 'appeal' stands in for terms associated with aesthetics - delight, beauty. After seeing the cast-steel nodes in Kenzo, Rice says, he understood that it was because these structures exuded 'craft and individual choice' ( $A n$ Engineer Imagines 29) that:

The cast-iron decorations and the cast joints give each of these structures a quality unique to their designer and maker, a reminder that they were made and conceived by people who had laboured and left their mark (An Engineer Imagines 29).

Cast steel, he concludes could have this same quality, 'Cast steel had the possibility of achieving the same personal contact' (Rice, An Engineer Imagines 29). Rice describes the conventional way steel structures in buildings are produced using machine rolled or

\footnotetext{
${ }^{19}$ As stated, Happold's review of An Engineer Imagines calls into question Rice's account of how the decision to cast the steel came about. However, I believe Rice's account is still relevant to this discussion as I am using it to explore his expression of his personal experience of the process rather than attempting to verify the exact truth of the event.
} 
extruded, visually and geometrically uniform members. Then he describes the effect of this type of manufacture as follows:

Surprise and personality are missing particularly for the general public, and with it all the feeling of contact and warmth between the person looking and the maker, whether designer or fabricator. The introduction of cast steel seemed a way to break this deadlock; a way to create out of the Centre Beaubourg structure something which by its element of surprise and unpredictability, by the unusual conjunction of casting among the more common steel elements, would make the structure part of an approachable and sympathetic building. The scale of the Centre Beaubourg would be the scale of the pieces rather than the scale of the whole (Rice, An Engineer Imagines 30)

Rice's comments express a desire to introduce some of the warmth critics say is missing from the engineering aesthetic. His suggestion of enlisting pre-industrial/-modern craftsmanship counters the mechanics and technology which Rogers and Piano see as the over-riding features of Pompidou. Compared to Rogers' and Piano's interpretations Rice's seem humanist and very un-Modern in sentiment. This example, where an engineer petitions for 'contact and warmth' seems to go counter to the image of the engineer as cold and mathematically and also seems to complicate the concept of the engineering aesthetic. It appears here that Rice is choosing a material and process to soften the Modernist aesthetic rather than letting technology and optimisation dictate the design of the building.

Rice seems aware of this. Two paragraphs on from his firm argument for cast steel he attempts to explain himself in the context of the architectural team:

Cast steel was the way to go. It became my contribution, a mission. I was, I felt, the most ordinary person there. I was determined to do my bit. Little did the bureaucracy know, or the industry which later on decided that this fixation with using cast steel was silly, out of place in the modern era of 
1971, that they were dealing with an engineer obsessed. Engineers are sensible people, after all, not like architects or other artistic types. They are prone to make decisions by rational arguments, as they are people with pragmatic values, people who have seen the light (Rice, An Engineer Imagines 30-31).

Rice's commitment to cast steel as a material is based on aesthetic rather than rational motivation. Rice seeks to elicit a feeling of fellowship between maker and occupant in order to counter a lack of personality. This aim seems contradictory to what Le Corbusier identifies as an engineering aesthetic driven by economy. To implement his obsession, Rice explains, the most important step was to find the right shape for the material.

When the solution came to the problem of design, Rice explains it 'simply and elegantly resolved all conflicts' (Rice, An Engineer Imagines 32). One of the other engineers ${ }^{20}$ suggests a 'suspended beam on a short propped cantilever, the so-called gerberette solution named after Heinrich Gerber, a nineteenth-century German engineer' (Rice, An Engineer Imagines 32). The design of the gerberette element falls more easily into the engineering aesthetic than the decision to make it with cast steel. It is a simple, unornamented display of the flow of forces. Rice explains:

'The forces and loads in the piece - I like the word piece, it makes me feel like an artist when I use it - were the principal determinants of its shape: slender at the tension tie end where the load is applied, deep and strong over the column where the load and moment reach a maximum, and slender again at the point of pickup of the beam' (Rice, An Engineer Imagines 33).

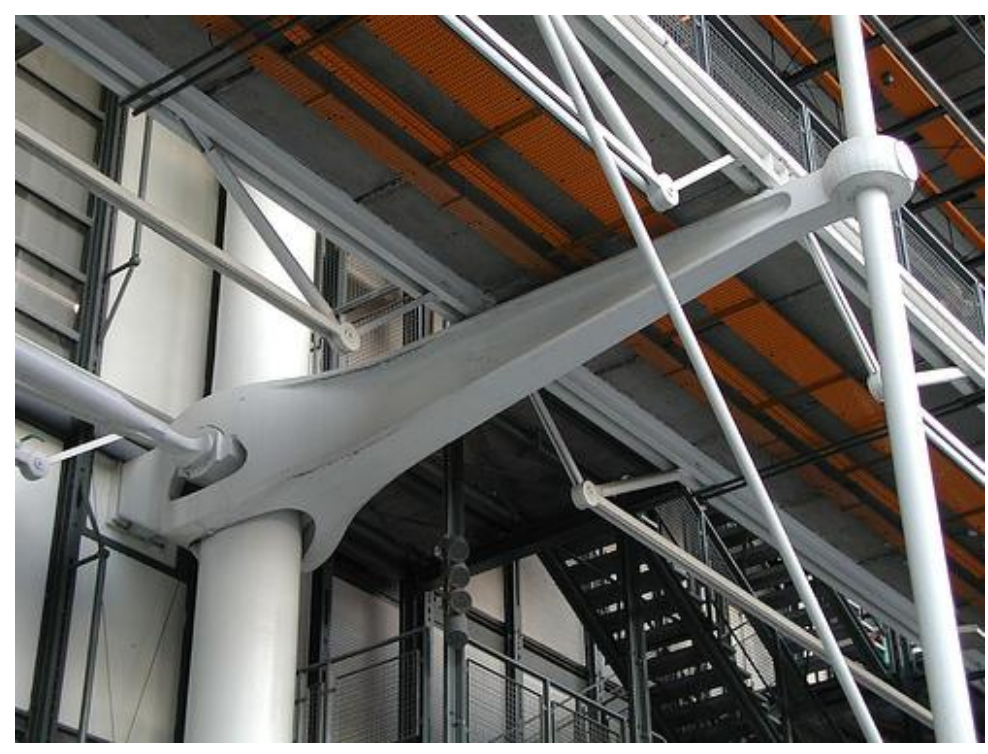

Figure 11: Gerberette (pav)

\footnotetext{
${ }^{20}$ Rice cannot remember who. Peter Rice, An Engineer Imagines (London: Artemis, 1994).
} 
Rice re-iterates this, 'Its shape was almost a structural diagram of the forces within it ... It had become an essay on how it works' (An Engineer Imagines 33-34). The restatement of this feature reflects the importance Rice placed on it for the success of the final design. This decision toward simplicity and the expression of force, suggests a desire to connect the element not only, through material, to the nature of its manufacture but, through form, to its structural action. The gerberette were difficult to manufacture. Rice describes the expense, conflict and troubles his insistence on cast steel caused. He concludes his chapter with the question, 'Was it worth it?' To which he replies:

No doubt at all. For me that question is simply answered. One day shortly after the opening I saw an old lady, dressed in black like the Irish mothers of my youth, sitting perusing the people and looking in wide-eyed astonishment. I watched her for a while, just sitting quietly, stroking the side of the gerberette, she was not afraid, not intimidated and she was on the fourth floor. And I thought that if somehow, by introducing elements like that, we can make people - people who would normally be alienated by things - feel comfortable, it proved to me that the thing that really matters is to introduce elements and materials into buildings in a way which reflects their real nature. The effect might not all be due to the cast steel, but that was certainly not negative. It was a positive contribution to the atmosphere and ambience. It was worth it (Rice, An Engineer Imagines 46).

Rice dedicates the largest part of his chapter on Beaubourg to the gerberette. This has the effect of elevating this element above all others in the structure. Rice describes the gerberette as warm, elegant and honest. This endows the element, the structure and in turn the building, with a moral agenda. One of the aims of Rice's book is to make the concepts of engineering accessible and perhaps he gives the building human characteristics for this purpose. However, despite this, the description does gel with the 
highest aspirations of engineering and many of the characteristics come directly from the agreed engineering aesthetic.

Rice's description of the gerberette offers an interesting study of the standardised measures of beauty promoted widely in the engineering profession. Rice's vision for cast steel was decidedly un-Modern and embodies a different aesthetic aim for Beaubourg than those expressed by Rogers and Piano. His insistence on the more difficult material appears to go against the principles of simplicity and rationality. Principles expressed in much of the engineering writing of the time. Yet, the gerberette in its finished form embodies simplicity and rationality through the expression of force. From Rice's Beaubourg chapter we can see he placed great emphasis on the felt response his design would create and in the end this is how he measured its success. 


\subsection{Dà kùchă (大裤衩) Big Boxer Shorts ${ }^{21}$}

China Central Television Centre (CCTV) Building / 中央电视台总部大楼

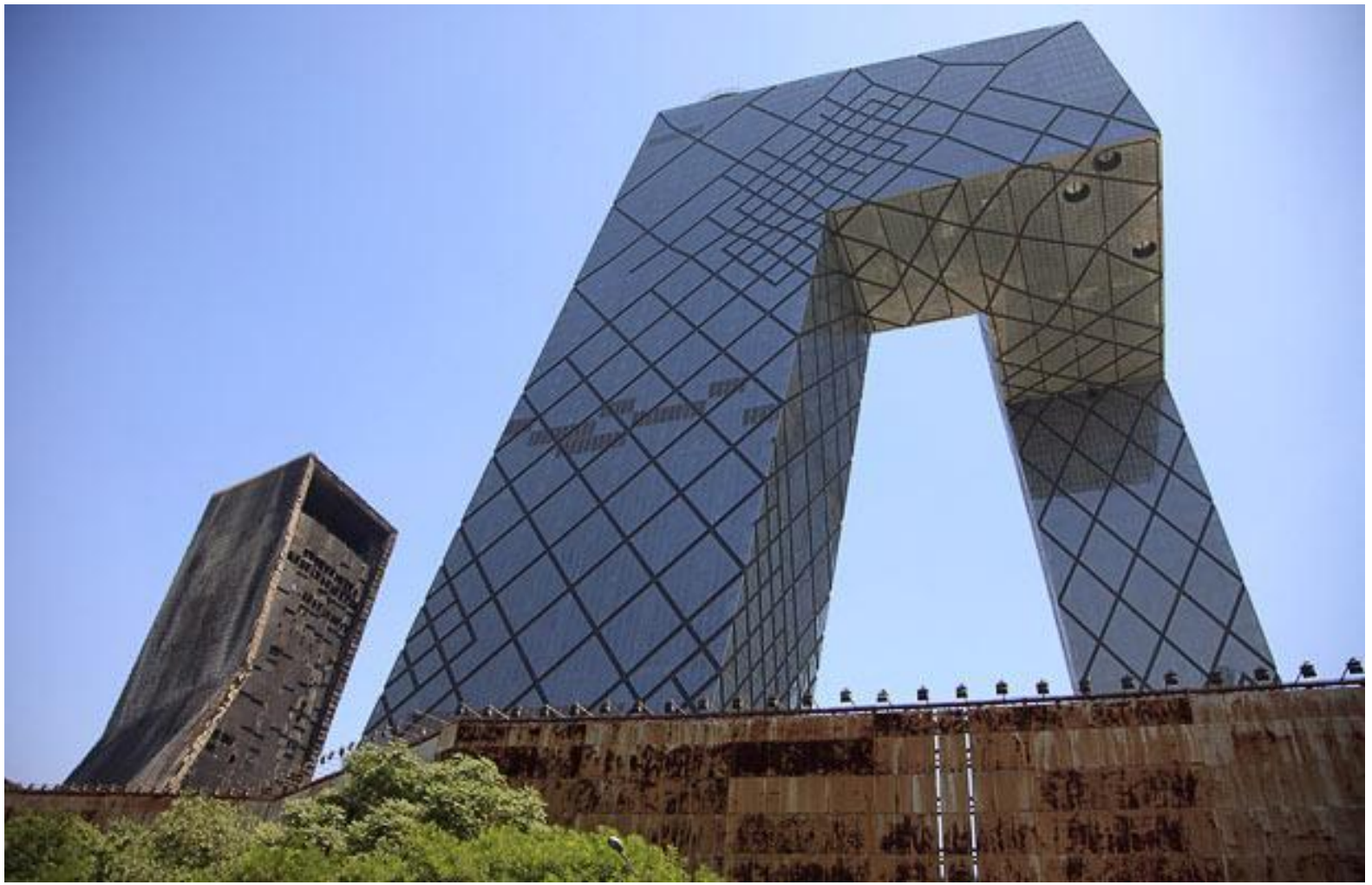

Figure 12: CCTV Building (Picture of the Day: Beijing Building)

In early 2002, my office received two invitations:

one to propose a design for Ground Zero, the other to propose a design for the headquarters of China Central Television in Beijing. We discussed the choice over Chinese food. The life of an architect is so fraught with uncertainty and dilemmas that any clarification of the future, including astrology, is disproportionately welcome. My fortune cookie that night read: STUNNINGLY OMNIPRESENT MASTER MAKE MINCED MEAT OF MEMORY. We chose China - Beijing Manifesto in Wired, Rem Koolhaas, 2004.

\footnotetext{
${ }^{21}$ One of the nicknames given to CCTV first coined by a Beijing taxi driver, Wikipedia, China Central Television Headquarters, 2011, Wikimedia Ltd, Available: http://en.wikipedia.org/wiki/China_Central_Television_Headquarters, 30 August 2011.
} 
While Rice measures the aesthetic success of Beaubourg against its ability to elicit comfort and delight through material and elegance, the Central China Television (CCTV) building elicits a different response.

Beaubourg began in the offices of an engineering company. Arup were looking for a project to collaborate on with the architects Piano and Rogers and the Pompidou competition was the one they suggested. Although Arup are the principal engineers on the CCTV building, the project began with an invitation to the architecture partnership OMA founded by the Dutch architect, architectural theorist and urbanist Rem Koolhaas. Because the genesis of this project lies in an architectural practice it is salient to explore the aesthetic concerns of these architects and Koolhaas in particular.

In his 2008 article for Urbane, Alex Paternack, argues that Koolhaas is 'better known for his writing and provocations than his buildings, which remained mostly on paper' (22). He notes that, before he was an architect, Koolhaas was one of the Netherland's most promising screen writers. Koolhaas came to prominence with his book Delirious New York in which he interrogates the idea of the 'Programme' a term synonymous with Modernism and the International style. The main preoccupation of Koolhaas' writing and design has been the city, its language, the performances taking place in it and the extent of its demise. Although not the inventor of the CCTV design ${ }^{22}$, Koolhaas is the name most commonly associated with it and its most vocal champion.

The OMA design for CCTV, like much of Koolhaas' previous work, seeks primarily to express an idea or concept. CCTV expresses the concept of interconnectivity and synergy in a literal loop. In this way OMA seek to elicit a thought response. It is interesting to explore whether this focus on conceptual expression precludes felt response. This can be done by looking at an earlier idea-based building project.

From 1972 to 1984, New York architectural group Sculpture in the Environment (SITE) constructed nine showrooms for the BEST Products Company of Richmond. Glenn Adamson and Jane Pavitt explain in their 2011 chapter 'Arch-art: Architecture as Subject Matter' that SITE 'treated the standard "big box" prototype - situated in suburban shopping centres surrounded by extensive parking lots - as the subject matter for an art

\footnotetext{
22 'According to Dan Wood, a former architect at the form [OMA] ... the loop idea was proposed by Fernando Donis, a Mexican associate at OMA. At first Koolhaas was hesitant because the design bore a strong likeness to a proposal for 'Movies strip' building by the architect Peter Eisenman. But it turned out that Koolhaas had dreamt up a similar design in Delirious New York' Alex Paternack, "Must See TV," Urbane October (2008): 22.
} 
statement' (103). This statement concerns the place of public art and architecture and aims for an architecture which is public art. Adamson and Pavitt explain that this aim 'led to the treatment of architecture as "idea, attitude and context" as differentiated from a composition of "form, space and structure" (103). In this way SITE seem to be aiming for a thought response rather than a felt one. It seems hard however to limit response to these buildings to the mind. The buildings express an inversion of structure - walls are collapsed, facades peel off. They do not appear as we expect functioning retail showrooms to. Instead, they look ruined.

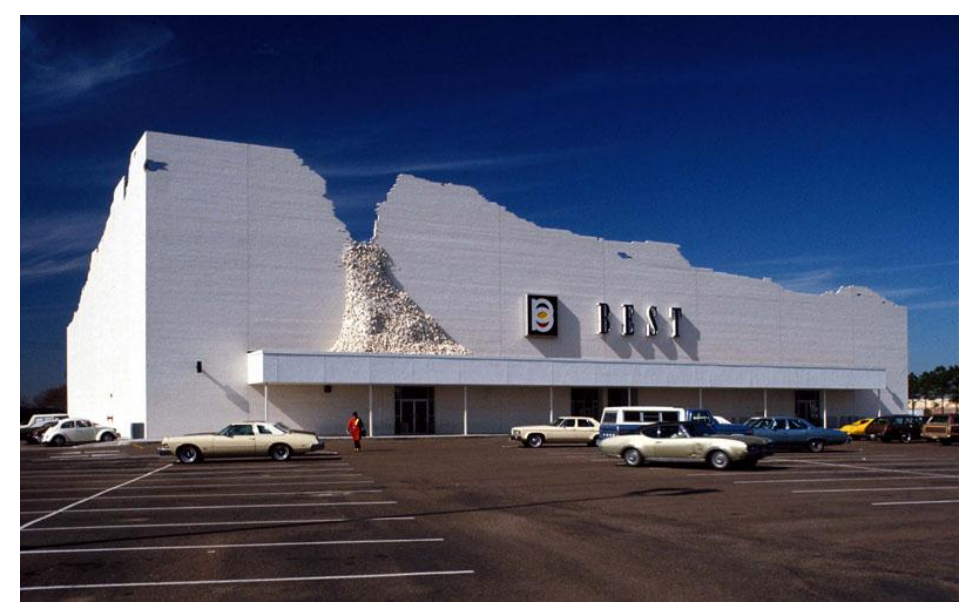

Figure 13: Indeterminate facade building, Houston, TX - 1974 (SITE)

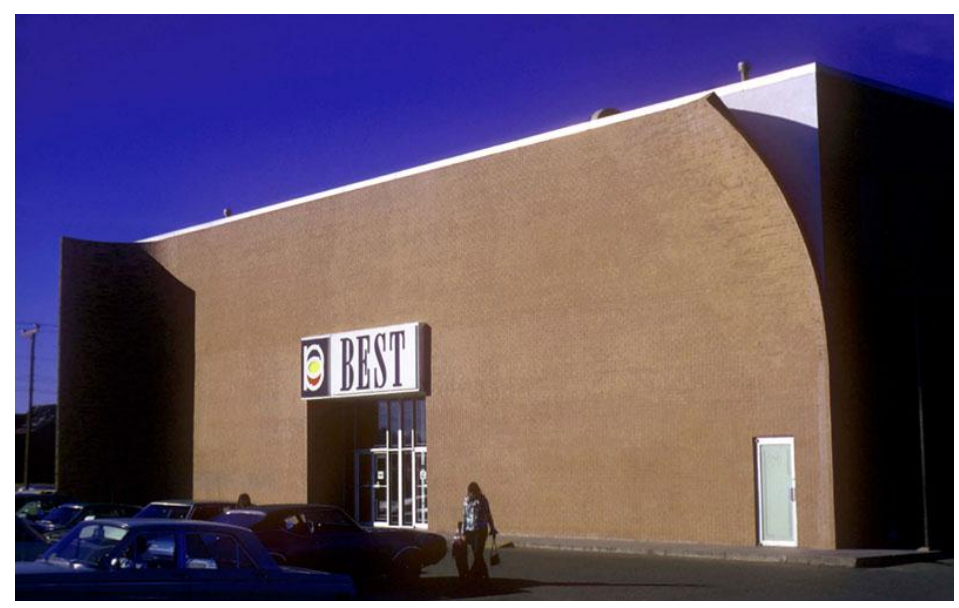

Figure 14: Peeling Project, Richmond, VA - 1971 (SITE) 


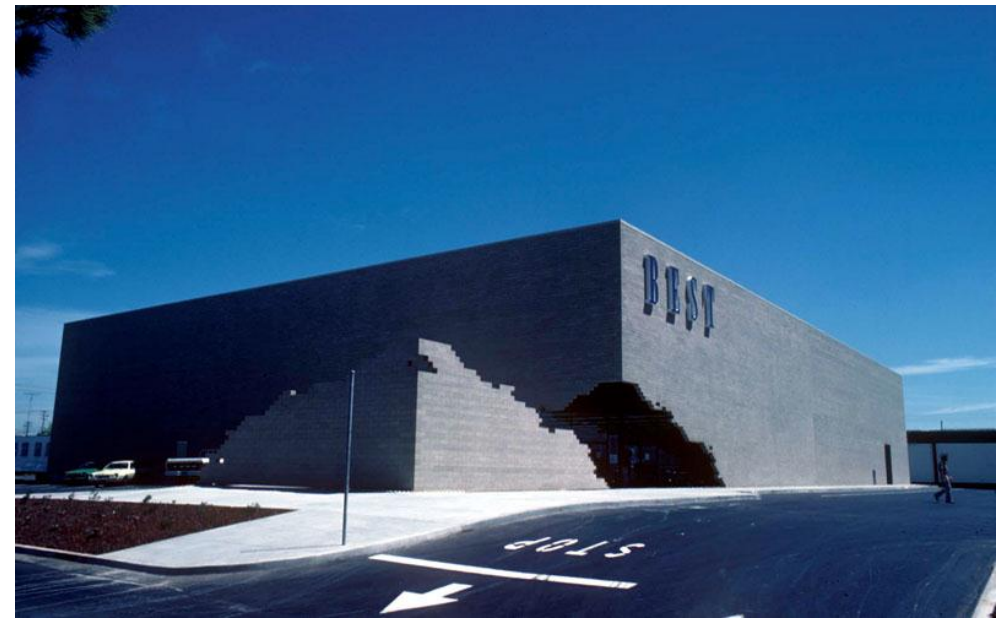

Figure 15: Notch Showroom, Sacramento, CA (SITE)

I don't think it's unreasonable to argue that ruined buildings elicit an emotional response and I think this argument bears out when, with the images of the BEST showrooms in mind, we consider an image taken after the February 2011 Christchurch earthquake.

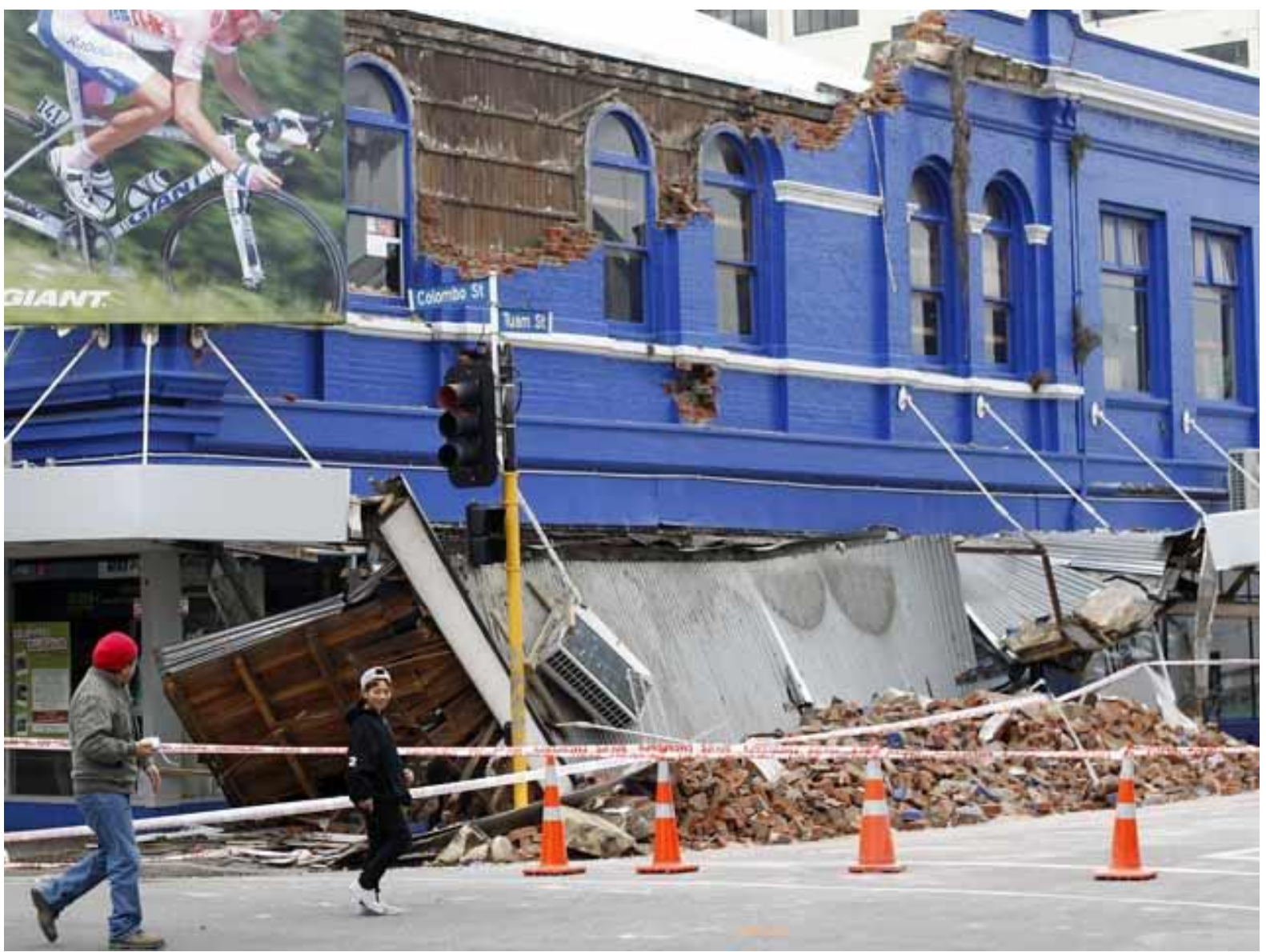

Figure 16: Corner of Colombo and Tuam Streets, Christchurch (Channel New Asia) 
But the showrooms are not ruined. They represent an exercise in 'sculptural shapemaking' (Adamson and Pavitt 103) which has been placed where we least expect to find one. This complicates felt response but does not negate it. We may feel shock initially but after we experience the building more closely we may feel delight at its awkward placement. This can be seen in the responses of people passing by the Notch Project BEST showroom in Sacramento which are captured in Howard Silver's 1981 documentary Public Places: Architecture of SITE.

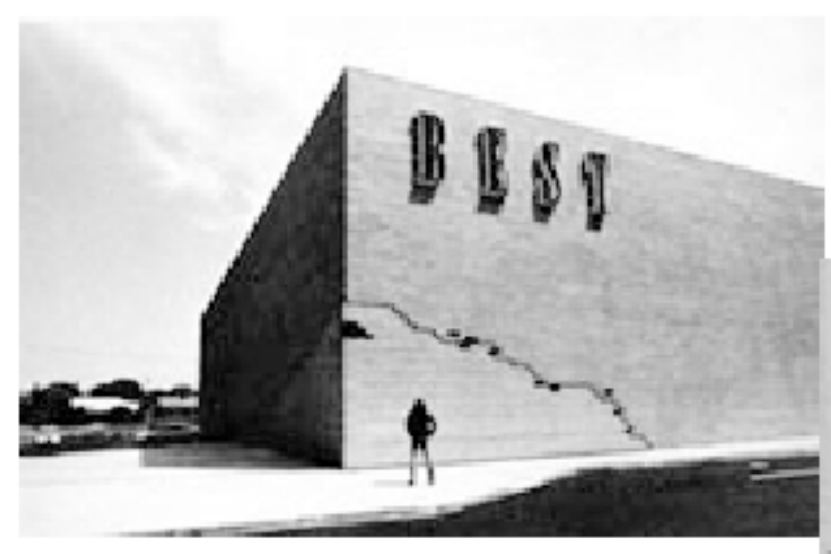

\section{Best Store in Sacramento, California when it is closed and open for business}

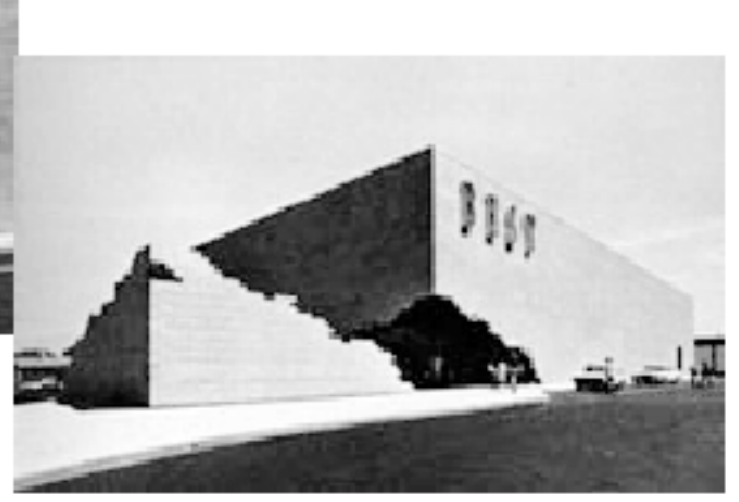

Figure 17: Best Store Sacramento ("Best Store in Sacramento, California When It Is Closed and Open for Business")

A man remarks, 'I think it's beautiful, it's like something from Egypt with the plain walls like that, straight lines' (H. Silver). This seems a very conventional response to an unconventional building. A woman remarks, 'You think in terms of an earthquake crack, then you wonder what's going on and then of course you become as curious as a cat and you look in through there and you see how they put it together' (H. Silver). These comments suggest a combined intellectual and felt response. Another man starts with an idea of a statement the building might make, 'You know in some ways, I think this is a product of our times, this kind of architecture, cause what better way can you ensure that you're not going to have any kind of break-in during the night than to enclose the entire thing in concrete' (H. Silver). He then carries on to express a feeling, 'So it makes sense but in some ways it's kind of disheartening and kind of sad that you have to have this kind of architecture' (H. Silver). He concludes by making sense of the building by placing 
it in a context of form which perhaps, makes it less disheartening, 'and to me it's still a rectangle despite this fissure' (H. Silver). These responses suggest that although SITE's BEST showrooms are not conventionally beautiful and they aim to express an idea rather than a feeling, they still elicit a felt response.

The felt response to CCTV is evident in the writing surrounding it. Paternack describes in his article the first time he saw the design for the twisted skyscraper which won OMA the contract for CCTV:

The white cover was blank save for the flat, black outline of the building. Even as a featureless icon it was vaguely familiar from somewhere; two hulking towers that leaned in and then bent toward each other, a skyscraper twisted in six places, as if M.C. Escher and Jorge Luis Borges had designed a set piece for Blade Runner. We pored over the images and diagrams and scale models - even the architect seemed amazed - and it felt no more real than looking at an illustrated book of myths, a Utopian fantasy from the ' 20 s, a storyboard for a dystopian Hollywood film. It was probably easier to think of it that way (22).

The shocking shape brought further controversy when it was presented on August 5 2003 at an event at the Tsinghua University. Koolhaas summarises the criticism in his 'Beijing Manifesto' published in Wired in 2005:

$[\ldots]$ the younger audience members questioned allocating resources to 'prestige', even while western China is ravaged by poverty; and the older generation of engineers was shocked to see the objective purity of their profession at the service of the unusual. A pact between the two sides - a coalition of the unwilling - could easily close a possibility that had just been opened. A refusal of the Promethean in the name of correctness and good sense could foreclose China's architectural potential (125). 
The engineers at the meeting argued, as engineers have argued for years, that not only was expression of material form beautiful it was also economically optimal.

At the end of his Beijing Manifesto Koolhaas attempts to light the road toward a new stability:

In communism, engineering has high status, its laws resonating with Marxian wheels of history. To prove the stability of a structure that violated some of the most sincerely held convictions about logic and beauty, the engineering firm Arup had to dissect every detail of our design. The effort to reassure only reveals the scary aliveness of every structure - elasticity, creep, shrinkage, sagging, bending, buckling. Serving as a hypnotic window, the computer analyzes and exposes the shocking vividness of the mineral world with the tenacity of a pervert.

I heard one of Cecil Balmond's engineers at Arup describe, without irony or noticeable wavering, how two sloping steel structures in our design could be connected only at dawn. They would be exposed to different solar heat gain due to their relative position on the ground and would be most likely to share the same temperature after cooling off overnight. I was elated and horrified by the sheer outrageousness of the problem we had set before them. Why do they never say no? (129).

In their descriptions of CCTV both Paternack and Koolhaas borrow from the language of the sublime. A concept associated with a sense of terror (Proudfoot and Lacey). Both Paternack and Koolhaas represent CCTV as monstrous and to a degree horrifying. Koolhaas even invokes Prometheus, the original monster-maker. Although he highlights the socially co-operative intentions of CCTV, its over-riding aesthetic has to be a sense of unease. So how do engineers, until now versed in simplicity and elegance, translate this new computer-enabled sublime aesthetic? It could be argued that, when faced with the architect's Prometheus, the engineers at Arup have little choice but to play 
Hephaestus, who compensated for his lameness by building two golden robots to help him move around.

In 2005 the first of a series of articles appear in The Arup Journal outlining the design and construction of the CCTV building. In the section of the article called 'Progress to construction' the eleven Arup engineers who author the article explain their reasons for beginning the series now rather than waiting until the building is complete. Chris Carroll et al. explain that given the 'challenging and unprecedented nature' of the project 'the fantastic story of the realisation of CCTV should start to be told now' ("CCTV Headquarters, Beijing, China: Structural Engineering Design and Approvals" 4). Although this story is told primarily in analytical language in order to communicate exact technical details of the process and design to other engineers, it would not be a complete representation of CCTV without expressions of its sublime nature. There are two features which characterise CCTV's aesthetic. First, its size; CCTV is 234 metres tall. While this is only a quarter the height of Burj Khalifa, CCTV has nearly $90000 \mathrm{~m}^{2}$ more floor area. In the Arup article descriptions of size and scale are used to express the hugeness of CCTV. The authors use measurements to describe the scale of the project and include a diagram comparing CCTV to the Statue of Liberty, Eiffel Tower and Jin Mao Tower. In this diagram, CCTV is more boldly outlined than the other buildings and shading is used to give the illusion that while the other three buildings are two dimensional, CCTV has girth and depth (Carroll et al. "CCTV Headquarters, Beijing, China: Structural Engineering Design and Approvals" 4).

The second sublime characteristic of CCTV is its shape which the authors describe variously as 'cranked and leaning', 'looped' and a 'continuous tube' (Carroll et al. "CCTV Headquarters, Beijing, China: Structural Engineering Design and Approvals"; “Case Study: CCTV Building, Headquarters \& Culture Center"). These two features combine to produce an ungainly form of huge mass, evoking Joseph Addison's definition of the sublime as 'an agreeable kind of horror' (261).

The expression of these dual characteristics, size and shape, can be analysed again in a later article about CCTV written by a group of Arup engineers and published in the CTBUH Journal. By 2008, when this article was published, construction was well underway and Carroll et al. quote large numbers to give sense to the hugeness of the project. The scale of the construction task has something of the sublime in it and some of the descriptions give a clear concept of the extent of CCTV. For example, the authors 
explain that the concrete pour for each raft took 54 hours (Carroll et al., "Case Study: CCTV Building, Headquarters \& Culture Center" 20). Details the authors include concerning the construction process give a sense of the sublime nature of the project. Carroll et al. describe the excavation of $870000 \mathrm{~m}^{3}$ of earth from the site which took place over a month, the authors begin a sentence which explains that each day $12000 \mathrm{~m}^{3}$ of earth was removed by explaining, 'Strict construction regulations in Beijing meant that spoil could only be removed at night ...' (“Case Study: CCTV Building, Headquarters \& Culture Center" 20). This detail is used in the sentence to express the difficulty of the work and how it was overcome but has the secondary effect of connecting the building with the dark and the traditionally mysterious nature of things that dwell there. Despite the two Arup articles being rational in their language they express the sublime nature of CCTV through the description of its size, shape and the magnitude of the construction task.

Despite the sublime nature of the aesthetic underlying CCTV the texts describing its structure still reflect a reach to the more traditional engineering aesthetic. One feature of CCTV is the engagement of the entire facade structure to brace the forces generated by the unconventional shape of the building. This feature is explained in the 2008 Carroll et al. article:

The system is ideally suited to deal with the nature and intensity of permanent and temporary loading on the building, and is a versatile, efficient structure which can bridge in bending and torsion between the Towers, provide enough strength and stiffness in the Towers to deliver loads to the ground, and stiffen up the Base to reinforce the lower Tower levels and deliver loads to the foundations in the most favourable possible distribution, given the geometry ("Case Study: CCTV Building, Headquarters \& Culture Center" 15).

This description uses quite conventional engineering language, in particular the language of optimisation, to describe an unconventional building. The structure is described as 'ideally suited', 'versatile, efficient' and delivering loads to the foundation in 'the most favourable possible distribution'. What is telling about this description, however, is the 
conditional clause at the end of the sentence: 'given the geometry'. This phrase shows the difference between the aesthetics of Pompidou and CCTV. In the gerberette of Pompidou, shape is designated by force, utility and material. Whereas in CCTV shape rules all other decisions. Ole Scheeren, OMA's partner in charge of the CCTV project and head of OMA's Beijing office, further emphasises this point when he says of the structural designers, 'They didn't interfere. We didn't have to make compromises' (Tuchman 32). This brave new world, where advanced computing systems make anything possible, apparent in the design and execution of CCTV, is documented in all texts written about the building through phrases like 'redefines the form'("Case Study: CCTV Building, Headquarters \& Culture Center" 14) and 'from the realm of sciencefiction into reality'(Paternack 22). However, also apparent in these texts is a gesture to principles of the conventional engineering aesthetic.

Each text written about CCTV includes a section about the expression of structure in the cladding of the building. As Carroll et al. explain, "The diagonal braces within the continuous tube structure visually express the pattern of forces within the structure and are an important aesthetic aspect of the cladding system" ("CCTV Headquarters, Beijing, China: Structural Engineering Design and Approvals” 6). What is expressed in the building's cladding, however, is not simplicity and elegance but another show of the complexity of structure needed to hold such a virtuosic building up. The design of the continuous tube of diagonal bracing is described by Carroll et al. as an 'extremely involved and iterative process' because of the highly indeterminate nature of the building ("CCTV Headquarters, Beijing, China: Structural Engineering Design and Approvals" 6). To achieve the expression of the structure, it wasn't a matter of leaving cladding off in certain places but of keeping the architect up-to-date and involved in the development of the bracing pattern. It seems that to achieve even this nod to expressed structure the process was difficult and, it could be argued, largely token.

An investigation of the hidden structures reveals that in CCTV, shape is king; structure is simply there to make shape possible. Carroll et al. explain:

Whilst the external tube structure slopes to give the unique geometry, the internal steel columns and cores are kept straight for functional layout and to house lift and services shafts. This resulted in a different configuration for every 
floor - the span from core to facade, and internal column to facade, change on each level.

Sloping cores were considered, to allow consistency of floor plate layout, but ruled out due to constraints on the procurement of the lift systems. Therefore, additional columns are needed on upper storeys where the floor spans increase significantly on one side of the core. Transfer trusses support these additional columns, spanning between the internal core and the external tube structure. They are typically two storeys deep and located in plant floors so as to be hidden from view and to minimize the impact on floor planning ("Case Study: CCTV Building, Headquarters \& Culture Center" 18).

Although delivered in conventional engineering language, stating clearly how problem after problem is solved in the most efficient way, these two paragraphs demonstrate the difficulty and uncompromising nature of the problems being set and the complexity of the solutions that were developed. This complexity can be seen again and again in statements like, 'Due to the vast number of elements in the model (10,060 primary elements) and the multitude of load cases ...' (“Case Study: CCTV Building, Headquarters \& Culture Center" 18). The engineers insist in their writing on showing how they have come up with the most optimal solution but never do they use the word 'elegant' or 'clean'. Steel, concrete and physics are bent, stretched and hidden to achieve shape. It seems OMA's obsessions with shape replaces Rice's obsession with material.

With such free, innovative ideas in mind why would authors spend time trying to justify CCTV in the language of the traditional engineering aesthetic? One answer can be seen in Janice L. Tuchman's article for ENR (Engineering News Record). Tuchman speaks with Ole Scheeren and Rory McGowan, director of Arup's Beijing office, and her article includes the following paragraph:

McGowan and Scheeren counter the idea that structural pyrotechnics or an unreasonable amount of resources were required to bring the CCTV structure to reality. 'The moment that something looks unusual or daring, there is an 
immediate suspicion that it must be outrageous', Scheeren says. CCTV uses about 250 kilograms of steel per sq. $m$, the same tonnage as a much taller but simpler new building nearby and half as much as another building in the area that handles earthquake loads with a heavy truss system. The Chinese seismic code generally stipulates a heavy kind of engineering', McGowan explains, but CCTV went through a special performance-based process because of its innovative design (33).

Engineer and architect seem eager to present CCTV as innovative but not outrageous or greedy. In his 1971 book, Structure: The Essence of Architecture, Wilson states, 'Little skill is required to design a building that will stand up' (26) after all a rock placed on a rock placed on a rock will eventually stand in a pile, given enough time and enough rocks. Wilson goes on to explain that an ideal structure is one that uses 'a minimum of material to obtain maximum results' (26). Scheeren and McGowan's defence of the structure and Carroll et al.'s retreat to the language of traditional ideas of engineering aesthetics suggest that the sentiment of Wilson's comment is still alive in engineering and architecture communities - that despite its daring the designers of CCTV still feel the need to defend the building in the language of the traditional engineering aesthetic. In amongst the language of the sublime we find the language of simplicity and rationality.

Tuchman's article continues with the heading 'Record-Setting Pour' which describes the unprecedented amount of concrete used in the foundations of CCTV. This transition from insistence on a kind of structural virtue to an expression of virtuosity may represent a glimpse to a future where engineers will no longer apologise for 'engineering pyrotechnics' but instead revel in the challenges of new shape and size. Many of the texts about CCTV represent it as a monument to China's brave embrace of the new. Scheeren says, 'They [China] took pride in making it possible' (Tuchman 35). Koolhaas affirms CCTV was conceived, 'not in the backward-looking US, but in the parallel universe of China' (129). Despite the language which harks to the old, there seems an eagerness in sectors of the engineering community to move with the challenges of the new, free forms of the future. This eagerness seems best expressed in Koolhaas' question 'Why do they never say no?' (129). 
To solve the problems associated with the subjectivity and range of felt response a building might elicit, engineers advocate for a correct aesthetic aim - that of beauty or delight. Having established this as the proper, even moral, responsive aim of structural design, engineers seek to emphasise a standardised way of measuring the degree to which a design meets this aim. They seem to agree that most viewers find delight in design which is simple and rational. They further advocate for a design which reflects truth of material and flow of forces. As well as adherence to this aesthetic of harmony and elegance, there are also examples of buildings which subvert or invert the aesthetic to produce a different response in the observer or occupant. Both the language of the beautiful and the sublime can be seen in the writing by engineers and even in the most extreme cases of inversion of traditional aesthetics, engineers temper their language of the sublime with the language of simplicity and rationality. 


\section{HOW MIGHT ENGINEERING LANGUAGE INFORM, ALTER AND ENLARGE THE LANGUAGE OF FICTION?}

My analysis of engineering texts identifies language choices made by engineers when faced with features apparent in built forms which are difficult to translate to written or spoken language. In particular I deal with language problems associated with: Action and Event, the Relationship of the Built and the Human, and Aesthetics or Felt Response. In this chapter I place the language choices made by engineers in response to these problems of expression in the context of fiction. This chapter is not intended as an exhaustive survey of fiction which displays characteristics of engineering language but is instead a summary of the thoughts I had while reading and writing toward the creative component of this thesis. The aim of my creative component is to highlight the strangeness of surroundings that we normally take for granted. This aim shapes my thoughts and the suggestions I make for how engineering language might inform, alter and enlarge fiction.

\subsection{Action and Event}

As I have shown, engineers must find ways of expressing in written and spoken language the simultaneous and contingent action apparent in built forms. My analysis identifies a variety of language choices engineers make to solve these problems of expression. The problem of expressing simultaneous action in linear language is solved by enforcing conventional narratives and using word compounds to maintain a sense of concurrent activity. The language problem of contingency is solved by the use of an 'if ... then' syntax and modifying and conditional phrases which allows the contingent action to be described in present tense. This, along with the use of names which include adjectives describing the action of elements under the contingent event, gives a sense of the latent capability of the building. Engineers choose present tense for its clarity, which has the effect of collapsing all change over time into an eternal present.

Engineers' use of narrative as a solution to simultaneous action, of course, immediately complicates my aim. The enforcement of narrative structure to events is a predominant and fundamental characteristic of imaginative writing. It could be said that engineers 
have borrowed the concept of the 'story' from creative writing. The narrative in engineering is odd, artificial, consciously imposed and recognised as such by readers from the engineering culture ${ }^{23}$. Although the enforcement of narrative is just as artificial in imaginative writing, the convention is heavily ingrained and not as readily recognised as artificial by readers of fiction.

Close reading of the engineer's narrative technique leads me to explore more forceful and conscious use of narrative. Through my analysis, I identify that event does not necessarily or automatically dictate narrative. Even if a set of events suggests an order or way of existing in time, this order does not necessarily need to be maintained in creative writing. Like the engineer who forces simultaneous events into linear narrative, the fiction writer is able to force linear lifetimes into non-conventional narratives. I find Jennifer Egan's 2010 novel A Visit from the Goon Squad very useful as a model for this type of story-telling. Egan's book presents fragments of a story in non-consecutive stories, which, although part of an overarching plot, are also completely self-contained. This technique of jumping from time to time, place to place, character to character reminds the reader that not everything is told. Years and sometimes decades of a character's story are left un-expressed, characters are put to the use of the overarching plot and then disappear. The ride is not altogether smooth and it alerts the reader more acutely to the artificiality of narrative form than a conventional linear structure would. Instead the reader is left with an acute awareness that the narrative is imposed by an author in order to craft, through the breaks and disruptions, a story which offers a fresh perspective on time, memory and age.

Another book which explores similar themes to $A$ Visit from the Goon Squad but appears on the surface to have a more conventional narrative is Julian Barnes' 2011 novel The Sense of an Ending. Barnes' novel works from a beginning, through a middle and to an end, ordered largely by the aging of the narrator. However, Barnes' work also makes the reader acutely aware of the formation of story through the narrator's constant 'on-screen' testing of memory:

Brother Jack gives me a supercilious wink, and forty years later I use what charm I have - no, let's exaggerate: I use a certain false politeness - to get information out of him. And then, instantly, I betray him. My contempt in exchange for your contempt. Even if, as I now admit, what he actually

\footnotetext{
${ }^{23}$ This can be seen in Charleson's description of 'force path' which explains that the description is metaphorical.
} 
felt towards me back then might have been just an amused lack of interest. [...] But $I-I-$ felt it as contempt at the time, remembered it as such, and delivered the feeling back. (106).

There are many examples of fiction which points the reader to the artificiality of narrative but I believe the engineering strategy of the 'force-path' offers a model which may not have been fully exploited by fiction writers. The description of a force path never backs up on itself. It moves unwaveringly from beginning to end. The 'story' unfolds without background or reminders. It is odd to offer such a conventional story structure as innovative but it seems that a fiction narrative which didn't rely on background or flashback, one where a reader was dropped into a life and watched that life unfold in strict linear order might, through its oddness, alert the reader to the artificiality of narrative. Perhaps this type of story-telling would seem so odd because it runs counter to how we experience present events through the lens of memory and past experience.

Engineers use word compounds to give a sense of simultaneous action and as language cues to actions which are invisible. This piling up effect to express simultaneous or hidden action can also be seen in imaginative fiction. In his 1955 novel Lolita Vladimir Nabokov, in an attempt to show many things happening at once, abandons conventional linear story-telling and frees his narrator to an explosive list:

I have to put the impact of an instantaneous vision into a sequence of words; their physical accumulation in the page impairs the actual flash, the sharp unity of impression: Rugheap, car, old-man doll, Miss O.'s nurse running with a rustle, a half-empty tumbler in her hand, back to the screened porch - where the propped-up, imprisoned, decrepit lady herself may be imagined screeching, but not loud enough to drown the rhythmical yaps of the Junk setter walking from group to group - from a bunch of neighbours already collected on the side walk, ... (97). 
Many writers of imaginative fiction use lists in this way, but the engineers' word compounds I identify work differently. While Nabokov's list gets much of its power from the free association of the objects it chooses, the word compounds of the engineers seem to work by a more systematic association. In this way the engineers' compounds not only give a sense of contingency and simultaneous action, but also give clear, objective pointers to what the word stands for. Nabokov moves abruptly from 'rug-heap' to 'car' to 'old-man doll', adding to the confusion of the scene, creating an impressionistic experience. In contrast the engineer seeks clarity and aims to communicate form through words. For instance, it is difficult, even if you don't understand the meaning of the compound, to unpack 'moment resisting steel frame' into anything except a steel frame which resists forces that want to rotate the frame around its axis. Even the more complex compounds like 'vertically orientated column flange mounted sliding joint' can be dealt with word by word to come up with the action and form of the element the term describes. The engineering compounds resemble literal building; they seem to have a similar logic to actual construction - if any word is moved then the sense of the compound changes. This idea of 'building up' words led me to imagine there might be a way of creating a similar effect in fiction. That a writer might treat each clause as something built from the last and attempt to pile clause on top of clause without terminating the sentence. That a fiction writer might try to write longer and longer sentences but maintain sense and not revert to associative, impressionistic lists. I imagine that these sentences might take some unpacking but would have a rhythm which implied built rather than lived or felt experience.

My research shows that engineers write predominantly in present tense which creates a sense of what Bucciarelli calls 'eternal timelessness'. In a conversation about present tense between my supervisors the engineer Andrew Charleson and the author Damien Wilkins on February 11, 2012, Charleson says, 'Present tense reads so much better, something "is" rather than "was" (Charleson). To which Wilkins replies, 'Engineers use present tense because it is transparent, declarative and simple. This is why literature hates it sometimes - it allows no room for ambiguity' (Wilkins). I believe it is possible to write a work of fiction which gives the sense of timelessness through techniques other than the use of present tense. An example of how this is achieved can be seen in $A$ Visit from the Goon Squad. In the book Egan breaks the flow of a story unfolding in present time to look forward to a future event. She presents these future events in future perfect tense: 
Four years from now, at eighteen, she'll join a cult across the Mexican border whose charismatic leader promotes a diet of raw eggs; she'll nearly die from salmonella poisoning before Lou rescues her (80).

Egan creates an impression that every moment in time is available to the narrative voice of her novel; that the narrator can take events from the future and insert them in the moment of the story. I believe this has a similar effect to the eternal timelessness created in the writing of engineers. It is as if events over all time sit, completed in a palette which the narrator can choose from to tell their story. In this way time is collapsed into an odd type of present point.

\subsection{The Relationship between the Built and the Human}

Built forms have an intrinsic connection to and relationship with people. However, for the engineer to do her work she must standardise human form. My analysis shows examples of engineers choosing to express a generalised population in their written translations of buildings. This presentation of the relationship between buildings and people maintains a sense of the standardisation of human form necessary for the engineer to design strong and functional structure.

While reading texts written by engineers, I always get the sense of a large group of people. I think this is a combination of the corporate voice and the generalised population. For instance, when Beca's ACENZ entry talks about people it talks about '300+ staff' and I don't think of one individual and then another and then another, I imagine one group of 300 all at once. Contemporary fiction is often characterised by a focus on the individual experience. In this type of fiction buildings become a projection or symbol of this discrete experience; buildings are put at the service of the human characters. Throughout this project I have been interested in the argument that most fiction values the individual human experience over the built environment it takes place in. I suggest in my essay that engineers invert this hierarchy by putting the generalised, often abstracted, population at the service of the built; individuals become average, ideal weights and live loads in order for the building to be designed. I was interested to 
imagine what this way of presenting the relationship between the human and the built might have to offer fiction. Three historic works of fiction are particularly pertinent when exploring this question. The first two are not well known and fall well outside the mainstream while the third, although canonised is didactic and therefore quite distinct from contemporary fiction. It is possible to see in these atypical works human characters serving the built.

Jean-François de Bastide's 1774 work The Little House: An Architectural Seduction is an example of a small group of texts which marry two literary genres: 'the erotic libertine novella and the architectural treatise' (Vidler 9-10). In his Preface to the 1995 edition of The Little House Anthony Vidler suggests that one genre provides an alibi for the other, stating:

Where Bastide in 1774 provided a writer's cover for [JeanFrançois] Blondel ${ }^{24}$ to step beyond the bounds of etiquette and criticise his own students and contemporaries in print, so for the novelist, architecture and its meticulous description was a device for holding eroticism with the bounds of propriety, or convenance, constructing a wall, so to speak, between the pleasantly erotic and the simply pornographic (9-10).

The Little House is largely an argument in taste in which the Marquis de Trémicour wagers the flirtatious yet virtuous Mélite that she cannot visit his petite maison and leave without being overcome with desire. This collision of polemic and sensuous agendas makes for some original formal characteristics. In 2010 the architectural practice Skene Catling de la Pena explained, in a note which accompanies their film La Petite Maison, that de Bastide's novella is 'designed to engage and educate the client [reader] through a provocative journey where the architecture is itself the generator of the narrative' (Skene Catling de la Pena). The petite maison sets the story. The characters' path through the house is governed by its architecture and this journey forms the plot of the novella. The seduction is brought about not by the touch of a hand or a lip but by the effect of the architecture:

\footnotetext{
${ }^{24}$ The famous architect Blondel supplied Bastide with the architectural details used in La Petite Maison.
} 
Trémicour was about to reply, but they had reached the centre of the main courtyard, and Mélite's gasp at her first glimpse of it cut him short (de Bastide 66).

He led Mélite directly to a salon that opened onto the garden, a salon unequalled in all the universe. He noticed Mélite's delight and permitted her to pause and contemplate its finery. Indeed, so voluptuous was this salon that it inspired the tenderest feelings, feelings that one believes one could have only for its own (de Bastide 67)

In the tradition of the erotic genre, the characters are presented as archetypes:

Mélite took to the company of men with great ease, and only kindly souls and the best of friends did not consider her a flirt. Her uninhibited manner, her airy talk, and a certain abandon were ample proof. The Marquis de Trémicour had his mind set on her seduction and felt assured of an easy success [...] A man of wit and taste, he was magnificent and generous, unrivalled in his charm. Yet despite these many assets, Mélite resisted him (de Bastide $57)$.

Whereas the architecture is individual and distinct:

The room's walls were painted a soft yellow; the marqueterie parquet combined amaranth and cedar woods and the marble was a Turkish blue (de Bastide 74)

In this way, the house becomes character and the people props in its story. This exchange of roles is clearly articulated in another example of libertine erotica, Dominique Vivant Denon's 1777 short story Point de Lendemain (No Tomorrow). In it the protagonist of the story, mesmerised by the description of his lover's secret room, says, ' $\ldots$ but I was very curious. It was no longer Mme de T- whom I desired, it was the little room' 
(Denon 741). In these examples, the buildings are not symbols of the characters but rather protagonists in their own right. In both cases the story of seduction is used as a vehicle to explore arguments of taste and the alluring effect of architecture.

A later French work, Victor Hugo's 1831 novel Notre Dame de Paris, also has at its base an argument. Hugo argues for the supremacy of architecture over all other art forms. In Notre Dame de Paris he is concerned that the invention of the printing press will see the demise of architecture as the primary form of creative expression. Hugo makes a case for the power and freedom of architectural expression in a time when the written word was heavily censored and had a limited audience. Hugo peoples his novel with characters that make his case for architecture as a higher art form - the poet, Pierre Gringoire is thwarted at every turn by a city he can't master. And it is the city that displays the greatest creative power in the book. Much like the small house in de Bastide's work, the city of Paris is used by Hugo as a generator of character and plot. Rather than a built landscape summoned to symbolise the human experience, Paris generates characters:

He had taken but a few steps in the long street, which sloped downwards, was unpaved, and more and more muddy and steep, when he noticed a very singular thing. It was not deserted; here and there along its extent crawled certain vague and formless masses, all directing their course towards the light which flickered at the end of the street, like those heavy insects which drag along by night, from blade to blade of grass, towards the shepherd's fire (Hugo Chapter IV: The Broken Jug).

In this description the generative power of the city becomes almost literal as faceless human characters grow out of its streets and buildings. 
Hugo's book is not called Esmeralda or Quasimodo but Notre Dame de Paris and all the human characters seem at the symbolic service of the city's buildings and Hugo's argument. As Hollis states in his book The Secret Lives of Buildings:

And, indeed he [Quasimodo] resembled Notre Dame of Victor Hugo's day, for he 'looked like a giant, broken and badly reassembled'. The heroine of the novel was a dancing gypsy girl named Esmeralda; and she too resembled Notre Dame - or at least Notre Dame as Hugo imagined she had been in 1482, for she had a strange and exotic beauty that captivated all who saw her. But the real heroine of the story was Notre Dame de Paris herself, and Hugo knew how his novel would end: in the wreckage of the hopes of hunchback, gypsy, and cathedral (228).

Hugo's aim is to argue the supremacy of architecture and this argument is strengthened by the placement of the built environment as master and creator of the people in it.

In these examples de Bastide, Denon and Hugo place the built environment at the centre of their work in different ways from Cather and other writers who focus on the individual human experience. Instead of using the built form as a symbol of the inner life of human characters, these works focus on the stories of the built environment and use characters to symbolise these stories. In this way de Bastide, Denon and Hugo's work hint at an inner life for the built form which is distinct from, and independent of, human experience. 
The engineer is uniquely placed as a guide to this unusual world. It is exciting to imagine what sort of fiction might be written from the point of view of a building's inner life. I can't help thinking that if a built form did tell a story of humans those humans would be described in terms of weight and load rather than the characteristics we normally read about in fiction. Further, I think a building is far more likely to express the generalised population described by the engineer than to distinguish individuals from a crowd. However, every time I imagine a story written by a building it is difficult to summon a human reader who would be able to read the work without projecting himself onto the text. It seems almost impossible to escape the temptation to read ourselves into objects. It only takes three windows for us to see a face.

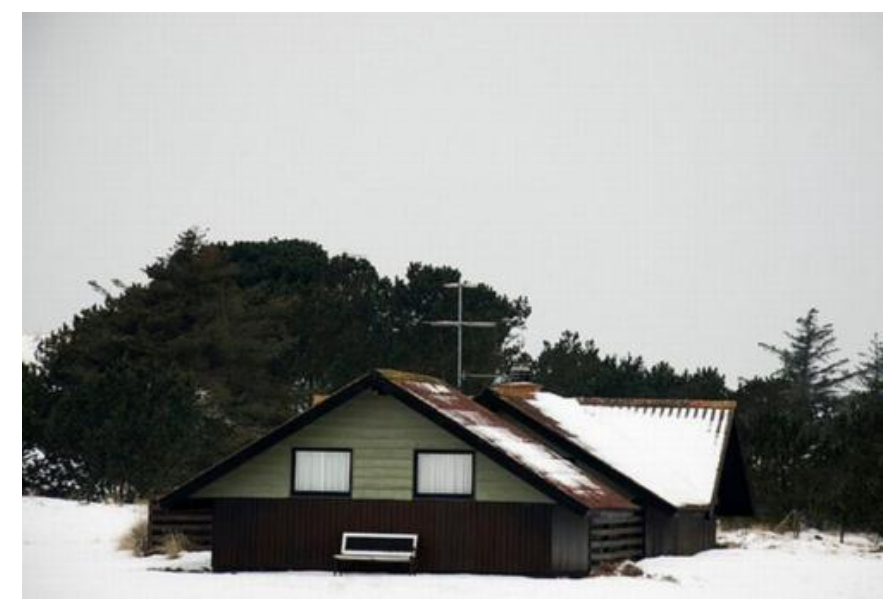

Figure 18: (Buildings That Look Like Faces)

\subsection{Aesthetics or Felt Response}

Newman's suggestion that a satisfying felt response can be generated by the rational event of a 'perfect engineering solution' begs the question, do engineers agree on the perfect engineering solution which would lead to this type of delight? From my analysis I identify measures for beauty apparent in the writing of engineers. The view of these texts is that simplicity and rationality hold the key to eliciting delight. My analysis explores how engineers apply these standards of beauty when they write about buildings designed to elicit less conventional responses.

The language of the beautiful and the sublime can be seen in writing by engineers and this forms a large lexicon for the description of built forms in fiction. Even in the most 
extreme inversion of traditional aesthetics, engineers temper their language of the sublime with that of simplicity and rationality. In engineering texts this mix of rational and transcendent language pulls the building into the context of traditional ideas of beauty which elicit delight rather than horror. In contrast, when analytical language is introduced to a sublime event in imaginative fiction the effect is opposite. Instead of calming the text, the cold, objective elements often increase the unease. An example can be seen in Mark Danielewski's 2000 novel House of Leaves:

Wincing slightly at what we can assume is at least moderate pain, he reaches the top rung where using a 100' Empire fibreglass tape with a hand crank, he proceeds to measure the distance from the far end of the master bedroom to the far end of the children's bedroom. The total comes to 32' 9 $3 / 4$ " which the house plans corroborate - plus or minus an inch. The puzzling part comes when Navidson measures the internal space. He carefully notes the length of the new area, the length of both bedrooms and then factions in the width of all the walls. The result is anything but comforting, In fact it is impossible.

32' 10" exactly.

The width of the house inside would appear to exceed the width of the house as measured from the outside by $1 / 4 "(29-30)$

It is clear from this example that the effect of precisely reporting the rational act of measurement elevates the panic apparent in the novel and increases the feeling of fear. It seems there is a great scope for the injection of empirical language into fiction and that the effect of this adoption of some of the characteristics of engineering texts could be used to a variety of emotive and impressionistic ends.

The huge, cranking form of the CCTV building in Beijing is expressed in the engineering texts in a way that reflects its sublime aesthetic. By choosing words like 'cranked and leaning' to describe the shape of CCTV engineers summon in the reader a response elicited by the building. This is also done by associating the construction of CCTV with the night and extreme labour. Description which uses word choice and 
connotation to elicit a felt response can be seen in the following sections from China Miéville's 2000 novel Perdido Street Station:

The city thrust upwards massively, as if inspired by those vast mountains that rose to the west. Blistering square slabs of habitation ten, twenty, thirty storeys high punctuated the skyline. They burst into the air like fat fingers, like fists, like the stumps of limbs waving frantically about the swells of the lower houses. The tons of concrete and tar that constituted the city covered ancient geography, ... (77-78)

Five enormous brick mouths gaped to swallow each of the city's tramlines. The tracks unrolled on the arches like huge tongues. Shops and Torture chambers and workshops and offices and empty spaces all stuffed the fat belly of the building, which seemed, from a certain angle, in a certain light, to be bracing itself, taking its weight on the Spike, preparing to leap into the enormous sky it so casually invaded (79).

Miéville creates a sublime object by using metaphors which transform buildings into monsters. What is clear when Miéville is compared with the engineering texts is the restraint apparent in the engineering texts. There seems a fine balance in engineering writing between expressing aesthetics in order to accurately describe a building and maintaining a rationality which will keep the description in the realm of objectivity. It is interesting to imagine a fiction which puts this type of restraint into action when describing the sublime.

In my critical essay I discuss the agreed standards of beauty and delight apparent in the engineering texts I analysed. I am interested particularly in how these standards are used to describe sublime structure. I believe this process of trying to make sense of something sublime using measures of delight adds an interesting feature to the writing. I imagine simplicity and rationality trying to hold an erratic, monstrous object. The engineering language around the descriptions of CCTV show a struggle between a desire to meet the old measures of rationality and simplicity and a yearning to fully embrace the 
new aesthetic where shape is everything and complexity and technology enables any shape imaginable. I am interested in this layering of aesthetic concerns and in particular the relationship between rationality and simplicity and the ornamentation of shape for shape's sake. In creative writing we are often taught to balance or harmonise opposing techniques like showing and telling, abstraction and specificity, lyricism and colloquial language. However, I am interested in exploring what happens in a text when rationality and ornamentation go to war with each other, both vying for supremacy so adamantly that the resulting tension is recognisable in the fiction. I am particularly intrigued by what would happen if rationality won areas of ornamentation-occupied land. I posit that if rationality was used for ornamentation, for emotive embellishment, for the sake of sound and art rather than clarity of communication the resulting text would be odd in useful ways. 


\section{CONCLUSION}

This thesis asks the question: in what way can the language of structural engineering inform, alter and enlarge the language of fiction? This might seem an odd question, strangely technical and removed from the normal business of a creative writer. It is the 'strangeness' that motivates this work. In my introduction I trace some of the personal history of this question. I argue that 'strangeness' is a useful term since it suggests something of the paradox of a large built form, which is manifestly solid and there but also basically a machine for balancing forces that are constantly in motion - a thing that might fly apart. I propose that one way of getting at the strangeness of our built environment is to express the hidden, inner world of the built form. Structural engineers are uniquely placed to be our guides.

I begin with a survey of the strategies fiction writers have adopted when accounting for built forms in their work. Here the traditional approaches have involved either symbolic or metaphorical deployment: the building as a marker of characters or moral; or a decorative function: descriptive detailing which dwells on the surface of these structures.

I contrast this with the discourse of engineering which is largely concerned with the inside of buildings through the science of force and materiality. I conclude that structural engineers present expressions of built forms which offer insight to the inner world of the building and ask if it is possible to adopt the features of this empirical language into fiction. After surveying research which investigates the pathways between rational, scientific discourse and imaginative literature I explore the limited research which has been completed investigating the pathways between engineering and imaginative literature. I conclude from this survey that the movement of 'metaphors, myths and narrative patterns' (Beer 5) from one language to another is a key creative aim of this project. I identify that this aim shares many of the characteristics of translation. This prompts me to investigate current ideas in translation theory.

My investigation of contemporary Translation Studies theory uncovers a change in focus from a search for universal rules for absolute equivalence to a concern with choices made by individual translators in particular situations to produce texts which are not subservient to their originals but works in their own right. This broadening ambit of translation studies allows me to use a translation theory framework as an analytical tool to identify features of engineering language which might inform, alter and enlarge the 
language of fiction. I use a Translation Studies framework adapted from Toury's DTS and Vermeer's skopos theory to analyse writing by engineers.

To use this Translation Studies framework, it is necessary to explore the engineering culture in order to make assessments about the acceptability of the texts I have selected to analyse. I discuss perceptions of engineers found in writing outside the engineering community then focus on writing by engineers about their profession. I conclude that writing from inside the profession interrupts or complicates some of the stereotypes found in writing from outside the profession and that this complication is useful to my creative aim of highlighting the strangeness of surroundings we normally take for granted.

Using Toury's criteria, I identify several engineering texts as assumed translations. Through analysis of these, I identify the problems engineers face in translating built forms into written and spoken language. In particular, I explore choices engineers make when faced with language problems associated with: Action and Event, the Relationship of the Built and the Human, and Aesthetics or Felt Response. I identified other language problems ${ }^{25}$. However, I believe these three are the most useful to my aim of discovering ways that engineering language might alter, inform and enlarge the language of fiction and offer the most scope for my fiction which aims to highlight the strangeness of surroundings we normally take for granted.

In relation to action and event, built forms display complex and often antiintuitive characteristics which the engineer must translate into written and spoken language. I explore how engineers translate the simultaneous and contingent action apparent in built forms into linear written and spoken language. The problem of expressing simultaneous action in linear language is solved by enforcing conventional narratives and using word compounds to maintain a sense of concurrent activity. The problem of contingency is solved by the use of an 'if ... then ...' syntax along with modifying and conditional phrases which allow the contingent action to be described in present tense. I discuss the habit of the present tense to create a sense of an eternal timelessness. Finally, I find that the use of names which include adjectives describing the action of elements under the contingent event, gives a sense of the latent capability of the building.

\footnotetext{
${ }^{25}$ These included problems associated with the expression of : gender and sex in built forms, natural forces with heavy cultural connotations or symbolism, iterations of three dimensional versions of a single built form,
} 
The engineer must solve problems associated with the relationship between the built and the human in order to translate the built environment in written and spoken language. I suggest the key problem is that, in order to build engineers must standardise human form to a general or ideal condition. However, as buildings are designed and populated by diverse individuals it is necessary also to reflect this in their writing. Architects and developers reflect this varied population by associating individual character traits with the building. From the example of the Burj Khalifa it can be seen that engineers also associate buildings with human character traits but their writing displays a tendency to emphasise continuity and context rather than individuality. I show the individual occupant is standardised into a generalised population when engineers write about people. The final example of this chapter shows that even when writing about the tallest built structure in the world, engineers temper superlatives with talk of context and continuity.

The chapter on aesthetics or felt response explores the features apparent in a built form which are designed to elicit response and discusses how engineers translate these into written language. Largely, it deals with delight and I explore texts in an attempt to uncover what engineers find beautiful or pleasing. Particularly, I investigate how engineers attempt to standardise delight and beauty in order to solve the problem of translating subjective felt response. My analysis of Rice's representation of the design and construction of the Beaubourg's gerberette reveals that in practice the relationship of the engineer, the simple and the rational is not as clear cut as other, more theoretical texts might suggest. Rice concludes that difficulty and passion plays a large part in the aesthetic success of the Centre Pompidou. Through an analysis of texts written about the China Central Television (CCTV) complex, I explore how the standards of rationality and simplicity relate to a building designed to elicit a less conventional response. The shape and size of CCTV complicates its structure and this makes it at odds with the aesthetic of rationality and simplicity. Yet, I find engineers attempting to make sense of the structure of this building in these traditional terms. I also find examples of writing by architects primarily, but also engineers, which attempts to reach for a new aesthetic which will fit an era of design when computer technology makes any shape and size possible.

To explore the ways engineering language might inform, alter and enlarge fiction I place the findings of my analysis in the context of imaginative fiction. I conclude that the techniques used by engineers to translate the simultaneous and contingent action 
apparent in buildings might offer fresh expressive pathways for fiction to: highlight the artificiality of narrative form, build sentences and creates an eternal timelessness. I suggest the language choices made by engineers when faced with the problem of translating the relationship between the built and the human might offer fiction an opportunity to experiment with point of view and the characterisation of a generalised population. The techniques used by engineers to translate aesthetics or felt response into written and spoken language lead me to imagine a fiction which puts rationality and lyricism at war to an extent that the tension between these two aesthetics can be read in the text. I am particularly interested in experimentation which uses rationality for ornamentation, emotion and music.

My critical research informs my creative project - a novel called I'm Working on a Building. In this work I have attempted to use some of the characteristics from the language of structural engineering as a way of amplifying what might usually be muted aspects of fiction. In basing the story of a female engineer around the buildings she inhabits, works on or moves through, I aim to restore some of the strangeness of these structures, and to promote into view aspects of the physical world which might ordinarily figure as background or veiled symbol. 


\section{REFLECTIONS}

The critical component of this thesis aims to identify characteristics of the language of structural engineering in order to explore ways these might inform, alter and enlarge the language of fiction. As a graduate of English literature I first turned to literary theory as a model for getting at these language characteristics. I thought if I could identify the literary features of engineering language then I would be able to transfer these to my creative work. How did engineers use metaphor differently to fiction writers? What was the narrative shape of an engineering text? While interesting, and possibly the only way I could have begun, this approach led to an analytical loop which proved unhelpful. I looked for literary features and I found them. And once finding them, what was I to do? Take the literary troupe back to literature? By using what I knew to analyse what I didn't, I made the engineering texts conform to literary conventions. I couldn't, using this technique get to what it was that was distinct about them. I decided I needed to deal with the texts as a language system, so I looked to linguistics and made several stumbling attempts at discourse analysis. While this threw up some interesting results, it didn't seem to give me room to deal with the language of engineering in any kind of expressive or evocative way, so it shut me out from the experience of what I was trying to achieve.

What I think is productive about translation studies theory for my project is that it blends literary and linguistic methods. It allows for some reading response of the texts but has its focus very much on the language traits and norms (grammar, word choice, syntax). Also, it helped me look at the texts as something different from a novel or a short story. It also has an awareness of context,action and purpose. This appealed because part of what I wanted to do with the results of my analysis was create buildings and characters in place and time and at work.

To my knowledge, the utilisation of Descriptive Translation Studies and skopos to engineering texts for the purpose of a creative project is a new application of a Translation Studies methodology. This new application brought with it some complexity and issues which were never fully resolved. The methodology was not intended to analyse how a physical object is translated into written and spoken language and I often questioned whether this process could ever truly be called translation. But, I felt supported in my undertaking by the broadening ambit of translation studies and by the results the methodology was producing. 
In hindsight it may have been more appropriate to use a rhetorical model. However, I believe that the insights I gained using the translation study's methodology were different from what I would have uncovered in a rhetorical analysis. I identify the buildings as the source of the texts I analyse, and I believe this gave them a presence in the texts that a rhetorical model would not have allowed. This presence coupled with a necessity to consider the building as text, or expression of a language foreign to written or spoken English, not only helped me analyse the engineering language in a way that made it fresh and unusual but also offered me a way of looking at buildings which maintained some of the strangeness I was so taken by that first time I had structural performance explained. I feel this methodological approach is worth exploring further.

I would be particularly interested in attempting to adapt the methodology so that it is better suited to analysing the translation of physical object to written or spoken language. To do this I believe it would be necessary to further explore the concept of building as text. During my research I identified several other opportunities for further research. These are discussed in the following section.

\section{Opportunities for further study}

Research into the pathways between rational and imaginative fiction has been limited primarily to the natural sciences. I believe there is an opportunity to analyse more deeply the pathways between engineers' technical and creative processes. In his conference paper 'Strong Words: The Creative Writing of Engineers' Moran proposes further investigation into the paths that 'connect creativity, engineering, and the written word' (9). When I explained my research to the engineers I met during this project many of them talked about their own technical writing process and one talked to me about his creative writing. I believe talking to engineers who also write creatively may uncover connections between creative and technical writing which could be used to enhance written communication in engineering. Further, I think it would be informative to investigate what engineers read, to explore whether they believe their recreational reading affects their work or technical writing. I spoke with several engineers about their favourite books and I believe the scope of their reading makes a compelling argument for further investigation. I also believe there is an opportunity to explore how the production of written documents fits with the rest of an engineer's work, particularly those parts which are creative. When I asked Wellington engineer Alistair Cattanach why 
he publishes articles he said, 'self-reflection and it stimulates innovation' (Alistair Cattanach). There is an opportunity to explore whether other engineers see a relationship between their writing and design processes. A component of this study could be an analysis of how engineers structure their narratives in writing that is used in the process of design.

I show that barriers to female participation in engineering professions are predominantly culturally-based. Therefore, it would be interesting to explore the culture of engineering through texts produced for and by female engineers. A Translation Studies framework could also be used to identify problems associated with gender apparent in the built form which must be solved to translate it into written and spoken language. The framework could further assess how engineers solve these problems and judge the impact of these solutions on the gender-characteristics of the profession.

I believe there is also scope to investigate the place of the individual in texts written and spoken by engineers. I have suggested architects aim to make a building more human while engineers aim to make humans more built. I think this idea could be explored by comparing the writing of engineers with the writing of architects in order to uncover differences in how these professions describe the relationship between the built and the human.

I believe this methodological approach has produced useful tools for experimentation in creative writing. There is definite scope to analyse languages from outside the culture of fiction using this model in order to produce creative work. I also believe my study raises some interesting ideas about collaboration and there is scope to explore how collaboration has been and might be applied to imaginative literature.

I conclude this critical essay with the following reflections on the creative component of this project.

\section{Reflections on the creative component}

My aim is that the fiction plays with and tests some of the ideas in the research essay rather than illustrates or enacts them. In some ways the fiction might also contradict the theoretical observations. For example, to what extent was I able to free my work from symbolism? Is the act of writing and indeed reading figuratively a reflexive one?

In a lot of ways the creative component of this project has been characterised and shaped by failure. I have written a great deal which was very unsatisfactory. 
Like any newcomer to a foreign language my first experiments were in sound and names. My work of this time is very listy. It's saturated in terms and names lifted straight from engineering discourse. A small piece of this work was published in an online poetry journal. And this, I think is where it belonged, it was far more poetry than prose. As I tried to sustain it for longer than a page it became impenetrable. Writing from this times remains in my submitted thesis as 'The Basement Flat' chapter where I use it for noise and sense.

These fragments turned strangely into an attempt to write a hybrid thesis. I thought I could sprinkle these noise works through a critical discussion of engineering writing. However, I couldn't make the academic writing fit and as I wrote longer and longer sections of creative work it took on this strange arrogance which made it really unappealing.

Time was getting on, so I decided to try and write a novel in a month as part of National Novel Writing Month. The novel was the story of an engineer on a tower at the end of the world, who becomes a building through a time ending fire. As a building my engineer can go anywhere in all times. I attempted to write this piece completely in present tense, with a truly omniscient narrator. It was very hard to write a place where all things are possible. There was very little tension strangely enough, and it felt loose and baggy and like my least favourite science fiction.

Despite trying to invent a new, post-human language system, what happened was that the buildings started talking to each other in a way that resembled the shallowest of human speech. I guess because I was unable to escape my own anthropomorphic limitations. I was people.

Part of this writing remains in the fantasy Catherine tries to muster toward Rankine Brown, here she tries to see buildings alive talking to each other the way she imagines other people see them (the windows eyes, the door a mouth).

But like all the other works which preceded it this failed novel was useful to my submitted creative work. It was during writing it that I first wrote 'she' and realised my engineer was a woman and I think I found ways to present the scope of this work in a more satisfying way through writing this literal full version of events I imagined for my engineer.

My critical work helped hone these early creative attempts into the work I submitted. I saw that I could embed the discourse of engineering into my creative work rather than having to overtly abandon what I found satisfying in imaginative fiction. I 
saw, especially through my work on the relationship between the built and the human, that it people were implied in buildings, that it was possible to talk about humans AND create fully rendered, buildings that maintained something of their engineering-ness and so offered an opportunity for readers to notice buildings anew. I found ways of experimenting with time which didn't necessitate an unreadable text. I gained insight into the felt responses buildings can illicit and the language engineers have built to talk about beauty.

When I read over my thesis I hope that it will teach people something about buildings, but I also hope it will teach them about people as well. And I feel any success I have in this aim is a result of the process which put me in close contact with engineers and their writing. 
Appendix 1: TABLES SHOWING ANALYSIS OF ASSUMED TRANSLATIONS 


\section{Assumed Translation 1}

1. IDENTIFY ASSUMED TRANSLATION (AT): Gledhill, Sean, G.K. Sidwell, and D.K. Bell. "The Damage Avoidance Design of Tall Steel Frame Buildings - Fairlie Terrace Student Accommodation Project, Victoria University of Wellington." 2008 New Zealand Society of Earthquake Engineering Conference. NZSEE.

\begin{tabular}{|c|c|c|c|c|}
\hline 2. CRITERIA MET FOR STATUS AS AT & $\begin{array}{l}\text { 3. SKOPOS \& CRITERIA MET } \\
\text { FOR ACCEPTABILITY }\end{array}$ & $\begin{array}{l}\text { 4. PARALLEL TEXTS USED FOR } \\
\text { COMPARISON }\end{array}$ & $\begin{array}{l}\text { 5. APPROPRIATE } \\
\text { SOURCE }\end{array}$ & $\begin{array}{l}\text { 6. SEGMENT USED } \\
\text { FOR COMPARISON } \\
\text { OF AT WITH SOURCE }\end{array}$ \\
\hline $\begin{array}{l}\text { Knowledge of text in another language which } \\
\text { translation replaces. (Paper used as surrogate } \\
\text { for Te Puni Student Accommodation) }\end{array}$ & $\begin{array}{l}\text { Skopos: Share knowledge, receive } \\
\text { feedback, increase prestige. } \\
\text { Acceptability: } \\
\text { - Follows guidelines for } \\
\text { formatting of papers } \\
\text { - Language follows norms of good } \\
\text { writing } \\
\text { - Building can be visualised - uses } \\
\text { diagrams } \\
\text { - Uses terms common to } \\
\text { audience } \\
\text { - Uses empirical terms - } \\
\text { mathematics } \\
\text { - They are reviewed as they are } \\
\text { submitted and the guidelines talk } \\
\text { about accepted papers. I think } \\
\text { they need to supply an abstract } \\
\text { first, then that is accepted and } \\
\text { the paper is reviewed. }\end{array}$ & $\begin{array}{l}\text { (Gledhill); ("Aurecon Recognised } \\
\text { for Seismic World First"); ("A } \\
\text { World First for a Multi-Storey } \\
\text { Steel-Framed Building"); } \\
\text { (Butterworth, Clifton and } \\
\text { MacRae); (Honey) }\end{array}$ & $\begin{array}{l}\text { Te Puni Student } \\
\text { Accommodation, } \\
\text { Victoria University } \\
\text { of Wellington, New } \\
\text { Zealand }\end{array}$ & $\begin{array}{l}\text { Seismic design } \\
\text { structure }\end{array}$ \\
\hline
\end{tabular}




\section{Assumed Translation 2}

1. IDENTIFY ASSUMED TRANSLATION (AT): Cattanach, Alastair, and Stefano Pampanin. . "21st Century Precast: The Detailing and Manufacture of NZ's First Multi-Storey Presss Building." New Zealand Concrete Industry Conference. October 2008. Rotorua Convention Centre, Rotorua. Concrete Society of New Zealand: 2008. Print.

\begin{tabular}{|c|c|c|c|c|}
\hline 2. CRITERIA MET FOR STATUS AS AT & $\begin{array}{l}\text { 3. SKOPOS \& CRITERIA MET } \\
\text { FOR ACCEPTABILITY }\end{array}$ & $\begin{array}{l}\text { 4. PARALLEL TEXTS USED FOR } \\
\text { COMPARISON }\end{array}$ & $\begin{array}{l}\text { 5. APPROPRIATE } \\
\text { SOURCE }\end{array}$ & $\begin{array}{l}\text { 6. SEGMENT USED } \\
\text { FOR COMPARISON } \\
\text { OF AT WITH SOURCE }\end{array}$ \\
\hline $\begin{array}{l}\text { Knowledge of text in another language which } \\
\text { translation replaces. (Paper used as surrogate } \\
\text { for Alan MacDiarmid Building) }\end{array}$ & $\begin{array}{l}\text { Skopos: Share knowledge, receive } \\
\text { feedback, increase prestige. } \\
\text { Acceptability: } \\
\text { - Follows guidelines for } \\
\text { formatting of papers } \\
\text { - Language follows norms of good } \\
\text { writing } \\
\text { - Building can be visualised - uses } \\
\text { diagrams } \\
\text { - Uses terms common to } \\
\text { audience } \\
\text { - Uses empirical terms - } \\
\text { mathematics } \\
\text { - This paper was presented } \\
\text { specifically to concrete industry } \\
\text { professionals. It addresses areas } \\
\text { of the structure which would be } \\
\text { of interest to this sector. }\end{array}$ & $\begin{array}{l}\text { ("Teaching and Research Building: } \\
\text { Summary of Submissions"); ("Update } \\
\text { One"); ("Application for Resource } \\
\text { Consent under Section } 88 \text { of the } \\
\text { Resource Management Act 1991"); } \\
\text { ("Assessment of Effects on the } \\
\text { Environment Victoria University of } \\
\text { Wellington Proposed New Building for } \\
\text { Teaching and Research"); ("Campus } \\
\text { Development Framework Teaching } \\
\text { and Research Building Project"); } \\
\text { (Alistair Cattanach); (Alastair } \\
\text { Cattanach); ("Alan Macdiarmid } \\
\text { Building on Target") }\end{array}$ & $\begin{array}{l}\text { Alan MacDiarmid } \\
\text { Building, Victoria } \\
\text { University of } \\
\text { Wellington, New } \\
\text { Zealand }\end{array}$ & $\begin{array}{l}\text { Seismic design } \\
\text { structure }\end{array}$ \\
\hline
\end{tabular}




\section{Assumed Translation 3}

1. IDENTIFY ASSUMED TRANSLATION (AT): Johnstone, Peter, and Pablo R. Alcantara. No. 1 Featherston St. Building 05-294. Wellington: Romulus Consulting Group, 2007.

\begin{tabular}{|c|c|c|c|c|}
\hline 2. CRITERIA MET FOR STATUS AS AT & $\begin{array}{l}\text { 3. SKOPOS \& CRITERIA MET } \\
\text { FOR ACCEPTABILITY }\end{array}$ & $\begin{array}{l}\text { 4. PARALLEL TEXTS USED FOR } \\
\text { COMPARISON }\end{array}$ & $\begin{array}{l}\text { 5. APPROPRIATE } \\
\text { SOURCE }\end{array}$ & $\begin{array}{l}\text { 6. SEGMENT USED } \\
\text { FOR COMPARISON } \\
\text { OF AT WITH SOURCE }\end{array}$ \\
\hline $\begin{array}{l}\text { Knowledge of text in another language which } \\
\text { translation replaces. (Report used as } \\
\text { surrogate for } 1 \text { Featherston Street) }\end{array}$ & $\begin{array}{l}\text { Skopos: Written for whole design } \\
\text { group (architects, clients and } \\
\text { other engineers) to be used as a } \\
\text { working document which } \\
\text { accounts all design decisions } \\
\text { made to date. } \\
\text { Acceptability: } \\
\text { - Follows guidelines for } \\
\text { formatting of design report } \\
\text { - Peer-reviewed } \\
\text { - Language follows norms of good } \\
\text { writing } \\
\text { - Building can be visualised - uses } \\
\text { diagrams } \\
\text { - Uses terms common to } \\
\text { audience } \\
\text { - Uses empirical terms - } \\
\text { mathematic } \\
\text { - Written in two discourse plain } \\
\text { English summaries and tables of } \\
\text { numbers representing results of } \\
\text { modelling. }\end{array}$ & $\begin{array}{l}\text { Resource information from Wellington } \\
\text { City Council; } 2010 \text { Site Visits }\end{array}$ & $\begin{array}{l}1 \text { Featherston } \\
\text { Street, Wellington } \\
\text { New Zealand }\end{array}$ & Place of 'people' \\
\hline
\end{tabular}


Assumed Translation 4

1. IDENTIFY ASSUMED TRANSLATION (AT): Beca. Owen G. Glenn Building: University of Auckland New Business School. Auckland: Beca, 2009.

\begin{tabular}{|c|c|c|c|c|}
\hline 2. CRITERIA MET FOR STATUS AS AT & $\begin{array}{l}\text { 3. SKOPOS \& CRITERIA MET } \\
\text { FOR ACCEPTABILITY }\end{array}$ & $\begin{array}{l}\text { 4. PARALLEL TEXTS USED FOR } \\
\text { COMPARISON }\end{array}$ & $\begin{array}{l}\text { 5. APPROPRIATE } \\
\text { SOURCE }\end{array}$ & $\begin{array}{l}\text { 6. SEGMENT USED } \\
\text { FOR COMPARISON } \\
\text { OF AT WITH SOURCE }\end{array}$ \\
\hline $\begin{array}{l}\text { Knowledge of text in another language which } \\
\text { translation replaces. (Entry form used as } \\
\text { surrogate for Owen G. Glenn Building) }\end{array}$ & $\begin{array}{l}\text { Skopos: Written to support entry } \\
\text { for competition. Purpose of entry } \\
\text { is to win. The argument of this } \\
\text { translation is 'The engineering of } \\
\text { this building is award-winning' } \\
\text { Acceptability: } \\
\text { - Follows guidelines of the } \\
\text { competition } \\
\text { - Language follows norms of good } \\
\text { writing } \\
\text { - Building can be visualised - uses } \\
\text { diagrams } \\
\text { - Uses terms common to } \\
\text { audience } \\
\text { - Uses empirical terms - } \\
\text { mathematics } \\
\text { - Beca won award with this entry. }\end{array}$ & $\begin{array}{l}\text { (University of Auckland Business } \\
\text { School); (Fletcher Construction); } \\
\text { (Wikipedia "Owen G. Glenn Building"); } \\
\text { (Clark) }\end{array}$ & $\begin{array}{l}\text { Owen G. Glenn } \\
\text { Building, Auckland, } \\
\text { New Zealand }\end{array}$ & Place of 'people' \\
\hline
\end{tabular}




\section{Assumed Translation 5}

1. IDENTIFY ASSUMED TRANSLATION (AT): Engineering an Idea: The realisation of the Burj Khalifa, Civil Engineering, March 2010

\begin{tabular}{|c|c|c|c|c|}
\hline 2. CRITERIA MET FOR STATUS AS AT & $\begin{array}{l}\text { 3. SKOPOS \& CRITERIA MET } \\
\text { FOR ACCEPTABILITY }\end{array}$ & $\begin{array}{l}\text { 4. PARALLEL TEXTS USED FOR } \\
\text { COMPARISON }\end{array}$ & $\begin{array}{l}\text { 5. APPROPRIATE } \\
\text { SOURCE }\end{array}$ & $\begin{array}{l}\text { 6. SEGMENT USED } \\
\text { FOR COMPARISON } \\
\text { OF AT WITH SOURCE }\end{array}$ \\
\hline $\begin{array}{l}\text { Knowledge of text in another language which } \\
\text { translation replaces. (Article acts as surrogate } \\
\text { for Burj Khalifa) }\end{array}$ & $\begin{array}{l}\text { Skopos: To celebrate the opening } \\
\text { of the Burj Khalifa. To put a } \\
\text { personal face on the event by } \\
\text { Barker describing his experience } \\
\text { of engineering the building. An } \\
\text { attempt to Americanise the Burj. } \\
\text { Acceptability: } \\
\text { - Follows guidelines of the } \\
\text { journal. Column is called 'First } \\
\text { Person', so acceptable for } \\
\text { personal reflection } \\
\text { - Language follows norms of good } \\
\text { writing } \\
\text { - Building can be visualised - uses } \\
\text { diagrams } \\
\text { - Uses common terms } \\
\text { - Uses empirical terms - } \\
\text { mathematics } \\
\text { - Peer-reviewed journal. }\end{array}$ & $\begin{array}{l}\text { (Baker); (Baker); (Weismantle, Smith } \\
\text { and Sheriff); (Baker, Pawlikowski and } \\
\text { Young "Reaching toward the } \\
\text { Heavens"); (Baker, Pawlikowski and } \\
\text { Young "The Challenges in Designing } \\
\text { the World's Tallest Structure: The Burj } \\
\text { Dubai Tower"); (Sutjiadi); } \\
\text { (Horlesberger and Pimiskern); (Lee et } \\
\text { al.); }\end{array}$ & Burj Khalifa, Dubai & $\begin{array}{l}\text { Expression of scale and } \\
\text { wind }\end{array}$ \\
\hline
\end{tabular}




\section{Assumed Translation 6}

\begin{tabular}{|c|c|c|c|c|}
\hline \multicolumn{5}{|c|}{$\begin{array}{l}\text { 1. IDENTIFY ASSUMED TRANSLATION (AT): Case Study: CCTV Building (In Council of Tall Buildings and Urban Habitat (CTBUH) Journal } 2008 \\
\text { Issue) }\end{array}$} \\
\hline 2. CRITERIA MET FOR STATUS AS AT & $\begin{array}{l}\text { 3. SKOPOS \& CRITERIA MET } \\
\text { FOR ACCEPTABILITY }\end{array}$ & $\begin{array}{l}\text { 4. PARALLEL TEXTS USED FOR } \\
\text { COMPARISON }\end{array}$ & $\begin{array}{l}\text { 5. APPROPRIATE } \\
\text { SOURCE }\end{array}$ & $\begin{array}{l}\text { 6. SEGMENT USED } \\
\text { FOR COMPARISON } \\
\text { OF AT WITH SOURCE }\end{array}$ \\
\hline $\begin{array}{l}\text { Knowledge of text in another language which } \\
\text { translation replaces. (Article acts as surrogate } \\
\text { for CCTV) }\end{array}$ & $\begin{array}{l}\text { Skopos: To share knowledge and } \\
\text { explain concepts behind CCTV } \\
\text { design } \\
\text { Acceptability: } \\
\text { - Follows guidelines of the } \\
\text { journal. } \\
\text { - Language follows norms of good } \\
\text { writing } \\
\text { - Building can be visualised - uses } \\
\text { diagrams } \\
\text { - Uses terms common to } \\
\text { engineering professionals } \\
\text { - Uses empirical terms - } \\
\text { mathematics } \\
\text { - Peer-reviewed journal. }\end{array}$ & $\begin{array}{l}\text { (Tuchman); (Carroll, Cross, Duan, } \\
\text { Gibbons, Ho, Kwok, Lawson, Lee, } \\
\text { Luong, et al.); (Webb); (Koolhaas); } \\
\text { (Paternack) }\end{array}$ & $\begin{array}{l}\text { China Central } \\
\text { Television Building, } \\
\text { Beijing, China }\end{array}$ & Aesthetics \\
\hline
\end{tabular}


Assumed Translation 7

1. IDENTIFY ASSUMED TRANSLATION (AT): 'Beaubourg' (p.25 - 47) An Engineer Imagines, Peter Rice

\begin{tabular}{|c|c|c|c|c|}
\hline 2. CRITERIA MET FOR STATUS AS AT & $\begin{array}{l}\text { 3. SKOPOS \& CRITERIA MET } \\
\text { FOR ACCEPTABILITY }\end{array}$ & $\begin{array}{l}\text { 4. PARALLEL TEXTS USED FOR } \\
\text { COMPARISON }\end{array}$ & $\begin{array}{l}\text { 5. APPROPRIATE } \\
\text { SOURCE }\end{array}$ & $\begin{array}{l}\text { 6. SEGMENT USED } \\
\text { FOR COMPARISON } \\
\text { OF AT WITH SOURCE }\end{array}$ \\
\hline $\begin{array}{l}\text { Knowledge of text in another language which } \\
\text { translation replaces. (Chapter acts as } \\
\text { surrogate for Pompidou Centre) }\end{array}$ & $\begin{array}{l}\text { Skopos: To share knowledge and } \\
\text { to offer a personal account of a } \\
\text { career as an engineer } \\
\text { Acceptability: } \\
\text { - Language follows norms of good } \\
\text { writing } \\
\text { - Building can be visualised - uses } \\
\text { diagrams } \\
\text { - Uses terms common to } \\
\text { audience } \\
\text { - Uses empirical terms - } \\
\text { mathematics } \\
\text { - Well received by reviewers and } \\
\text { recommended by engineers }\end{array}$ & $\begin{array}{l}\text { (N. Silver); (Copans et al.); } \\
\text { (Colquhoun); ("Developing the } \\
\text { Structure"); (Happold "Beaubourg: } \\
\text { Architecture or Engineering?"); (Eiffel } \\
\text { and Eiffel); (Rice "Unstable } \\
\text { Structures") }\end{array}$ & $\begin{array}{l}\text { Centre Pompidou, } \\
\text { Beaubourg, Paris, } \\
\text { France }\end{array}$ & Aesthetics \\
\hline
\end{tabular}




\section{Assumed Translation 8}

1. IDENTIFY ASSUMED TRANSLATION (AT): Ivy, Robert Adams. Fay Jones: The Architecture of E. Fay Jones, FAIA. Washington, D.C.: American Institute of Architects Press, 1992.

\begin{tabular}{|c|c|c|c|c|}
\hline 2. CRITERIA MET FOR STATUS AS AT & $\begin{array}{l}\text { 3. SKOPOS \& CRITERIA MET } \\
\text { FOR ACCEPTABILITY }\end{array}$ & $\begin{array}{l}\text { 4. PARALLEL TEXTS USED FOR } \\
\text { COMPARISON }\end{array}$ & $\begin{array}{l}\text { 5. APPROPRIATE } \\
\text { SOURCE }\end{array}$ & $\begin{array}{l}\text { 6. SEGMENT USED } \\
\text { FOR COMPARISON } \\
\text { OF AT WITH SOURCE }\end{array}$ \\
\hline $\begin{array}{l}\text { Knowledge of text in another language which } \\
\text { translation replaces. (Article acts as surrogate } \\
\text { for Thorncrown Chapel) }\end{array}$ & $\begin{array}{l}\text { Skopos: To celebrate the } \\
\text { architecture of Fay Jones. To } \\
\text { share information } \\
\text { Acceptability: } \\
\text { - Language follows norms of good } \\
\text { writing } \\
\text { - Building can be visualised - uses } \\
\text { diagrams } \\
\text { - Uses terms common to } \\
\text { audience }\end{array}$ & $\begin{array}{l}\text { (Douglas); (Ivy); (Koerble); (Stegers); } \\
\text { (Jones "Transforming the Past for the } \\
\text { Future: The } 1990 \text { Aia Gold Medal } \\
\text { Address"); (Jones "Selected Details: } \\
\text { Making Light of Wood Joinery") }\end{array}$ & $\begin{array}{l}\text { Thorncrown } \\
\text { Chapel, Eureka } \\
\text { Springs, Arkansas, } \\
\text { USA }\end{array}$ & Aesthetics \\
\hline
\end{tabular}


Appendix 2: RATIONALISED WORD LISTS FROM PRELIMINARY CONTENT ANALYSIS 


\section{Assumed Translation 1}

Gledhill, Sean, G.K. Sidwell, and D.K. Bell. "The Damage Avoidance Design of Tall Steel Frame Buildings - Fairlie Terrace Student Accommodation Project, Victoria University of Wellington." 2008 New Zealand Society of Earthquake Engineering Conference. NZSEE.

\section{NARRATIVE POINT OF VIEW}

THIRD PERSON NARRATION. 'To meet the need Connell Wagner developed and has refined a new system' (8). 'Connell Wagner was tasked to undertake the design' (1) Individuals not named but names in the author field. 'We note ...' (5)

\section{VOICE}

Passive in Introduction, 'Connell Wagner was tasked to undertake the design of the new multi-story ... to incorporate ...' (XXX) Then active in the rest of the paper.

\section{TENSE}

Past indicative, 'Connell Wagner was tasked' (3) Mixture: 'The purpose of the damage avoidance design of this project was to ensure (PAST INDICATIVE) that after a large earthquake, the student accommodation buildings could be utilised (FUTURE INDICATIVE) for administration or as a mixed use facility, while other university buildings were under repair (PASSIVE PRESENT), ensuring (PROGRESSIVE PRESENT) the University can continue (PRESENT INDICATIVE) its operations' (3) About the buildings, PRESENT 'The buildings are...' (3) Buildings not completed until 2009, so maybe source of this translation is a plutonic idea in the engineers head. Oddness here 'The proposed buildings extend (PRESENT) up to 11 storeys ...' (3) The proposed building is talked about in the present, in that paragraph the rest of the mentions of the building use the past indicative (which I think shows intention). In the 'Background Research' section there is a mix of tense when talking about the options considered: PRESENT, simple present used to describe the technology as it is today, PROGRESSIVE 'Using an unbonded prestressing cable this connection can (INDICATIVE) be made to act in a similar way ...' (6), Strange use of MAY'These solutions may be located in the transverse short direction of the Tower and the Edge Building' (6) I think he means 'can be' it's not a possibility it is fact. Also, still some 'would'. When it comes to talking about the structure and how it will act in the earthquake first paragraph starts in PERFECT 'transverse bracing frames consisted of...' (9) then the rest of the paragraph is in simple present which could show present actions in a commentary 'consists, allows, controls, limits, and then finished with 'have' PERFECT. 'Under seismic lateral loads the CBF's are designed to uplift' (9) They are designed to, it's no indicative of their action, the writer is describing what they are designed to do. Then there is the conditional paragraph, 'for the column to rock upwards' (9) Move to simple present but can that also be future? 'Initially, once seismic column axial tension forces over some gravity loads, the Ringfeder prestress provides a further uplift threshold. ' (9) Shows time that this will happen in the pre-fix for the sentence. But it is mentioned only once and then it is in the present - so the earthquake is set in motion then it all happens now. 


\section{NOUNS}

SYSTEM, BUILDINGS, TECHNIQUES, STRUCTURES, CONCRETE, STEEL, TORSION, WALLS, LATERAL FORCES, FRAME, BASE PLATE, HINGE, SHEAR,

Nominal word compounds: RIGID BEAM COLUMN JOINTING SYSTEM, SEISMIC RESISTING SCHEME, TRANSVERSE BRACING FRAMES, COUPLED CONCENTRICALLY BRACED STEEL, TENSION LIMITING BASE LEVEL HINGE, BASE HINGE, PRESTRESSED RINGFEDER FRICTION SPRINGS, VERTICALLY ORIENTATED HINGE JOINT FRICTION PLATES, SLIDING BOLTS, RIGID CONCRETE DIAPHRAGMS, TRANSVERSE BRACING FRAMES, COUPLED SHEAR WALLS, CONCRETE SHEAR WALL PLASTIC HINGE FORMATION, CONCRETE SPALLING, STEEL, SHEAR WALL, FLOOR SLAB, WALL EDGE CONES, FIXED-HEAD BORED CONCRETE PILES, SEISMIC LATERAL LOADS, FRICTIONS SPRING ELEMENTS, SPRING COMPRESSION FORCE, COLUM TENSION, COUPLING BEAM, VERTICALLY ORIENTATED COLUMN FLANGE MOUNTED SLIDING JOINT, ROCKING MECHANISM, CENTRAL TURNED DOWN BOLT, SLIDING HINGE JOINT FRICTION PLATES, RINGFEDER FRICTION SPRING, FRICTION PLATE HYSTERESIS CURVE, GRAVITY AXIAL LOAD

\section{PROPER NOUNS}

RINGFEDER SPRINGS, HERA, UNIVERSITY OF AUCKLAND, VICTORIA UNIVERSITY OF WELLINGTON, CONNELL WAGNER, FAIRLIE TERRACE

SEISMIC ENGINEERING, SLIDING HINGE JOINTS (presented as a proper noun) DAMAGE AVOIDANCE DESIGN, DAMAGE AVOIDANCE' PHILOSOPHY, DAMAGE AVOIDANCE DESIGN FEATURES, DAMAGE AVOIDANCE FEATURES, Same words presented in difference ways, they are a proper-noun in that they refer to one specific thing. 'THE TOWER AND THE EDGE BUILDING.' (6) In some places it is the 'Tower' building 


\title{
VERBS
}

Weird phrases that seem to make proper nouns but include verbs: 'Coupled concentrically braced frames', prestressed Ringfeder Springs', 'sliding hinge joints' (8) (look at tense of these it is not - hinges that will slide, they are sliding, even though for the most time, if there is not an earthquake they will not be sliding. Just realised this is exactly like the word 'building' it is a verb but it is a noun and it refers to one part of the buildings life, the part where it is being built? Or what is the tense of 'building' isn't it progressive present? DEVELOPED, REFINED, UTILISED, CONDUCTED, FEATURED, CONSISTED, COUPLES, PROVIDED, CONSISTED CONSISTS, ALLOWS, CONTROLS, LIMITS, HAVE, ENABLE, PRELOAD, SET, PROVIDE, PROVIDE, REDUCING, STIFFEN, PROVIDE, ARE DISTRIBUTED, BEHAVE, RESISTED, OVERTURNING, CONSISTING, ACTING, RELATES, SPALLING, BUCKLING, REINFORCING, UTILISING, BRACED, RESISTED, BEARING, CONTROLLED, RESISTED, ARE DESIGNED, LIMITED, RESIST, RESULTING, OVERSTRENGTHS, OVERCOME, ROCK, OVERCOME, OVERCOME, ROCK, OVERCOME, OVERCOME, ROCKING, COMPRESSES, CONTROLLING, ENSURING, ROCKING, DISSIPATES, PRESTRESSED (COMPRESSED), CONNECTED, WORKS, OVERCOME, PROVIDES, EXCEEDED, ENGAGED, EXCEEDED, UPLIFTS, WAS, PROVIDE, MEANING, CONSIST, UTILISING, COMPRESSED, RESIST, SUPPORTED, FORMED, IS, ALLOWS, MOVE, CLOSING, DECREASING, LOADS UP, TRAVELLING, UNLOADING, FULL LOCK UP, UNLOADED, PROVIDE, REACHED, EXCEEDED, PROVIDED, REACHES, OCCURS, BECOMES, DESIGNED, YIELDING, DESIGNED, PROVIDED, CONNECTING, PROVIDED, PREVENT, DISPLACING, FOLLOWS, FOLLOWED, DOES NOT, CHANGES, REFLECT, RESULTING, Verb as noun: 'If SPRING TRAVEL is reached or exceeded further PROTECTION TENSION LIMITING DEVICES are provided. Upon TRAVEL EXCEEDENCE the RINGFEDER SPRING effectively reaches LOCK UP. When this occurs, the SPRING STACK becomes almost a SOLID STEEL STACK. The TURNED DOWN PRESTRESSED BOLT is designed to begin YIELDING at approximately $90 \%$ of SPRING LOCKUP.' (10) NOT 'further devices that limit tension' or 'When travel is exceeded' or 'the springs lock up' or 'the spring stack solidifies' or 'is designed to yield at...' Last one might be correct because it starts to yield there and 'yield' has a very specific meaning.

\author{
ADJECTIVES \\ DAMAGE AVOIDANCE DESIGN, NEW, MULTI-STOREY, 'SHORT, STIFF, HEAVY BUILDINGS', \\ 'TALL, RELATIVELY LIGHT, FLEXIBLY STEEL', 'EXPENSIVE AND COMPLICATED', COST EFFECTIVE \\ NEW SYSTEM', HIGH-RISE STEEL FRAMED BUILDINGS', 'SLIDING HINGE JOINTS', POSSIBLE \\ DAMAGE AVOIDANCE DESIGN SOLUTIONS', CHOSEN SYSTEM', 'DETAILED DESIGN'. \\ Adjectives about recency - LATEST, CURRENT, MODERN (LOTS), RECENT, NEW \\ Adjectives about context or rather about how this fits with past ideas - PREVIOUS LOADING \\ STANDARDS, APPROPRIATELY HIGH LEVELS, TRADITIONAL DESIGN PROCESS, WELL \\ DOCUMENTED RECENT, NUMEROUS LEADING \\ Adj about money - COST EFFECTIVE, EFFECTIVE \\ Adj about scale - BIG, HIGH, TALL, LARGE, BIG, MULTI-STOREY, HIGH-RISE, PROJECT WIDE, \\ VERY STEEP \\ Adj about materials - CONCRETE, STEEL, STEEL \\ Adj about numbers - FEW, NUMEROUS (No empirical measure on the introduction.) \\ Adj of utility - MIXED USE FACILITY, STUDENT ACCOMMODATION \\ Adj of position/placement - ELEVATED, STREET LEVEL ACCESS, 'LOWER' CBD SITES, \\ TRANSVERSE, PERIMETER LONGITUDINAL, LATERAL.
}


ADVERBS

Most of the adverbs are of the first class and refer to circumstantial information about the action, event or process: VERTICAL, POTENTIAL, EXTERNAL, HORIZONTAL, EFFECTIVELY, UPWARD 


\section{Assumed Translation 2}

Cattanach, Alastair, and Stefano Pampanin. "21st Century Precast: The Detailing and Manufacture of NZ's First Multi-Storey Presss Building." New Zealand Concrete Industry Conference. October 2008. Rotorua Convention Centre, Rotorua. Concrete Society of New Zealand: 2008. Print.

\section{NARRATIVE POINT OF VIEW}

THIRD PERSON OMNISCIENT NARRATION. Written by two engineers. However, there are some similarities in voice between Cattanach interview and this paper. The use of terms like 'plug and play' and 'as they would in a car', seems to be examples of what he talked about in his interview, about using metaphor or analogy to explain complex concepts because here he uses metaphors from computing and automotive technologies. Also, the predominant active voice and the conversational tone, and less frequency of complex nominal word compounds seem to match his interview and the presentation I attended. This is a paper written for New Zealand Concrete Industry Conference so original skopos is the same as Gledhill et al. but these features are different in the two texts.

\section{VOICE}

Mainly active, building or element is agent 'springs begin to yield', 'springs return the building', 'this wall acts to'. In some places the concept of post-tensioning is the agent in these sentences 'it [design concept] divides the building's seismic actions into ...', 'The posttensioning acts to clamp these joints closed and hence spring the building back to vertical'. Less passive, 'Spring action is provided',

TENSE

Past tense used to describe activity in the past: 'After few conceptual designs and feasibility studies attempted in the past few years' Use of AFTER to place activity in past rather than using 'were'. Also, use of 'were' 'these science buildings were constructed' Present tense throughout even though the building was not complete at the time of publication 'The building comprises' but also use of future tense 'The building will be situated' Seems to be split between the actually building and the building created in design. The completed building in design and the partially completed building on the real site.

\section{NOUNS}

BUILDING, DOUBLE-TEES, FRAMES, MEMBERS, BEAMS, LOADS, BEAMS, COLUMNS, COLUMNS, ERECTION, 'PLUG AND PLAY' DEVICES, LITERATURE, CONCRETE FRAMES, LITERATURE, BUILDING, SHEAR WALLS, BASEMENT SERVICE TUNNEL, WALLS, PAIRS, STEEL BEAMS, HYSTERETIC ENERGY ABSORPTION, LITERATURE, CASE, MECHANISMS, HYBRID SYSTEMS, ENERGY DISSIPATION, FLEXURAL YIELDING, ROCKING MOTION, BASE, TOP, SHEAR WALLS, STRESS, FEATURES, DETAILING, FEATURE, SHEAR WALLS, INCORPORATION, CAPPING WALLS, SHEAR WALLS, WALL, SEISMIC MOVEMENTS, SMALL EARTHQUAKES, WALLS, BASE, TOP, VERTICAL POST-TENSIONING, BENEFIT, PROJECT, BASE MOMENTS, BASEMENT SERVICE TUNNEL, JOINT

Nominal word compounds: DEADLOAD/ERECTION SAG, OVERTURNING LOADS, ROCKING MECHANISM, RE-CANTERING CAPABILITY, BASE, ENERGY DISSIPATION, EXTERNAL DEVICES, BEAMS, COUPLED ROCKING/POST-TENSIONED WALLS, STEEL COUPLING BEAMS 


\section{PROPER NOUNS}

MAINZEAL, PRESSS Ltd, WELLINGTON CITY COUNCIL, CONCRETE STRUCTURES Ltd, SAP, RUAUMOKO, CAD-CUTPANKOW BUILDERS, TEACHING LEARNING AND RESEARCH BUILDING (change of name, building not named until later, building described in this text can be tied to original through structural system - NZ's first - and site details), VICTORIA UNIVERSITY'S KELBURN CAMPUS. Presentation for concrete industry conference, main proper nouns are names of contracting companies.

\section{VERBS}

COMPRISES, SPANNING, SPAN, MINIMISED, RESIST, ASSIST, PROVIDED, BOLTED, ALLOWS, PROPOSED, TESTED, BRACED, SITUATED, PROVIDE, ADOPTING, PROVEN, SEPARATED, PROVIDED, RE-CANTERING, LOWERS, ALLOWS, ACTS, STIFFENS, ALLOWS, ROCK, MINIMISING, LANDS

\section{ADJECTIVES}

SIX THREE-BAY, POST-TENSIONED, PRE-TENSIONED, GRAVITY, CENTRALLY POST-TENSIONED, EXTERNAL, VERTICALLY POST-TENSIONED, LONGITUDINAL, FOUR 3.08M X $0.4 \mathrm{M}$, THREE .061M DEEP, TWO, RESPECTIVE, INNOVATIVE, LARGE, IMPORTANTLY Use of empirical measure as adjective.

\section{ADVERBS}

Most of the adverbs are of the first class and refer to circumstantial information about the action, event or process: OFF SITE, EXTENSIVELY 


\section{Assumed Translation 3}

Johnstone, Peter, and Pablo R. Alcantara. No. 1 Featherston St. Building 05-294.

Wellington: Romulus Consulting Group, 2007.

\section{NARRATIVE POINT OF VIEW}

THIRD PERSON NARRATION

\section{VOICE}

Mainly active with building or elements of building being agents: 'The plant area is split over...', 'It is located...' ' '...rigidity of the building coincides ...'

Structure of text seems set by pre-existing form. Voice reverts to summary when heading allows. '1.3 Environmental Factors / Design life - In accordance with building code. Concrete covers - In accordance with the concrete code - NZS 3101:2006, Sections 3 and 4' Text depends on knowledge of texts outside itself. 3 pages of explanatory text versus 10 pages of tables and references. Several appendices not included are referred to. Tables use numbers and symbols but some words which act mainly as supplementary information to the tables 'Specific design may need to be undertaken for compressors'

\section{TENSE}

Mainly simple present tense 'The plant area is split over 2 levels', 'The units are spaced', but also uses Present Perfect Continuous '...components have been designed ...' Extensive use of the predictive modals 'SHALL' and 'WILL' and 'MAY': 'shall be designed', 'will also consider' Often these modals are coupled with a past participle this gives an added sense of certainty or determination. This is done particularly when the text talks about complying with regulations. 
NOUNS

STRUCTURE, RETAIL SPACE, CAR PARK, OFFICE SPACE, PLANT AREA, $4{ }^{\text {TH }}$ FLOOR, TOPMOST FLOOR LEVEL, BUILDING, FLOOR PLATE, TOTAL, FLOOR AREA, CORNER, TERMS, FLOOR AREA, BUILDING, LIFT CORE, DIRECTIONS, BUILDING, FRAMES, FLOOR SLABS, TOPPING CONCRETE, CENTRES, TIMBER, INFILL, AREA, HOLLOWCORE SYSTEM, END CONDITIONS, HOLLOWCORE, END ROTATIONS, STRUCTURE COMPONENTS, DESIGN CODES, DESIGN OF BUILDINGS, STANDARDS, EARTHQUAKES, CONDITIONS, DESIGN PROCESS, LAYOUT, LOCATION, ECCENTRIC LOAD, BUILDING, ISSUES, BUILDING CONSTRUCTABILITY, DESIGN LIFE, BUILDING CODE, CONCRETE COVERS, STEEL FINISH, DURABILITY, BUILDING CODE, INITIAL STAGE, SCHEME DESIGN WORKS, PERIMETER, LOADS, CONSIDERATION, ARCHITECT'S, BUILDING PLAN FORM, BUILDING, BUILDING, SEISMIC GAP, DESIGN STAGE, CALCULATED STORY DRIFT RATIOS, CODE, LIFT CORE WALLS, DIRECTIONS, SHEAR FAILURE, HYBRID COUPLED SHEAR WALLS, FRAMES, EARTHQUAKE ACTION, INTENTION, DESIGN PROCESS, BEAM, COLUMN, ELEMENTS, FRAMES, FOUNDATION INTERACTION, ANALYSIS, AXIAL STIFFNESS, PILES, GROUND BEAM, COLUMNS, GROUND BEAMS, PILES, DUCTILITY FACTOR, ANALYSIS, DESIGN PROCESS, FORCES/MOMENTS, ANALYSIS, DESIGN CALCULATIONS, STRUCTURAL ELEMENTS, CODE, STRENGTH REDUCTION FACTOR, ANALYSIS, SEISMIC ACTION, DYNAMIC SHEAR MAGNIFICATION FACTORS, EFFECTS, HIGHER MODES, DESIGN PROCESS, BENEFIT, RESISTANCE, CONSEQUENCE, DESIGN CRITERIA, DUCTILITY, EQUATION, WALLS, FUNCTION, PROPERTIES, CHALLENGE

Nominal word compounds: BORED PILE FOUNDATIONS, BUILDING'S MAIN LATERAL LOAD RESISTING ELEMENTS, HYBRID COUPLED SHEAR WALLS, CENTRES OF MASS AND RIGIDITY, LATERAL RESISTING ELEMENTS, CENTRE OF RIGIDITY, CENTRE OF MASS, LIFT CORE WALLS, FOUNDATION GROUND BEAM, HYBRID COUPLED SHEAR WALLS, , SYSTEM OF DUCTILE LATERAL LOAD RESISTING FRAMES, INTERNAL GRAVITY FRAMES, CENTRE OF RIGIDITY, CENTRE OF MASS, COUPLED SHEAR WALLS, SEISMIC OVERSTRENGTH FORCES, COUPLED SHEAR WALLS AND FRAMES, WALL FLEXURAL OVERSTRENGTH, PLASTIC HINGE REGION, DYNAMIC SHEAR MAGNIFICATION FACTOR, MAXIMUM ALLOWABLE SHEAR

\section{PROPER NOUNS}

No. 1 FEATHERSTON STREET BUILDING, FEATHERSTON AND BUNNY STREETS, WELLINGTON TRAIN STATION, WELLINGTON HARBOUR, PARLIAMENT BUILDING, WELLINGTON, NZS 1170, NZS 3101 - 2006, NZS 3101:2006, SECTIONS 3 AND 4, METHOD B OF NZS 3101:2006 APPENDIX D, ETABS 3D MODEL, EQUIVALENT STATIC, MODEL RESPONSE SPECTRUM METHODS, EQUIVALENT STATIC METHOD, EQUATION 11-29, INORGANIC ZINC SILICATE PRIMER

\section{VERBS}

COMPRISING, WELL BE BUILT, LOCATED, OVERLOOKS, ARE, COINCIDE, LOCATED, MAKE, SERVE, SPACED, ALLOW, ACCORDING TO, HAVE BEEN DESIGNED, GETTING, COINCIDE, CHALLENGE, DEEMED, REDUCE, CONSTRUCT, DISCUSSED, SUPPORTING, COATED, DECIDED, USE, TAKE, MADE, COINCIDE, RULED OUT, STIFFENING, EXCEEDING, ENTAILED, COUPLED, DESIGNED, ACTS, TRANSFERS, COUPLED, SHALL BE DESIGNED, PREVENT, SHOWN, GOVERN, SHALL BE FOLLOWED, WILL ALSO BE CONSIDERED, INCORPORATING, SUPPORTING, SHALL BE DESIGNED, ASSUMED, SHALL BE SUBSEQUENTLY CHECKED, SHALL BE TAKEN INTO ACCOUNT, MAY NOT GOVERN, CONSIDERING, SHALL BE USED IN DETERMINING, CALCULATING, SHALL ALSO BE TAKEN INTO ACCOUNT BY CALCULATING, DESCRIBED, MAY BE DERIVED, MAY BE MET, AFFECTED, REFLECTED, TAKEN 


\section{ADJECTIVES}

Numeral adjectives used gives indication of the precision required for this text. Skopos is a design report which will be used by other members of team to make design decisions so needs to be accurate but also needs to be read by a range of audiences: 16-STOREY, 1, 2, 12, 2, 45,000M2, 75MM, 2M,

TOTAL, BIGGEST, TO DATE, HEAVILY LOADED, MAXIMUM, LATEST, SPECIFICALLY THE NEWLY INTRODUCED, ALTHOUGH NOT YET LEGALLY ENACTED, RIGOROUS, PRELIMINARY, OPTIMAL, LARGE, SAND BLASTED, EXPOSED, GRAVITY, TORSIONALLY, ARCHITECTURAL, DUCTILE, CONCRETE ENCASED, N-S AND E-W, UNDESIRABLE, DEAD, LIVE, NORMATIVE, HIGHER, REDUCED, ANTICIPATED

\section{ADVERBS}

Adverbial phrases: AS NEARLY AS POSSIBLE, ASSUMED, TO DATE, AS MUCH AS POSSIBLE, AS FOLLOWS,

Very few other adverbs: UNDER, DURING, NORTH, EAST, WEST 


\section{Assumed Translation 4}

Beca. Owen G. Glenn Building: University of Auckland New Business School. Auckland: Beca, 2009.

NARRATIVE POINT OF VIEW THIRD PERSON OMNISCIENT NARRATOR. It is written in the offices of Beca yet doesn't show this at all; 'Beca undertook ...' Skopos for this text is to win a competition therefore it is saying an interesting thing about not pushing your own achievements, it reads more like an external, un-involved narrator write this.

\section{VOICE}

Mainly active, often with Beca or members of Beca team as agents.

TENSE

Moves between past and present mainly. The design and construction is in the past, the building in all its glory is in the present.

\section{NOUNS}

RESULT, VISION, BUILDING, COMPETITION, TEACHING AND RESEARCH EXCELLENCE (text often turns verbs into nouns, which has the effect of making these activities things which happen without human agency), ECONOMY, CHALLENGE, STRUCTURE, VISION, FORM, FUNCTIONS, BUILDING, PROJECT, STAGES, CONSTRUCTOR, CONTRACTORS, TEAMS, RESULT, POSITION, CITY FRINGES, BUILDING FORM, TOWER, ATRIUM, PODIUM, SQUARE, DESIGN, FEATURES, BRIDGE, ATRIUM, WALLS, FACADES, ENDS, BUILDING, LEADERS, BUSINESS COMMUNITY, POSITION, VIEWS, BUILDING, TOWER, PODIUM, SQUARE, AREA, TOWER, ATRIUM, PODIUM, TOWER, SPACE, PODIUM COMPLEX, CAR PARKING, SPACES, TEACHING SPACE, STUDENTS, LECTURE THEATRES, CASE ROOMS, COMPUTER LABORATORIES, ACADEMIC OFFICES, TEACHING FACILITIES (Again, activities are articulated in the spaces they will take place in rather than the people who will be completing them), CONSTRUCTION, EXCAVATION, PORTIONS, CAR PARK, LECTURE THEATRES, PODIUM, TOWER, STAGES, FUNCTIONS, CAR PARK, DATA CENTRE, TEACHING FLOOR, LECTURE THEATRES, THEATRE, COMPUTER LABS, STUDENT POPULATION OF 2,600, MAIN ENTRY FOYER, FLOOR, SPACES, OFFICES, MASTERS AND PhD AND POST-GRADUATE COURSES, AREAS, GROWTH, CONCRETE, REINFORCING STEEL, STRUCTURAL STEELWORK, TOWER FACADE, CUTAINWALL PANELS, SPACE, RESEARCH, INTERVIEW, FOCUS GROUPS, MEETINGS, SENIOR ACADEMICS FROM THE UNIVERSITY, INTERESTED PARTIES, INITIAL CONCEPT BRIEF, REQUIREMENTS, TECHNOLOGIES, GROWTH, SCHOOL, KNOWLEDGE EXCHANGE, STUDENT MOVEMENTS, BREAK-OUT SPACES, CORRIDORS, STAIRS, LINKAGES, COMMUNICATION, STUDENTS TOTALLING 6000, 300+ STAFF, ENVIRONMENT, CAMPUS, DESIGN, LOCATION VISION, KNOWLEDGE SHARING, COMMUNICATION, ASPECT, IMPRESSION, SUSPENSION, WALKWAYS, STUDENTS, TRANSITION

Nominal compounds: 'WHOLE BUILDING DESIGN PHILOSOPHY' (Parenthesis to ensure these words are read as a noun), PRECAST DOUBLE TEES, 
PROPER NOUNS

UNIVERSITY OF AUCKLAND BUSINESS SCHOOL, VICE CHANCELLOR JOHN HOOD, BECA, NEW ZEALAND, FJMT-ARCHIMEDIA, UNIVERSITY OF AUCKLAND BUSINESS SCHOOL, BUSINESS SCHOOL, NEW ZEALAND'S ECONOMY, AUCKLAND DOMAIN, WAITEMATA HARBOUR, RANGITOTO, AUCKLAND, GRADUATE SCHOOL OF ENTERPRISE, EVACUATION \& GROUND RETENTION CONTRACT, MAIN BUILDING RETENTION CONTRACT, MAIN BUILDING CONTRACT, BECA, STANFORD, WHARTON (PENNSYLVANIA, HASS (BERKELEY) UNIVERSITY OF SOUTHERN CALIFORNIA, PEDFLO, DOMAIN, HARBOUR

VERBS

UNDERTOOK, UNDERSTAND, LEARNING, FOSTER, PROVIDED, CREATING, REACHING OUT, DESCENDING (Nb. It is the 'pedestrian walkway' that descend not pedestrians), SIT, PROVIDING, WANTED TO CREATE, TEACHING, WOULD HELP TRANSFORM, PRODUCE, CONSTRUCT, INTEGRATED, ADOPTED, LEADING, CO-ORDINATING, WORKING, INCORPORATING, INCORPORATES, SPANNING, CANTILEVERED, OPENED, HELP DRIVE, BRIEFING, INCORPORATING, COVERING, MEASURES, COMPRISES, UNDERTAKEN, WERE CONSTRUCTED, HANDED OVER, ACCOMMODATES, ACCOMMODATING, COMPRISING, SERVES ('The floor serves a student population...' how odd that the floor is the agent in this sentence and the students are being acted on), PROVIDES, INCLUDES, ALLOCATED, MEASURES, COMPLETED, START

\section{ADJECTIVES}

Adjectives concentrate on concepts of big and better and high and higher ARCHITECTURAL DESIGN (In this context this is seen as a very good thing, it elevates the design),ICONIC, FUTURE, COST-EFFECTIVE, RAPID, INNOVATIVE ENTREPRENEURIAL, IMAGINATIVE AND STUNNING, ELEVATED, DISTINCTIVE BOOMERANG SHAPED, LARGE PUBLIC, FULL-HEIGHT, EXPANSIVE, WINNING, ARCHITECTURAL, UNUSUAL, LONG, CENTRAL, DOUBLE-LAYERED, SIX METRES, NEW, WORLD-CLASS, ELEVATED, ICONIC, FULL-HEIGHT, EXPANSIVE, LARGE PUBLIC, ENCODED, THIRTEEN LEVEL, TWO 600-SEAT, TWO 300-SEAT, 150-SEAT, 75-SEAT (rooms described by how many seats not how many people they can hold but people are implied in this way of measuring space), SECOND LARGEST, SEPARABLE, FOLLOWING FUNCTIONS, SEATING 32, PUBLIC, LARGE MULTI-FUNCTIONAL, LARGE, FUTURE, EXTENSIVE, SPATIAL, TEACHING, HOURLY, HIGHLY VISIBLE, STRIKING, MASSIVE, PEDESTRIAN (Adjectives seem to share sense of expansion and progress. Which mirrors the texts concern with the aim of the building to 'help transform New Zealand into a more innovative, entrepreneurial economy' but also the general theme of capitalism and the business world. This maybe to draw attention to the buildings place in this world.

\section{ADVERBS}

Adverbs to do with progress: RAPID, FORWARD, BEYOND, 2001, THEN, FEBRUARY 2008, EIGHT YEARS AGO, SEVEN YEARS, 2004, THE LAST IN LATE 2007, FOLLOWING, LARGE NUMBER OF ( $\mathrm{Nb}$. This is a 'large number of student movements' again - student movements rather than 'students moving', because 'a large number of students moving' is of no use to an engineer because it can't be measured but student movements can. 


\section{Assumed Translation 5}

Engineering an Idea: The realisation of the Burj Khalifa, Civil Engineering, March 2010

\section{NARRATIVE POINT OF VIEW}

FIRST PERSON NARRATION. In section called THE BURJ KHALIFA TRIUMPHS under heading FIRST PERSON. Very strong in this piece is the idea of UNDERSTANDING, TAMING AND WORKING WITH THE FORCES OF NATURE but also a secondary narrative concerning Baker's journey from small town boy to engineering the tallest building in the world. He places this accomplishment in context with the people he has worked with over the years.

VOICE

ACTIVE Baker is in story-telling mode.

TENSE

Moves from PAST to PRESENT as it moves from what has been done to the present time from which Baker writes this piece. 
NOUNS

TWISTING, TRADITION, PRACTICE, ARCHITECTURE AND ENGINEERING, OPINION, DESIGNS, BUILDINGS, TASK, VISION, INTEGRATION, DESIGN DISCIPLINES, CASE, NAME, TOWER, INAUGURATION, NATURE, SKYSCRAPERS, ARCHITECTS, STRUCTURAL ENGINEERS; MECHANICAL, ELECTRICAL AND PLUMBING ENGINEERS; INTERIOR DESIGNERS, AREA, CONSULTANTS, ATTENTION, SOLUTIONS, PORTIONS, FLOOR PLATE, DESIGN, PRECISION, BUILDINGS, STATURE, SWISS WATCH, COMPONENTS, BUILDING, USEFULNESS, SPACE, EFFICACY, ARMATURE, STRUCTURE, COMPONENTS, MECHANICAL SYSTEMS, VERTICAL TRANSPORTATION, TENANT SPACE, CARE, WATCHMAKER, CONCEPT, DESIGN, STRUCTURE, INDIVIDUAL WALLS, BEAMS, COLUMNS, CONNECTIONS, BEAMS AND COLUMNS, STEEL BEAM, WEBS, FLANGES, BEAM, GROUND, LAMPPOST, BEAM, PIECE, THE WIND, STRUCTURE, FLOOR PLATES, REAL ESTATE, CLIENT, ASSIGNMENT, IDEA, OPINION, STRENGTH, CLARITY, VISION, DEVELOPMENT, BUILDING, CASE, DESIGN TEAM, IDEA, DEVELOPMENT, BUILDING, DESIGNS, SPREAD SHEETS, ERRORS, STRUCTURE, DESIGNER, SIMPLICITY, IDEA, BUILDING, DESIGN PROCESS, DECISIONS, SITUATIONS, BUILDING, BUILDING, SIZE, ONSET, SKYSCRAPER, DEVELOPMENT, OFFICE ANNEX, OFFICE, SPACE, FUNCTION, TOWER, CATEGORIES, BUILDING HEIGHTS, STRUCTURE, PRINCIPLES, ARCHITECTS AND ENGINEERS, GEOMETRY, FORM, TOWER'S, ITERATION, HUB, IDEA, RESISTANCE, AXLE, ELEVATORS, TOWER, WIND, VIEW, UNIT

Nominal compounds: STRUCTURAL AND BUILDING SERVICE SYSTEMS, FORCE OF GRAVITY, VOLUMES OF SPACE, FORCES OF NATURE, CONJUGATE BEAM THEORY, CLARITY OF VISION STRUCTURAL SYSTEM, BUTTRESSED CORE, CONCRETE WALLS, THREE WINGS, CENTRE CORE, CONCRETE CORE, Y-SHAPE PLAN

Nouns which deal with specifically with wind: CHALLENGES, BUILDINGS, FORCES OF NATURE, SHAPE, BUILDING, TEAMS, WIND TUNNEL, WIND TUNNEL, TEST, WIND CLIMATE, SHAPE, DATA, WIND TUNNEL, PROBLEM, INFORMATION, MODEL, TOWER, THE WIND, FORCES, FORCES OF GRAVITY, BUILDING, STRUCTURE, WIND FORCES, PROCESS, GREATLY REDUCED FORCES, BUILDING, WIND TUNNEL, TOWER, DESIGN PROCESS, TOWER, BUILDINGS, SITE, DESIGN, WIND TUNNEL, WAYS, WIND, TOWER, IMPORTANCE, WIND TUNNEL, DESIGN PROCESS, FLOOR PLATES, 'ARCHITECTURAL NOTCHES', WIND FORCES, STRUCTURE, ELEMENTS, GRAVITY FORCES, CONCERN, BUILDING, DESIGN, STRUCTURAL SYSTEM, ELEMENTS, GRAVITY, WIND, GRAVITY FORCES, POSITION, WIND FORCES, FOUNDATIONS, CONCRETE STRUCTURE, REINFORCEMENT, FEET, YOURSELF, WIND, WEIGHT - Lots of words can be used as other parts of speech, but that might just be English. Very few different verbs used for the 'wind'. Again some nouns become proper nouns because they can only mean one thing in engineering, but when this is a more general audience a looser piece so to speak does that change? Is there more room for interpretation? How is his noun use around those expressive bits of the text? Is there more use of adjectives? Check this when writing up or when doing close read for last stage. 
PROPER NOUNS

FULTON, MISSOURI, SKIDMORE, OWING \& MERRILL LLP (SOM), SOUTH DEARBORN STREET, CHICAGO, BURJ KHALIFA, SOUTH DEARBORN DESIGN - The appearance of these American names next to the Burj has an odd effect of Americanising the structure. Baker's life and career-story projects itself onto the Burj, in a way it is only possible because of an American life.

BURJ KHALIFA, DUBAI, SEARS TOWER, GEORGIA ARMANI HOTEL, COUNCIL OF TALL BUILDINGS AND URBAN HABITAT, MIDDLE EAT, EGYPT'S GREAT PYRAMID AT GIZA, DUBAYY

VERBS

LIKE TO THINK, CONTINUE, DEVELOP, GO HAND IN HAND, REALISES, THINK WILL BE BUILT, DESIGN, CREATING, CALLED, CHANGED, ADDRESS, ACHIEVE, RELIES, REQUIRES, FIR, ARRANGED, MAXIMISE, PLACED, THINK, CONSIDERED, FIND, LOOK, CANTILEVERING, CANTILEVERS, NEEDED, RESIST, HAD TO BE, UTILISING, NEEDED, RESIST, BEGAN, DETERMINE, FOCUSED, ROOTED, GUIDE, DOING HAND CALCULATIONS, GIVES, CONCEPTUALISED, CONTAINS, HOUSES, INCLUDES, EMBODIES, HOLDS THE RECORD, RECOGNISED, RANKS, HAVE HAD THE DISTINCTION OF BECOMING THE WORLD'S TALLEST, EXCEEDS, BUILT, RETURNS, HELD, UTILISING, WORKED TO CREATE, RECOGNISED, DEVELOPED, NAMED, CONSISTS, CREATE, BUTTRESS, PROVIDES, ACTS, ENCLOSES, RESISTS, SUPPORT, ALLOWS, OVERLOOKING, ASK, CITE, ENGINEERING, UNDERSTANDING, TAMING, WORKING, WORKED, TRIM, TAILOR, RELATED, PANIC, LOOKED, ANALYSING, DETERMINE, CAUSING, USE, CHANGE, RETEST, SHAPED, TUNED, 'CONFUSE', STAY, USED, STABILIZE, RESIST, RESIST, ENABLED, IMAGINED, WORKING, PROPOSED, INFORMED, BUILT, DESIGNED, COMPLETE, GOING, OBSERVING, USING, DISCOVERED, CHANGING, REDUCED, USED, DEVELOPED, USE, RESIST, ACHIEVED, 'MANAGED', RESIST, SAVES, SPREADING, STABILIZE, USE, TOPPLING OVER

\section{ADJECTIVES}

Adjectives about scale:

COLLABORATIVE, HIGH PERCENTAGE OF, CLEAR, WELL SUITED, CAREFUL, TALL, VARIOUS, EXTREME, VARIOUS, GREAT, EFFICIENT, SUCCESSFUL, SMALLER, METICULOUS, IMPORTANT, TALL BUILDING, MULTIPLE, ONE GIANT, MULTIPLE, LARGE, EXTREMELY, ECONOMICALLY VIABLE, CLEAR, VERY TALL, GREAT, SUCCESSFUL, ENGINEERING, TALL, SIMPLE, MATHEMATICAL, CLEAR AND SIMPLE, EFFICIENT, INTRINSIC, ESSENTIAL, UNIQUE, GREAT, OF SUCH GREAT SIZE, ADJACENT, SEPARATE, MIXED-USE, RESIDENTIAL, SPECIAL, PREVIOUS HEIGHT, WORLD'S TALLEST, DISTINGUISHED, TALLEST, WORLD'S TALLEST MAN-MADE, GEOMETRIC, ORGANIC, TRIAXIAL, SPIRALLING, NEW, HIGH-PERFORMANCE, SIX-SIDED, HEXAGONAL, SIMPLE, TORSIONAL, MAXIMUM, NEIGHBOURING, WIDE ENOUGH, NARROW ENOUGH

Adjectives specifically about wind design:

TRADITIONAL, INITIAL, WIND, POOR, RAW, GREATLY REDUCED, TALL, CHANGING, MAJOR, TALL, VERTICAL, UPLIFTING, STRONG 


\section{ADVERBS}

OFTEN, WITHOUT QUESTION, AFTER, LARGELY, PARTIALLY, CRITICALLY, IN SUCH A WAY, EFFICIENTLY, THAN WE EVER, IN MANY WAYS, NEVER, SWIFTLY, GREATLY, LATER, FURTHERMORE, IT IS COMPARABLE, YOU ARE THEN ABLE, PREVIOUSLY, WELL OVER 100 TIMES, UPON, ACCURATELY AND EFFICIENTLY, TOGETHER, OUT OF THE GROUND, FROM THE SIDEWALK, IN A SIMPLE WAY, ULTIMATELY, EASILY, LUCIDITY, GREATLY, EASILY, AGAINST

Phrases of interest: 'A ROOM WITH A VIEW', CULMINATION OF MAN'S DESIRE TO GE EVEN HIGHER, PEOPLE AND CULTURE OF ITS HOME 


\section{Assumed Translation 6}

Case Study: CCTV Building (In Council of Tall Buildings and Urban Habitat (CTBUH) Journal 2008 Issue)

NARRATIVE POINT OF VIEW

THIRD PERSON OMNISCIENT NARRATIVE presented as if by an external, unmoved narrator.

\section{VOICE}

ACTIVE with the design being the agent in most cases.

\section{TENSE}

PRESENT TENSE almost throughout, no account for what has happened in the past or what will happen in the future as a rule.

\section{NOUNS}

HEADQUARTERS, TELEVISION-MAKING PROCESS, BUILDING, TOWER, FORM OF THE SKYSCRAPER SYSTEM, COLUMNS, BEAMS, BRACES, SKIN, BUILDING, APPROVAL, BEHAVIOUR, BUILDING SAFETY, SEISMIC EVENT, FORM, PROGRAMME, STUDIO SPACES, CHALLENGES, INTRODUCTION, TOWER, TOWERS, STRUCTURAL ENGINEERS, CONTRACTORS, CHALLENGES, STRUCTURE DESIGN, CONSTRUCTION, DEVELOPMENT, STRUCTURAL CONCEPT, COUNTRY'S BROADCASTER, PLANS, CHANNELS, YEARS, EXPANSION, DESIGN COMPETITION, HEADQUARTERS BUILDING, ARCHITECTURE, ENGINEERING, BRIEF, TERMS, FUNCTIONS FOR PRODUCTION, MANAGEMENT, ADMINISTRATION, SITE, RESPONSE, 'GHETTOES', COMPLEX, PROCESS, PROGRAMME, BUILDING, LAYOUT, END-PRODUCT, LOOP

Nominal compounds: EXPERT PANEL PROCESS, PERFORMANCE-BASED ANALYSIS, NONLINEAR ELASTOPLASTIC TIME HISTORY, FINITE ELEMENT ANALYSIS, GRAVITY STRUCTURE, TRANSFER TRUSSES, PERFORMANCE-BASED SEISMIC DESIGN, EXPERT PANEL REVIEW PROCESS, LOCAL DESIGN INSTITUTE (LDI), THREE DIMENSIONS,

\section{PROPER NOUNS}

CHINA CENTRAL TELEVISION, EXPERT PANEL, CCTV BUILDING IN BEIJING, CHINA CENTRAL TELEVISION (CCTV), OMA (OFFICE OF METROPOLITAN ARCHITECTURE), ARUP, EAST CHINE DESIGN INSTITUTE (ECAD), BEIJING CENTRAL BUSINESS DISTRICT (CBD), CCTV BUILDING, BASE, TOWER, OVERHANG

\section{VERBS}

CONTAINS, REDEFINES, COMPRISED, GAIN, CARRIED OUT TO JUSTIFY, MADE EXTENSIVE USE OF, ADVANCED, EVALUATE, ENSURE, INCLUDING THE NEED TO ACCOMMODATE, POSED, ERECTING AND CONNECTION, PRESENTED, EXPAND, COMPETE, ACCOMMODATE, ORGANISED, DESIGN, WON, ALLIED, ACT, WOULD BE CONTAINED, DECIDED, DOING JUST THIS, SHOULD BE POSSIBLE TO BREAK DOWN, TEND TO FORM, MAKING, CREATE, FORCE, INVOLVED, MIS AND PRODUCE, DESIGN, COMBINES 
ADJECTIVES

NEW, ENTIRE, 234M TALL, PRIMARY, CONTINUOUS, STRUCTURAL, LEANING, VARIED, LARGE, ADDITIONAL, TWO MASSIVE, FURTHER DESIGN AND CONSTRUCTION, STATE, 18-200, COMING, INTERNATIONAL, NEW, ESSENTIAL, UNUSUAL, TELEVISION, NEW, CHOSEN, ARCHITECTURAL, COMPLEX, COMPARTMENTALISED, BETTER, WINNING, 473,000M2, 234M

TALL, SINGLE, INTERCONNECTED, NINE-STOREY, LEANING, 13-STORY

ADVERBS

UNDER, INCLUDING, GLOBALLY, SUBSEQUENTLY, EFFICIENTLY 


\section{Assumed Translation 7}

'Beaubourg' (p.25 - 47) An Engineer Imagines, Peter Rice

\section{NARRATIVE POINT OF VIEW}

FIRST PERSON NARRATION

\section{VOICE}

ACTIVE Almost conversational in tone. Rice is present as a narrator throughout the piece, he does a lot of his remembering on the page. Often asking himself questions in an attempt to try and remember details. There is repetition of nouns which gives the piece a lyrical quality and helps reinforce some of his points.

\section{TENSE}

PAST TENSE Like Baker in the Burj piece Rice is in storytelling mode so everything is recounted in simple past. 
NOUNS

IDEA, TOME, ENGINEERING STRUCTURES, NINETEENTH CENTURY, APPEAL, DARING, CONFIDENCE, PRESENT, STRUCTURAL ACHIEVEMENTS, WARMTH, INDIVIDUALITY, PERSONALITY, COUNTERPARTS, ELEMENTS, EVIDENCE, ATTACHMENT, CARE, DESIGNERS, MAKERS, GOTHIC CATHEDRALS, CRAFT, CHOICE, DECORATION, JOINTS, STRUCTURES, QUALITY, DESIGNER, PEOPLE, MARK, CAST STEEL, QUALITY, CAST STEEL, POSSIBILITY, BUILDING MATERIAL, TIMES, NEED, RELIABILITY, PREDICTABILITY, MATERIALS, PROCESS, ABSENCE, FLAWS, OUTCOME, PROCESS, STRUCTURE, CAST STEEL, CORE MATERIAL, STAGE, LOGIC, CHOICE, CAST STEEL, STRUCTURE, STEEL STRUCTURES, BUILDINGS, STEEL SECTIONS, I-SECTIONS, CHANNEL SECTIONS, TUBES, ANGLES, EXTRUSION, LINES, QUALITY, UNIFORMITY, ROOM, EXPRESSION, STEEL STRUCTURES, ELEMENTS, SURPRISE, PERSONALITY, PUBLIC, FEELING OF CONTACT, WARMTH, INTRODUCTION, CAST STEEL, ELEMENT OF SURPRISE, CONJUNCTION, CASTINGS, STRUCTURE, BUILDING, SCALE, SCALE, PIECES, SCALE, THE WHOLE, FACETS, BUILDING, ARCHITECTURE, MOVEMENT, PEOPLE, PIAZZA, FACADE, PIAZZA, FLOOR PLANS, EFFORT, PLACE, PEOPLE PLACE INDIVIDUALS, MONUMENT, COMPETITION, SOLUTION, PEOPLE, INTIMIDATION, CULTURE, AFFINITY, CULTURE, FREEDOM, SOUND, LANGUAGE, TECHNICAL, LANGUAGE, CULTURE, ALIEN, RIGID, PRESUMPTIVE, BARRIER, DEPARTMENTS, PROTESTANT UNIVERSITY, PLACE, PLACE, CAST STEEL, CONTRIBUTION, CAST STEEL, MISSION, BUREAUCRACY, INDUSTRY, FIXATION, ERA, ENGINEERS, ENGINEERS, PEOPLE, ARCHITECTS, ARGUMENT, PEOPLE, VALUES, PEOPLE, CAST STEEL, STRUCTURE, SETS, WORK, STAGE, TEAM WORK, WORD, COVER, BLANDNESS, SALUTE, CREDIT, IDENTITY, ARTEFACT, TEAMS, PEOPLE, PEOPLE, ATTITUDE, WILLINGNESS, PRESENCE AND CONTRIBUTION, OTHERS, MOMENTUM, TEAM, STRUCTURE, GERBERETTE SOLUTION, ENGINEER, STRUCTURE SYSTEM, BRIDGES, SOLUTION, CONFLICTS, STEP, ELEMENTS, COLUMN, TIME, GERBERETTE, BEAM, KEY, GERBERETTE, COLUMN, COLUMN, TIE, GERBERETTE, THING, BEAM, IDEA, KIND, SHAPE, IDEA, TIE, COLUMN, BEAM, DESIGN, GERBERETTE, MONTHS, SOMETHING, VISITS, EXPERTS, VISITS, FOUNDRIES, FORCES, LOADS, PIECE, THE WORD PIECE, ARTIST, DETERMINANTS, SHAPE, TENSION TIE END, LOAD, COLUMN, LOAD AND MOMENT, BEAM, POINT OF PICK UP

Nominal compounds: HOLLOW ROUND POLE, SUSPENDED BEAM PROPPED CANTILEVER, CAST STEEL (this appears in list above to show reputation of this term), ARTISTIC TYPES,

\section{PROPER NOUNS}

BEAUBOURG, CENTRE BEAUBOURG, PIANO \& ROGERS, IRELAND, LOUVRE, NATIONAL GALLERY IN LONDON, CENTRE BEAUBOURG, SYDNEY OPERA HOUSE, EIFFEL TOWER, RENZO PIANO, RICHARD ROGERS, LENNART GRUT, HEINRICH GERBER, LAURIE ABBOTT, JOHNNY STANTON 


\section{VERBS}

BORN, HAD BEEN WONDERING, THAT GAVE, LATCHED ON TO, LAVISHED, EXUDE, GIVE, LABOURED, LEFT, MADE, CONCEIVED, ACHIEVING, ABANDONED, ELIMINATED, PRODUCED, BEING USED, DECIDED, EXPLAINING, LED, MADE FROM, PRODUCED, ROLLING, GUARANTEE, GUARANTEE, LEAVES, MISSING, LOOKING, SEEMED, BREAK THE DEADLOCK, CREATE, TO MAKE, FIND THEMSELVES AT ONE, AIMS, OFFERED BY, TO CREATE, WOULD NOT FEEL INTIMIDATED, COMING, OVERWHELMED, REALLY WANTED; FEEL GOOD, NOT AFRAID AND OVER-HUMBLE; FELT, DETERMINED TO DO MY BIT, KNOW, DECIDED, USING, DEALING, SEEN THE LIGHT, TAKEN, WE HAD, MADE, TOO, BEFORE WE KNEW, WE COULD MAKE IT WORK, KNEW, GOING, TALK, USED, CLAIMING, MADE UP OF, COMPLEMENT, WORK, ACCEPT, MAKE POSSIBLE, WORKING, NO LONGER SURE WHO, KNOW, SUGGESTED, INVENTED, RESOLVED, DESIGN, ADOPTED, FOUND, STRUGGLE, CASTING, SUPPLIED, HELP, SERVES, GOING FROM, HAD TO MAKE, HELPED US UNDERSTAND, MAKES ME FEEL, APPLIED, REACH, LACK

\section{ADJECTIVES}

NINETEENTH-CENTURY, VICTORIAN, SOME , LARGE, SPECIAL, TODAY'S GREAT, UNIQUE, SAME PERSONAL, STANDARD, PROVEN, MAJOR, FULL, MAIN, STANDARD, CONTINUOUS, GEOMETRICAL, LITTLE, PERSONAL, PRECONCEIVED, FACTORY-PRODUCED STANDARD, MORE COMMON, APPROACHABLE, SYMPATHETIC, IMPORTANT, LARGE CLEAR, ENORMOUS, INTENSE, EXPRESS, POPULAR, ORDINARY, CLEAR PERSONAL, RURAL, ONLY, FOETID, AUSTERE, ACCESSIBLE, ORDINARY, SILLY, OUT OF PLACE, MODERN, OBSESSED, SENSIBLE, RATIONAL, PRAGMATIC, THREE SEPARATE, MISUSED, DIFFERENT, INDIVIDUAL, REAL, SOCALLED, NEXT, SOLID ROUND, GOOD, SINGLE, SLENDER, DEEP AND STRONG, SHORT

\section{ADVERBS}

SIMPLY, QUICKLY 


\section{Assumed Translation 8}

Ivy, Robert Adams. Fay Jones: The Architecture of E. Fay Jones, FAIA. Washington,

D.C.: American Institute of Architects Press, 1992.

\section{NARRATIVE POINT OF VIEW}

THIRD PERSON OMNISCIENT NARRATION

\section{VOICE}

ACTIVE evocative language, which calls on some of the tropes of imaginative literature. The chapter begins with an excerpt from Walt Whitman's Give Me the Splendid Silent Sun. The voice evokes a sense of the transcendental - the spirit of some higher being in nature, the perfectness of the building to the place, as if Jones has created something which is natural or God-made.

\section{TENSE}

PRESENT TENSE This gives a sense of an unmediated experience. The text evokes the experience of approaching and then being near and in Thorncrown 


\section{NOUNS}

TEMPLE, WOODLAND, BRANCHES, PLAN, ROOM, FORM, BUILDING, VISITORS, BUILDING, SITE, ORNAMENT, STRUCTURE, FORM, MASTERPIECE, ARCHITECTURE, DISTILLATION, POWER, PEOPLE, POETRY, LANGUAGE, DEBT, VOICE, LANGUAGE, PLACE, TIME, LANDSCAPE, VERSE, EXPERIENCE, INTERIOR, CAVERN, ROOF, PART, FOREST, WALLS, LIGHT, SHADOW, PILGRIM, SILENCE, SETTING, APPROACH, LEAVES, DISTANCE, CHAPEL, SUNLIGHT, TREE, LIGHT, SHADOW, DOORWAY, FOREST, WOOD, BRACING, EYE, PERSPECTIVE, CHAPELS, BUILDING'S, CHAPEL, WAYFARERS, PLACE, RELAXATION, BUDGET, SITE, SLOPE, CONTOURS, BUILDING, MINISTRY, FOREST, RESTRICTIONS, OPPORTUNITIES, TREES, STRUCTURAL, MEMBER, EXAMPLE, TWO MEN, WOODS, PINE, TRUSSES, PLACE, SIMPLICITY, PIECES, 'PROPORTIONING', 'ASCENDANCY', INSPIRATION, SPACE, WALLS, RESULT, REVERSAL, CRITIC, EYE, ROOM, CROSS-BRACE, BRACELETS, NAVE, 'OCULI', KALEIDOSCOPE, LEAVES, SKY, WALLS, SKYLIGHTS, MATERIALS, MINIMUM, STONE, WOOD, GLASS, CLOTH, METAL, PIECES, ALMS BASIN, DOOR HANDLES, LIGHTING GRATES, DETAILS, ONES, ECONOMY, SAPLING, INSTANCE, MOTIF, PEWS, LANTERNS, WALLS, METAL, COLUMN, LECTERN, CHAPEL'S CROSS, STAKE, ALTAR WALL, MAN, UNIVERSE, BUILDING, RECOGNITION, EXPERIENCES, PLEASURE, MEANS, CHAPEL, SPACE, TERMS, PHILOSOPHY, STRUCTURE, SPACE, PHYSICAL, METAPHYSICAL, TIMES, YEAR, PEOPLE, SLOPE, SUNDAY SERVICES, TRUTH, NATURE, DISTINCTION, OPPORTUNITY, BUILDING, ARCHITECTURE, WRITING, LITERATURE, POETRY, SPELLING, GRAMMAR, SYNTAX, WAY, CHAPEL, EFFECT, LIGHT PLAY,

Nominal compounds: STONE FOUNDATION, WOOD COLUMNS, FOLDED ROOF, GABLED SHED, FORCE OF TRUTH, 'PRIMAL SANITY', WORKS OF ART, JONES, CHAPEL'S POTENTIAL, BUILDING'S DIALECT, DISCIPLINE OF WOOD CONSTRUCTION, PILGRIMAGE CHAPEL, PLACE, LANDSCAPE, MEDITATION, EXTERIOR, SENSE OF DIRECTION, A BEND IN THE PATH, GLASS END WALL, ROCK OUTCROPPINGS, SUMMER TOURIST COLONY, FLOOR SLAB, GOTHIC BUTTRESSING, INTERIOR INTERLOCKING WOODEN ARMS, 'OPERATIVE OPPOSITE', INTERIOR DIAGONAL CROSS-BRACING, 'A GREAT LATTICE STORM, HOLLOW STEEL JOINTS, DIAMOND FRETWORK OF LIGHT, ILLUSION OF INFINITY, ROOF'S RIDGE, 'THE SENSE OF DRAMA', FLAGSTONE FLOORS, FIELDSTONE PERIMETER WALLS, OAK PEWS, METAL BAR STOCK, SENSE OF DISCOVERY, AUTHORITY OF NATURE,

\section{PROPER NOUNS}

THORNCROWN CHAPEL, ARKANSAS FOREST, WHITMAN, WRIGHT, MAYBECK, GREENE BROTHERS, JAPANESE TRADITION, THORNCROWN'S, AMERICAN, WALT WHITMAN'S, LE CORBUSIER'S, RONCHAMP, THORNCROWN, JURA MOUNTAINS, JIM REED, OZARK, HIGHWAY 62, EUREKA SPRINGS, JONES, SAINT CHAPPELLE, PARIS'S, GOTHIC, JONES, AIA HONOR AWARD JURY, MIRCEA ELIADE, 


\section{VERBS}

SAVE, TOUCHES, MARRIED, RISES, DRAWS, INTEGRATES, RECOGNISED, DISTILS, OBLIGED, SPEAKING TIED, EMERGES, EVOKES, SEEMS, DEMATERIALISED, DRAWN, STRUCK, DRAWN, OBSCURE, APPEARS CAUGHT, SEEMS, DAPPLE, BLURRED, OPENS, FOOLS, EXTENDING, FORESEEN, COMMISSIONED, PROVIDE, LOVED, TRACED, LIES, TRANSFORMED, COULD CARRY, SAYS, EMPLOYED, ASSEMBLED, RAISED, ACHIEVED, INTERLOCKED, CITES, ACHIEVES, REPLACED, KEEP, OFT-CITED, CALLED, CARRIES, ANIMATES, LINK, REPEATED, PRODUCE, CREATE, SUGGESTS, SAYS, SAW, ENLARGED, INCREASE, REDUCED, REINFORCE, APPEARS, SUPPORTING, LINING, POSITIONED, CONNECTING, BROUGHT, NOTED, ARRIVING, USING, REARED, DRAWS, FIND, ATTRACTED, POINTS, SAW, CREATE, SAYS, MAKING, HOPED

Verbal phrases: CONNECTING MAN TO THE UNIVERSE, 'MOVE PEOPLE IN A SPECIAL WAY', SUGGESTS IT MIGHT SOAR, HE DREAMED OF TO CRADLE HIS MINISTRY, CARRIES THE EYE UPWARD,

\section{ADJECTIVES}

SIMULTANEOUSLY RATIONAL AND INTUITIVE, GLASS, INTERIOR, CLEAR, BLUE, INCIDENTAL, CROSS, METAL, TRANSPARENT, CORRECT, MANIFEST, ELEMENTAL, MAN-MADE, LAYERED, MAGNETIC, IRRESISTIBLE, HARMONIOUSLY UNIFIED, ARGUABLY, GREAT, INTANGIBLE, AUTHORITATIVE, BILLOWING WHIT, NEIGHBOURING, SOLID HOLY, PEAKED, LARGEST, MANMADE, NATURAL, ANGULAR GOTHIC, ASCENDING, CROSSED, WOOD, PATTERNED, ENTIRE, FINISHED, RICHNESS, LITTLE, LIMITED, HEAVILY WOODED, HEAVILY TRAVELLED, LARGER, UNIFIED, INDIVIDUAL, LIGHT-FILLED GOTHIC, SINGLE LUMINOUS, SMALLER, SIMILAR GRAND, UPRIGHT, OPPOSED, LOZENGE-SHAPED, TALL, CLEAR, LANCET, ABSOLUTE, SMALL, LARGER, MOVABLE, SLENDER, SYMBOLICALLY, SMALL, INTERNATIONAL, MINIMAL, SPIRITUAL, FAMOUS, SACRED, SMALL, HARMONIOUS, CORRECT, SPECIAL

\section{ADVERBS}

OUTSIDE AND INSIDE, BEGINNING AND END, OVERHEAD, THROUGH, APPROXIMATELY TWO MILES FROM, THROUGH, UPWARD, COLLECTIVELY, 


\section{WORK CITED}

Abrahart, R. J., L. M. See and D. P. Solomatine eds. Building Decision Support Systems Based on Fuzzy Inference. General Assembly of the European-Union-of-Geosciences. Apr 24-29 2005. Springer-Verlag Berlin. Print.

Adam, Pip. Alan MacDiarmid Structure. 2011. Digital image. Wellington.

---. Notes from Soil Mechanics Lecture. 2010. Digital image. Wellington.

Adamson, Glenn, and Jane Pavitt. "Arch-Art: Architecture as Subject Matter."

Postmodernism: Style and Subversion, 1970-199o. Eds. Adamson, Glenn, Jane

Pavitt and Paola Atonelli. London: V\&A Publishers, 2011. 98-105. Print.

Addison, Joseph. Remarks on Several Parts of Italy. 1753. Google Book Search. 1753. Web. 4 Jul. 2010.

Ahearn, A.L. "Words Fail Us: The Pragmatic Need for Rhetoric in Engineering Communication.” 2nd Asia-Pacific Forum on Engineering and Technology Education. Jul. 04-07 1999. Ed. Zenon Pudlowski. Victoria: UNESCO International Centre for Engineering Education, 1999. Print.

"Alan MacDiarmid Building on Target”. Victoria University News. Victoria University of Wellington, 10 Aug. 2009. Web. 23 Jul. 2010.

Allchin, D. "Scientific Myth-Conceptions." 4th International Seminar for History of Science and Science Education. Jul 23 2001. Canada: John Wiley \& Sons Inc, 2003. Print.

Allied Press. 2009. Digital image. Daylife. Web. 20 Jan 2012.

"Application for Resource Consent under Section 88 of the Resource Management Act 1991". Wellington, 2008. Victoria University of Wellington. Web. 23 Jul. 2010. >.

“ARC222: Structural Systems.” Victoria University of Wellington School of Architecture:Courses. Victoria University of Wellington School of Architecture, 14 Nov. 2011. Web. 22 Feb. 2012. 
Archer, Beth. Introduction. The Voice of Things. Ed. Beth Archer. New York: McGraw-Hill Book Company, 1972. 3-25. Print.

Arnold, Adam. "Revealed: Height of World's Tallest Building." Sky News Online. Sky News, 4 Jan. 2010. Web. 17 Jun. 2011.

"Assessment of Effects on the Environment Victoria University of Wellington Proposed New Building for Teaching and Research.” Victoria University of Wellington, 2008. Victoria University of Wellington. Web. 23 Jul. 2010.

Association of Consulting Engineers New Zealand. Guidelines for Preparing Submissions to the ACENZ Annual Awards of Excellence 2010. Auckland: Association of Consulting Engineers New Zealand, 2010. Print.

“Aurecon Recognised for Seismic World First.” The Wellingtonian, 22 Oct. 2009: 21. Print.

Aurecon. ACENZ Awards: Victoria University Student Accommodation. Wellington: Aurecon, 2009. Print.

Baker, William F. “Engineering the World's Tallest : Burj Dubai.” Lehigh University. Bethlehem, Pennsylvania. 20 Mar. 2009. Khan Lecture Series. Web. 22 Feb. 2012.

---. "Engineering an Idea: The Realisation of the Burj Khalifa.” Civil Engineering March (2010): 44-47. Print.

Baker, William F., D. S. Korista, and L. C. Novak. "Burj Dubai: Engineering the World's Tallest Building." Structural Design of Tall and Special Buildings 16.4 (2007): 36175. Print.

Baker, William F., James J. Pawlikowski, and Bradley S. Young. "The Challenges in Designing the World's Tallest Structure: The Burj Dubai Tower.” Structures 2009: Don't Mess with Structural Engineers. American Society of Civil Engineers, 2009. Print.

---. "Reaching toward the Heavens.” Civil Engineering March (2010): 48-55. Print.

Banfield, Marie. "Darwinism, Doxology, and Energy Physics: The New Science, the Poetry and the Poetics of Gerard Manley Hopkins.” Victorian Poetry (2007): 175-94. Print. 
Barnes, Julian. The Sense of an Ending. London: Jonathan Cape, 2011. Print.

Beca. Owen G. Glenn Building: University of Auckland New Business School. Auckland: Beca, 2009. Print.

Beer, Gillian. Darwin's Plots: Evolutionary Narrative in Darwin, George Elliot and Nineteenth-Century Fiction. Cambridge: Cambridge University Press, 200o. Print.

Benjamin, Walter. "The Work of Art in the Age of Its Technological Reproducibility." The Work of Art in the Age of Its Technological Reproducibility, And Other Writings on Media. Eds. Michael William Jennings, Brigid Doherty, Thomas Y. Levin. Trans. E.F.N. Jephcott. Cambridge: Havard University Press. 19-56. Print.

Best Store in Sacramento, California When It Is Closed and Open for Business. Digital image. LiveJournal. Web. 2 Dec. 2011.

Bow, James. Corridor. 2009. Digital image. Bow. James Bow. Web. 1 Feb 2012.

Bright, Steven. 1 Featherston Street. 2009. Digital image. Wellington.

Brown, Colin. "Engineers Can Build a Low-Carbon World If We Let Them.” Opinion. New Scientist, 7 Oct. 2011. Web. 20 Jan. 2012.

Browne, Michael E. Schaum's Outline of Theory and Problems of Physics for Engineering and Science. Schaum's Outline Series. New York: McGraw-Hill, 1999. Print.

Bryce, P., S. Johnston, and K. Yasukawa. "Implementing a Program in Sustainability for Engineers at University of Technology, Sydney: A Story of Intersecting Agendas.” International Journal of Sustainability in Higher Education Vol. 5:3 (2004). 267-77. Print.

Bucciarelli, Louis L. “The Epistemic Implications of Engineering Rhetoric.” Synthese 168 (2009): 333-56. Print.

Buchanan, Julie. “Aussie Discrimination Higher in Male Dominated Careers Professions.” IPENZ Engineers New Zealand, 6 Jan. 2009. Web. 1 Mar. 2011. 
Buildings That Look Like Faces. 26 Aug. 2011. Digital image. Buildings That Look Like Faces. Web. 26 Aug. 2011.

Burke, Ronald J. "Women and Minorities in STEM: A Primer." Women and Minorities in Science, Technology, Engineering and Mathematics: Upping the Numbers. Eds. Burke, Ronald J. and Mary C. Mattis. Cheltenham: Edward Elgar, 2007. 3-27. Print.

Butterworth, John, Charles Clifton, and Greg MacRae. "Developments in Steel Frame Joints in New Zealand.” The Structural Engineer 86.16 (2008): 20-21. Print.

“Campus Development Framework Teaching and Research Building Project.” Victoria University of Wellington, 2007. Victoria University of Wellington. Web. 23 Jul. 2010.

Carroll, Chris, et al. “Case Study: CCTV Building, Headquarters \& Culture Center.” Council on Tall Buildings and Urban Habitat 3 (2008): 14-24. Print.

Carroll, Chris, et al. "CCTV Headquarters, Beijing, China: Structural Engineering Design and Approvals." The Arup Journal 2 (2005): 3-9. Print.

Cather, Willa. Alexander's Bridge. 1911. Virago Modern Classics. Vol. no. 339. London: Virago, 1990. Print.

Cattanach, Alastair. “NZ's First Multi-Storey PRESSS Building.” IPENZ Members Talk. Victoria University of Wellington, 12 March 2009. Presentation.

Cattanach, Alistair. Personal interview. 13 Aug. 2010.

Cattanach, Alastair, and Stefano Pampanin. . "21st Century Precast: The Detailing and Manufacture of NZ's First Multi-Storey Presss Building." New Zealand Concrete Industry Conference. October 2008. Rotorua Convention Centre, Rotorua. Concrete Society of New Zealand: 2008. Print.

Channel New Asia. Photogallery: 2010 Quake in NZ's Christchurch. 2011. Digital image. Channel New Asia. Web. 1 Dec. 2011.

Charleson, Andrew. Seismic Design for Architects: Outwitting the Quake. Oxford: Architectural Press 2008. Print. 
Cheng, W., and E. Mok. "Discourse Processes and Products: Land Surveyors in Hong Kong." English for Specific Purposes 27.1 (2008): 57-73. Print.

CISabroad. Te Puni Panorama. 2009. Digital image. Flickr. Web. 19 Jan. 2012.

Clark, Helen. "Official Opening of the Owen G. Glenn Building." beehive.govt.nz. New Zealand Government, 21 February 2008. Web. 3 Aug. 2010.

Collins, Nick. “Fashion's Brave New World”. Fashion. Telegraph, 2011. Web. 7 Oct. 2011.

Collins, R., S. Y. Li, and D. Cheung. "Language Professionals in Engineering Faculty: CrossCultural Experience.” Journal of Professional Issues in Engineering Education and Practice 126.1 (2000): 32-34. Print.

Colmenares, Margarita H. "Margarita H. Colmenares." Journeys of Women in Science and Engineering: No Universal Constants. Eds. Ambrose, Susuan A., et al. Philadelphia: Temple University Press, 1995. 82-87. Print.

Colquhoun, Alan. "Critique.” Centre Pompidou. New York: Rizzoli International Publications, 1977. Print.

Copans, Richard, et al., writ/dir. “The Georges Pompidou Center”. Architectures1 : A Collection Presented by Richard Copans and Stan Neumann. La Sept Vide, RMN, 2001. DVD.

Council on Tall Buildings and Urban Habitat. “About CTBUH”. CTBUH. Council on Tall Buildings and Urban Habitat, 2011. Web. 17 Jun. 2011.

Danielewski, Mark Z. House of Leaves. New York: Pantheon Books, 200o. Print de Bastide, Jean-François. The Little House: An Architectural Seduction. 1774. Trans. Rodolphe el-Khoury. New York: Princeton Architectural Press, 1995. Print.

Denon, Vivant. "No Tomorrow.” Trans. Lydia Davis. The Libertine Reader: Eroticism and Enlightenment in Eighteenth Century France. 1777. Ed. Michel Feher. Michigan: Zone Readers, 1997. 720-47. Print. 
"Developing the Structure." Centre Pompidou. New York: Rizzoli International Publications, 1977. Print.

"Doors Open at Alan MacDiarmid Building”. Victoria News. Victoria University of Wellington, 4 Oct. 2010. Web. 23 Jul. 2010.

Douglas, Lake. “The Poetics of Revealed Construction.” Progressive Architecture 68.5 (1987): 104-09. Print.

Egan, Jennifer. A Visit from the Goon Squad. London: Constable \& Robinson, 2010. Print.

Eiffel, Jean, and Marie Eiffel. "Beaubourg: Innovations to a Trojan Horse." Centre Pompidou. New York: Rizzoli International Publications, 1977. Print.

el-Khoury, Rodolphe. Preface. The Little House: An Architectural Seduction. By JeanFrançois de Bastide. New York: Princeton Architectural Press, 1995. 19-54. Print.

Engel, Heinrich. Structural Systems. Stuttgart: Deutsche Verlags-Anstalt GmbH, 1967. Print.

Expo Socialism. North Korea People's Republic. 2011. Digital image. Flickr. Web. 19 Jan. 2012.

felibrilu. Burj Khalifa from the Taxi. 2011. Digital image. Flickr. Web. 24 Aug. 2011

Fletcher Construction. "Owen G. Glenn Building for the University of Auckland Business School”. Projects. Fletcher Challenge, 2010. Web. 3 Aug. 2010.

Florman, Samuel C. Engineering and the Liberal Arts: A Technologist's Guide to History, Literature, Philosophy, Art, and Music. New York: McGraw-Hill, 1968. Print.

Florman, Samuel C. The Existential Pleasures of Engineering. 2nd ed: St Martin's Griffin, 1996. Print.

Glancey, Jonathan. “Peter Rice.” Obituaries. The Independent, 29 Oct. 1992. Web. 1 Mar. 2011.

Gledhill, S., G. K. Sidwell, et al. 'The damage avoidance design of tall steel frame buildings Fairlie Terrace Student Accommodation Project, Victoria University of Wellington.' 
New Zealand Society of Earthquake Engineering Conference, 11-April 2008, Bayview Wairakei Resort, Wairakei, New Zealand. Wellington: NZSEE. Web. 30 May 2012.

Gledhill, Sean. Personal interview. 20 Apr. 2010.

GNS Science. "Wellington Fault." Major Faults in New Zealand. GNS Science, 2011. Web. 18 Mar. 2011.

Grant, David. Stock Market. n.d. Digital image. Te Ara - the Encyclopedia of New Zealand, Wellington. Web. 19 Jan. 2012.

Groening, Matt. “Think Exist”. Quotations webpage. Think exist, 2011. Web. 1 Mar. 2011.

Guy, Sandra. “Changing the Equation.” SWE 56.5 (2010): 20. Web. 20 Jan. 2012.

Haldar, A., and R. K. Reddy. "A Random-Fuzzy Analysis of Existing Structures.” Fuzzy Sets and Systems 48.2 (1992): 201-10. Print.

Hamilton, Kelly. "Some Philosophical Consequences of Wittgenstein's Aeronautical Research" Perspectives of Science. Massachusetts: Massachusetts Institute of Technology (2001): 1-37. Vol. 9. Print.

Happold, Ted. “Beaubourg: Architecture or Engineering?” Centre Pompidou. New York: Rizzoli International Publications, 1977. Print.

---. “Essential Engineer.” RSA 143.5456 (1995): 85-86. Print.

---. "A Personal Perception of Engineering." Happold: The Confidence to Build. Eds. Derek Walker and Bill Addis. Great Britain: Happold Trust Publications Limited, 1987. 2736. Print.

Harris, Richard. "This Machine Can Suck Carbon out of the Air." National Public Radio, 19 Sept. 2011. Web. 7 Oct.2011.

Hirschberg, Dana. “City Scape: San Francisco.” 2011. Digital image. Dana Hirschberg Photography. Web. 1 Feb 2012. 
Holden, Charles. “The Aesthetic Aspect of Civil Engineering Design.” The Aesthetic Aspect of Civil Engineering Design. London: Institute of Civil Engineers, 1944. 25-42. Print.

Hollis, Edward. The Secret Lives of Buildings: From the Parthenon to the Vegas Strip in Thirteen Stories. London: Portobello Books, 2009. Print.

Holtzapple, Mark T., and W. Dan Reece. Foundations of Engineering. 2nd ed. Boston: McGraw-Hill, 2003. Print.

Honey, Tommy. "Uphill Battle for Commanding Heights.” Architecture NZ 2 (2009): 82-91. Print.

Horlesberger, M., and C. Pimiskern. "Burj Dubai: Building at the Very Highest Level.” Bauingenieur 83 (2008): 388-92. Print.

Hornig, Lilli. Foreward. Journeys of Women in Science and Engineering: No Universal Constants. Eds. Susuan A. Ambrose, et al. Philadelphia: Temple University Press, 1997. ix-xiii. Print.

Hugo, Victor. "Notre-Dame De Paris.” 1831. Trans. Isabel F. Hapgood. The Hunch Back of Notre Dame. Project Gutenberg. Web. 19 Dec. 2011.

Huxley, Aldous. Literature and Science. London: Chatto and Windus, 1963. Print.

Inglis, Charles Edward. "The Aesthetic Aspect of Civil Engineering Design.” The Aesthetic Aspect of Civil Engineering Design. London: Institute of Civil Engineers, 1944. 43-69. Print.

International Business Times Staff Reporter. “Scientists to Test 'Artificial Volcano' to Counteract Global Warming”. Science. International Business Times, 2011. Web. 20 Jan. 2012.

itsabitblurry. Aotearoa New Zealand Auckland University Library [16] 260311 o92o F8 1/30. 2011. Digital image. Flickr. Web. 19 Jan. 2012.

Ivy, Robert Adams. “Special Feature: Fay Jones.” Architecture \& Urbanism 245.2 (1991): 57120. Print. 
Johnston, Stephen, Alison Lee, and Helen McGregor. "Engineering as Captive Discourse.” Society for Philosophy and Technology 1. 3-4 (1996). Print.

Johnstone, Peter, and Pablo R. Alcantara. No. 1 Featherston St. Building 05-294. Wellington: Romulus Consulting Group, 2007. Print.

Jones, E. Fay. “Selected Details: Making Light of Wood Joinery.” Progressive Architecture 50.8 (1969). Print.

---. “Transforming the Past for the Future: The 1990 AIA Gold Medal Address.” Almanac of Architecture and Design. Eds. James P. Cramer and Jennifer Evans Yankopolus. 6th ed. Atlanta: Greenway Communications, 1990. 35-36. Print.

Kersting, A.F. "The Garabit Viaduct, over the Truyère River near Saint-Flour, France”. 2001. Digital image. Encyclopedia Britannica Online. Web. 20 Jan. 2012.

Kinch, Samuel Sean. "Quantum Mechanics and Modern Fiction.” Proquest Dissertations and theses (2001). Web. 24 Apr. 2009.

Kit, Jonathan Ah. Library Building (1 of 6). 2005. Digital image. Flickr. Web. 19 Jan. 2012.

Koerble, Barbara. “Texas Jones.” The Architectural Review 190.1142 (1992): 38-45. Print.

Koolhaas, Rem. “Beijing Manifesto.” Wired 8 (2004): 120-29. Print.

Le Corbusier. Towards a New Architecture. 1927. Trans. Frederick Etchells. London: Architectural Press, 1946. Print.

Lee, H. J., et al. "Design and Analysis of Heavily Loaded Reinforced Concrete Link Beams for Burj Dubai." ACI Structural Journal 105.4 (2008): 451-59. Print.

Lem, Stanislaw. “The Solaris Station.” LEM . PL. Stanislaw Lem: The Official Website, 8 Dec. 2002. Web. 15 Jul. 2011.

Levy, Bernard-Henri. “A Monument of Audacity and Modernity.” The Guardian. The Guardian, 9 Oct. 2007. Web. 20 Jan. 2012

limipolexG. Illuminated Pineapple. 2009. Digital image. Flickr. Web. 19 Jan. 2012. 
Linsey, J. S., K. L. Wood, and A. B. Markman. "Modality and Representation in Analogy." AI Edam-Artificial Intelligence for Engineering Design Analysis and Manufacturing 22.2 (2008): 85-100. Print.

Lowenstein, Richard, dir. He Died with a Felafel in His Hand. Fandango and Notorious Flims Pty. Ltd., 2001. DVD.

Makropoulos, C. K., D. Butler, et al. (2005). Building decision support systems based on Fuzzy Inference. General Assembly of the European-Union-of-Geosciences, Vienna, AUSTRIA, Springer-Verlag Berlin.

Matsuda, P. K., and C. M. Tardy. "Continuing the Conversation on Voice in Academic Writing.” English for Specific Purposes 27.1 (2008): 100-05. Print.

---. "Voice in Academic Writing: The Rhetorical Construction of Author Identity in Blind Manuscript Review.” English for Specific Purposes 26.2 (2007): 235-49. Print.

Maximus. Te Puni Accommodation. 2009. Digital image. Eye of the Fish. Web. 19 Jan. 2012.

McNeil, Sue. "Sue McNeil.” Journeys of Women in Science and Engineering: No Universal Constants. Eds. Susan A. Ambrose, et al. Philadelphia: Temple University Press, 1994. 276-79. Print.

Medwadowski, Stefan J. “Aesthetics of Wood Structures.” Bulletin of International Association for Shell and Spatial Structures 26.2 (1985). Print.

Miéville, China. Perdido Street Station. London: Pan Macmillan, 200o. Print.

Ministry for the Environment. "About Climate Change". Ministry for the Environment. New Zealand Government, Nov. 2010. Web. 11 Nov. 2011.

Moran, Tom. "Strong Words: The Creative Writing of Engineers.” IEEE International Professional Communication Conference. IEEE, 2008. Print.

Morrell, Jack. “Romantic Rocks, Aesthetic Geology.” British Journal for the History of Science 39.143 (2006): 614-15 Print.

Nabokov, Vladimir. Lolita. 1959. Middlesex: Penguin, 1980. Print. 
Newman, Frederick H. “The Interrelation of Engineering Design and Architecture.” Frederick H. Newman: Lectures on Architecture. Ed. Andrew Leach. Gent: A \& S Books, 1951. 45-63. Print.

Obama, Barack Hussein. “Inaugural Address”. The White House Blog. The Whitehouse, 21 January 2009. Web. 3 Mar. 2011.

Orlyg. Pompidou. 2004. Digital image. Flickr. Web. 19 Jan. 2012.

“Owen G Glenn Building: Facilities and Resources.” Auckland University Business School. Auckland University Business School, 2010. Web. 3 Aug. 2010.

Hallett, Stephen, and Bob Palmer. "Soil Water Regimes Under Hard Surfaces: Exposed Soil Substrates.” Digital image. Cranfield University. Web. 1 Feb 2012.

Paternack, Alex. “Must See TV.” Urbane October (2008): 22-30. Print.

pav. Gerberette. 2004. Digital image. Flickr. Web. 19 Jan. 2012.

Petroski, Henry. "Want to Engineer Real Change? Don't Ask a Scientist." The Washington Post. The Washington Post, 25 Jan. 2009. Web. 1 Mar. 2011

Picture of the Day: Beijing Building. 22 May 2009. Digital Image. The Telegraph. Web. 20 Jan. 2012.

Pluciennik, M. “Archaeological Narratives and Other Ways of Telling.” Current Anthropology 40.5 (1999): 653-78. Print.

Poikonen, Marko. Would You Like to Have One of These Individualistic Apartments? N.d. Digital image. Flickr. Web. 19 Jan. 2012.

Pollio, Vitruvius. The Architecture of M. Vitruvius Pollio: Translated from the Original Latin by W. Newton Architect. 1791. Gale Group. Web. 1 Aug. 2010.

Powell, Abigail, Barbara Bagilhole, and Andrew Dainty. "The Good, the Bad and the Ugly: Women Engineering Students' Experience of Uk Higher Education”. Cheltenham, 2007. Women and Minorities in Science,Technology, Engineering and Mathematics: 
Upping the Numbers. Eds. Ronald J. Burke and Mary C. Mattis. Cheltenham: Edward Elgar, 2007. 47- 71. Print.

Proudfoot, Michael, and A.R. Lacey. "Sublime." The Routledge Dictionary of Philosophy. Eds. Michael Proudfoot and A.R. Lacey. 4th ed. New York: Routledge, 2010. 391. Print.

Quirk, Tom. “Historical Essay.” Alexander’s Bridge: Willa Cather Scholarly Edition. Ed. Frederick M. Link. Google Book Search. Web. 22 Feb. 2012.

Rice, Peter. An Engineer Imagines. London: Artemis, 1994. Print.

---. "Unstable Structures." Columbia Documents of Architecture and Theory 1 (1990): 71-90. Print.

Ritchie, Ian. “ ‘An Engineer Imagines' by Peter Rice”. Ian Ritchie Architects. Ian Ritchie Architects, 24 May 1994. Web. 25 Aug. 2011.

Robbe-Grillet, Alain. Jealousy: A Novel. 1957. London: Calder, 1965. Print.

---. “Nature, Humanism, Tragedy.” For a New Novel: Essays on Fiction. 1958. Ed. Richard. Evanston Howard. Evanston: Northwestern University Press, 1989. Print.

Romm, Joe. "World's Engineers: Technology We Need to Address Global Warming Already Exists!” Clean Technica. Important Media, 30 Sept. 2011. Web. 7 Oct. 2011.

Salvadori, Mario George, and Robert Heller. Structure in Architecture. 2nd ed. Englewoof Cliffs, N.J.: Prentice-Hall, 1986. Print.

Sarukkai, Sundar. "Beauty in the Beast (Art, Technology).” Leonardo $37 \cdot 3$ (2004): 175-76. Print.

---. "Mathematic, Language and Translation." Meta 46.4 (2001): 664-74. Print.

---. "Mathematisation of Human Sciences - Epistemological Sanskritisation?” Economic and Political Weekly 30.52 (1995): 3357-60. Print.

---. “Translation and Science.” Meta 46.4 (2001): 646-63. Print. 
Schaffner, Christina. “Skopos Theory.” Routledge Encyclopedia of Translation Studies. Ed. Mona Baker. London: Routledge, 1998. 235-38. Print.

Schaible, Robert M. "Quantum Mechanics and 'Song of Myself': Getting a Grip on Reality.” Zygon 38.1 (2003): 25-48. Print.

Schambelan, Elizabeth. "The View from Below: Elizabeth Shambelan on the So-Called Utopia of the Centre Beaubourg.” Artforum International. New York: Artforum International Magazine, 2007. Oct. Print.

Silliphant, Stirling. “The Towering Inferno.” Drew's Script-O-Rama. Web. 1 Mar. 2011.

Silver, Howard, dir. Public Places: Architecture of SITE: Virginia Museum of Art exhibit on SITE. Arts into Production, New York, 1980. MOV file.

Silver, Nathan. The Making of Beaubourg: A Building Biography of the Centre Pompidou Paris. Cambridge: MIT Press, 1994. Print.

SITE. Indeterminate Facade Building: besto4.png. Digital image. SITE: Projects. Web. 1 Dec. 2011.

SITE. Notch Showroom: besto5.png. Digital image. SITE: Projects. Web. 1 Dec. 2011.

SITE. Peeling Project Showroom: besto2.png. Digital image. SITE: Projects. Web. 1 Dec. 2011.

Skene Catling de la Pena. "La Petite Maison.” Vimeo New York Architecture and Design Film Festival, 2010. Web. 8 Mar. 2011.

SLClaassen. "Burj Khalifa Model”. 2010. Digital image. Flickr. Web. 19 Jan. 2012.

Society of Women Engineers. “Aspire. Advance. Achieve at Every Stage of Your Career.” Society of Women Engineers. Web. 22 Feb. 2012.

Stegers, Rudolph. “Thorncrown Chapel: Eureka Springs, Arkansas, USA.” Trans. Julian Reisenberger. A Design Manual: Sacred Buildings. Ed. Rudolph Stegers. Switzerland: Birkhauser Verlag AG, 2008. 80-81. Print. 
Stinner, Arthur. "Science, Humanities and Society: the Snow-Leavis Controversy." Interchange 20.2 (1989): 16-23. Print.

Stokan, Steven. Geometric Detail of Thorncrown Chapel's Structure, Eureka Springs, Arkansas, USA. 2006. Digital Image. Steven Stokan Photography. Web. 1 Feb 2012.

Sutjiadi, Hendry. Personal interview. 15 Jul. 2010.

Sustainability Society, The. "Vision." The Sustainability Society. IPENZ, 2011. Web. 11 Nov. 2011.

Tarkov, John. “A Disaster in the Making.” Sons of Martha: Civil Engineering Readings in Modern Literature. Ed. Augustine J. Fredrich. American Society of Civil Engineers, 1989. Print.

"Teaching and Research Building: Summary of Submissions.” Victoria University of Wellington. Victoria University of Wellington, Feb. 2008. Web. 23 Jul. 2010.

Tenopir, Carol, and Donald W. King. Communication Patterns in Engineers. New Jersey: Institute of Electrical and Electronics Engineers, 2004. Print.

Terralink. 18 Esk Place, Aranui, Christchurch. 2011. Digital image. Zoodle. Web. 19 Jan. 2012.

Toury, Gideon. Descriptive Translation Studies and Beyond. Benjamins Translation Library. Philadelphia: John Benjamins Publishing Company, 1995. Print.

Tuchman, Janice L. "Looping, Leaning Tube in Beijing is an Antidote to the Skyscraper." Engineering News Record July 21 (2008): 30-35. Print.

"Update One.” Victoria University of Wellington. Victoria University of Wellington. Web. 31 Sept. 2010.

Vidler, Anthony. Preface. The Little House: An Architectural Seduction. By Jean-François de Bastide. New York: Princeton Architectural Press, 1995. 9-18. Print.

Walker, Derek, and Bill Addis. Happold: The Confidence to Build. Great Britain: Happold Trust Publications Limited, 1997. Print. 
Washington, Katrina D. “Katrina D. Washington.” Journeys of Women in Science and Engineering: No Universal Constants. Eds. Susan A. Ambrose, et al. Philadelphia: Temple University Press, 1995 . 413-416. Print.

Waugh, Evelyn. Brideshead Revisited. London: David Campbell, 1993. Print.

Webb, Michael. "Made in China.” The Architectural Review 224.1337 (2008): 34-37. Print.

The Engineer's Aesthetics - Interrelations between Structural Engineering, Architecture and Art. Third International Congress on Construction History. 2009. Print.

Weismantle, P. A., G. L. Smith, and M. Sheriff. "Burj Dubai: An Architectural Technical Design Case Study.” Structural Design of Tall and Special Buildings 16.4 (2007): 335-6o. Print.

Whitby, Mark. “An Engineer Imagines.” CBS Business Library. The Architectural Review, Dec. 1994. Web. 25 Aug. 2011.

Wikipedia. “China Central Television Headquarters.” Wiipedia. Wikimedia Ltd., 13 Feb. 2012. Web. 22 Feb 2012.

---. “Owen G. Glenn Building.” Wikipedia. Wikimedia Ltd., 21 Jan. 2012. Web. 22 Feb. 2012. Wilson, Forrest. Structure: The Essence of Architecture. London: Studio Vista, 1971. Print. “A World First for a Multi-Storey Steel-Framed Building." Steel Construction New Zealand March (2008): 3-5. Print. 

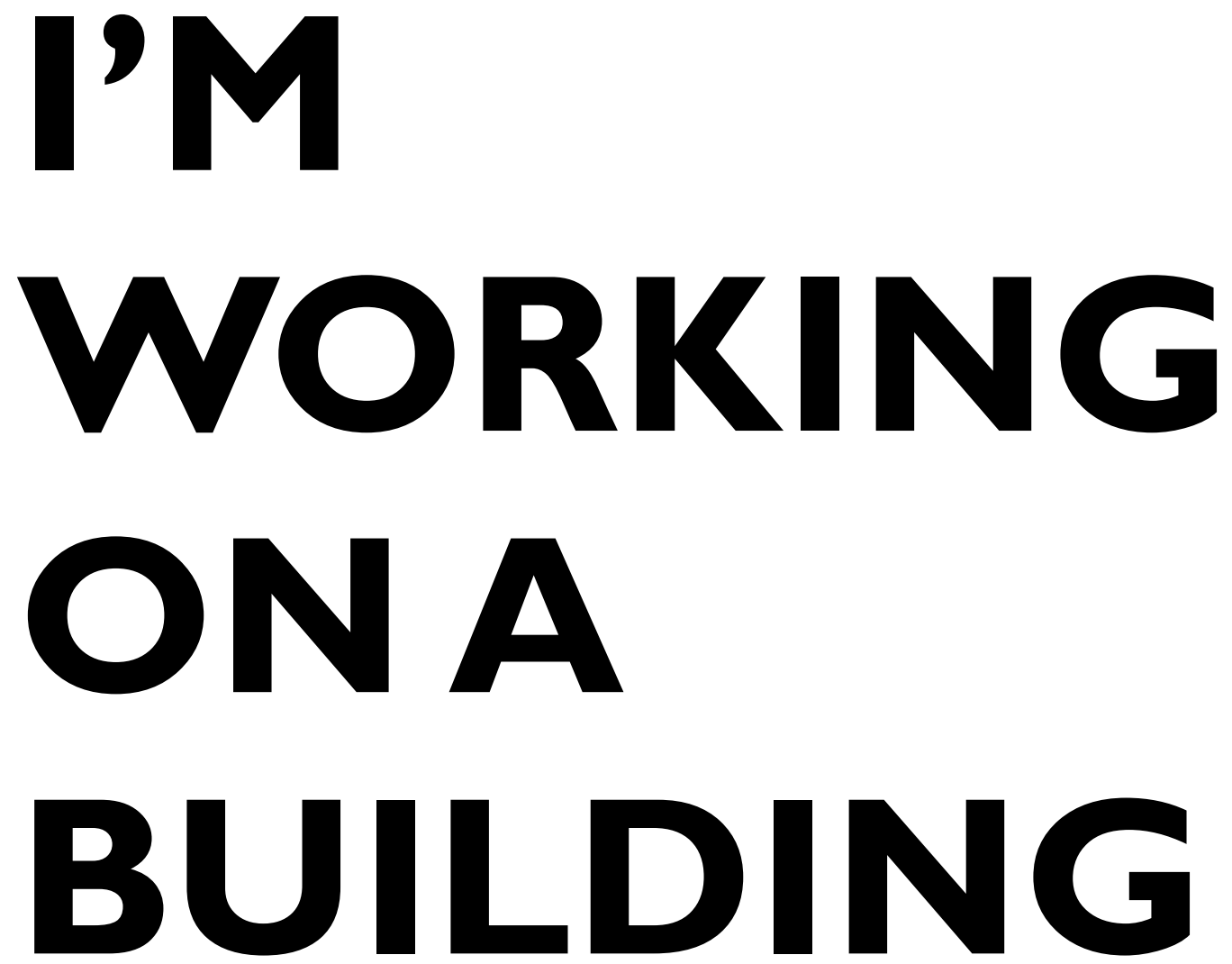


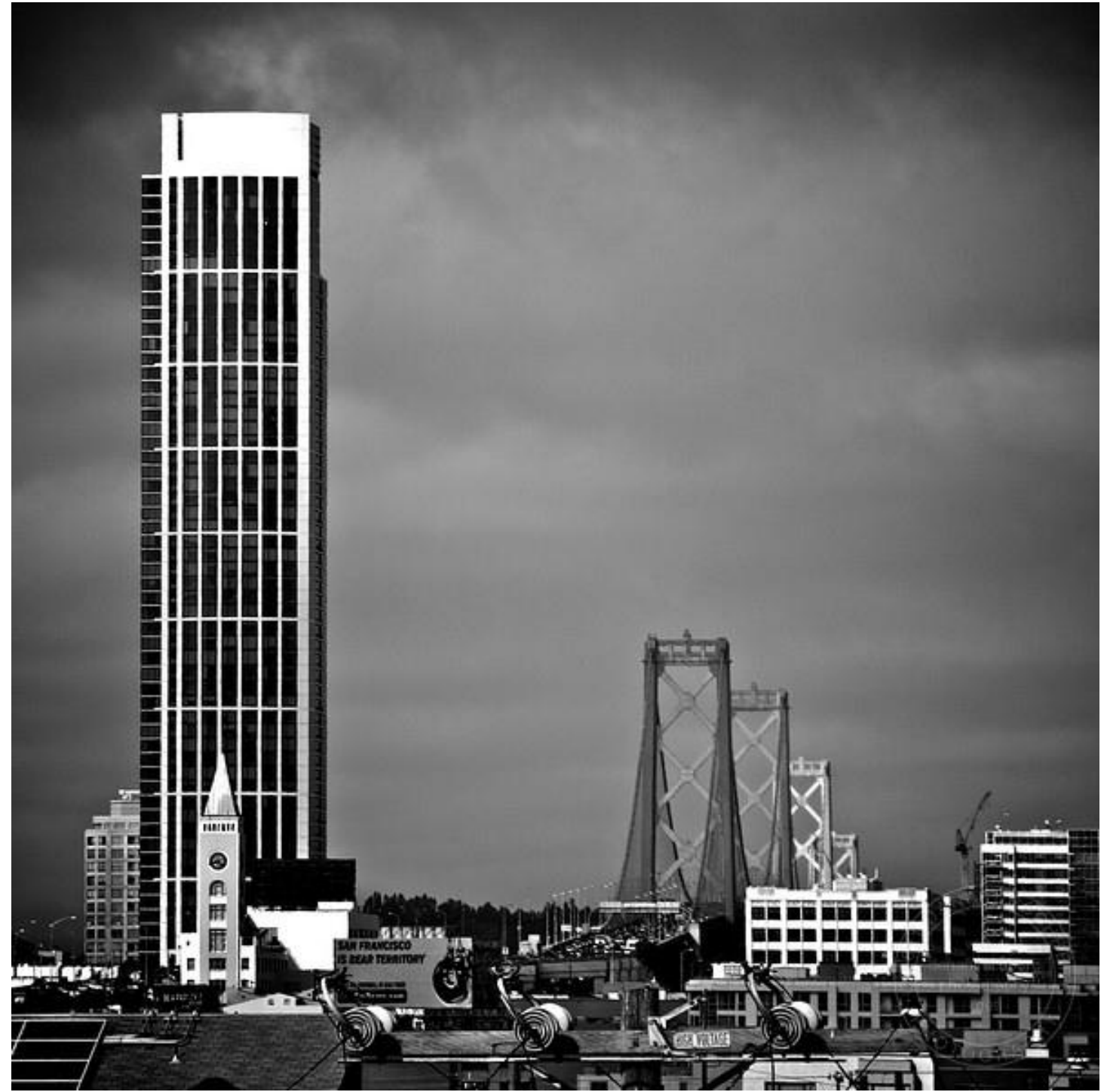




\section{Beaubourg}




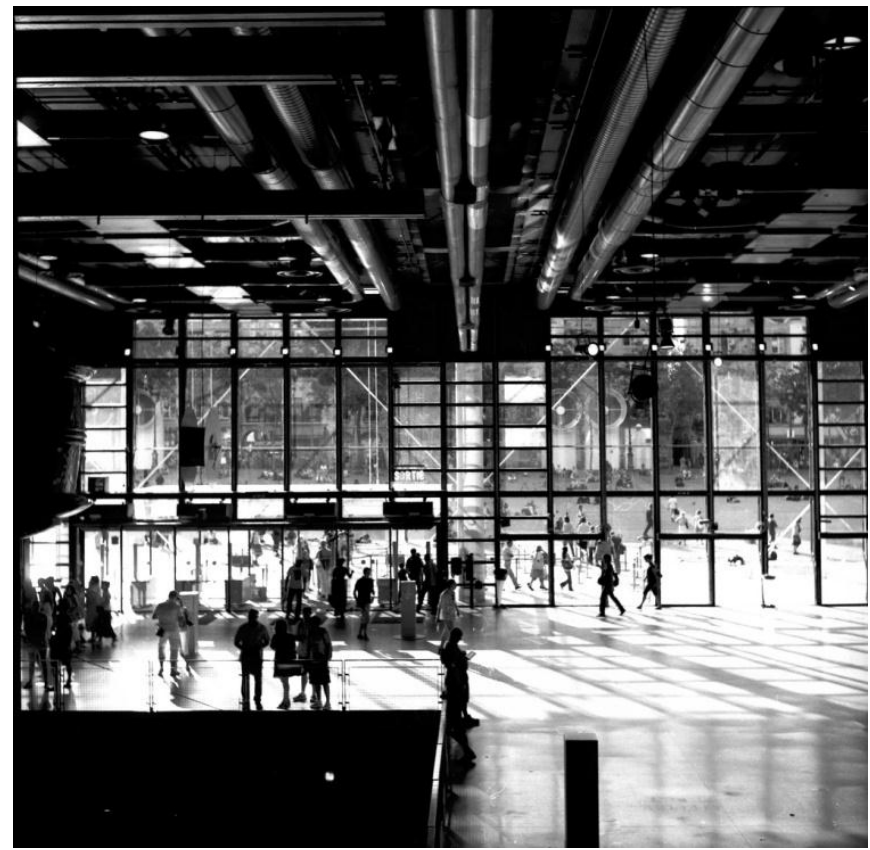


The markets moved out of Les Halles in 1969, unable, finally, to compete with the new economy. The stomach of Paris was quickly long empty streets under old iron and filthy glass beside a lorry park with nothing parked in it. Then they took that down and began to dig. The trains were coming and the supermarkets and the hypermarkets and convenience but for a while it was a hole next to an empty lorry park at the foot of Saint Eustache where there were rats and junkies and hookers. For a while, before they poured concrete and tied steel and stood in hardhats and wide ties and flared pants and looked at plans and made Les Halles grand and busy again and when it was - ribbon cut, cheers raised - the lorry park looked worse, and emptier. Beaubourg was ugly and old, no one sold their products out of trucks at Les Halles anymore. They delivered them every day from loading zones: clean meat wrapped in clean plastic, artisan cheese, fresh green vegetables. Someone needed to do something about Beaubourg - it was bringing everybody down. What Beaubourg needed was culture, a container of culture, so it wouldn't bleed out like it had before, so the rats wouldn't come, or the hookers, or the junkies. Did anyone want to build a container for culture? A box perhaps. And they did and the ground was broke, and the digging dug, and the box put in place piece by piece and the sun rose on Beaubourg and it reflected off the exterior escalator and the large round ducts: blue for water, green for air, but it sunk into the gerberettes and stayed there. She was four when they opened the Centre Pompidou.

At thirteen Catherine is standing close to a hotel window but not pressed against it. Like an acquaintance, or a well-behaved daughter. When she breathed out Paris quieted behind a clean white veil which lasted just until she inhaled. She watched it and it occurred to her that the condensation was one exact unit's worth which returned from and to her, over and over again without diminishing, which was foolish. She exhaled longer and the patch of humid translucence grew and grew and was still there when after a short intake she breathed out again. Catherine looked around the room. Everyone was still asleep. Her younger sister lay like she'd fallen from a great height. Tangled in sheets and soft woollen blankets. There wasn't a sound from her parent's room. All she could hear was the noise of the building. The mechanics first, air conditioning, an elevator. Then as she stood stiller, breathed less - slowing herself almost to suspension, the vibration under the noise. The hum under her bare feet, the sound the air made as it travelled round the room, the force of the walls holding the roof in place. She looks behind her, at her sister still sleeping, at her parents silent door then rests an arm against the wall, a cheek, an ear and breaths everything in, through her skin. Like amphibia, she whispers without noise and she closes her eyes and thinks of a spadefoot toad under the weight of this wall and 
the next, and the next, hurt and flat, then dead. They had been in Paris eight hours. Everyone was still asleep, but Catherine was awake.

'They won't speak English to you,' she said it quietly to her father. So no one would hear above the sweet bread smell and the high-pitched clank of the hotel restaurant. He looked at her but Catherine was concentrating on a brochure she'd picked up in the lobby. Her mother spoke some French, her sister also but her father spoke none and refused to learn any.

'Well, what shall I do?' Richard asked, as he caught himself on his way into a shrug, into some incredulous tone, some sense of entitlement.

'Ask me,' Catherine said. 'Or Isabel.' She glanced at her mother who was wiping something off Isabel's blouse. 'Don't ask Diane.'

'Don't be rude to your mother,' he said, smiling at the waitress who poured his coffee. Catherine shrugged.

They went everywhere. Everywhere that everyone else went. Diane had made sure of it. She'd talked to Fenella's mother and Petra's, the girl's French teacher and the travel agent. Every day they were somewhere new eating things they'd never tasted, listening to music. Filling themselves up on Paris. 'And on the eighth day they rested.' Isabel didn't get it and then did and told Catherine loudly, in a mix of French and English it was not d'accord to make fun of Jesus.

'I wasn't making fun of Jesus,' Catherine said, 'I was making fun of God,' which made her sister furious and their mother laugh in a refined and gorgeous way.

Everyone was tired except Diane who wanted to go shopping. Isabel, Richard and Catherine lay on the double bed in their pyjamas watching television while Diane dressed. An ad came on for an exhibition of modern art. Richard and Isabel were playfighting.

'What's that?' Catherine asked.

Diane looked round the corner from the bathroom and shrugged.

'Shh,' Catherine said to her father and sister. The screen filled with Pompidou, shot from the courtyard, people walked in and out and the dates and the name of an exhibition filled the screen.

Eventually the television got boring. Isabel flicked through channels over and over as the three of them stared blankly at the screen.

'We need to get out of this room,' Richard said sitting up, swinging his legs off the huge, high bed.

'Can we go to Pompidou,' Catherine asked. 
They caught a taxi. Richard didn't trust Catherine with the map. 'This city is cunning,' he said. 'Those maps are useless.' He had to concentrate hard on not being startled by it. The way it crammed in - how old this part of the city was, how much older than him. How it reached back further than he could fathom. He felt like he would drown in how old it was and all the people that had walked here and knocked on the doors and thrown things from the windows. It was older than caring. It probably never had. It was hardness and chaos he thought, tried not to think. It was dirty. That's what people said. There were dogs everywhere, and pigeons. There was always a strange smell in the air. When they walked toward Pompidou he could see large glass jars of eggs pickled in brine through the windows of the cafes, their shells still on - they were everywhere but he wouldn't eat one. Nothing was clean. He could probably say that when he got home. He probably wouldn't say it to Diane and he definitely wouldn't say it to Catherine but the whole city disturbed him. It wasn't like the brochures. But when he got home he would own it. He would say how he felt almost sorry for the French, how much better it was in Auckland, how everything was dirty. 'The life,' he'd say, toasting the large windows of his large house and Rangitoto. 'The life,' he always said as he looked toward the city Auckland was becoming.

There wasn't much at Pompidou, some art, a library - an ordinary library, a music school. The three of them went up the escalator, stopped at the lookout and looked out. Before them, the tower called out above all the stone, like it was making an argument for iron. Catherine closed one eye and held out her hand to rest it in her palm. Then Isabel winked and blew at it until the sun came from behind a cloud and played through it. 'That's all it has to say,' Isabel said and she made legs with the first two fingers of her hand and walked them across the roofs. When they hit a steep one she would walk them up to the ridge then slide them down a hip or field. Catherine watched her thinking, Rake, gable, dormer. Far in the distance Richard thought he could see a cluster of something modern, rectangular, mirrored perhaps.

'Over there,' he said pointing and squinting, only making out the shape of them and the girls nodded. They watched some aeroplanes come in. 'Come on,' he said.

Catherine followed Isabel and Richard through the foyer. The shadows the steel frame cast swept up and over them to drop again onto the floor and wait for her. She watched them on her own feet and felt them as they climbed her body, noticed the quick snap of the lightdark as they sped over her eyes. She lifted her arms slightly in front of her so she could pick them up from waist-height - they wouldn't go through her. She felt so solid.

It was hot, no one spoke English. The Pompidou was cavernous, Isabel ran ahead and when he turned to tell her to hurry up Catherine was gone. He called to Isabel who returned to 
his side. It seemed impossible for Catherine to be lost in all that open space - but she wouldn't be found. It was crowded but surely his own daughter would stick out to him in the pack. Surely. He didn't know whether to walk or to stay put. For a split second he considered getting Isabel to stay where they were while he looked for Catherine. Then he thought about it - losing two children - deux enfants. He thought of the hand gestures he could use for lost, the faces he could pull. He believed the longer he stood there the more likely it was that Catherine would come back. Believed it to the bottom of his heart then suddenly saw how ridiculous it was. His heart raced and the Pompidou spread out around him wider. There was so much space. He could see it, like it was making more space deep within the space that was already there, he could swear it was getting bigger as he tried to work out what to do and where to start.

'Where's Catherine?' Isabel wasn't troubled, except slightly by the break this was causing in her forward momentum. She looked around and up and around.

'I'm not sure what to do,' he said calmly, in an off-hand way.

'She can catch up.' He could feel Isabel beginnng to walk away. She hadn't moved but he could feel her making the decision to walk away and he wondered if she was right. Would Catherine go with anyone? She treated everyone as if they were made of the same cloth - sister, teacher, mother, stranger. He couldn't be certain that she hadn't gone with anyone. It didn't feel like the building would hold her, it felt like it would lift her up somehow, float her out of the foyer, out of the gallery into the air above Paris, over the crush of it, the shambles, so she could see it all.

'Maybe if we go up?' Isabel said.

For a moment what she said made no sense.

'Then we could look down. We'd be able to see everything just about.'

It still didn't seem quite right but he couldn't stand still any longer. He looked foolish. There was some kind of traffic to the place. People seemed to be able to walk and not fall over each other. It wasn't as simple as keeping to the left but he was sure where they stood was in the road of it all. Isabel walked away and he followed her.

They walked back and forward, up and down for what seemed like an hour, Isabel stopping every now and then to ask people if they had seen her sister. No one had. He stopped and looked out over it all then raising his eyes slightly he saw Catherine across the clear extent under the strung ceilings, standing behind something so large that he couldn't help realising it held the bridge she was standing on up. She was reading something and idly stroking the gerberette winding her hand under the lip of it. It had been cast from nothing and made and now it stood below his vague daughter, complete and capable of holding her weight and the 
weight of the people who walked behind her. Catherine looked up and in the strangeness of seeing him see her lifted her hand from the steel and waved. He felt like he hated her. She had no respect for big. He'd grown up in a house with a dirt floor. He'd taken nothing and he'd gambled it and come out with almost everything. Now he traded other people's money for the promises of money. Catherine didn't understand how wealthy he had made them. How far he had brought himself, through wit and guile. He looked at her hand as it wound back round the steel. She swallowed it up. It had been the same with the iron of the tower, she would place a hand or a foot and make it disappear into her, make it not matter, make it something from her, like her. It had always been like this and now that he saw it he hated it. He was sure she could tell that he couldn't make anything. The solid things she enlisted pointed it out to her over and over. He couldn't hold the product of anything he'd made and all she seemed to understand took up space and could be leaned on or held. He had never liked her but he had tried but today felt like the end of something, as if she had gone away and something else had returned that wasn't her. Like she'd finally travelled far enough away to be transformed into what she really was. Far enough so he felt like he might not see her again and having wiped the idea of her in some way from his mind he could see her now and he realised he'd always hated her. Then he noticed the pool of light that she hadn't stood in, people walked in and out of it, it was dappled by the leaves of the trees outside and he suddenly felt a quiet triumph, as if he'd hit her, because now he could see this too - that she was nothing in nature. She could swallow an entire room, open her hand or her mouth, sit at an angle to a wall, but in a field, on a mountain, in low shrub or a stand of trees she was lost, awkward. She'd come to the shore groaning for breath, coughing, spitting. Rivers scared her, even to be at the bank. If she was left for long in the shallows of a lake, she would probably die. He smiled at her and waved back, he didn't need to do anything. Everything powerful she had was manufactured and contingent. She couldn't destroy the air. He looked out at the courtyard, at the trees and took delight in the downfall. He could carry on with her and win because he put his stake in nothing. He wasn't tied to anything solid. What he had was agile, new, she was stuck in some old economy.

Isabel was at his side then looking at Catherine with him. 'She must have been here the whole time,' she said. 'She wouldn't have known we were looking for her.'

Catherine was standing very still.

'Like stone,' Isabel said, and she walked toward the bridge that would take them to Catherine.

When they got back to the hotel there was a message waiting for Richard at the 
reception desk asking him to call his office in Auckland. He was irritable that night and the next day Diane took back two of the handbags she'd bought. 
Fort Street 


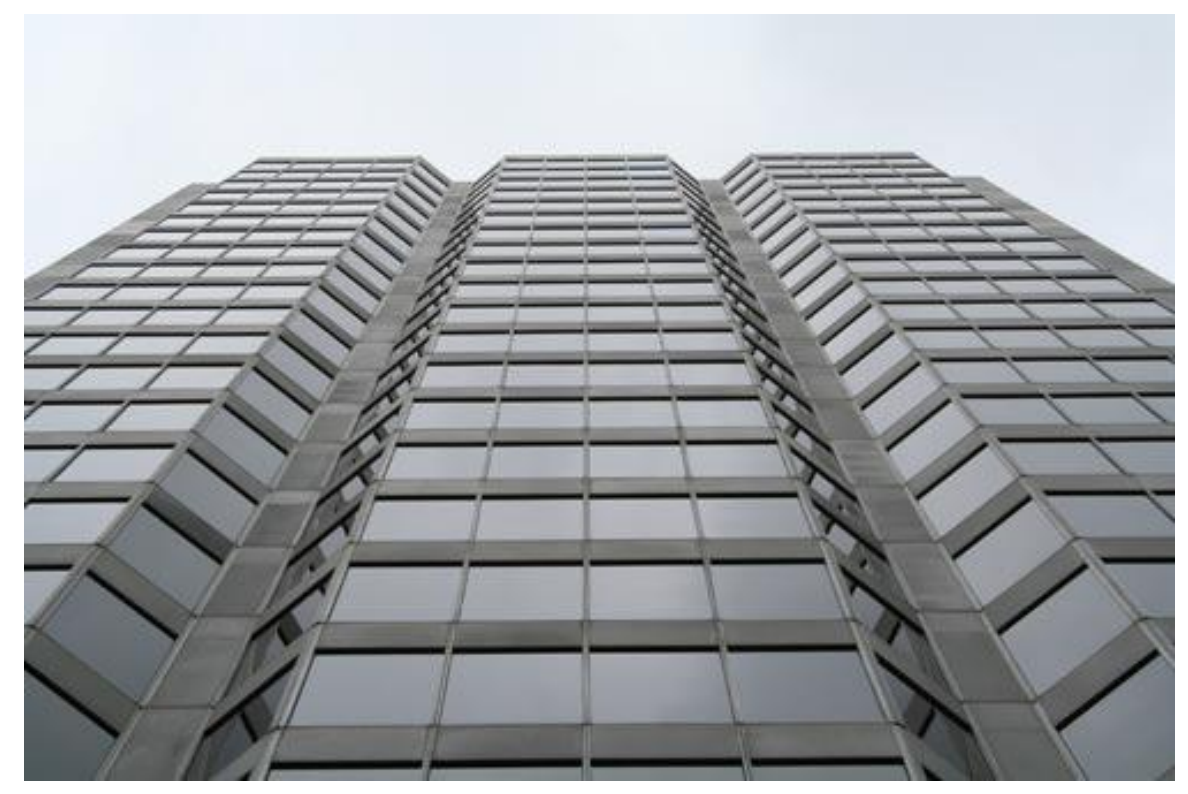


It was all gone in a year: the private school, the cars, the boat, the business. The case workers were busy, the school teachers were indignant and protesting and the parents drank and drank and didn't have the means to keep them and didn't have any interest to discipline. All the adults were worried about themselves, so the adolescents of the recently, quickly rich were signed away into independent circumstance.

'How far the mighty have fallen,' Catherine said as she and Tansy stood in front of her unconscious parents, asleep in what was left of the lounge furniture, lights on, television on. Her mother was dressed up and sunk into her shoulder-padded linen jacket.

'It's inspirational,' Tansy said.

'Aspirational,' Catherine corrected. 'It's a fucking nightmare. Diane!' she shouted, and her mother wouldn't move an inch. 'Diane, I'm leaving.' Isabel was asleep too. Catherine kissed her goodbye and slid a note under her pillow telling her to leave as soon as she was able. It's a sinking ship, she wrote. Then she and Tansy searched for food, money, jewellery and walked down Paritai Drive in the brightest breaking dawn. They walked round the bay to the city, beside the sparkling sea and spent the day sitting in Aotea Square, taking turns asking people for money and cigarettes.

'It's a hot one,' Tansy said with a radiant smile. 'Could you buy us a Coke?'

At first they stayed with men. They'd go to the Queen of Darkness on Fort Street and pick up a man and go back to his place. One of them would fuck him, or both of them, but not if they could help it, it was twice the work. They'd stay there while he slept, steal food. It got old quickly and the men started to want to fuck in their cars. Tansy and Catherine each had exactly as many clothes as fitted into a canvas army surplus bag and a pair of Dr Martin eight ups that they never took off, not to fuck, not to sleep. Winter was coming. Then Tansy noticed that there were more and more office buildings that didn't have lights on at night, or in the day, there were no cars in the carparks. She pointed it out to Catherine who became transfixed by it. Sometimes Tansy would lose her and find her standing on the street looking at the dark, high buildings. One night Catherine led Tansy down an alley, onto a skip then took a screw driver out of her pocket and worked a vent cover off its brackets. They crept in on all fours. Catherine replaced the vent behind them then kicked out a steel panel. They were in a corridor about a metre up, Tansy jumped then Catherine. They climbed the stairs, poking into the dark corners of each floor like animals in a new run and finally fell asleep under their jackets on the thin carpet of an empty office high above the city. Tansy woke to find Catherine standing in front of a large window but when she walked over Catherine wasn't looking at the sky her small fingers were walking over 
the tiniest landscape of the deep sill - measuring it. They slept a few nights on the floor then carried some foam they found in the skip up the stairs. Then one night as they came round the corner of the alley there were two security guards. One was on top of the skip with the vent cover in his hand, so they ran.

Catherine told their friend Ilmars about it, outside the Occidental a few nights later. She wouldn't stop talking about it, almost shouting, with excitement, with offence. Ilmars was at art school, and he talked to his father, who was in property management and finally, after all their clothes were soaking and the laces on one of Tansy's boots got so short she had to tuck it into the fourth and fifth eyelets, a man who owned an office block and had escaped overseas said, 'Sure, why not.' Ilmars explained it best, he got tax off if his building was empty and there wasn't anybody wanting inner-city office space at the moment, and there wouldn't be for a while the way things were going, so he didn't care if they stayed there and he didn't want any rent. He didn't give a fuck. 'Burn it down,' he'd said over the phone in Ilmars' dad's office. Ilmars' dad handed him the keys and said, 'Don't fucking burn it down.' No one wanted inner-city office space and they wouldn't, Tansy said it to herself often. The recession felt like it would last forever.

They always slept in. If they weren't at school they couldn't have an independent circumstances benefit. They could have an unemployment benefit but not until they were eighteen. So they needed to be at school. But they always slept in. If they stayed up all night they couldn't sleep in. Catherine had said it holding up the boxes of capsules she'd stolen, shaking them so the sheets rattled. They couldn't fail. It was the sleeping that was fucking them.

'We could get a job,' Tansy said. They were lying on their backs on their bed, boots on.

'You can't get a job until you're 15,' Catherine said.

'You can get a dispensation. We could get a job.'

Catherine was holding the sheet of capsules in straight arms in front of her face, reading the silver labels.

'We could get a job,' Tansy said.

'Huh, yeah, yeah.'

'Or we could get a job where they don't care how old you are.'

'I wish we had windows.' Catherine was squinting, and drinking from a bottle of gin and squinting.

'If we got a job, we could have windows.'

Catherine shook the box and looked at Tansy, she shook the box in front of Tansy. 'We 
can't fail. We stay awake. We go to school. I'm not quite ready to be a teenage stripper.'

'What about market research?'

So they stayed up all night snorting Benzedrine talking fast, and lost track of everything. Tansy was pretty sure Catherine had disappeared for a while and she'd slept and then Catherine was there, dressed, shaking her and Tansy was dressed and their bags were packed for school and Catherine had packed a lunch from somewhere and they had ten minutes to get to the bus and they got to it and they walked through the gate at 8.45, wide-eyed, chewing their cheeks, looking around the home-room as the teacher told everyone about sports day and lost property and that there was a new woodwork teacher if that affected anyone in the room. Catherine stared at the teacher and Tansy had a dream that Catherine had a dream that this was all a dream. Tansy looked at the other people who sat around them in the classroom, she could see all their worries, parents, school, clothes, she hoped she hadn't thrown her head back and laughed open-throated at them. 'We're free,' Catherine whispered in her ear, reminding her, petitioning her, and Tansy nodded. The corridors were crowded and loud and Dominic was there, skipping to keep up with them. Catherine kept looking back at him getting caught up in the people. She stopped when he reached her and held a fist slightly in front of him, fingers down, and he reached in his pocket and she dropped four pills into his hand and he gave her money. 'See, we already have a job,' Catherine said to Tansy, with her eyes, with the impatience of the way they looked at Tansy and then behind her, then above.

'Are you going now?' Dominic said.

Tansy nodded.

'I'm going to maths,' Catherine said.

'How the fuck are you passing maths?' Dominic asked.

'I'm passing technical drawing too,' she said, patting him on the shoulder. She kissed Tansy goodbye.

Tansy and Dominic hid outside under the cafeteria building and smoked cigarettes. It was cold. Tansy finished her cigarette and stood up.

'Are you going?' Dominic asked.

'It's warmer in the classrooms.'

'We're late now.'

Tansy shrugged. 'I've got art.'

'Do you like art?'

'Not especially.' 
'How is she passing maths?' he said.

Tansy shrugged.

Dominic smiled and shook his head but he thought he knew. From the distance he perceived himself to be at he felt confident that he had a clear view and from that sight and from his understanding of these times and this place and Catherine he thought he knew how she was passing maths and what she wanted and how he fitted into all of that and how he would fit, in the future, later.

'Do you have Social Studies?' Tansy said.

'Yeah. The New Deal.'

'Good grief.'

They began to climb the stairs beside the cafeteria.

'We could go to my place,' Dominic said.

He lived close to the school in a house that had been flash but was crap now. It often looked to Tansy like his parents didn't live there any more, she knew his father didn't but he insisted his mum was there, making dinner, doing washing, she just worked during the day. There was a spa pool at Dominic's house but it didn't work, it was cold and had a cover over it. There had been mosquito larvae in it over summer, tiny humping see-through things. It was never warm at Dominic's house but there was usually something to drink.

'Is there anything to drink?'

'Yeah,' he said.

Tansy stopped climbing the stairs, she squinted and looked out over the playing field. 'Nah, honestly, we stayed up all night just so we could get here. I'll go to Art.' She was starting to fade.

Social studies was easy, he said, because he could just sit and listen. How would she get through Art? Tansy shook her head.

'Are you going tonight?' Dominic asked.

'We are going tonight.'

They came to the top of the stairs, the women in the cafeteria were making filled rolls, Tansy could smell the bright white buns and the butter and tomatoes going in them, she could hear the crack of the lettuce, she wanted to sleep but instead she'd go to the bathroom, break open the only cold capsule that was left, the one that had rolled off the bed and onto the floor that she'd had her foot on for half an hour while Catherine searched for it. She'd work it open and spill it onto the toilet seat and with something, her bus ticket maybe, split out all the tiny barrels of Benzedrine, carefully tethering her breath so they didn't blow away. Then she could 
get through Art and probably Economics after that. Tansy and Dominic hugged each other and went to class.

The three of them made it until lunch. They sat in a corner of the field and smoked cigarettes and Tansy whined, 'Can we go yet?' And Catherine said, 'Yeah,' she was ready to go too. She only had Art and she hated Art, so they could go and they should go to Dominic's and have something to drink. And a spa.

They drank the afternoon away and watched television, Catherine did homework, copying equations from a big book that she held with her fingers keeping several pages open. She watched the television occasionally. Then at five she looked at her watch and said to Tansy, We have to go. 'We have that thing,' and they left.

That night, they walked up some stairs in the dark, and S.P.U.D. were playing. It was a large open space. Everything had been cleared out. 'What was this?' Tansy heard someone ask and someone else looked around and said, 'An office? A bank?' Tansy yawned. Glen Campbell was shouting and everyone else had their heads down. There were some pricks there but it was all right. She was pretty sure Catherine had blacked out, even from where Tansy was, at the back, she could see it, the slightly different way she held herself, her eyes. Catherine was up the front, beside the speakers nodding her head while Dominic shouted in her ear, looking down mainly but looking up every now and then, meeting his eye, throwing him off slightly - how close they were, how much closer when she looked at him, smiling. Dominic looked serious but Catherine was smiling, daring him to be serious - go on, go on, care about something and did he care. Catherine the house, thought Tansy, watching Dominic. This door? No this door is barred. How about the window? How about I tunnel in from where I am? How about I walk back and forwards in front of the tall gate in the hedge until someone leaves it open? And the door. Anything could happen. Tansy thought about going over and stopping anything nasty but she was tired. The staying up all night was a nightmare.

Tansy played the day over in her head as she watched Dominic shouting at Catherine, just to check if there were any signs that anything of significance was going to happen tonight. It looked unlikely. Dominic was still talking and Catherine was still nodding her head and smiling like she was trying to break her head in half, she kept swapping her beer can from one hand to the other so she could scratch each arm in turn. The man she'd given a blow job to in the toilets had cut their drugs with quinine. Tansy tried it out, The man I had sex with in a toilet cut our drugs with quinine. She tried it out with one of the girls in her class, 'That's sad about your mum not letting you go to that party, I had sex with a man in a toilet for drugs and he cut them with 
quinine.' 'Excuse me, Mr Andrews, Cathy and I will be late back from lunch, the needle exchange is closing early today and we have to go and have sex with someone in a toilet at a bar before we get there.' Tansy walked over and tapped Catherine on the shoulder, Dominic might have still been talking. Catherine leaned toward Tansy.

'I want to get a job.'

'What?'

'A job. I want to get a job.'

Catherine looked at her, and was suddenly, awkwardly still.

'I think I'm going to go home and get a job.'

The song finished and everyone clapped.

Catherine pulled her lips tightly shut to the side of her face. 'Now?'

'What?'

'Are you going home now? Cause you should stay. And you should stay one more night cause, the best paper for jobs is Wednesday and Saturday and it's Thursday and you could go home on Friday and get sorted and then get a paper on Saturday and get a job. That's what I'd do. If I were you. Is that what you'd do Dominic? Don't ask Dominic. Dominic would go home right now. Fuck Dominic. Dominic has a job. Don't you Dominic?'

Dominic shifted, couldn't quite hear them but nodded and said, 'At a bakery.'

'At his dad's office. Dominic's got a cadetship at his dad's office and then if he likes it they'll give him a job. Cause Dominic's dad owns the office and is still very rich. Dominic has choices. So he would probably leave right away but fuck, you should stay one more night. And then I can help you quit school tomorrow. And you could see the careers advisor but you'll need to organise all that so you don't - like - you know, fuck up your independent circumstances benefit because you don't want to be left,' she was talking faster and faster, spitting it all at Tansy, looking all around, scratching again, scratching her neck now as she looked to the left and to the right and behind herself and all the time shouting at Tansy. Then the crowd started to jump and the two of them were pushed to the front and they were jumping and all the time Catherine kept talking, 'You need to look at your options and I think staying one more night gives you a few more options, that's what you need to realise at this point Tansy, there are all sorts of things that will need your attention and you need to start sort of manning up to them, thinking them through.' The crowd took them to the front, there was no stage, the audience was in amongst the band now. Catherine kept talking, Tansy stopped listening, she was itchy now. Her hands, her arms, her bitten-back nails butting at the itch, she looked at Catherine's longer nails, the purpose with which she scratched, the marks it left and there was some relief but now 
her head was itchy, the part of her head where the hair started behind her ear. Catherine was right, she should stay one more night. The best paper was Saturday. The floor was under her, the ceiling was above and Catherine was beside her, rocking her head from side to side, looking at the floor and mumbling now, run almost all the way out of steam. Then suddenly, Catherine looked up and around, she was gasping slightly, like she'd run out of air in the close room. She smiled and grabbed hold of Tansy's hand. She dragged her out of the crowd, out of the room, down the stairs, out of the building into the cradle of Fort Street.

'It's like being in a whale,' Tansy spoke from the bottom of herself, so deep, her words fat in her chest, fat in her mouth. The buildings grew out of the ground as they walked through them into the dark star sky. Catherine looked strange in it, the air, the weather, Tansy tried to release her hand but Catherine held tight. It was a trick. It wasn't outside Catherine was taking her to. Not the wide fresh space. Catherine didn't want to be on the streets no matter how high the buildings rose or how close they came, she was taking Tansy inside. Tansy slowed but Catherine led her own. Then they were at Ilmar's father's friend's building. No one would want it for ages - the recession would go on and on. Catherine pushed Tansy against the door as she unlocked it, forcing her thigh between Tansy's legs, kissing her with a laughing open mouth above the sound of traffic Tansy heard their teeth bang ceramic. The lock clicked and Catherine pushed her harder to open the door - kissed her deeper then pulled her off, still so close not a thing could get between them, 'Not dust,' Catherine whispered in Tansy's mouth. The deadbolt bolted. 'A wall,' Catherine said, ' a step, a step, a column, another door.' They fell on the bed but Catherine stood Tansy up again, moved her against a wall, then the window sill, she scraped Tansy's tight skirt over her hips, kissed her neck, her cheek, her closed eyes while she worked her hand through stockings and underwear, until finally she found her. This door? Why this door is wide open, always has been, come in, you know your way around, make yourself at home.

Tansy woke at midday. Catherine was gone. Dominic didn't know where, which was exactly what Catherine would have told him to say. He was the only person in Auckland left with money. Tansy signed out of school and tried to get a job in Auckland and then got a job in Sydney, at a backpackers, and fell in love with a man who pulled a firearm on a police officer. She visited him every weekend so he could touch his baby which was in her stomach making her tired and sick.

For the first few weeks she rang Dominic often and for the first few weeks he said he still hadn't seen or heard from Catherine. But when Tansy moved to Australia, once she had a 
flat, a letter arrived from him saying Catherine was fine - he was looking after everything. Everything would be fine. He and Catherine had found a flat in Grafton. She was going to university - how had she passed maths? There were bars on the windows of the house Tansy shared with three others, so they could keep them open all night. Parakeets flounced in the magnolia trees in the street outside. She hadn't met the man with the gun yet but it was hot and damp and all the houses were in the shade. She imagined Catherine would work late at university. Dominic probably got home first to the wooden villa they rented. How timber will choke poor Catherine, she thought. Like a forest, she thought, and the weather - if the house didn't get her the outsides would. Poor Catherine, she thought, Poor Kitten. All she would be able to do was work hard and late. 
23 Symonds Street 


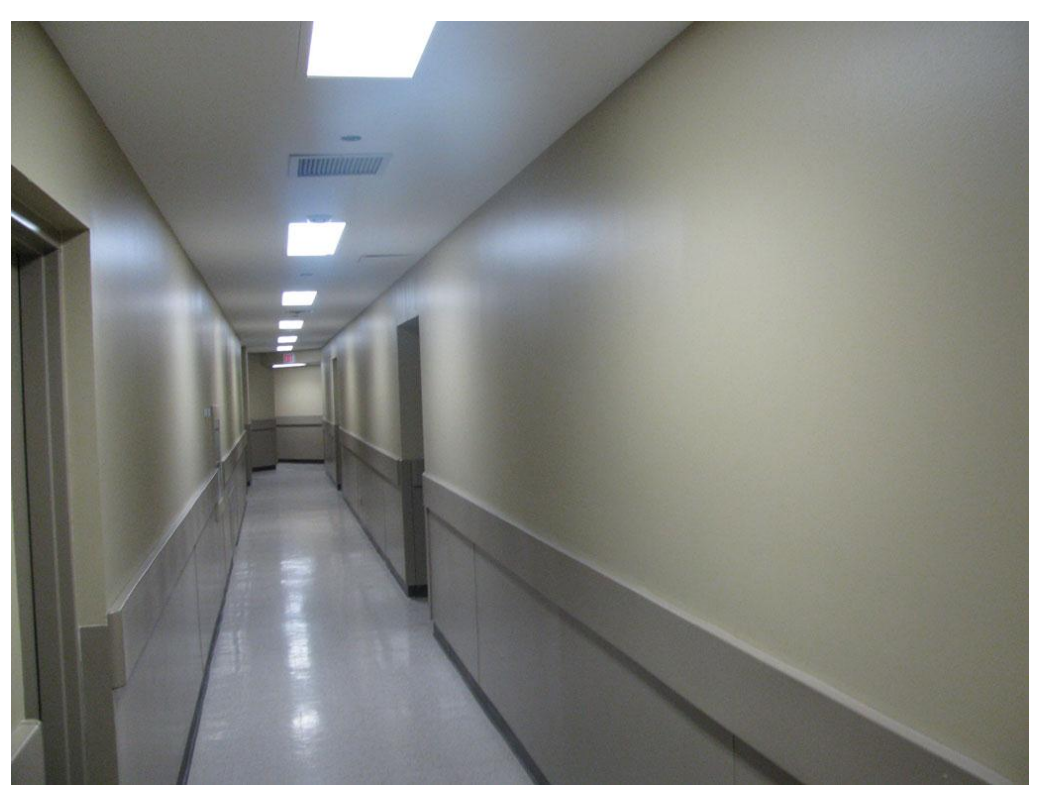


Needing a cigarette, he'd let himself out of the undergraduate workspace, out of the architecture department and then walked through the buildings to the street. He wished he could keep walking. It was April and he was behind. Anton had been behind all of first year and now he was behind again, working late again, by himself. He thought he was just going to walk to the courtyard outside the architecture building, but now he was on the street and now he was walking toward the engineering school, which terrified him. Somewhere inside himself he figured he had hoped it would - terrified him into working harder, but really it was just another diversion. He looked around, up, trying to get some sense of awe but he felt nothing. They were buildings.

He said he'd always wanted to be an architect and he had, but then the lectures started and he'd laughed, loudly, and everyone else was silent. He felt like a virgin watching pornography. He knew this went there, he got that it should be awesome, that it was awesome but he had no idea what he was looking at, not really. It was a disaster. He'd scraped through. At the end of the year he went to a course advisor. She suggested a couple of summer courses, to maybe segue into Art History. He lasted a week. He couldn't stand it. It was amplified in Art History. He tried English, and felt like he would rot away. History, Philosophy, he'd taken some Psychology courses as part of his first year. He looked around and around the university, then he started looking at technical courses. What was it he liked doing? That seemed to be the key but it was too late, he was so conscious of it now every time he did something, anything, he asked himself, 'Do I like this?' and it was gone.

He'd worked himself into a lather, his father said, when Anton finally talked to him about it - not the virgin pornography thing. His father still thought he was a virgin, couldn't imagine Anton had seen pornography. He'd posed it as a problem he was having about wondering if he should continue with architecture, considering his marks. 'Not everyone can excel,' was what his father had said, which Anton realised he knew but had always thought didn't apply to him and didn't seem to apply to this problem, because he was sure if he could just 'have sex' so to speak he could excel but his father knew very little about similes or metaphor or how to get the sex Anton needed and Anton didn't want to talk to him about that. So it went - round and round in his head.

He quit the summer papers and got a job selling sports clothing and equipment as one checkout assistant in a bank of many checkout assistants. There was always a sale, they wore $\mathrm{t}-$ shirts. Sometimes he masturbated in the staff toilets during his lunch break - silently, inwardly, trying to disturb and comfort himself, some kind of emotional aneurysm, but he wasn't even sure the problem lay there. He needed to break himself somehow, so he would wake up, after 
coming, after vomiting, after hitting himself hard enough, somehow altered in the world, but nothing changed anything. No end of trying to slap himself into shape changed anything. So he worked late and when that got too much he walked away from the architecture school, hunting exhaustedly.

He'd seen her from a distance, sitting on the steps of the engineering school, leaning against the column beside the step. She looked like she had her eyes shut. In his head she had her eyes shut, in his head at that moment, and in that moment as he made her up over the times over the years. She had her eyes shut feeling the forces of the building run through the column to the ground like some mysterious heroine grown from sperm spilt on sand, raised by foxes and once free of them, still pre-verbal, still tiny, displaying some innate engineering instinct, placing one rock on another over and over again until she had built the perfect structure, and the universe woke up and stretched. As he walked closer she came more and more into focus as his solution, his saviour. It made such perfect sense: an architect, an engineer - a female engineer.

He slowed his walk and began his approach. This was the last thing in what was, for him, a long list of last things. He knew it wouldn't work. He was behind, it was April. Soon he wouldn't care, he would learn how to pretend, to masquerade and be happy with middling marks and a middling career doing fit-outs for offices. Soon he would find other interests, things he really enjoyed that made him feel the way he thought buildings should. He knew this and right now he held on desperately to caring, to worrying and hoping that she was the last thing, and she held the key. She was asleep. He'd tried, quiet questions, coughing, but now he was pretty sure she was snuffling. He began to walk away. Suddenly she gave a grunt which made him turn before he thought about it and she was sitting bolt upright face open, looking around until her eyes met his. 'I fell asleep', she said. He nodded. She laughed and said, 'Fuck,' drawing out the word as she stretched her arms out wide, then high. 'I only sat down for a minute. Can I have a cigarette?' He gave her a cigarette. She must have been doing extra work, he thought, she couldn't be behind, maybe she was doing her masters, maybe she was a protégée. He walked over to her and gave her a cigarette. She smelled slightly acidic, maybe she was a chemical engineer. His hope was exploding like a star millions of miles away.

'Are you in engineering?' he asked.

'Yup.' She rubbed her eyes, palms in, the burning tip of her cigarette waving back and forward in front of her forehead and fringe.

'Chemical?'

'Structural.'

His heart grew - like she was building it up. 
'You?'

'Architecture.'

'Oh, long way from home,' she laughed, huffed, coughed a little, rubbed the back of her wrist.

'This is nice,' he said, waving past the Rec Centre at the square, concrete biology building across the road, surely it was a building engineers dream of. She looked at him, sideways, he could feel her. 'Solid,' he said.

'Do you like solid?' she asked.

'Yeah, it's brutal,' he said, now he was sideways looking, trying to look down across the road and back at her at the same time, she was wearing boots, and some kind of frock, it wasn't a dress. Her hair was long and black. 'It says what it is.'

'Do you like that?'

'Yeah, it's honest.'

'It's square,' she said, nodding her head.

'Yeah,' he said.

'It's a lab building,' she said.

'Yeah,' he said.

'It has to be square.'

'Yeah, like from its core.'

'Yeah, and because it needs large floor plates for all the lab equipment.'

'Yeah.'

'Columns and beams.'

'Yeah.'

'Bully boys.' She stubbed the cigarette out on the step beside her, ground it back and forth in a line. A panic raised in him, she would go - he didn't understand what the size of the floor plate had to do with the shape of the building. Couldn't the floor plate be large and round? A momentary calmness came over him. This, he thought, is why I am the architect and you are the engineer. He smiled, audibly laughed, then it was back. Why was the building so square? And almost to punish him for having to ask, all the squareness fell out of it, before his eyes, in his heart. It was concrete again - stone, not even stone, stone would have given it something, he felt nothing more for it than he felt for the plastic cigarette lighter in his hand, less, he could feel that in his hand. He noticed his face, how it would have looked to her, in those few moments and he couldn't look at her.

'Do you think it would help if we had sex?' 
He looked at her.

'This,' she waved her hand in front of his face like she was wiping something from a pane of glass in front of it. 'Do you think it would help this if we fucked?' She was laughing. Laughing at him?

'Hmm,' he said.

'Hmm,' she said. 'We could fuck in the square building.' She pointed at it, finger out back and forward, back and forward.

He hoped she couldn't see the effort on his face - to hold back the question, to stop himself from asking. To think only of the building, and the floor-plate, and her.

She began to rifle around in her bag, pulling out papers, and a purse and finally a set of keys. He wondered if he was even really there until she held the keys up in front of his face, rattling them slightly from side to side. He coughed, not for any greater purpose, his throat was blocked and he coughed to clear it. She leaned forward and he stood up quickly and she laughed, still sitting, then stood up too, saying, 'I knew, I knew.'

The street was empty and so was the road. They crossed it together. She led him up the short steep steps and, reaching the heavy glass doors, turned the key in a lock and let them in. It began to square again but this time like a grid of squares rather than one complete shape. Like the hall he stood in had been traced from grid paper in soft lead pencil to make it stretch to the door at the other end of it. Yet, out of this neat shape other spaces escaped - alcoves, corridors - he couldn't quite see them but they seemed to extend beyond the boundaries the building took up. He was sure she was singing something which sounded like, 'Column, beam, column, beam'. The space was what was hitting him. It was smaller now, chattering rather than declaring one clear word. He stopped when he thought he was in the middle of the building, where it felt like the dead centre of the length of it, and turned back and forth judging his position. He felt like maybe he was getting it but he didn't like it. It broke apart and the sharp corners bit at him itching, pricking. Was he getting it? Then he noticed her turning into one of the upsetting corridors and disappearing. He followed her, and when he rounded the corner was lost again. He didn't know where the street was, couldn't see the shape of it, he was in a small hallway which was rectangular, he told himself. It was a rectangle in a square made of squares, which rattled around unfixed because he couldn't tell where he was. He was in a hallway, linoleum-floored, with a ceiling of average height and average width. The ceiling seemed higher, though, than it had been in the foyer, like it had popped open. 'People like space,' she said, 'shelter and space,' she turned to him, still walking away from him. 'But you can't have both.' She tripped slightly and laughed and went back to singing. The hallway was narrow and high. 
All the time she was ahead of him, humming, not looking back, touching the walls every now and then. She was speaking to it. They were laughing at him, everyone, the plumbers, the engineers, the electricians, they could all see it. Around a corner and around a corner and through a door there was a dark stairwell and she turned and pulled him into the darkest part, under the stairs. He could see her smiling, every part of her - the muscles in her arms flexed with the lack of any kind of concern. She held him tight, he watched her every move like a spectator from a distance, like there were two of him, because it was going to happen at any second. She would open up somehow and all the secrets would come flooding out. He had her in his hands, she was soft. Then she shifted, unbalancing him and he moved his arm quickly to catch himself, brace himself against the wall, and the wall was hard and the stairs sunk and stretched above them all in reverse of how they usually were when he used them. Solid bending, he thought, but they'd been cast that way, when the concrete was wet and before it was this. She'd been on her way home from drinking when he'd seen her. When she was drunk, it seemed she would also rather sleep outside than eat the dinner Anton kept for her every night. Waiting. How was her day? How was her work? When she was drunk she would always rather fuck someone else. He could keep her but he couldn't have her. Poor Kitten. Poor Kate. Anton would never learn anything and he was inside her and what she knew was of no use to him and he didn't think he liked her and soon he wouldn't care and he came and everything ran cold. 
Te Puni Student

Accommodation 


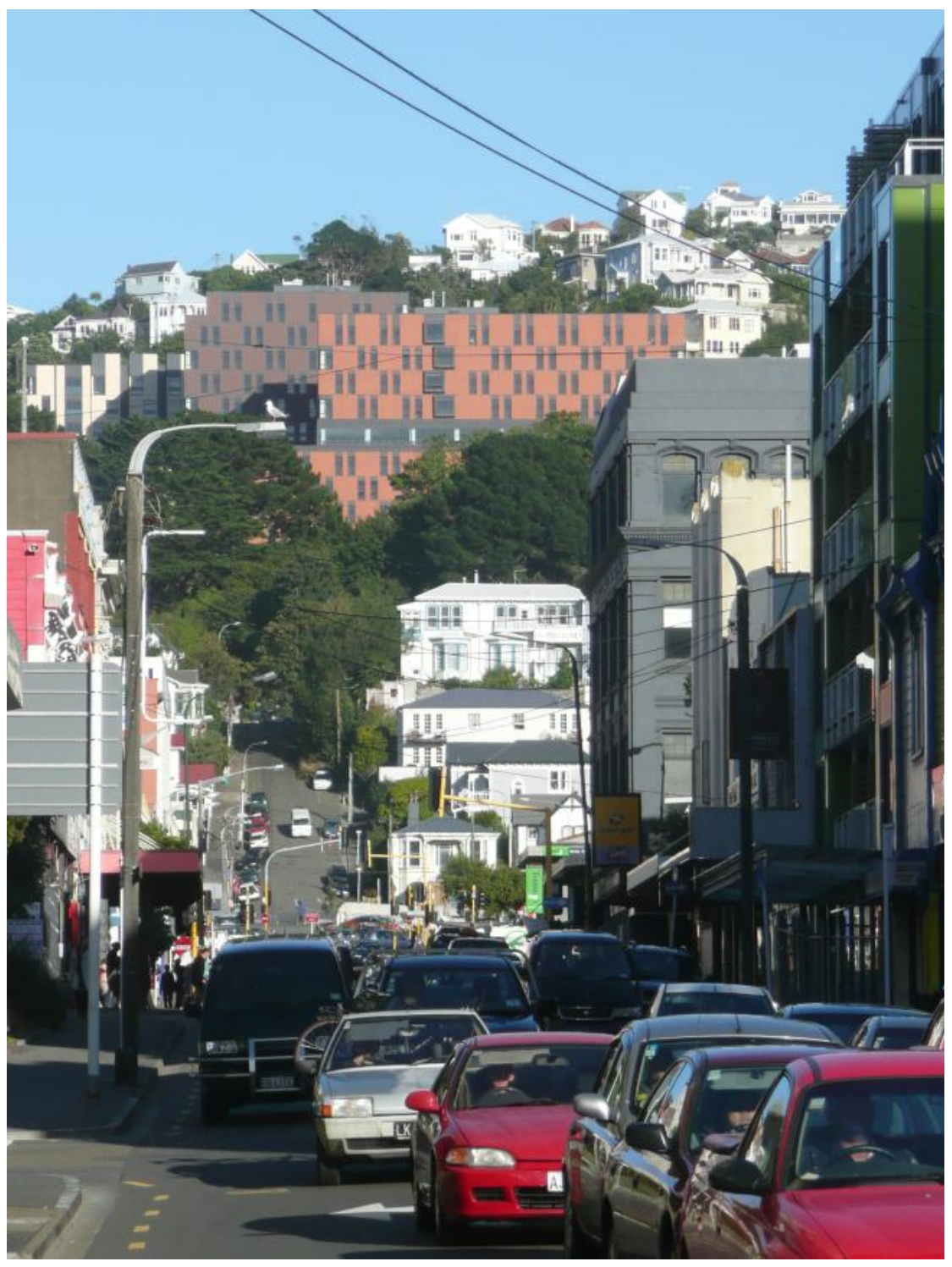


They lived there. Ate there, slept there, studied. They would talk to each other in the corridors, in the lounges. They watched television there, answered emails, received physical mail - went to reception.

The receptionist would need boxes behind her to reach into and hand the students mail they received.

'Write that down.'

They stayed in their rooms as well. Lived their lives and their other lives: social networking, shopping, playing games. Young people did that. They showered there, some of them had sex with some others of them. They shat there, pissed, vomited if they were ill.

They were ill there. Sometimes gravely. Sometimes they were gravely ill without knowing. Sometimes they were walking around dying. Other times they were lying down feeling dreadful and not very ill at all. Hardly anything to worry about.

They worried there, sat and thought long and hard about things, as if they could think them into being how they wanted them to be. They exercised there. Despite the gym close by, they put down a yoga mat, or not, and did yoga, or press-ups, or sit-ups. They lived in them. All three buildings: The Edge, The Tower, The Terrace. Stepping down the hill, he'd said, stepping down the hill, showing their worst sides to the city. Making a wall, so no one could see in, see the students living there. They looked little in it, when you saw them in the glass walled deck, in the floor without walls, from below them, as you walked between Te Puni on your way to the valley, or the playing field, or the indoor soccer pitch. The little people - they read books there long books and short articles and they asked each other about things. Formed study groups, one of them goes out for snacks, colourful soft things and brown crisp things, and drink that bubbles, in cans, that keeps them awake, as they look out over the city lights and try and remember torts and equations and management theory and art, some of them would work at trying to remember art. That's what they did there, and smoked, some of them would smoke cigarettes and some of them would play loud music and cook, they needed somewhere to cook.

Kenyon watched Anton writing it all down, desperately, someone would say it and he would write it down.

'And if an earthquake comes?'

'If. When.'

The students would need to move into each other's rooms. Some of them would go home. Some of them would die.

'Not in Te Puni.'

'Not in Te Puni but probably some of them would die.' 
'How many?' It wasn't important, some of them would have to move into some of the rooms - double bunk to make room. Or move out altogether. The shaking would hit the floorplates and the walls and the movement would over-ride the tension springs and the building would rock, things would fall down and people would be hit with books and desks and everything non-structural that wasn't tied down and the lights would go out, the halls would be grey and lifeless, then everyone will run.

'Remembering Napier.'

'Remembering Tokyo.'

'The Twin Towers.'

Everyone will run, except the Fire Wardens who will find their hard hats and their vests and shout, 'Stop running,' loudly and hoping others would say it too: 'Stop screaming and stop running.'

So, eventually, Te Puni will be empty and then the administration will move in. The university had to go on eventually. The library will still be standing but the space frame would be gone.

'It's going.'

'Really?'

'Yes.'

'I'd love to be there to see that crash to the ground.'

Decisions would need to be made quickly about exams. Would there be exams? Would there be exams when there were supposed to be exams? Would there be exams in Te Puni? No one was sure, but there would be meetings and the search and rescue teams would need somewhere to stay. And the engineers - while they were assessing the city. And the builders from out of town.

They weren't going to shut up for a long time. Kenyon looked at Anton. Anton had worked for him for eight years, six and a half years longer than anyone else. Kenyon knew Anton had seen it all before. They would talk and talk and shout and get excited and then in a couple of week's time, the fit-out would look exactly the same as any other student accommodation in any other city in New Zealand, possibly the world, but Anton kept writing. There was a digital recorder on the table capturing it all, Anton just wrote because he couldn't stand being in any way involved. Kenyon could tell. In the beginning, before the excitement, he'd called on Anton, but the other architects were standing up now, walking back and forward, drawing on the whiteboard. It was all unfolding, alive with possibility. The fences were down but there was nowhere to run. Kenyon wished Anton was writing something else down, something 
vigorous and awful. Te Puni standing after the apocalypse, in the darkness, under a red sky - ash floating. Kenyon liked to think that Anton thought about Te Puni being there after all of them, by itself, useless, pulled down eventually by vines - that this gave Anton some kind of rise, anything. It was well after lunchtime. They were nowhere near finished. Kenyon had no idea why he did it, why he didn't just get Anton to draw up the plans, the same old plans from the start.

'This is good,' Kenyon said, and nodded, everyone in the room looked at him and was silent. 'This is very good. I think we should keep this going.' Kenyon wound his hands round each other to show 'going forward' then he stopped and looked at his watch, 'But I think we should get some food.' Kenyon stood up. 'Anton and I will go and get some lunch, you all keep going and when we get back we'll break for a bit then keep going. This is good.' Kenyon had his jacket half on. Anton followed him out of the office.

'Do you need a jacket?'

Anton grabbed it from the back of his chair.

It was wonderful outside. Anton had to stop himself from raising his face to the sky, or closing his eyes in joy. It was fresh but the sun was out, he couldn't believe his luck. The wind blew slightly, he did the buttons up on his jacket. It was magnificent.

‘Are you taking notes?' Kenyon asked.

'Not comprehensive ones.'

'We've got the Dictaphone though.'

'Yeah, Sarah can type it up if you want.'

Kenyon looked up ahead of himself. 'Yeah, Sarah could do that pretty fast.'

Anton nodded.

'Maybe you could start the drawings tomorrow.' He looked at his watch again. 'Maybe even today, maybe we'll be done before today.'

Anton nodded, the sky was laid out over them. Blue, puffs of white cloud, glorious.

'It's probably going to end up pretty regular, isn't it?'

Anton nodded.

'Fucking student accommodation.'

Anton nodded.

'There's so many fuckers to please.'

'Mm,' Anton said.

'We'll be right though. You start the drawings and we'll have something to show them in a couple of days.' Kenyon reached out and held Anton's shoulder, buoyed him, consoled him, 
this dirty business, these boring clients. Was this why he did it? He was the boss, he could do whatever he wanted. 'What shall we get for lunch?'

Anton shrugged, 'We could order in some pizzas?'

'Yeah,' Kenyon looked behind him, 'but we could have done that from the office.' He was looking all around, he didn't come out much on foot during lunchtime, and everything around the office had changed. 'Was there a bakery round here?'

Anton looked around too, he couldn't remember a bakery. 'There's that café,' he pointed to it, shielding his eyes from the sun with his hand.

Kenyon looked at it, the people coming and going with brown paper bags and re-useable cups. 'Yeah, that could work.'

They crossed the road together, there wasn't much traffic. The block was mainly occupied by high-end furniture stores and design offices. The ceiling of the cafe was high, and all the edges were hard, it rattled and banged loudly. It looked like every other cafe in town. 'What are these?' Kenyon said, looking around at the branding.

'There's a few of them.'

'Why are they all so noisy? Jesus, what would it take?'

'Carpet?' Anton said. 'Baffling?'

Kenyon looked at him, he was serious. Anton was always serious - as seriously looking at the counter food and the blackboard as he would a floor-plan as he would a holiday picture or an execution. Kenyon wanted to knock at his head, like it was a nut. He wanted to ruffle his hair, like they were in a commercial for some old man, young man bonding product. He felt that old. They had the same trousers on though. 'Have you worked out what these are for?' Kenyon twisted slightly to point out the zips that were in the side-pockets of the black linen trousers.

'Huh,' Anton turned to look at Kenyon twisting from one pocket to the other, smiling incredulously. 'Oh.' Anton shook his head.

'Like my change is going to escape.'

'I guess if you were on your head for some reason.'

'Cart wheels?'

'Trapeze?'

Kenyon was a good boss. 'It's not useful,' he said.

'It's beautiful?' Anton tossed it into the middle of them. Not really expecting it to float, he might have even shrugged as he said it. They both looked at the zips on their trousers for a minute.

'We should have a beer,' Kenyon said. 'Do you want a beer, Anton.' 
Anton looked out at the tables on the street. 'Yeah, let's have a beer, I'll shout.'

The beer was cold and served in tall tumblers, neither of them had their sunglasses and Kenyon only had his dress jacket but Anton shouted, then Kenyon bought the next round, then Anton got the next. Kenyon ordered some pizzas on his cell-phone for the others. It was a beautiful day. The sun got low though.

'How far is it to Te Puni?' Kenyon said, lazily, happily, he wanted something to happen.

'Huh?'

'How far, from here?'

Anton shook his head, 'An hour's walk?'

Kenyon nodded. 'Do you know what I like?'

Anton shook his head and sipped his beer.

Kenyon thought quickly, 'I like the Massey Memorial.'

Anton nodded, 'I like strippers.'

Kenyon laughed into his glass. He looked at his watch, the time had passed. 'Do you think they've left yet?'

Anton nodded.

A woman with a blunt blonde bob collected their glasses. She was wearing a collared shirt and when she leaned forward Anton saw the tiny, symmetrical beaks of two birds tattooed on her chest. Shouting at each other.

Anton drained his glass and collected his cell-phone and wallet off the table. 'They're probably closing.'

'Did you sleep with Catherine?' Kenyon wanted something to happen.

'What? No. What?'

'She seems to hate you like someone who's had sex with you.'

'She doesn't hate anyone.'

'Not me. She doesn't hate me.'

'She doesn't hate anyone,' Anton said.

'She really hates you though. She's so reasonable with everyone - polite. But it really shows with you, the seams start to stretch, on her whole being polite thing.'

'You're trying to flatter me. I don't even register to her,' Anton said.

'Nah, I can see it. You should sleep with her.'

'I'm married.'

'Take the bull by the horns.' 
'Nice.'

'She'd go.'

'Ah?'

'I reckon she'd go. She's got nice hair.'

'Maybe you should sleep with her.'

Kenyon looked across the road narrowing his eyes slightly, like there was more glare than there was.

'Have you slept with her?' Anton said.

Kenyon smiled at him. He really wanted something to happen.

Anton's face pulled slightly. Kenyon was sure he was thinking about it, putting it all together, how great a boss Kenyon was. 'I've got her number.' Kenyon took his cell-phone out of his pocket.

Anton wanted to leave. 'What could I have done?' He'd say to Alice when he arrived home smelling of beer, happy, well after the kids had gone to bed. 'What could I have done?'

'I've got her number.' Kenyon turned on his phone.

'So have I,' Anton said.

Kenyon smiled.

'We've all got her number, she's our fucking engineer. Jesus, Kenyon, she's an engineer.'

'She's a hot engineer, Anton.'

'So's Michael Winter.' He hoped that would end it, lift it. A few jokes about Anton being a big poof, then home, maybe not home, maybe out for a burger and then home, but without Kenyon. He'd put him in a taxi.

Kenyon nodded and raised his eyebrows.

'Have you slept with her?' Anton asked, not looking at Kenyon. 'Does Jacqui know?'

'What can I say?'

'No? You could say no. I'm just having you on.'

'I'm just saying.'

Anton shook his head and laughed. 'Come on, Kenyon, I'll get you a taxi.' Anton rang a taxi and it arrived and Kenyon went to get in it and then got out again and took Anton's arm and shook his hand. 'I'm glad we did this.'

'Me too.'

'You should sleep with her.'

Anton shook his head and smiled.

The taxi went round the water. Kenyon imagined he could see the memorial. It was the 
first thing that had come into his head. Wellington was all so low, so safe, anchored down, base isolated. He should go up there, now. Get the taxi driver to drop him off across the road, walk up the narrow path, in the dark, his eyes would adjust, or maybe they wouldn't, maybe he would have to feel his way up, in the dark, but the marble would shine, he was sure of it. It was Kairuru marble with a base of Coromandel granite. It had been designed by some Auckland architects. Seven columns in a semi-circle, white, shining, he was sure in the moonlight, in the darkness, illuminating themselves. He was sure. Still cold, in the heat of summer and tonight, in the cloudless autumn. Our Rome, he thought, and laughed at himself at everyone in New Zealand. It was stone from Nelson, it was only eighty years old, probably not even that. There had been a gun pit there, to keep Wellington safe from invaders. Anton didn't realise he was still able to change everything. How could he? He would, though; Kenyon said it under his breath, to himself, to Massey. He got his phone out of his jacket pocket. 'You could have her,' he wrote and then he sent it to Anton. 
18 Esk Place 


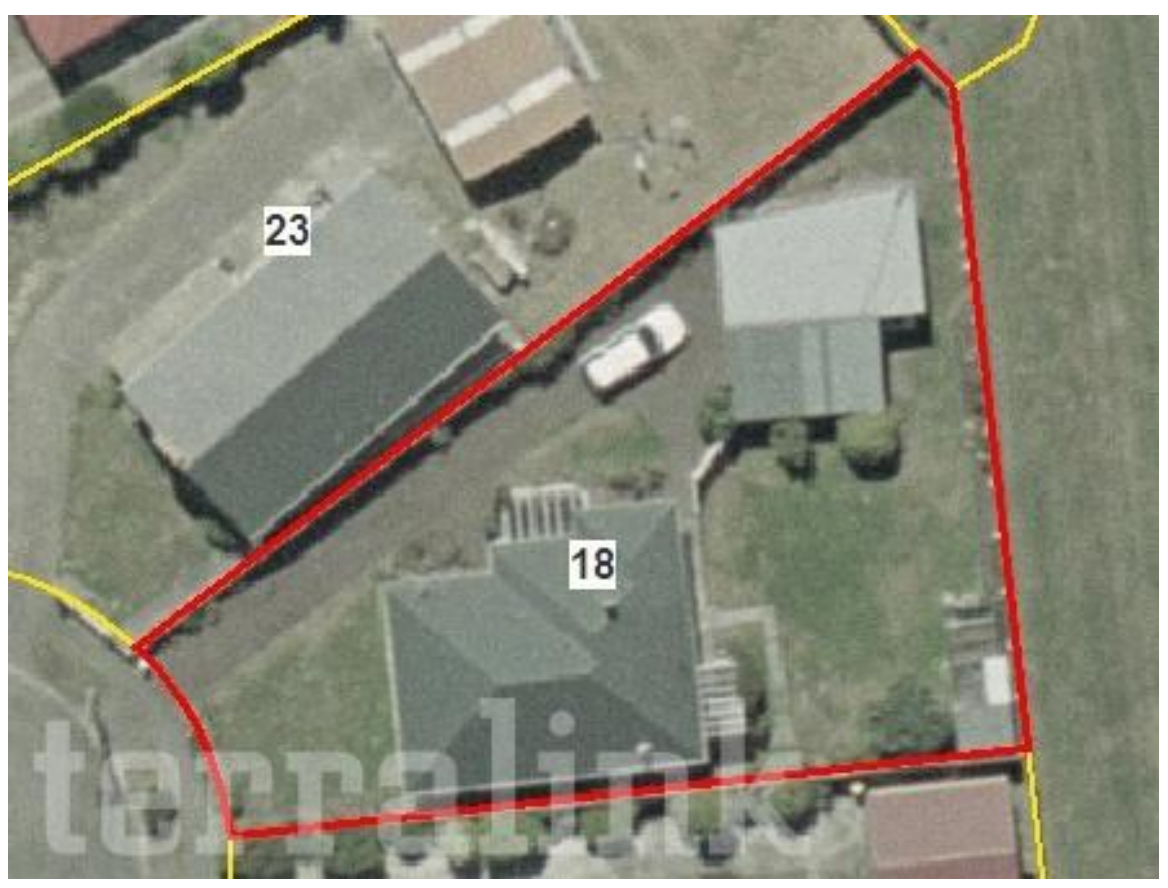


It's a two-bedroom square house in the suburbs with a large garage at the end of its long driveway. The section is flat and flanked on two sides by a short hedge, there's a gate to Bexley Park. It's a perfect property for children and pets and well suited to young professional first home owners.

Catherine comes out of the bedroom where she and Dominic sleep. Dominic was in the kitchen, leaning, both hands down on the bench, looking out the window which, in the dark, meant at nothing but his reflection looking back at him, then Catherine's reflection behind that, which he shifted his eyes to watch. She was dressed and he was dressed. He started out early each day, so he could go to the gym before work and get a park. It was a good house for a normal life.

Catherine opened the plastic clip on a bag of frozen bread, reached in and, hand stretched, worked a single slice apart from the others then put it in the toaster and the red elements glowed.

'Are you going to eat that before we go?' Dominic said into his coffee cup.

Catherine nodded, 'Or in the car. It won't take long.'

Dominic nodded and poured the rest of his coffee into the sink. The cup was white and had a small black cat on it, beside a coloured ball. The toast popped. See? Catherine waved the toast around as she went to the refrigerator and cupboard and another cupboard, until she found what she was looking for. As she buttered the toast she balanced on one leg and tried to pull the back of her sling-back shoe over her heel. Dominic wasn't sure why she bothered. There were buses every twenty minutes. 'You're cute,' he said and kissed her as he went to the door. 'Oh, are we going?' she said, fumbling the lids back on jars, wiping the crumbs off the bench with one hand into the other.

By the time she scooted into the passenger seat of the car she had butter and jam up one of her cheeks. She put the toast in her mouth and zipped up her bag. Dominic warmed the car up, to reduce the wear on it. 'All set,' Catherine said, sitting up and reaching back for her belt. She smiled at Dominic and he smiled back and rubbed the side of his face. 'Such class,' she said, pulling down the visor and rubbing her cheek like a child in the mirror.

They talked about their days on the way, laughed a bit about one of Dominic's clients, put on voices. Catherine sang along to a song on the radio. 'I love this.' She got all the words wrong and they laughed again. 'Primo.' They got a park in the building close to both of their offices and next to Dominic's gym. Catherine was pretty sure they could leave home later and still get a park but it was good to beat the rush and this way Dominic could have a nice long shower. It was still dark and their breath showed. 'We need our hats,' Dominic said. Catherine 
agreed, she had the bottom part of her faced tucked into the collar of her jacket so only her eyes were showing.

There was loud music in the gym and bright lights and it was warm. Catherine loved how warm it was, she squeezed into Dominic's side with a quick hug. When she was in Christchurch this is how it was. They owned two properties now, an apartment in Wellington and Esk Place. They had two cars. It made sense. The project had gone on longer than Catherine had anticipated, then the next project had started, then the next. It made sense. Christchurch had come as a shock to her, Dominic had to admit. His promotion had come through and he'd had to make the decision quickly - that day, right there. His father had pulled some strings and got her a better job than she would have got in Auckland but she'd never fully settled in Christchurch. He'd never offered to relocate but neither had she. The work in Wellington was more suited to her and they talked every night and when they were together it was like she'd never been away. They never surprised each other, they respected each other and when it was important to either of them the other was there.

'Okay,' Dominic said. 'Lunch?'

Catherine pursed her lips and looked to her left then she held up a finger theatrically and pulled her diary out of her bag. 'An early one?' she said.

Dominic thought for a moment. 'Eleven?'

'It doesn't need to be crazy,' Catherine said, still looking at her diary, her finger on the page. 'Quarter to twelve?'

'Yup.'

'Yup,' she kissed him. 'Happy gymnasium.' She turned to leave.

Dominic called her back, 'Oh, are you here Thursday?' Catherine turned around, eyebrows raised. 'Thursday. Are you here on Thursday?'

Catherine shook her head. 'Sorry, Wellington Thursday and Friday.'

Dominic nodded. 'What time are you away today?'

Catherine walked back to him. 'Three today, but I'll see you at lunch.'

'Did we say lunch?'

'Yeah, does that work?'

'Argh, it's Wednesday.'

Catherine smiled and nodded.

'No, I can't do lunch today. Fuck. Sorry. I'll say goodbye now.'

'I'll call you tonight.' 
She caught an earlier flight to Wellington and when she arrived at the office everyone was in the board room doing the DomPost quiz. She went to her desk and soon William was there.

'Did they kick you out?' Catherine said, not looking up from her computer.

'No.'

'You're a liability, William.'

'There are never any questions about moment resisting frames.'

'You need to get out more.'

'It's probably too late.'

'Probably,' she said, opening her email. 'Oh, damn.'

'Dixon Street?' William said.

'Dixon Street.'

'Anton,' William said.

Catherine said nothing.

'He knows,' William whispered.

'He doesn't know,' Catherine said, packing up the things she needed. 'And neither do you.'

'And neither does Dominic.'

She looked at him. 'There's a line,' she said.

'I'm only saying what you're thinking.'

'I'm not thinking that.'

'Michael put you on Dixon Street cause he knows,' William said.

'Or, the building industry in New Zealand has a very small population and it's a coincidence. And a long time ago. And we're all grown-ups.'

Everyone started coming back from the board room. Phones started ringing as the receptionist put through calls.

'Yeah,' William said, disappointedly, 'you're probably right.'

'I've worked with him before,' she said, 'when I was in Christchurch. He does a lot of fitouts.'

'You're still in Christchurch,' William said.

Catherine leaned over him to reach a pen which was on his desk. When she was low and close to his ear she whispered, so no one else could hear, 'And you're still a bitch.'

'I've said it before and I'll say it again. It's a miracle there's only one architect.'

'Cock of the walk,' Catherine said.

'One so far,' William said. 
'It only takes one to put you off all of them,' Catherine said. 'Don't get your meat where you get your bread.' She looked around her desk to check she had everything, 'If you're going to get meat, that is.'

'Elegant,' William said, and he waved her away.

Anton saw Catherine signing in at reception. He was sitting at his desk looking at a floor plan, shifting things about at the last minute: walls, doors, desks. They had a meeting with Kenyon. She walked toward him. Over the years he'd seen her. Along the way he was sure private things gave her joy and pride but what he'd seen from a distance was Catherine becoming very, very good at her job and that was all he saw of her joy and her pride.

'Hello,' said Anton.

She said, 'Oh. What? Oh. Hello.'

'Hi,' Anton said. He looked back down at the plan.

The building had been retrofitted, for earthquakes. There were large K-braces at intervals along the floorplate. You could put a desk beside them but only at a certain angle and then only if you could guarantee the person working at the desk would always look up before they went anywhere, didn't read a piece of paper as they stood, or call out to a co-worker as they walked away. It was hardly his problem but he thought about it. Anton's problem was the board room. The place for the board room was the open floor between the two central K-braces. The obvious thing was to stand glass partitions as close as possible to them at either side, so it looked like they were there to frame the glass. Anton's job was mainly the obvious thing but he just hadn't been able to stomach it, lately.

Kenyon, opened the door of his office and leaned out, 'Anton,' he called. Catherine was looking at him too - briefly as his name was called.

'Yup,' Anton said. He ruled four lines on the plan, rolled it up and went to the office.

'Is this the last floor?' Kenyon said, not looking up from the plans he and Catherine were standing over on the desk. He was talking to Anton.

'Yup.'

'We're behind,' Catherine said. Anton noticed the cuffs of her jacket were slightly too long. 'But we'll make up time on the utilities fit-out. The contractors are well on with the other floors.'

Kenyon flicked through the large plans on his desk, then held out his hand for the plan Anton was holding. Anton gave it to him and walked toward the desk. Catherine pushed a corner of the plan to hold it flat, her small fingers stumpy under the jacket cuffs. 
They all looked at the plan until Kenyon said, 'Is this the board room?'

'Yup.'

'Is that a K-brace in the middle of the board room?' He was looking at Anton now, he didn't want to be but he was, agitated, mystified.

Catherine adjusted her position, she moved Kenyon's finger so she could see. 'Oh yeah,' she said, smiling.

'For fuck's sake,' Kenyon said. This was not what he'd meant.

'Yup,' Anton said, he wasn't smiling. 'It's a feature of the boardroom.'

Catherine put a hand over her mouth and looked away from the plan.

'A feature no one can see past,' Kenyon said. Catherine was laughing now, he could see her. Laughing at Anton, like she owned the place.

'Expressed structure.'

'Anton, put the fucking board room in a clear space and then send the plans to the contractors.'

'Yup.' Anton rolled up the plan and left the room.

'Hold on,' Catherine called out, 'Anton.'

He came back just inside the door, twisting the plans in his hands.

'That desk,' she took the plan off him unrolling it in the air. 'This one,' she rolled it smaller so she could hold it with one hand and point with the other, 'Can people get up and down from that desk? Jesus Anton.'

'You fuckers put it there,' Kenyon said. 'They'll just have to hire short people. Change the boardroom and send it out.'

Catherine followed Anton out, carrying the plan. He would make her up every so often, when she came to mind - when he saw her name somewhere, when they were in the same room - he made small pliable models of her which he carried through the rest of his degree, through his marriage, through the birth of his children, she could tell. He'd kept something of her to make her up with. But she wanted it back now. He'd had it long enough and there was no need for it because she suddenly felt she was finished. 'You have to do something about that desk. I don't care what he says.' She followed him to his drawing board. 'That desk isn't going to work there, it's too close to the brace. Is it like that on every floor? How can we get utilities to a desk that close to the brace and how are people going to get out of the desk? Andrew?'

'Anton.'

'Whatever. Anton. You need to change it, it needs changed, change it now.'

Kenyon shouted something from his office that no one could hear. 
'Fuck you,' she said. People were looking, she lowered her voice. 'Jesus Anton.'

Anton wished it wasn't about the desk. He wished they were fighting about something else.

'No,' Kenyon came out of his room now, to make himself heard. 'Change the boardroom. Send the plan.'

'Fuck Anton,' she looked at him. 'You present uninspired, shitty work over and over. Have some fucking pride.'

'You fuckers put it there,' he said.

'What the fuck does that mean?'

'You put it there. Talk to me about being uninspired - they call you K-Brace Incorporated. Can no one in your firm find any other seismic solution? Eh? No, no I think everyone will find that you cannot. So don't come in here and tell me about uninspired and lack of flair. You're a fucking engineer - go engineer something we can use.'

He wanted to give it back now. He wanted no part of her. She saw him look around at all the dullness and at her and behind his eyes she imagined he came to the conclusion that this was his finest hour.

'You haven't got a clue what I can do,' she said, and as soon as she said it everything she could do came to mind.

She cancelled both of her Thursday meetings and organised a late night flight home. She didn't call Dominic. She caught a taxi to Esk Place and quietly went in. When she opened the bedroom door he was with a woman she recognised as Honor, and so it was. Catherine punched the wall and as Honor scrambled for her clothes smashed a large mirror over her back. Dominic rushed to pull her off Honor and she punched him, spitting as he reeled backward, holding his face. Honor ran from the room naked and Catherine could hear her calling the police. Right then and for years Dominic thought about the injustice of it. For all the years of bullshit - the nights she arrived home drunk and smelling of sex and concrete. All the times he could hear her laughing at him from another room. For all that, Dominic thought, It should have been me walking in on her. Me getting the free pass out.

'But it isn't,' Catherine shouted at him through tears.

He watched as everything he'd built crumbled in front of him. 'You fucking slut,' he shouted at her.

'But it isn't,' said Catherine.

She was so smug and she deserved to be, everyone said so. Everyone except Honor. The 
police took Catherine away while she shouted out vindictive platitudes, so the neighbours could hear, so everyone could see how it wasn't her fault - how she was the wronged one. In the dark and the audience of the quiet neighbourhood Honor put her arm around Dominic and said, 'You deserve better. You've always deserved better.'

The next day she got a call from Michael. Craig was taking over Dixon Street. He was new, he needed something straightforward. There were several openings, which project did she want? She knew straight away and when she told him, he didn't say, 'Are you sure?', he didn't hesitate at all, he just said, 'Okay.' 
Rankine Brown 


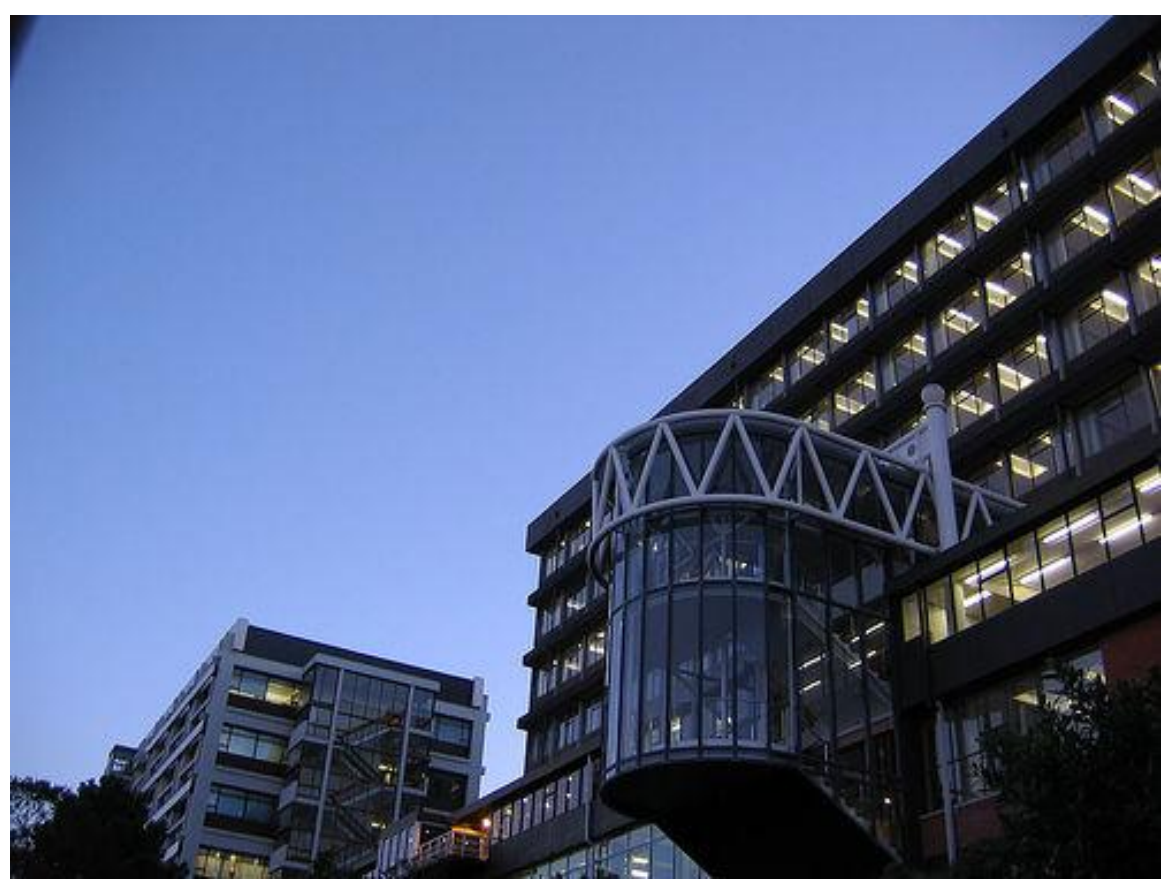


No one entering the building looked up. A long shot across the second floor showed them though - the relatively deep ceiling recesses at regular intervals, like a large child lying on its back pushed rectangular forms into the concrete as it set. Students and librarians are busy at work under giant, empty ice trays, the light plays into the hollows. People like space. They like to be warm and dry and safe but they also like space. They want to feel like they're outside when they're inside. No one likes low ceilings or an excess of walls.

The waffle slabs act as broad, reinforced concrete beams which run to sixteen main columns. Steel reinforcing bars run in north-south, east-west directions through the slab. The concrete in between these reinforcing bars was removed to create a two-way concrete joist system but no one looks up.

'Is it dreadful?'

Catherine turned from the computer, taking out one of her earphones but keeping her eyes on the screen. 'The building looks good, there are some nice shots of the waffle slab.'

'Wait until you get to the bit about lower insurance premiums,' William said.

'Don't ruin it,' Catherine yawned and stretched but still watched her screen.

'You should watch it tomorrow.'

'I've only got until tomorrow.' She paused the video.

'And you've had it for weeks.'

'And I've had it for weeks.'

'And you can't come for a drink with me?'

She shook her head, starting the video again.

'And I should leave you alone?'

'And you should leave me alone.' In the screen, reflected into the round face of a librarian, she saw William walking away, putting his jacket on. He turned out most of the lights in the office, then the light above Catherine, then turned it back on again before it had fully finished stuttering off. The office was empty. There was only the librarian now. No ghosts. Catherine rubbed her eyes again.

She wished they'd designed the waffle-slabs, wished she was fact-checking some clickety old super- 8 of the slabs going up. A man in a suit, maybe he'd be smoking. Hand-drawn diagrams of the height, the light, the span, the sharp end of the pen that drew it, the place where the draftsman pressed hard, then lighter, something outside catching his attention, or he'd sneezed. Catherine put her hand out and covered the librarian's face, so she could feel the fuzz come off the screen, she turned her hand over and over, felt the synthetic material in her shirt snap at it, like scrapping. She looked at the tiny split of a scar in between the knuckles of her 
hand. Every time she looked at it she could feel her elbow, the slightly new shape she'd made it, the way the ball didn't quite return to the socket any more. Like she was Hephaestus. She laughed, remembered the neighbours' faces. 'What am I? Hephaestus?' If she kept at it she could make herself scream, if she thought long enough about it her brain would storm and she'd feel dizzy - her stupid slapping, their faces, naked, her stupid shouting, punching the wall. No one got away as cleanly as she thought she would. She looked behind her, there was no one there, it was hours until morning. She paused the video again, wound the cursor back past the long-shot of no one looking up to the screen of white letters on black, SEISMIC RETROFITTING 'EARTHQUAKE PROTECTION OF A LIBRARY BUILDING WHILE IN USE'.

They'd inserted seismic isolation units at the base of the sixteen main columns so that in the event of an earthquake the return period would be lengthened and therefore the shake Rankine Brown experienced would be less intense. Metal props on hydraulic jacks were placed around the columns, at their base and on the three floors above. The supports were raised until they took the weight usually experienced by each of the columns. They'd estimated the total weight of Rankine Brown at between 800 and 1000 tonnes. As they lifted the jacks a small horizontal crack would appear in the column as it shifted from compression to tension. Instead of shrinking under the pressure of the building as it had always done, it hung from the slab above it. With the column free of its responsibilities the thread of a diamond saw cutter could be wound round the base of the column to cut it through. A camera crew had caught it all. 'Our patented seismic isolation units,' the voice-over said.

She'd been asked to check the promotional video before it was sent out. The librarian again, saying the retrofit project was relatively unobtrusive. Students taking books from stable shelves, working at computers and reading at desks. The librarian's cheerful voice, the students happy, the staff happy. Catherine had been there during the cutting. The librarians had put signs everywhere offering students earplugs which they could collect from the main issue desk on Level 2. They didn't work. People mistook the vibrations for sound but it was a subtle returning shake. It was almost imperceptible on some floors and in some parts of some floors but it was there and would have been impossible to place if you didn't understand it. It felt like an illness, like seasickness perhaps, and the students would go to the main issue desk and ask for earplugs and the earplugs would just lock the shake in. It came out of the students' pores because that's what waves do, keep travelling, but eventually, the diamond saw would complete a cut through one metre of concrete and steel leaving a clean, wet gap, separating the base and the column with a sort of pop. The students above feel strange in their sea-legs, then solid and surer but then it all begins to shake again as the men below begin the second cut a metre up from the first. 
This time the students check their chairs, the fittings around them and each other. They read the sign again, trying to believe it is sound until the second cut is complete and they feel the absence of it, in their bodies and they take out their earplugs.

There's a shot of the saw being threaded through a small hole drilled through the corner of the column. Then of the contractors checking the metal supports with spirit levels. Plumb. There's a rhythm to it all, the heavy work, an almost physical telepathy with the cutting, the raising. Catherine had watched several of the columns cut, stood just behind, checking the containment of the dust, the path of the water. Supervising the contractors, shouting, 'Hang on,' when she had to, stopping everything in its tracks, feeling the concrete dust dough in her mouth despite the containment and the masks, flicking it off her trousers, stomping it off her boots. Then, when everything looked right to her again, 'Okay!'

They were all standing very close as the whine started up and one of the contractors had shouted to another, 'Can she hear us?' And the other man replied, 'If she can, we'll know.' Catherine had just got back from Christchurch, from Esk Place, from the ranting and the being big. She hadn't slept, despite being right, completely right. She'd told the lawyers not to call her at work, she was busy. The concrete dust got under her wedding ring - she would decide when it was over. Rankine Brown was floating. There was a pop. She felt it lift under the pressure of so little downward force. Almost nothing. Like lightness was entering it from every direction directions that hadn't existed an hour ago. And the lightness came into the spaces that had always been there. The hollow floors. Air. Light. The concrete in the columns opened tiny porous gaps out of which escaped dust, adding to the lightness in infinitesimal and acutely noticeable ways. Giddy ways. The steel, embedded deep in the concrete, lay suspended and barely stressed. Was this some slow creeping explosion? It steadied itself slightly. Catherine saw pressure, in the corners, on several storeys where the forces fell out, washed out, fell, and from here down Rankine Brown was free, hanging now but with the promise of walking, running. An elevator arrived on the seventh floor. A live load transferred into the slab half to the west, half to the east, travelling along broad beams into columns. Each column took its share and the load travelled down and down and in one column was gone. Lost to it, all in a split second. Catherine looked up and through. The slab above the hanging column was four millimetres higher than the rest. It puckered, the other slabs shrunk around it, three point nine-nine, three point nine-eight. Catherine watched the men move the diamond drill, she moved to see it closer, and when they looked at her she nodded, sending the waves into the floor plate and up and up so it ran everywhere, shaking all the students and all the librarians and her and Rankine Brown until they were through. 
Catherine removed her mask and wiped her face. One of the people from the film crew was talking to one of the contractors, waving his arms about a bit, the contractors pointed at Catherine. As many people as possible got out of the road so, now, it's just a shot of the cut section contained in the specially designed cradle aligned with steel runners. The tonne of concrete slides out, you can just see one of the contractor's legs behind it, pushing, then a second contractor walks in to pull. No one says 'Ta-da!' but it's the moment the magician slides his assistant's mid-section out from inside her. The whole process looks like dentistry in the video - clean, ordered, easy. The base isolation unit is fed into the gap at the base of the column. Cut to close-up. Cut to mid-shot. It's fixed with grout and bolted into place, separating Rankine Brown from the earth and the rock and the plates and a blonde woman reads a book under the waffle slab roof.

Catherine writes an email, 'It all looks fine. Nice work.'

It's quiet and cold outside. She walks down Willis Street, Dominic and Honor asked her to leave the Wellington property. 'Fine,' she said, 'fine.' She'd rented an apartment on Webb Street, bought new things as she needed them, things she'd always meant to buy but had been too busy to get: a decent can opener, sharp knives, a couch she could sleep on. She'd be fine. She looked up at Rankine Brown on the hill, couldn't help but, all freshly isolated. She slowed and stopped and turned. They'd done an amazing thing. They'd broken it and held it and fixed it again so that it could be different. She watched it, on the hill, lights lit, from here she could almost see how the others saw it - in pictures, in pretend. She tried to look at it like they would, tried to give it eyes, a mind. It heard floating now, it was free from the ground. 'Can she hear us?' Voices came and whispered, Skating and Flying and Catherine watched Rankine Brown hear bigger. Saw it go somewhere bigger, somewhere so huge Rankine Brown was small in it. A town that got out of town. Some place where all the miles have dissipated and there's no law except feelings and stories. Shell structures billow out, as they free themselves from their tension rings and become flat and slide under things. Tension structures slowly snap everything holding them to the ground. The centenary cables recoil slowly, deliberately and the tents float away. Rankine Brown under a sky of tension structure clouds and over a sea of shell structure, Now like fish,' they sing. 'Now like fish.' And why would she go home? Rankine Brown spends more and more time in the big place, the place where not one of them needs to stay what they are until one day she meets a large structure with a domed roof, it asks her who looks after where she is? Where she really is. He's older, regular, he stays gravity loaded. He stands, he says, because of gravity, not in spite of it. She discerns it immediately; un-reinforced masonry, each brick held in place by 
the weight of the one above it, in smaller and smaller circles until it all stands, falling from an opening in the apex of the dome. He's grateful, he says, so he comes here, keeping his shape to show his gratitude and talks to others, and he's seen her here a few times, floating, moving freely and he thought to himself, when he woke, back in the embrace of forces, he thought, Who is looking after where she is and he thought, I will come back to this place tomorrow and ask her. He stands at once in front of her and around her and under her. This is how it is here. He holds his shape but not his position in space, not his size, or his orientation and that is how he asks his question, by enveloping her. She is not sure if she will reply, if she can reply. He's closer - closes in on her and says, don't worry, just go back and look after where you are, be there just for now. Don't come back.

Catherine looks at Rankine Brown again, from the dark, from the cold wind around her and she just can't see it, the mysterious place, the person inside the building. It was far more magical than that. It was material dug from the ground and remade. A mountain moved and made useful, then defiant in the face of even the mountains moving. The windows weren't eyes, they were a slow moving liquid sand, pounded and heated into shape by machines built by men. It wasn't robotic, it offered no refuge except shelter and storage. Ta-da, Catherine said and turned and made for home. 
Alan MacDiarmid 


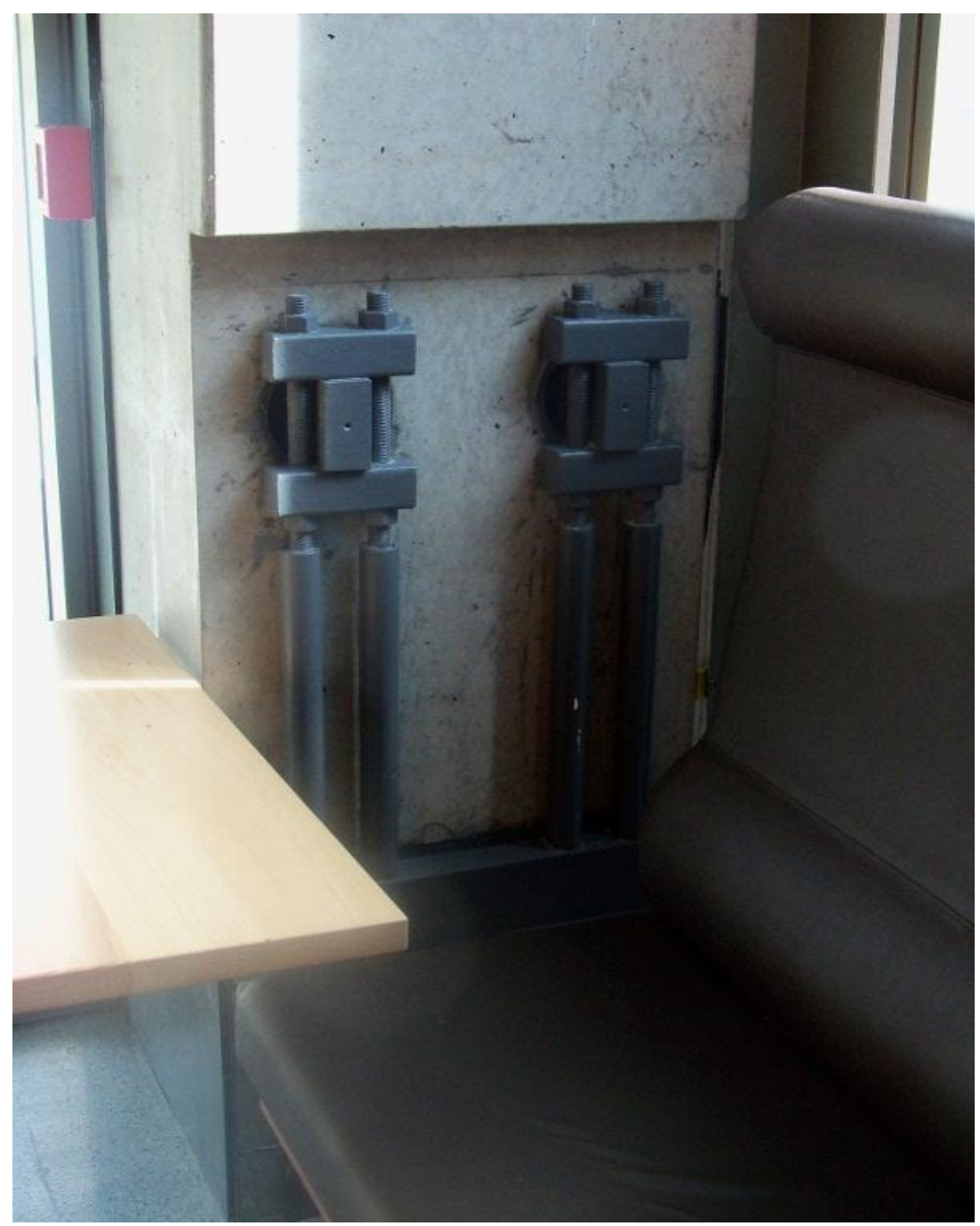


While we stood at the lights Catherine said we should take the cable car. It was just William and Catherine and me, now. We were meeting Michael up the hill. He had his car but we didn't want a lift.

'It's a nice night,' William had said.

Catherine and Michael had hummed and I nodded.

Catherine had an apartment in town, on Webb Street, and William was meeting some other friends at the presentation. I'd caught the train in. None of us had our cars and the evening was softening up in the cooling light.

William looked at his watch and then me and I said, 'I haven't been on the cable car.' So we changed our path and walked down Lambton Quay. It was about ten past five when we got to the station. The presentation started at six. There were only a few tourists in the cable car by then but we stood up. A woman with a lanyard round her neck and holding her ticket tightly, said to me, 'Which way does it go?' I could hear William and Catherine behind me, shifting, I could almost hear the look Catherine was giving William, mouth aghast, wide-eyed.

'Um, I pointed up the hill.' The woman said thank you and made her way to the higher end of the cable car.

'You're a rocket scientist,' Catherine said to me and we all laughed politely.

Victoria University was a sprawl, like they were all becoming. This campus stepped its way up a steep hill split in two by a busy road. There was a glass-sided overpass above the street but no one was there.

'It's not like Canterbury,' I said.

'Or Auckland,' Catherine said.

William agreed with me.

'Maybe it's a bit like Auckland', Catherine said. Thinking of the Merton Road campus and the way the art school always felt like it was trying to run away from the rest of the Symonds Street Campus.

Michael was sitting on a steep grassy rise when we got there, knees up, resting back on his elbows. His jacket was beside him with his keys and his phone and his wallet. He was facing the building site as if it were a movie screen. There was going to be a talk and then a walk round. Before they put the walls up they wanted to show everyone the shock absorbers and the dampeners.

'Is this where The Hobbit's playing?' William asked and we all sat down on the slope next to Michael. 
Michael looked around and smiled at us but he didn't change his position until he raised his arm and pointed, saying, 'That's them I think. Is that them, Craig?'

I'd done some testing of PRESSS systems at university. Everyone at Canterbury that year had. I'd been a technician on a shake-table test. Most of the students were working on timber high-rise now but there was still a lot of work being done.

'Those elements there,' Michael said. 'Eh, Craig?'

I followed to where his hand was pointing. 'Yeah,' I said. 'That's them.'

Michael turned slightly to William and Catherine who were just up the hill from him. 'That's them.'

They were both already looking at the metal shoes and screws that stuck out from the top of the columns and they nodded and said, 'Yeah,' to thank Michael for pointing them out.

'They're late,' William said. He meant the contractors who were still walking around the site. A crane lifted a skip down from the roof.

'Tidying up for the walk-round,' Catherine said.

'It's a pretty tidy system,' I said, felt I had to say because it was new and I'd had some tiny part in making it possible and it was a really tidy way of building. I was sure the speaker would mention that, and I wanted to look good and there was nothing wrong with that, not with being new. Although, it was a bit wasted on William and Catherine and Mike because they really didn't have much say about much but they did decide who they wanted to work with and maybe one day when they were trying to think who they needed on a rocking system they might remember us, sitting on the hill as the sun went down and the shadows got long and me with a comment that proved to be correct. They'd been working together for a while now, especially William and Catherine. Michael hadn't been there as long but he and William had been to engineering school together at Canterbury. Three other guys from my year had been employed there and I imagined knowing them for as long as these three had known each other. I imagined how it might be like being in a rock band. Like how you get to know what the other person is going to say. Like you all sit down at a problem and you know instinctively what the solution is going to be. I thought about that but it always splintered when I tried to put any past to any of them. I couldn't imagine any of them anywhere except where they were at the time I was thinking about them. Right now, here on the hill, all three of them smiling at something Michael had said about someone they had seen who they knew. William said, 'That's not nice,' through a chortley, stifled laugh. Catherine hid her mouth behind her hands but she was laughing too.

Quite a few engineers were arriving now, filing into the lecture theatre, but we stayed on the hill.

'Are there drinks?' Michael said suddenly. 
'Are there?' I said.

'Not before the walk-round,' Catherine said.

'On the walk-round?' Michael said, turning to Catherine who was shaking her head and raising her eyes.

'Are you sure?' William said.

'Yup,' said Catherine. 'They won't let anyone up there after they've had a drink.'

'It's not like the old days.'

'It's exactly like the old days,' Catherine said.

'Not the nineteenth century.'

'No,' said Catherine laughing. 'They were pissed as newts in the nineteenth century. Everyone.'

'Drank it like water,' William said.

'Like tea,' said Michael.

'Yes, they weaned babies on bathtub gin in the nineteenth century,' Catherine said.

'They didn't have bathtubs,' Michael said.

'They had bathtubs,' Catherine said, raising the end of her sentence in an accusatory way.

'They had steam engines,' I said, not really thinking but saying it. Watching all the other engineers going into the lecture theatre, wondering how long we would be able to stay on the hill, messing about.

'See,' said Catherine.

Michael shook his head now.

'And sewage,' William said.

'Not until Bazalgette,' I said.

'God bless Joseph Bazalgette,' the three of them said together and then laughed.

It felt like a competition now, like when you try not to look away. I didn't want to be the one to stand up, or suggest we stand up. The ground was getting cold but it was soft and there was plenty going on in the building. I noticed Michael's hand was brushing over the grass beside him and Catherine's hair was moving around in the warm breeze.

'Well,' said William, hitting the ground with one of his hands. He sat up and began to collect his stuff. We made the same standing up movements. The hill was steep so we walked in a diagonal down it, crossed the carpark and went into the lecture theatre. Everyone was already seated and it was almost full but we found four seats near the middle, and some people moved along for us. Just as we sat down, the Chair of the Wellington branch came to the microphone and the noise of the lecture theatre subsided and he introduced the speaker. Then the speaker 
began. I turned slightly to look at Michael and Catherine and William, I wanted to get out my notebook. They were all looking forward. Catherine took notes. Michael put his hand out to borrow her pen and he wrote a note on his hand. William had his hands folded across his chest and his eyes slightly squinted. So I turned to the speaker and listened.

At the end there was a question about grout and then several others about cladding and strength of materials. After fifteen minutes the Chair made his way to the podium to thank the speaker.

'The number of questions shows this has been an interesting session,' he said. 'It was a great presentation, very clear, lots of pictures we can relate to, Alistair took us through it showing us plans and elevations, rocking walls, rocking frames, it's innovative, basically it 'blows us away'. We're all looking forward to having a wander out there and maybe one day when we have a big shake we will get to see how the building performs.'

Everyone in the audience laughed.

'You'll find me in South America,' Alistair joked. He was working on the computer, closing down his presentation but he stood up as everyone applauded. The Chair handed him a bottle of wine and Alistair said thank you.

Next the site manager came to the podium to outline how the snakeline would work. Catherine and William were already talking to each other. Whispering. Catherine was drawing something on a bit of paper as she talked and William was pointing to parts of what she drew. As everyone stood up she was smiling and nodding and William said, 'Yeah, that's what I mean.'

The large group of people from the lecture theatre soon fell into a line. Michael, William, Catherine and I stayed together without much effort. Michael was talking to an architect walking in front of us. I couldn't quite make out what he was saying but it sounded like they were talking about the student accommodation fit-out. Anton kept indicating down the hill where the buildings were, like they could see them from here.

'Don't you think, Craig?' Catherine said suddenly.

'Sorry,' I said, leaning toward her as we walked.

'William should take a holiday.'

I looked at her involuntarily. I had no idea how to reply.

'He hasn't had a holiday in years,' she said.

I looked at William. I couldn't tell if he was in the conversation any more, or if he ever had been.

'Have you?' she said, turning to William.

William shook his head. 
I nodded, slowly, like I was mulling it over. It didn't seem to be any of my business. I couldn't quite fathom how it was any of Catherine's business either. I looked at William again. He seemed comfortable with the conversation. Catherine also didn't seem to have altered in any way. She could have just as easily been talking about maths. Maybe she was. 'Where would you go?' I finally fixed on, and questioned it the minute it was out of my mouth. We were climbing stairs now. Catherine and William were looking around as we climbed so I thought maybe we were finished, maybe I had finished it but then William shrugged and said, 'Asia.'

Catherine shook her head and said, 'Fuck off.'

William laughed.

I laughed too.

'Not for work,' Catherine said. 'A holiday.'

William shrugged and pointed to one of the shock absorbers in the top of a column we passed.

Catherine looked at it and nodded.

It occurred to me uncomfortably that Catherine and William might be going out together. She was wearing a wedding ring and so was he and I suddenly thought perhaps they were married and perhaps I had missed that. Then I checked the rings again and I realised they were different rings and it was even more confusing. Did people buy different rings for their weddings? It hadn't mattered and it didn't, but now with the holiday comment I wasn't sure. Surely, it really didn't matter.

We reached the roof and it was beautiful again. There was a warm breeze and all the engineers dispersed from the snakeline and looked at different columns and beams. Everyone was impressed. Every question they asked, every problem they raised seemed thought out and solved.

'New things are like that,' Michael said. We were standing under a column and he was asking me about the grout gutter and I explained it as best I could. I made sure to point out that I didn't know that much about things but every time he had a question it seemed I had a reasonable explanation.

'It's a beautiful night,' I said after we'd exhausted the system and we were looking out over the city.

'Yeah,' Michael said.

The city looked glorious. I'd never lived in Wellington until now, and now I was here I was living in Titahi Bay with an aunt. It was just until I got my footing, I'd promised myself. Wellington was a small city, compact. It sat in the arms of a green rise, like the buildings of the 
city had been drawn in with one resolute movement. I noticed Michael looking over at William and Catherine. I was sure he was looking at them and I felt on good enough terms to say, 'Where are Catherine and William?' And he pointed them out. So I said, 'Are they married?'

'No,' Michael said.

I nodded.

'But they're married,' I said. I was waving my arms around, trying to indicate I meant, to different people.

'No,' Michael said. He reached out and touched the column. He looked up at the shock absorber one last time. 'We should get those two and go and have a drink,' he said.

We walked over.

'What do you reckon?' Michael said.

'Yeah,' said Catherine. 'Sure gives it a lot more space.' She looked round the slab we were standing on.

'It's really tidy, too,' William said.

'And below,' Catherine said. Meaning the cranes and the trucks.

'Look at this view,' said Michael. And for a moment we all just stood and looked at the view.

'It works well in the gap,' Catherine finally said and we all nodded.

Michael nodded.

Catherine looked at Michael, 'When did you last go on holiday?'

'Are you the holiday police?' William said.

'I'm just saying,' said Catherine.

'It's the zoo job,' Michael said.

'What?' Catherine was smiling and indignant all at the same time.

'Of course,' William said, he turned to me. 'She wants the lead on the zoo job.'

'I never said that,' she said.

'Do you?' Michael asked.

'I'm just saying that you and William haven't had a holiday for a while.'

'We've got a lot on our plates,' William said.

'You've got an awful lot on your plates,' Catherine said. Everyone was laughing now.

'And we've both got allergies,' Michael said.

'Did I mention the allergies?' Catherine said.

'And the noise,' Michael said.

'There is the noise, I hadn't thought of that.' 
'You hate animals,' William said. They were all still looking out over the city but I was looking at them.

'But I'm good with aluminium,' Catherine said.

They both nodded.

'You'll get it,' Michael said.

Catherine nodded, 'Yeah probably.'

They were calling everyone down for drinks.

'But if you two were on holiday,' Catherine said. And we all laughed again.

We went for the drinks. I bumped into a guy I'd been at engineering school with in Christchurch. He'd just got back from Australia, he'd been working on a stadium.

'It's big there,' he said and I nodded. 'Like the continent. It's huge.'

'Stable as,' I said.

'Yeah,' he said. 'It's kind of boring. I'm glad I'm back here.'

'To the skinny isles,' I said and we raised our glasses to New Zealand.

He went home and I ended up standing next to Michael and Catherine and William because I didn't know many other people. They were talking to lots of engineers who they introduced me to. I shook hands and I listened. The crowd was getting thinner and Michael looked at his watch. 'Dinner?' Catherine said. William was a starter right away and I said I felt quite hungry but Michael wanted to call Donna. 'She could come?' Catherine said, but he was already on the phone to her and walking away.

We walked down the hill toward town. Michael left his car at university, he said he would pick it up later. It was still light but the sun was going down. We ended up halfway up Cuba Street. There were lots of people walking up and down and as we crossed the road you could see some students playing basketball outside the architecture school.

'Where shall we go?' Catherine said.

William laughed, 'We were following you, Tigger.'

'Oh,' she looked up and down the street. 'I hadn't really thought that far.'

'We could go to that Chinese place,' Michael said. 'But I suppose you'll be having plenty of that soon.'

'How about Middle-Eastern?' Catherine said, pointing to a restaurant across the road which had a few people standing outside, smoking.

'Yeah, let's do that,' said Michael. He put his hands in the pockets of his jacket and led the way. 
We sat at a square wooden table, there were gold textiles hanging from the walls. We ordered more drinks and some food. While Michael and I ordered, William and Catherine started talking about something else, Catherine spun the menu over and over in her hands and tapped it on the table, like she was collating paper. They weren't looking at each other but Catherine was smiling. We ordered too much food. Everyone said it as the dishes arrived and arrived, but we ate a lot of it. We picked up olives and zucchini fritters in our hands and filled bread and mopped up hummus and beetroot dip. After an hour we were still picking at it all. Catherine was eating the tabbouleh out of the serving dish.

'This was a good idea,' I said. The food was delicious.

'It was a great idea,' Michael said.

'What will you eat in China, William?’ I asked.

William shrugged his shoulders. 'I reckon there'll be everything,' he said. 'It's such a massive city now.'

'Are you going to go overseas, Catherine?' I said.

She had a mouthful and she shook her head as she chewed. 'I'm pretty happy here,' she said.

'And she has big alimony,' William said.

'I don't have big alimony,' she said to me, like she was making a play out of being sure I knew.

'What about you?' Michael said to me.

'I haven't really thought about it.'

'Really?' Catherine said. 'You really haven't thought about it?'

'Well,' I said.

'Well,' said Michael, he was breaking a piece of bread.

'Maybe. I don't know.'

'It's pretty good here,' Catherine said.

'Yeah, but it's different for you,' William said.

'Why's it different for me?'

'Yeah, why's it different for her?' Michael said.

'You know.'

'No,' they both said together.

'You know,' said William.

'I could get a job overseas,' said Catherine. 'It'd probably be easier to get a job overseas.'

I suddenly realised that William meant because Catherine was a woman, like she needed 
to stay anywhere that would have her. I felt really uncomfortable. 'My friend's just got back from Australia,' I said, picking some crumbs off my plate with my finger. 'Have you ever worked in Australia, Michael?’

'Nah,' Michael said, he was looking round for the bill and he was looking at his phone and it looked like he was ready to go.

Michael caught a cab to his car and we went out drinking. Toward the end of the night we were sitting in a quiet, dark bar not talking, then William's phone chimed. He picked it up and read the message.

'Is that your wife?' I said.

'No,' said William.

'Will she not wonder where you are?' I said.

He looked at me, 'No.'

'William has quite an open marriage,' Catherine said, swaying slightly as she emphasised the word 'open'.

'Like you?' I said and immediately regretted it.

'Yeah,' she said. 'Yeah, but mine is impressively open. Like huge hangar doors open. Like, um, no walls at all open.'

'She's getting a divorce,' William said.

'I'm getting a divorce,' she said.

'But she thinks if she keeps wearing the wedding ring no one will notice,' William said.

She leaned toward me, 'Everything I've learnt,' she said. 'I learnt from him,' and she pointed at William and then she mouthed what looked like 'Cagey,' or 'Spacey,' or something. I was too tired to much care. I had no idea how I was going to get back to Titahi Bay. I hadn't thought about it when we'd started out. I'd kept an eye on the time through dinner, but then I'd just forgotten.

We left the bar and as we walked down the street I said, 'I don't know how I'm going to get home.'

'Oh,' Catherine said. 'I didn't think of that,' and we all stopped in our path.

'You can stay at mine,' William said.

'Will your wife not mind?' I said.

'No,' said William.

'He doesn't have a wife,' Catherine said.

I looked at William. 
'He's just got a wedding ring,' Catherine said. 'We both do.'

'Is it complicated?' I said.

'Not if you just take everything as you see it,' Catherine said. 'I have a wedding ring. William, also, has a wedding ring.'

I still didn't get it.

'You have a silver tie pin,' said William. 'We have wedding rings and you have a silver tie pin.'

'Neither of us are any more exciting than that,' Catherine said.

'Why don't you just have a silver tie pin, then?' I asked.

They looked at each other and Catherine began to laugh. 'Because,' she said. 'We have wedding rings. Oh, for fuck's sake,' she said. 'Don't ask so many questions. We never take anyone out drinking. We never do, do we William?'

William shook his head.

'Don't worry about it,' she was smiling. 'We are all very boring people.'

'Maybe he watches too much TV,' William said.

'Do you watch too much TV?' Catherine asked me.

I didn't think I did. So I shook my head and we walked Catherine back to her apartment and caught a taxi from there to William's house. The next day he loaned me a shirt and from then on we all went out most weeks, for dinner, sometimes a movie. Occasionally, Michael would come. And eventually Catherine stopped wearing a wedding ring but William never did. She said she lost it. Put it down somewhere and forgot to pick it up again. Or maybe it fell off when her hands were cold and she was walking somewhere, quickly. That's what she said at the Christmas party when someone noticed it was gone. Donna nodded, neither she nor Michael wore rings and they never had she said. 'They're too easy to lose.' 
中央电视台总部大楼

Central China Television

Headquarters 


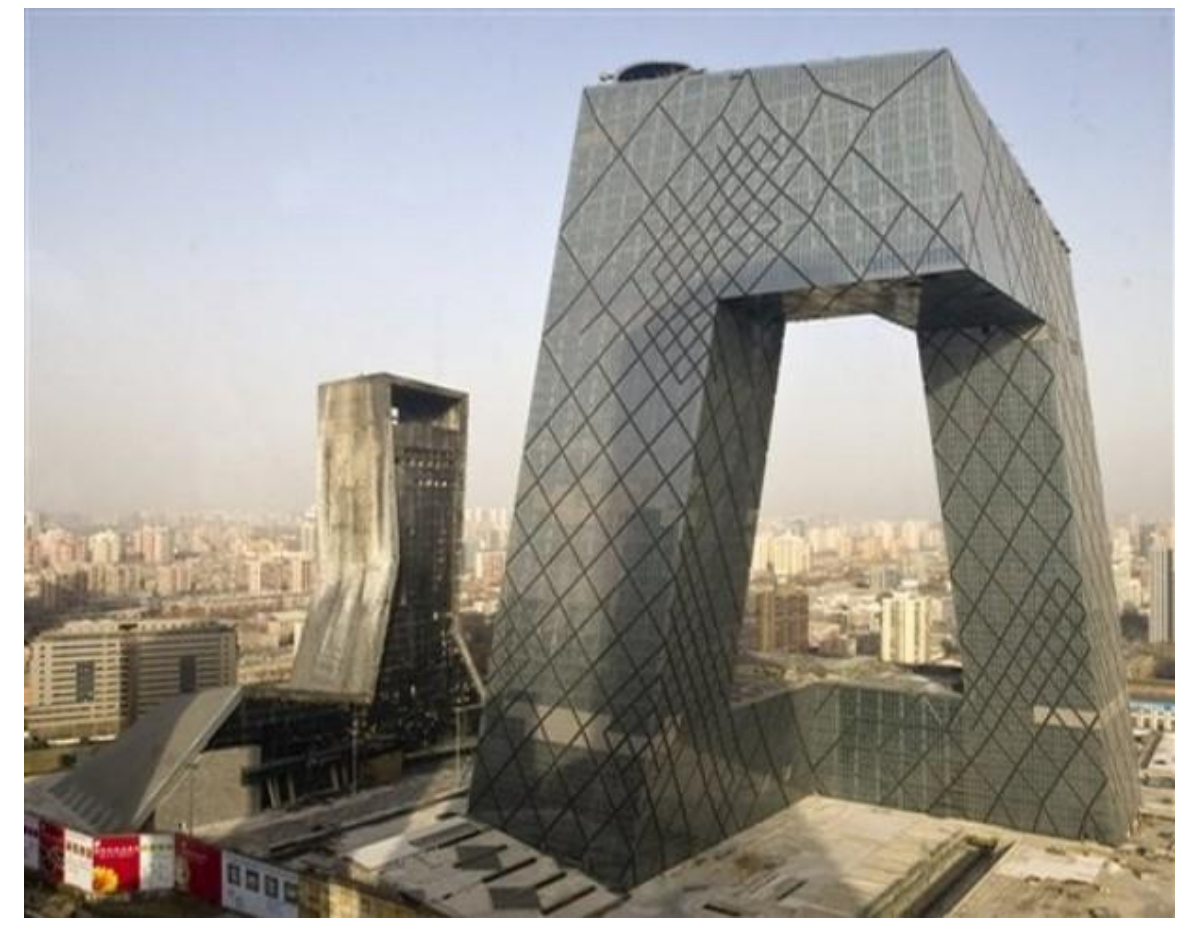


Fay Jones worried Michael. He shouldn't, Fay Jones was none of his business. His business was Featherston Street and Te Puni and the new Resene factory in the Hutt. But the tree houses worried him more than they should. They made him angry, which was ridiculous. He wouldn't say anything to anyone. It was so quiet - in the trees, in the rock, the clear open spring - so ridiculously quiet, it was like the tiniest rock in his shoe. Sometimes when he closed his eyes all he could see was Fay Jones: Cooper Memorial Chapel, Pinecote Pavilion, Thorncrown, the Fullbright Peace Fountain climbing, higher and higher, closer, making it hard for him to breathe, shadows of lattice and height all raining down on him, belting him on the head, the arms, that small part of his mind which was peaceful, getting in there - huss huss giddagidda. He felt like biting and tried not to blink, or stop working. It was better if he kept working, walked slowly from one job to another, made jokes, offhand, casual but always on time. It would all pass. An easy smile, a low, measured way of speaking. 'It's under your hat.' A good-natured display of mock impatience with everyone's faults. It didn't bother him when he was working. He just couldn't fathom how the truss worked, it was like a frame but was a truss that was a frame. Thorncrown worried him. He'd never been anywhere. He'd wanted to but he'd never been anywhere. To Sydney. He'd been to the Sydney Opera House and the bridge and some taller buildings and he'd ridden on a train. And Fiji, he'd been to Fiji. He opened his drawer slowly, smoothly and took out the folder he needed for the next piece of work he was doing. It was a truss, but it had a bending moment in it. That seemed ridiculous. William had just got back from China. He'd arrived on a late flight but came to work, tired and slightly at odds. Michael would ask William about China, maybe he would go to China, maybe he would go home and tell Donna that he was going to China, by himself, because he worked hard and it was his time, maybe he would see if William wanted to go to China again. Maybe this would shift Thorncrown and with that, it was back, worrying him, but he was already on his way to William's desk, he'd picked up his wallet as he'd stood up, he was going to ask everyone to have coffee, to welcome William back.

'Does anyone want coffee?' he said as he walked through the office. He had his jacket on. All over men reached for wallets and jackets and some shook their heads and said, 'Sorry,' and others shook their heads and looked at their computers and then, as if someone had taken them by surprise, said, 'Oh hell, why not?' It would all be there when they got back. Michael stopped at William's desk, he was on the phone. Michael made the shape of a coffee mug held in his hand and lifted it to his mouth and poured it and poured it. William looked up through the fug of his lack of sleep and the long trip and the long day ahead and nodded, as soon as he finished the call, pointing to the phone while he nodded. Michael didn't wait for him. The 
receptionist was saying to everyone, 'Sign out,' without looking up and catching a few of the men as they left, Craig, Donald, handing them small pieces of paper with messages on them which the men looked at and stuffed in pockets in trousers, in jackets, in the top of their shirts. Michael checked himself in the glass doors of the office. What would he wear in China? He didn't even care now what William said, didn't care if he said it was the worst place on earth, didn't care if he said you couldn't get nice food there or nice clothes or if it was dangerous or if they cut off your hands if you stole. He could see now - China, the sound of it pushed out the stupid wood and stone. It was hard on his teeth, stressed on his cheeks, his lips drew back around it, like he was warning people off and it kept away the weak Fay as it drifted out of him like he was giving up. 'William looks tired from China', he said to one of the other engineers and when that one went up to order his coffee, 'I wonder if William will tell us about China?' to another. All the wood and the light couldn't get him now. Featherston had all his attention, it suddenly came to him how the bridge on the paint building should work, the springs were ideal for Te Puni, a brilliant idea, people would talk about the springs for a long time.

Michael waited for William to come down and he walked behind him to the counter to order his coffee. William was yawning and swaying, his lack of sleep sat about him like an invisible bubble - like bubbles are, invisible. And so, Michael said as they waited while the barista made their cups of coffee in that hissy way, 'So, how was China?'

William looked at him and suddenly Michael realised this wasn't how he and William spoke. William looked at his change, to give Michael a chance to close it all over again and he did, coughing slightly, hurrumphing, making as much of motion as he could, now that he realised he shouldn't be there, with William, alone, in the queue, the question chiming as the seconds took it away. Steam and heat slowed down, it was uncomfortable, unbearable, but Michael couldn't leave and William couldn't leave and Michael saw the fine strong wood all just waiting to box him in, like it had the power to actually kill him. It was almost unmanageable but they'd managed it, for years, since university they'd managed it in a reasonable way. And now, William looked at him again and ran his hand through his fringe. Michael looked away from the scar. Looked down at his hands. Then their coffee was ready. Michael waited for William to get his. They walked back to the table where the rest of the men were and so as not to look odd, William asked about Michael's weekend and he said, 'Fine, busy, yeah.'

Everyone at the table was talking, had broken off into ones and twos. They were talking excitedly, like they never got to just talk. They were mainly not talking about work. It sounded like it was work but it was mainly about other things, books perhaps, movies. Michael was never quite able to start, he usually waited for someone to speak to him so that he could hit the ground 
running, so to speak, catch up. He positioned himself looking away from William, not sure how he would claw it all back. He listened intently to the man to his left, which left William sitting, comfortably, sipping his coffee and watching all the conversations which were taking place. William could get away with almost anything. His eyes moved over everyone, one by one, he smiled if he caught anyone's attention.

'China was good,' he said, to Michael's back.

Michael nodded.

'It was brighter than I thought it would be, smarter. I spoke to a couple of companies over there.'

'I'm going,' said Michael, turned slightly now, but still not looking at William, awkward. 'For a holiday, or maybe for good. I'm talking to a few companies.'

'I thought you were happy here.'

'Not overly,' Michael said. 'Not finally. It's a big world.' He hated how it opened up, how this craziness just unzipped, but he couldn't stop it, it was away - like it had bolted. Like if he didn't keep lying about China, Thorncrown would come back, or Pinecote or even that small private home with the fresh water spring that flowed over the wall of the downstairs entranceway. William could have crippled him now, he only needed to turn casually to the person next to him and say, 'Michael's going to China,' and he would have been got. Hobbled, a fool and Michael knew that and something about it made him calm - handing it all over to William made it safer, somehow - like it wasn't his responsibility any more. Like it wasn't his fault, like it was William who was the fucker, William the home-wrecker. William.

Eventually, someone looked at his watch and as he did one of the receptionists came shushing over to the table, another small paper message in her hand. It was for Michael. It was Featherston. 'The crack,' she said in his ear. All the receptionists knew too much, it annoyed him. In the back of his left eye, it drove in. He pushed his thumb and forefinger into an eye each and nodded. Then the receptionist started round the table, JT was looking for Craig, there was someone waiting for Catherine.

'Catherine.' Could Catherine come and see him after that, Michael asked, and William, would they need William? Catherine nodded like she was still thinking, but she'd be right, Michael thought, you could always rely on Catherine's first answer. He looked at William again, looked at him being tired, the tiredness loosening up all of him, like he was drunk. He looked at his watch. Michael wanted to be drunk. He felt it on his throat, like a hand gently touching him there, or like the arteries were winding up his neck like they weren't his, like a vine - but not tight, the branches of a tree. Or some awful lattice, he thought to himself, hating, not sure that 
he wouldn't cut himself open right there - wishing he was alone and drunk and hurting himself, peeling his skin off, somehow. All of the awful things. He stood rooted, and for a long moment had no idea how he would come back from this - walk to the lift, push the button, walk to his desk, put his wallet in his jacket, log back into his computer, look up from his computer and see all of this and carry on.

William would have to give a talk. He'd gone to China on the company's back, ostensibly, to look at the engineering and deliver a paper at a conference and talk to the company's Beijing office. Later, Michael knew, he would have to give a talk to everyone, in the big board room, with slides of the buildings he'd seen. Michael, desperate, went to the talk - him in a blue shirt, short sleeves, sitting toward the back of the room taking scratchy notes in a moleskin notebook. William speaking, showing: the bubble building, the birds nest and then the Central China Television Building - aped over, like it was waiting. 'What's disconcerting,' William would say, 'is that you can see the sky reflected in it. So that it sort of looks like it's rotating.' And then click, a picture from another angle, from inside. It was heavily engineered. It looked like a rebellion from a distance but it was so heavily engineered - braced and braced and braced, it would never walk. The elevators could have been angled, but they weren't. It made Michael feel full looking at the wireframes, more and more and more steel. Another slide, a confined space, cut off by nests of steel braces, there was no room around it. Three desks, four you could have fitted into the space that was taken up by steel. Everyone in the room laughed smugly, 10,000 welders, a workforce that made anything possible. 'Even ugly things,' someone said, they laughed again. Rem Koolhaas - almost everything he'd designed had never been built and now this, engineers that didn't say no, officials who changed building codes, and his 10,000 welders. The price of concrete and steel had gone up while they built it, it was like a small country the effect it had on the world economy. William thought it was awful, there were people starving, possibly not in China but there were people starving. It wasn't right. Michael thought it was amazing. Amazing that someone had stood it up and that it was standing up, sure by crutches and braces and strings, but it was standing up.

'You're all laughing,' Michael said. 'But it's standing up.' Then he stopped, looked up and tried to hide his surprise at having said it. Everyone was looking at him, so he said, looking back at his notebook, drawing spirals that got bigger and bigger, 'You couldn't have done it here.' Maybe you couldn't do it anywhere except there, or North Korea. People laughed, so Michael laughed, but he knew he was right. You couldn't have done it anywhere in the world except China. He thought, Take me to China. He thought, I want to bend things over and make the biggest things possible. Take me to China. In his head as he stood in the lift after coffee, 
watching William talk easily with the others, he imagined getting rich, really rich, white-manmoney-in-the-east kind of rich and buying Thorncrown and moving it to under the CCTV building and then ordering one of the millions of welders to take out the elements of the braces one by one until finally CCTV sat down on top of the stupid wooden chapel. Smack, it went in his head, like skin hitting skin and that would be the end of that. He resisted the urge to rub his hands together.

As they left the lift Michael said, 'So shall we see the crack?' Catherine held back and turned and joined them so the three of them were standing in the reception area. William looked at Catherine. She looked up, away from them, they all knew William would have to say it. It was like that with Catherine.

'Well,' she said, drawing it out even more.

'Yeah,' said William, 'we should go and see it.'

'It's probably nothing,' said Catherine.

'It should be nothing,' said Michael, 'I'll ring the site manager and send you an email.' He walked back to his chair.

Eventually, he and William would be alone together again. If it went the way it always went, which Michael suspected it would, suspected it couldn't go any other way. At a printer, in an office, both of them the first to arrive, the last to leave, at a site - perhaps today at Featherston Street. Catherine was probably the only one of them who could make an accurate assessment of the crack but she wouldn't go by herself. Perhaps today, awkwardly on top of the building, in the wind, looking over the city. Michael would take his camera, so he had something to do. He wished it wasn't like this, but it was. Michael stopped. Did he? He doubted it. He looked out over the office, there were at least thirty of them and Catherine and another thirty men in the other office, where they drafted everything. It was the biggest firm he had been in for a while, big enough to never have to talk to each other, big enough for it not to look strange. So big that he could watch William all day without being noticed, gauge his movements so it wouldn't get to the point it had. William could do the same. It could go on for a lot longer but William would go to China most likely and Michael would stay here for as long as he could and then probably go to Hong Kong, then get a transfer to Taiwan and it would start all over again. Michael's phone rang, it was Donna, she was going out for her run but she wanted to check first that he'd emailed the electrician about the power-points in the new extension. 
1Featherston Street 


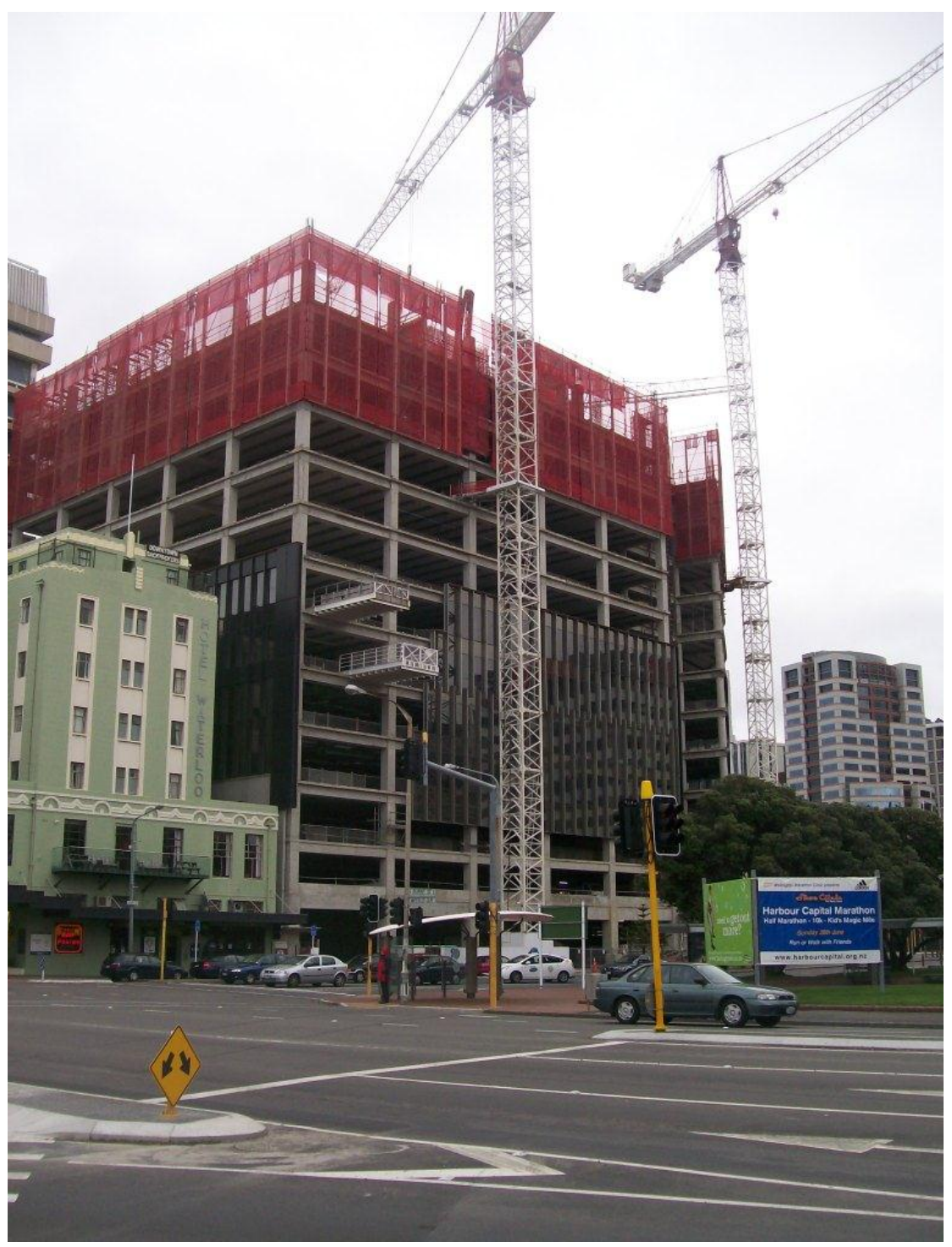


After lunch, Michael stopped at Catherine's desk and asked if she was ready to go. She nodded, looking at the clock on her computer and then at her watch. She bent under her desk to get her safety boots and hard hat. Michael leaned slightly on the top of the partition of the cubicle she and William and Craig worked in, waiting. Putting the hat on her desk, Catherine slipped off her flat pumps with opposite feet, pulled on heavy socks over her black stockings and worked each foot into the large, lace-up, steel-capped boots. Michael talked to Craig who was working in the cubicle next to her. She looked back under the desk, then started lifting papers and folders on top of her desk. They'd all been given new high-visibility vests when the company had changed its name, she'd had hers on a couple of times but now she couldn't find it. Michel looked at his watch. She lifted her hard hat to check under it.

'It's in your hat,' Michael said, raising his eyes to Craig.

'Oh,' she said, raising her eyes to Michael. She pulled it out as she stood up to make sure it was the vest, picked up a folder from her desk and they left the office. William was waiting at reception for them, he told the receptionist they were going to Featherston Street, she typed as he spoke and asked if they had their cell phones. They did, but it would be good if she could take messages.

The three of them walked together along Lambton Quay, through a channel of tall buildings which cast square shadows on them. Michael and William talked about the building they were visiting and another building and about a cement plant and the fissure in one of its basement columns. She nodded and said, 'Hm,' when they said, 'You were down there, eh Catherine?' and 'Yeah,' when they said, 'That's how it is wouldn't you say?' She walked, looking straight ahead, holding her folder, vest and hard hat by her side, swinging them slightly with the arc her arm made as she walked in step with the men. She would catch her reflection occasionally and adjust her dress shirt over her tailored skirt. Her hair was long and still slightly wet from the shower she'd taken that morning, it was pulled into a pony tail that flicked as she walked.

They could see the building they were walking to from blocks back. All three of them looked up as it appeared from behind the line of other buildings and grew as they got closer. The building was sixteen storeys high, the top twelve levels were office space then there were two levels of car parking and a ground level of retail. It had about $3,000 \mathrm{~m}^{2}$ of floor plate, in terms of floor area it was the biggest in Wellington. It was L-shaped. Like a leg bent at its knee or an arm at its elbow it strongheld the corner of Featherston and Bunny Streets. The cladding was designed to break up the face of the building so it would read like three moderate buildings but for now it was huge. The roof was on but the building was still open so the concrete 
columns, beams and floors that held the building up stood uncomplicated, framing the sky like an exhibition of sky and clouds. Four cranes stood around the building and it was alive with workers in hard hats and orange vests. The frames closed as the engineers got nearer until by the time they stood at the base of the building all they saw when they looked up was one tiny part of the building disappearing into the sky.

They turned off the footpath through the hoardings and past the site-hazards board where all of them put on their hard hats as if they were part of a civil tattoo. They climbed narrow steel stairs set into the scaffolding which framed the building. The stairs led to a narrow scaffold bridge flanked by shipping containers which were being used by the construction workers as rooms to leave their things in: lunches, jackets, bags. They met several construction workers coming and going from the rooms, without looking they made way for each other in the close space, often touching, and carried on. Once past, a few of the construction workers turned slightly to look at the three engineers walking away from them.

The site office was set up in what would be an actual office when the building was completed. The engineers stopped at a clipboard on a wall just inside the door and Michael and William stepped back, still talking to each other. Catherine signed herself in and passed the pen to one of the men, she waited while they signed and together they walked to the site manager's desk. He stood up as they came toward him. He was new and when the men introduced Catherine he mistook her for an architect and immediately, realising his mistake, apologised. She raised her hand and shook her head and made a joke at her own expense about women and maths and heavy lifting and put him at ease because she was at ease.

They'd come to see the small crack in the north-west side of the roof. No one was overly worried, they just thought it was a good idea to have a look at it. Catherine said again that it seemed fine but she thought it was prudent to look at it in person, and the others agreed, everyone agreed. The site manager listened and nodded, there was a calendar behind him with a woman on it, and she peeped out from one shoulder then the other as he put his vest and hard hat on. Michael and William and Catherine pulled their vests on too. Catherine drew her ponytail out from under the vest's collar as she made a comment about a game of rugby the others were talking about that made them all laugh and say, 'Yeah,' and nod.

They walked from the office still talking about sport. There were no windows or walls, only concrete. Columns stood at regular spaces, holding the long, deep beams that ran over them which, in turn, held the hollowcore floor slabs of the storey above. Some of the timber infill was still visible and it broke the grey colour of the plane but not its geometry. It was an argument of order; every regular framed shape tied back to the hybrid coupled shear walls which 
ran from deep in the earth to the sixteenth floor. The shear core's position had been drawn and re-drawn so that now the building's centres of mass and rigidity coincided as nearly as possible. So, the dog-leg could act like a square. The lateral loads that tried to twist its wings off would be resisted here at the building's point of greatest strength and rigidity. They walked past the huge square core and without looking, or a break in their talk, were gently impressed by its weight and its power and the elegant solution it provided.

The floor would seem bigger when the walls and the ceilings and the furniture came in. That's what one of them would have said if there was a visitor with them, someone who wasn't an engineer or a construction worker, not in a worrying way, just to make small talk as they walked the wide expanse to the caged lift. A visitor would comment on how odd the empty space seemed, they would get disorientated by it, turn left when they should turn right, looking at the small things, the nail guns, the cords. 'What I never get used to,' one of the engineers would say, 'is the way it actually looks bigger once everything is in here. It's odd don't you think? Like when you buy a house and you worry that all your furniture won't fit, and it does.' But it was just them so they talked about sport and other buildings.

The lift arrived and they kept talking. The lift operator slid the steel door open for them and they stepped from the solid concrete to the cantilevered lightness of the lift. None of them looked particularly where their feet were going. They acknowledge the lift operator who pulled the door shut behind them and they moved toward the end of the large lift which hung out over the street. The lift stopped at each floor to pick up more men. Catherine held her folder against her chest under casually folded arms and stepped back and back until she was pressing against the caged wall at the end of the lift. The men talked and she watched the view. The tiny railway station, the shrinking sea. She was short among the men, the lift was noisy and it was hard for her to hear. Most of the men from her firm had worked with her for a long time and they knew it was hard to join her into conversation in the loud noises and small spaces of a construction site. She would say, 'Sorry,' and 'Pardon,' as if they'd called her from another conversation. So they didn't talk to her, they leant into each other and shouted in deep voices and laughed but they never talked or laughed about her.

When they reached the sixteenth floor they had to push past the ball of men in overalls and vests and hard hats. Catherine smiled, looking each man she passed in the eye if he was looking. From the sixteenth floor they climbed more temporary steel stairs that rang under their heavy boots. Catherine climbed the stairs at a pace and slightly away from the banister so her skirt wouldn't catch. They reached the roof, adjusting their final step to the slope of it and their eyes to the brightness of it. The wind was high and messy. Catherine took control of the 
conversation, shouting without shrill above the wind about what she needed to see and asking the site-manager questions about aggregate sizes and dates, which he recalled from his head. She asked about the weather. He shouted, didn't she have all that, she shouted that she did, but just, what did he remember about the weather, off the top of his head. Michael and William walked to the edge of the roof to look at the view.

Catherine and the site-manager walked to where the crack was and looked at it, from standing first, circling round it. Then, as they shouted things at each other, they looked behind themselves to see the wind coming, blowing originally from the North, then worried into downwash flows off the large exposed buildings on Waterloo and Whitmore which channelled and intensified the gusts between themselves. It blew in their faces as they looked and took their words as they shouted about where the crack was sitting in the scheme of things, in the wind and the rain and the sun. It wasn't large and it wasn't deep she said, the site-manager agreed. It was there, though. She bent to look at it, squatting with her knees together, her skirt stretching slightly to take the change in her shape. She touched the crack with her hand then lay her pen next to it, she stood and called for Michael to bring over his camera. She looked at the pen again, and it hopped slightly. All the sounds of the normal things were gone. All she could hear was the deepest noise of the Pacific plate locked against the Australian plate and trying to push under and finally, suddenly rupturing. In one violent movement the energy of the compressive and shear strain of ages and tonnes was free. Underground and along the ground vicious swells beat through rock and soil from the rip in all directions and at different frequencies, reaching the Featherston building's deep bore pile foundations, animating them into a billow which the superstructure amplified. At once, and from the mass of every part of the building, inertial forces sparked and resisted the drive to move. Catherine looked up at Michael and William coming toward her and they were oddly taller, then shorter. The roof plate surged and she was knocked forward onto her knees. Things began to fall and other things stayed put and shook. She tried to regain her balance and instead slid as if she were being grated against the concrete floor. She grabbed out for something solid, there was nothing. She thought calmly, Stay down. Then one of the large air-conditioning units moved assertively with noise and she thought, Fuck.

It was like falling, trying to save herself from falling this way then that way, with nothing to hold on to. She knew exactly what was happening, she knew every element, where it was going and how far it would go before it returned and it was no consolation; it shook and shook and shook from every direction, there was no ordering it and there wasn't a part of her that wasn't wanting it to stop. She tried to crawl to somewhere still, then tried not to, tried to stay put, not move, move with the shaking but nothing was any good. She found herself close to the 
crack, it opened a little, then folded over itself. The crack was fine, she thought, with a laugh, here it is being fine. She turned to show the site-manager. He was a metre from her, smiling in terror. She smiled back trying to say with her smile and her eyes, 'Shit eh? Shit!' Like she knew what to say, like when she was talking about weather and aggregate, like even now, in all this, it was important to him and to her that she didn't look like she shouldn't be there. Shit, she smiled as she was thrown backwards, looking quickly to see where she was going.

There was nothing to hold on to, she grabbed at the flat concrete but there was nothing to hold on to, below her she could almost feel the beam of a moment frame, she looked down and imagined the roof plate moving over it, she could see the bending moments around the rigid joints between beam and column by rotation. The regular shape of the frame like a handle for her as it resisted the shaking by bending and shearing action. She reached for it and caught hold of a length of steel casing pipe but it wasn't attached anymore and instead of anchoring her it came effortlessly with her hand as her whole body was pushed again back from it, forcefully toward where it used to be attached. She looked up and saw all the men again, fighting the jolting rock of the concrete slab, the ladders, the scaffold falling, most of them down flat on their stomachs, grasping, reaching, some shouting, holding their hard hats with their hands, flapping around, some private part of them all on display to all of them. She tried to get up again and one of her knees came down hard on the slab again and she tried again to reach for something that would hold her still. She looked over a concrete parapet to the sky and followed it big and over them, all the way over them. She felt suddenly ill, dry-retched, threw up and everything was still again.

All around her men found themselves, picked themselves up; the noise of voices replacing the noise of steel and concrete shifting. She wiped her face and shirt, pulled her skirt over her knees, one of them was bleeding and swollen, and stood up, checking if she could help anyone. There was dust everywhere and men were making their way down the scaffold stairs which stood, still braced firmly to the building. She wandered in that direction. 'You all right?' they said to each other as they waited for their turn to climb down the stairs and 'That was a bit of a rock'. No one helped her more than any of the men, no one helped her less. Car alarms were sounding, there were new noises, odd noises, coming from the new place they were in. A fire had started in the High Court across the road. They could see smoke coming from the building, no one pointed.

On the lower floors there were men shouting and some were panicking and everyone was shaking and cold and pale but they helped each other and before long all the men that had been on the roof and the upper floors and Catherine were further down the building. They 
walked down and round, in stern slow lines. Catherine felt sick again. She walked out onto the eighth floor to throw up. The crane that had stood beside the western wall was at an angle, lying down and against the building. She walked toward it, stopped and put one hand against a column. Resting all her weight through her straight arm she bent over and threw up. She straightened, wiping her mouth with the back of her hand and looked at the base of the columns she could see. Most of the cover concrete had spalled off them, it lay in distinct, chippy piles, as if the columns had grown up quickly from the floors. With the covers gone she could see the closely-spaced spiral ties stabilizing the steel reinforcing bars and confining the cracked concrete so it didn't fall out from the column core. The base of the columns had failed, like they were supposed to, sacrificed themselves in ductile yield so they didn't shear and take the whole building with them. The floor plate was cracked a little, some scaffolding had come down, there were personal things lying around, dropped or shaken off people, she could see a safety boot someone had stepped out of, or fallen out of, someone's cell phone, broken. She looked up, the beams looked in good shape. She thought how well they had done, all of them.

Then the noise came again and the building rocked around her and under her. She could see the concrete shifting in the columns and thought of a heart without a chest in a Victorian book she'd seen - beating in a cage. Everything was elastic, ductile, she could feel the shear core holding the wing she was in from twisting like it was playing with someone bigger. It was coming from everywhere again and the building next door, an older, shorter building came closer and closer and as she watched, disappointed but completely resigned, its floor slab slammed over and over into the perimeter columns of the building she was in.

Catherine was thrown to the ground. She grabbed again at the flat floor which again offered no purchase. In her mind she anticipated it all, what would happen: like a train pulling out from a station, she would hear the columns finally shear at their mid-section then pull the beams with them, then the floors. Every second from then, the building would be something new and the new thing would finally twist the floor open and pull her down so she was falling and watching the building coming down on top of her exactly as she expected it would. Look at you, she thought, watching all it would become. Be monsters, she said, and it was.

She felt all the air as it was knocked out of her, she would hit the bottom of the hole eventually and the building would come down and down and down on her. Something might form a small roof long enough for her to roll onto her side and put her arms above her head to shield herself from it all falling on top of her. She shut her eyes tight, bracing herself and imagined the noise of it falling and falling, then silent. As the building shook she tried to imagine the weight of it, if she arrived in a tiny space inside all the ordered things she said they needed to 
hold up enough space to put the cars and the people and all their things in, broken into small pieces, finding their own way. She would lie there, unable to put her arms down, unable to straighten her legs, stiffening up in the cold and the dust. Trying to cough while the sides of her ribs and her stomach were pinned tight, letting out a tiny cough and taking up shallow, steady breaths that would make a tide in the fine dust floating in the space her arms made around her face. She opens her eyes and it is as if she hadn't, except for the dust that floats into them, nothing changes. She closes them then opens, wide, to see the darkness she will be in. It is close and at the same time goes huge distances in every direction, she looks as far as she can, confused with the blindsight of her other senses, her arms pressing on her face and head telling her she is looking down the short tunnel of her arms and her elbows, but she won't see her arms or her elbows, her arms and elbows will simply disappear in the darkness, spread out into it, becoming black and then part of it. She knows she will be caught, she won't be able to move but she hopes it will feel like floating in the darkness, like the dust. But then she remembers smell and it calls her, the washing detergent she used on her shirt mixed with body odour and vomit and deodorant and blood coming from her broken nose. She could move her tongue and taste the blood. She can't shout or speak, she will hear others shouting but there won't be enough room to take the breath she needs, when she prepares to speak the broken concrete and steel around her choke the inhale and she will cough her tiny cough. She shuts her eyes. It is cold and then she is very hot. The arm under her head takes her attention, everything is cramped but it is tingling with pins and needles. She will move her fingers slightly and a few chips of rubble fall a couple of centimetres. She will open her eyes and shut them again and she will listen. Things that aren't her will push their way from lung to blood and then the blood races round her, the dust will make her concrete. She will meet the sharp hard bits with her fingers as if to say hello again, long time no see. Her hands, pinned behind her head, run over the small space they have, her pinky catches on the smooth round of a steel reinforcing bar, it is bigger but she will have no idea which way it is bigger so it is only the reach of her smallest finger in the tiniest space, it is a smooth centimetre bordered by a skirt, millimetres high. It is life-sized to her small finger, it is a bench that a sink is set into, a place to for a toaster, a cup, a small black cat. It is a desk her finger might sit at and work and take calls from and lose things on. She slows its travel, it exhausts her. You can't design for this, she thinks as if she was saying it to someone, later, in a meeting room, where she is trying to explain, perhaps she is shouting, trying to save her job. It will be a heap soon, if they wanted her to design for this there would be nothing but heaps, heaps and bunkers, she couldn't design for this. She imagines thinking all this below the heap while high above her through metres and metres of broken concrete floors and columns and 
beams and scaffold, more beams and columns and floors and scaffold will fall and hard hats and thermos flasks and paper and nails all in the orange of the fires in the darkness of dust blocking out the sun. She thought about her parents and she thought about William and Michael and how they will get out, how she will be the last one in the building and how this will be somehow what she always expected, like a safe return, like retribution. But, she thought, looking around her as the floor stayed and stayed, as the train didn't leave, It is not as simple as that, and she had to try again.

She got to all fours - hands, knees, the casing concrete raining around her, the outer columns pushing x-shaped belts in their mid-sections, everything shouting and shaking and failing toward the next door building's rigid solid fist, punching. She got from knees to crouching, still pushing at the violent floor with her hands like a sprinter at the start of a race. Something non-structural and tube-like and heavy fell across her head and shoulders and she fell flat, breaking her nose and the bone and the skin of her cheek. Exquisite pain wrapped her head, pushed at her teeth, her eyes, anything it could bear down on. The building wanted her to stay down, nothing in her wanted to move, surely the others were dead, surely she would be dead soon too, surely everything was lost but she started, fell, and she started again, running for the shear core which rocked and shook just like they'd taught it to. She fell and pulled herself along the ground until she could stand again and then she stood again and ran and when she was inside the core crawled to a corner of it and holding her knees tight to her chest, she listened to the parameter columns fail and the floorplate fall to them, closing off the place she had been standing in. The shear core wailed a little toward it and the rhythm of it changed slightly but it stood, unaware of Catherine, who all the forces tried to spit out of the corner. She pushed hard at the floor with her feet to hold herself there, and when she was thrown she would crawl back and hold herself there again. All around her elements were breaking free and rioting against each other, everything was louder and louder, then she heard shouting, heard herself shouting, loud wordless sounds coming from inside all the boom of the building resisting. She didn't know it, she tried to call it back from the whine of the steel chafing and the ground moving under it but it didn't know her. If she could write a note, she thought, but where would its mouth be? Stop its mechanics somehow, weren't they hers? 'Remove the letter from its forehead,' her precursors said - truth, death - and she thought again and suddenly, of Michael and William. 
Thorncrown Chapel 


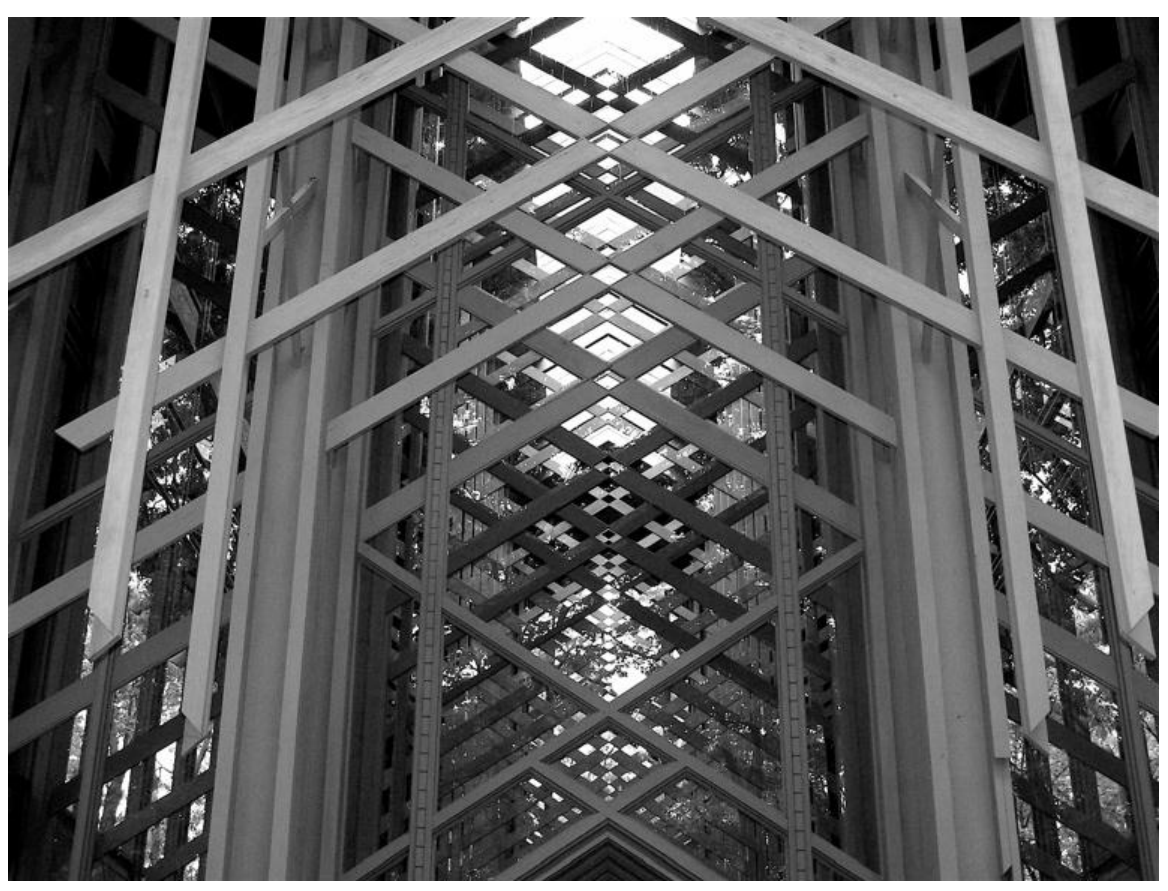


We're running through a wood of disorganised trees with uneven branches and roots that spill from under the ground into the path, laughing. We are two young men laughing. We are in the bush in Hanmer Springs. 'It's in North Canterbury,' we tell our mothers. 'A couple of hours out of Christchurch.' We came here in buses from the engineering school, on a Friday. The sun is spluttering over us as we run. I'm in front. We started laughing when we were deep enough in to be covered. I started, or you started. The bush closes up behind us as we run. We are looking forward to drinking. You've got a girlfriend but I'm not seeing anyone in particular. We're like elves, or dwarves, or something else supernatural. Woodlandish we run and the sun spills on us as we laugh. This is as far away as we've been. We're supposed to be looking for something, it's a team-building exercise but because of the lick of the light and the looking forward to drinking and us, everything disappears except the laughing and the trees and the sex we're not having. We start to get out of breath and you slow to a jog and I slow to a walk and you catch me up and get your tobacco out of the back pocket of your jeans and we each roll a cigarette and smoke and walk to where we think the foot-bridge is.

It will be there, and we will write down the date that is on the plaque that is on the bridge on a piece of paper we were given for the scavenger hunt, but we're not there yet. I look at my watch and add up how long it is, exactly, until we can drink, I'm conservative with my sums. We're away from home and we're really looking forward to drinking. Drinking like we did the week before we came here in a noisy nightclub when you told me I looked like your brother and you told me how much you wanted to have sex with your brother and I wanted to have sex with you - very much. Then your girlfriend came back from the dance floor.

Our team will do badly. There is a lack of strategy that, as we walk through the mongrel wood - the laughing still close, we don't see. We split our team up, thinking it would be faster and it is for a while, but at the end we won't all arrive at the same time and some of us will stand at the finish line with some of the answers, watching team after team come in together to beat us. We will probably be last or we probably won't complete the exercise at all and one of our lecturers, a man who is decent and courageous, will explain the point of the scavenger hunt and how it demonstrates something bigger, something that will be useful when we are all working as engineers. Our team will be a good example of a bad example.

Then it will be time for drinking. We will drink and drink, finally and with purpose. I will fall down in the car park and won't be able to get up and I'll moan. My mind will be completely alert but my body won't work. You will call me a pussy and say I can't handle my drink and help me up. Large parts of my body will press against large parts of your body and you will tell me again, softly and in my ear, how much I look like your brother and we will laugh. 
When we get back to Christchurch we will go to more bars and you will move into your girlfriend's flat and I will sleep with one of the women you flat with. This will upset you greatly. We'll have a loud, drunk fight on the street outside a bar. I'll spit at you and you'll push me. I'll regain my footing and punch you in the face and in the stomach. You'll recover quickly and grab the back of my head with both your hands and smash your head into my head, splitting it open from above my hairline to the top of my eyebrow. This will end the fight. After stitching and time it never closes properly and anytime I want to think of you, I have you under my fingers as I sweep my hair out of my eyes.

You will sleep with someone who looks like your sister, if your sister is a blonde woman with no hips who isn't your girlfriend. You tell me you woke up with her, but you can't be sure. I'll say, 'Oh you can be sure.' Neither of us will know why you've come to me. I will pick a piece of tobacco off my tongue and look out over the backyard of your girlfriend's flat, but not yet.

Now, we are walking in silence, smoking, toward the bridge and the plaque and 1902. Without looking up you say, 'This is bullshit,' and I laugh in a snorty way and say, 'Nice day though,' and you call me a pussy and I say you're the pussy and we laugh for a moment and you shake your head like it's all bullshit. I slow barely so you're leading and I can see you, even when I'm looking down. I watch the silent swing of you as you walk down the path through the ferns and the short trees and part of me knows we will never be together like this again. I imagine you, imagining we are dead and this is what it looks like.

The low green bushes straighten and grow into other hemisphere's wood. Their branches become ordered and high up. They thin, so the sun comes in in sheets then is gone and it is cold. The noise of our walking feet changes as they land on dusts, then centimetres, then metres of snow that suck our feet back each time we take a step. We grow older as we walk through the unseasonal snow - years adjust us as we walk. Eventually we're wearing dress pants and dress shoes and collared shirts. We're grown men, structural engineers, you're married to Donna but I'm not seeing anyone in particular, there's been an accident; something we built has failed. You can't find your camera and we have stopped, finally, fighting. I pull my short, cotton shirt-sleeves in vain over my skinny arms, you fold yours over your chest but neither of us blow on our hands or stop and jump because nothing can hurt us now. I try your name slowly in the vapoury air, making a big deal of the start of it and the end of it, 'My Kill,' and it is round and large and floats. I walk through it. You try mine with the same theatrical start, "Will He Um. Can you hear me at the back?' We laugh again and look at each other. Everyone we know is dead to us because they're alive. You know where you're going and as the snow falls suddenly from nowhere and in all directions I follow you up an incline, digging my thin-soled leather shoes 
deep onto the snow, cutting steps like you.

I look at you as you reach the top and the light of Thorncrown warms your face and as I climb and look to where the light is coming from the chapel grows from Ozark mountain stone, like trees do - close and slight until, when my feet find level ground, it stands in front of me properly made and if, now built, you took it away it would appear as if the hill had fallen. Lying along the slope, the building has one glass wall facing the valley. Its opposite wall faces the rocky, wooded hillside.

In plan it's no more than a single room, in form no more than a gabled shed but it lifts our cold dead hearts to its highest pitch where they stop, pulled back with all the forces by the parade of cross-braced structural frames coupled into the steep roof. Like the opposite of a Gothic cathedral, it is landing rather than flying. Pulled together by light interior members in tension rather than pushed together by outside mass.

One clear symmetry calls itself out of the lattice storm. Two diagonal crosses - saltires like other ordinaries extended to the edges of the field, opening up large diamonds, triangles. Repeated and repeated, rattling on our eyes: slim stands of wood arranged again and again into the same strange truss. I count it off: the timber posts down each side of the space, the short cross-braced members and their vertical hanging rods. Then towards the ends of the eaves the long, raking, inclined members. It's not obvious how it works. Some of the members just join to the vertical posts, it's not fully triangulated. So, if there's a thrust down an inclined bit of wood then its associated post has to bend to take the force of that thrust. There are bending moments but there are no bending moments in a conventional truss. It's not immediately obvious how it works. Every constructional element is exposed, readable from within and without. Every framing member, every connection, every nut, bolt and screw shows and if any one part is removed, the building will collapse. Even the vertical elements that appear non-structural stiffen the slender diagonal members. It's everything it is but it's not immediately obvious. It's a truss that's a frame that's a truss.

You're still in front of me, standing as still as you can, shaking in the cold. It's still cold. You turn round to look at me and you're smiling, open and broad and you say, 'I bet we won't get out of here,' and you mean the same, but I agree so I can't take your wager. You nod your head toward the chapel and we walk to it because we are going inside it.

We crunch crunch our way to the heavy tall doors which are open. It's not much warmer inside. The oaks and the maples and the dogwoods shelter us from the worst of the wind and the glass walls stop the rest of it but we leave the doors open and the weather comes in through the holes in the rock. We are completely held from harm, nothing worries us. We look down the 
aisle to the altar end which opens to a small grove of trees, a rock outcropping and a steel cross. The frames are high above us and around us. Now that we can't see all of them they each seem individual, smaller and in their new scale they point out the other small things to us. The lecterns, the pew supports, the door pulls and the exterior cross are all painted in an icy blue. They dance about in the gray stained wood of the chapel and the trees and the white snow.

You walk down between two pews to a post and for the first time I see that the two sticks of wood that form the columns hold between them a stack of small wooden blocks, one on top of the other. You run your hand over the smoothness of the sticks, then the bump of the blocks, then the smoothness again. Everything was carried here two men at a time - nailed together and lifted by hand. Nothing is so big that it can strike us down. I wish the sun would come out and it does and a sparkle of light rings out inside the roof like bells do. We look up. At both levels where the inclined wooden members meet in the crutch of the cross they stop and are joined by a little world of steel plates and almost miraculously the very centre of the joint is open and transparent and there are jewels of light penetrating through each of the frames. Like the light in the Canterbury bush we are in kisses us, this light stutters down on us - nothing more than light and shade, reflection and transparency. 
류경호텔

Ryugyong Hotel 


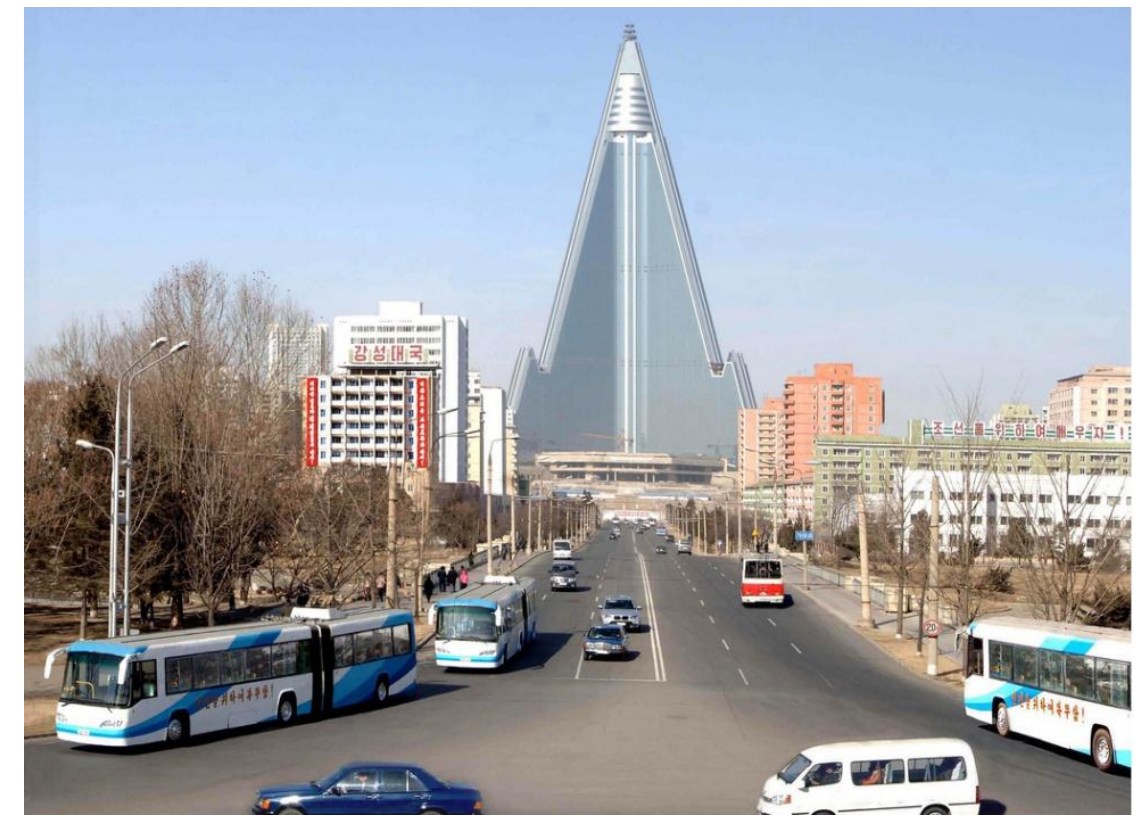


Donna was beside the sea when the earthquake struck. She ran most lunchtimes, changed at work, drove to Balena Bay, stretched on the sea wall then ran in the direction of the city beside the rocks, then the golden sandy shore. She turned round when she got to the swimming pool. Sometimes it rained in her face the whole way, sometimes she could see all the way to where the Hutt river started. It cleared her head, she said, and made the afternoons more productive. She was just rounding the corner into Oriental Parade when the ground dropped from under her step. She fell and was thrown about. Then the strangest sound made her look up and the city was gone, lost under a cloud of dust. The sea wall fell and the sea came in over rocks and broken stone. When it was still again, Donna climbed, first on all fours, then, as the water rose, standing up waist deep in salt water which was dark with silt. It occurred to her she could swim, but she looked out and the sea was deep and mean. She couldn't see the road any more so she just kept walking until she found a place she could climb up onto. When she reached the road the earth rolled over again and the hill fell bringing all the houses with it. She fell flat and her teeth chimed shut. When it stopped she couldn't get her bearings, she walked one way, scaling piles of damp rich soil then another but she couldn't find her car. Her clothes were soaking and as her skin dried it tightened and stung with the salt. The wind was up. She looked across to the city, tried to make out Featherston Street. Then found herself walking that way, climbing over dirt and rocks and broken buildings, her feet slipping in her wet shoes. It took her six hours to get to the cordon. The city was shut. She didn't have her cell phone. Her husband, she explained to the police officer and he suggested she go home and nodded toward a crowd of people walking out of the city. Some had handbags, some had no shoes. She stayed up all night but Michael never came home. It took six weeks for them to pull out a piece of him that they decided wasn't part of anyone else and another four to identify that part, conclusively, as him.

Each morning she went to a briefing held in a room at the hospital in Newtown - it was hard to get to. Everyday day different roads were shut. Some of the engineers from Michael's firm were working with the search and rescue teams. Most of them didn't recognise her and when they did asked how she was. One morning the woman Michael worked with was there, black-eyed and short-haired, with a bandage across the bridge of her nose and stitches in her face and the back of her head. Donna caught her eye and Catherine looked away quickly, but not without a scowl which Donna read as disgust but then downgraded to pain, or irritation. Donna replayed it, though, and when she did it was always directed at her, and from the corner of Catherine's sunken eyes, at the memory of Michael. The engineers left after the preliminary briefing with the search and rescue teams and the families were left in the room with grief counsellors and people from MSD. Sometimes the rescue dogs were led in so the children could 
pat them. One day a coroner asked Donna if she and Michael had any children, which she thought he would know. They were having trouble finding Michael's dental records, they were in town somewhere and no one could get into the building. There were no teeth, but here was the coroner talking about a full set of teeth. This is how we are kind to each other now, thought Donna, In the hope that lies in the promise of teeth. They needed a blood relative but she told them there wasn't one - not in Wellington. Could she drop in something Michael had worn recently, then?

'Tomorrow?' she asked.

'As soon as possible.'

As the weeks went by it became more and more apparent that her husband was gone. Her brother-in-law was in the States. Her sister-in-law in Europe. Her parents had been dead for years. She was an only child and she and Michael had no children of their own. The office she worked in was closed and her manager had rung and asked if she would consider moving to Auckland or New Plymouth. Her feet seemed light on the streets as she ran round her neighbourhood.

There was a hole that ran the length of one side of the house. The chimney was gone, it had landed on the next door neighbours' car. A builder Michael worked with who lived close came round and put tarpaulins up so the wind wouldn't come in the hole in the roof or the wall. He said she probably wouldn't be able to stay there. She cooked what she could on the gas barbeque and read and cried by candle light. Some university students brought her a chemical toilet. The wind came in. It was freezing.

Early one morning before the sun was up, Donna walked to the hole in the wall. The tarpaulin flapped, letting in the dark. She bent low and watched it beat, watched the hedge beside the house appear and disappear, playing her focus between the blue single surface and the tangle of the branches and roots. She was pretty sure there was a hedgehog living there, or a rat. There were bound to be rats. She climbed out of the hole. She was wearing track-pants and a polar-fleece, she folded her arms against the cold. The bricks from the wall were on the ground beside where the wall used to be. No one had taken them away. She reached out for one and placed it where it might go. She squatted and thought about the shape bricks made in a wall Humpty-Dumpty, Kilroy. She picked up another brick and placed it next to the first. Then she put one on top, straddling both the first bricks, making a letter $\mathrm{T}$. The mortar in between the bricks had been shaken off but not smoothly, they didn't fit together neatly any more. She picked up another brick and blew on it, some of the dust came off, but some of it stuck to the brick. It probably wouldn't work. Then she looked at the garage, the door was swung open, had 
been since she finally made it home on the first day. Inside, she could see some large sheets of plywood for the extension they were building. Donna walked over in her bare feet and pulled one out. It was longer than she was tall, wider, she had trouble carrying it. When she got to the hole she laid it against the wall, then went back to find a hammer and some nails. She leaned against the ply and hammered nail after nail into whatever she could find to hammer the wood into. And when she stepped back it stayed. When the sun came up, she'd covered most of the gap in the wall. She walked away without looking at what she'd done, showered and drove to the hospital. As she sat down at the briefing she saw Catherine again, across the room speaking with a group of men. She'd met Catherine twice, once at a Christmas function where she wore a bright blue dress. She'd been funny and easy, she'd lost her wedding ring. Everything lay on her lightly. She was good friends with William, but William was gone now, too. There was no ease in her today. Her face was pulled around the scars that redefined it. She was vigilant, talking closely to one of the men, moving herself to try and hold his eyes, to stay in his face as she made insistent chopping movements with her hands. Donna couldn't imagine her in the blue dress any more. Then Catherine stormed out. Donna followed her down a corridor and as she turned a corner Donna said her name. Catherine stopped and turned to face her.

'Do you know who I am?’ Donna asked.

'Yes,' she said, and walked away.

Two days later, in the morning, Donna was inside putting cups back on shelves when there was a knock at the door. When she opened it, it was Catherine.

'I could do your assessment,' she said.

'Hello,' said Donna.

Catherine riffled through an A4 envelope she was holding, 'I've got the forms and I could do the assessment,' she held the forms out to Donna, to show her, 'of the damage. I could assess the damage.' Donna looked at them and looked back at Catherine. Catherine looked away, out over the rubble of the chimney into the neighbour's yard. 'It could take a while otherwise. There aren't that many engineers around. It would mean you could get started,' she waved the forms at the pile of bricks, 'with the repairs. With the', she flapped her other hand slightly, 'insurance.' She looked at Donna again. 'I could do the assessment now.'

Donna folded her arms and shrugged her shoulders slightly, 'I think we'll be all right,' she said.

Catherine nodded and turned and left. That afternoon she called al-Qahira.

'Miss Lyndon,' the woman said, 'Anwad has been trying to reach you. Thank you.' And she put Catherine through. They'd read a paper she'd written, then they'd contacted the office in 
Beijing, William had been there and they'd talked to him but he had said he couldn't imagine her wanting to relocate. 'He said you were pretty happy there.' Then there was the earthquake and they wondered if perhaps her circumstances may have changed. All this was in the email they'd sent.

'Some people worry,' Anwad said, 'about the location of the work. But it is all very,' he drew the word out a little while he searched for the next one.

'Controlled?' Catherine said.

'Yes,' he decided, 'controlled. Delineated. The work pays well, as I said, and many foreigners enjoy the experience. The work won't be taxing but the circumstances make it a unique opportunity.'

Catherine met her sister at the food hall in Auckland International Airport. There were three hours until her flight so they had lunch. 'When will it be back to normal?' Isabel asked. Catherine shook her head. She'd spent weeks in the CBD. They worked in teams of three or four, each building fell down differently and they had to search for some record of its wholeness and order in the shambles. 'The smell must be awful,' Isabel said, because that's what the newspapers said. The smell didn't worry Catherine. It felt in the city like anything could happen, like any shape was possible, like some counter-physics was in play and everyone was making their best guess. 'Run it again,' she said to one of the engineering students who was modelling some measurements she'd brought back from the city and he did and it came out the same. 'I just can't see where it's going to,' he said. 'Well it has to be going somewhere,' Catherine said, and she was right but they just couldn't account for it, tonnes and tonnes of weight was standing up but they didn't know how. She rubbed her face, they'd been working all day. It was dark outside now. Under her hands she could feel the place where her cheekbone had been reconstructed and the scar that ran through her eyebrow across her nose, she could feel the break in her nose. Everything might fly away. Isabel and her parents thought she was going to Seoul even though she said Pyongyang every time she'd talked to them. One of Isabel's clients from the salon had been to Seoul on holiday - Isabel had got them to write down the name of some restaurants and a shopping centre. Catherine didn't correct her, just thanked her and put the note in her backpack. 'Do you like your hair short?' Isabel asked. Catherine shrugged. Isabel scrunched her face up, like she was looking very closely at her, 'Looks good,' she said, reaching out to pull some of her fringe over her forehead. Catherine smiled at her and they hugged goodbye. 'We'll see you in August,' Isabel said. 'Can you call? No. Sorry, you told me that. Right, 
see you in August.' Catherine gave Isabel one last hug. 'Try and find some girls to hang out with,' Isabel said as she walked away. 'You've been hanging round with boys for too long.'

Catherine's guide met her at Sunan International Airport. He asked about her trip and if she would like to rest. 'I'd like to get started,' she said. 'I understand there's time pressure.' So they collected her luggage and drove to the office. On the way they stopped at the Grand Monument to Kim Il-sung. The driver stopped the car and opened Catherine's door. Her guide was holding a small bouquet of flowers and he led her past the life-sized bronze statues and the giant stone replica of the flag of the Workers' Party of Korea. At the central statue he handed her the bouquet and she laid it with the others at the feet of Kim Il-sung. As they drove through the rest of the city, her guide explained where they were and pointed out several landmarks. 'This is the Arch of Triumph. It is the tallest triumphal arch in the world. It is bigger than the arch in Paris.' Catherine nodded. 'It was built in 1982 to honour President Kim Il-sung's military resistance against Japanese rule.' As they drove round the arch a bus passed them and several cars. The traffic was light as they turned into a road which was flanked by concrete high-rise buildings. They past several cranes and there were quite a few fishing boats in the river. There were very few people. 'Pyongyang is a tidy city,' Catherine said. 'Thank you,' said the guide.

They parked the car outside an office block and climbed several flights of stairs to the engineering office. They stopped at a desk near the door to the office and her guide spoke to the receptionist who smiled at Catherine then walked through another door and returned with Nazif. Nazif was managing the project for the Egyptian developers. He shook hands with Catherine and showed her to the room she would be working in. There was one computer in the corner and the rest of the room was filled with men and woman at drawing boards.

'Our leader has made sure we're very advanced in Korea,' Nazif said. 'he has supplied a well-trained and plentiful workforce who can be utilised to achieve the highest results.'

'Very good,' Catherine said and she smiled at Nazif and her guide and Nazifs guide. Catherine enjoyed the pace of the work in Korea. Everything happened in front of her. She spent the day walking round the drawing boards, looking at the plans that were being drawn up and soon she found herself testing most things on paper with a pencil. Usually, the computer stayed turned off. She mainly worked. Her guide would wait with her while she worked into the night. He would read or just sit and look out the window of the office. Sometimes she would need him to translate something and he was always quick and correct. The kitchen at her hotel packed small dinners for her which were left in her room by the women who changed the bottled water in her refrigerator early each morning. Her guide also had a packed dinner and 
they would sit and eat together. Sometimes he would read her articles from the newspaper. Sometimes he would sing along with the radio, it was the only time she noticed it, even though it was on all the time. Sometimes they would just sit, not talking and eat.

They delivered the first set of construction papers on a Thursday and Nazif gave a short speech to the small group and their guides and interpreters. A representative from the NKPR gave a speech explaining that they were pleased. Nazif asked Catherine to come to his office, after the celebrations, when everyone had gone home.

Nazif's office had small windows that looked out on the bright and dry Korean winter. When Catherine arrived he called her over to a corner and stood her in front of him. He got her to crouch down slightly, then look up. The top of Ryugyong poked weakly above the roof of the building which was butted against theirs. They could have opened the window and touched it.

'On Monday we start a new project,' he said.

Catherine looked at the tiny poke of the ugliest building, at the crane on top of it.

'Would you like to stay and start another project?' Nazif asked.

'On Ryugyong?' Catherine asked.

'Perhaps,' Nazif said.

'I'm happy to work on anything,' she said. 'You decide where I would be most use.'

'Good,' said Nazif. So together they began to build Ryugyong again. It came to life in their hands, in the hands of the people they employed. It would still be useless but it would shine. Come home. Like a holy mountain. She received a letter inviting her back to Wellington for the opening of part of the CBD.

'If you go to Wellington,' her guide explained, 'you'll need visas. Shall I get you the appropriate forms?'

It was a long flight, she said. She looked out at Ryugyong, watched the light clip the new cladding, as if it were a space shuttle. She was living in the future now. No, she replied politely, she wouldn't go to Wellington. Wellington would have to wait, she thought, for her and for Ryugyong. The next day an official arrived with a small bag which he handed to Catherine. The people in her office gathered around. Inside was a green cashmere cardigan. Everyone applauded and the official said they were grateful for her work. The cardigan was made in Kaesŏng, he said. 'It's beautiful,' she said. 'Such fine workmanship. Thank you.' He had KFC vouchers as well. They were very happy with her work, with her dedication. He reached into the pockets of his jacket. Did she like to eat chicken? That night she and Nazif took their guides to KFC and they ate chicken and fries. As they walked home, Nazif said, 'I think I prefer Korean food.' And they all nodded in agreement. It was a cold night. 
Nazif asked if she would come to dinner with the Macedonians. None of the other foreigners were available. The Macedonians were electrical engineers, sent by the company who was installing the telecommunications aerial on top of Ryugyong. The aerial was funding the rest of the tower almost completely by itself. The revolving restaurant had been green-lit the day the contract for the aerial was signed. No one asked who the aerial belonged to. There was at least another six months' work left now the aerial was being installed.

'Would that be inappropriate?' Nazif asked.

'Sorry?' Catherine said.

'If her boss was with her, say me, it would be appropriate for an Egyptian engineer to go out for dinner with co-workers. Is it appropriate for a Western engineer??

'Do you mean a female engineer?' Catherine asked.

'Is it appropriate?' Nazif asked.

Catherine hadn't thought about it. 'Yeah,' she said. 'Is there no one else?'

'There is a karaoke competition at the NGO bar and everyone will be at that.'

'Maybe we could take them there after dinner,' Catherine said.

'Of course,' said Nazif. 'Would that be all right?' he asked his guide who said he would ask the official downstairs.

They met at her room. Nazif looked at his watch. They were late. The Macedonians would be waiting. Catherine quickly picked up her things off the bed. Her guide was speaking with Nazifs guide, and they didn't stop as they left the room, one holding the door open for the other - their hands in the pockets of their trousers. The guides walked a few feet in front of Nazif and Catherine, still talking. It was dim in the hallway. The lights were off and there was very little light coming in the windows. Nazif and Catherine followed the guides to the elevator.

'They want to see the hotel,' Nazif said, pressing a button for the floor the restaurant was on.

Catherine hummed in reply, pinning her hair up at the back, adjusting the collar of her jacket.

'I'd prefer they didn't,' Nazif said.

'See it. Or visit it?' she said.

Nazif nodded, she was right.

'You could organise to drive them by,' she said. 'They can take some pictures. It'll be sunny tomorrow. It looks good in the sun.' 
'It looks great in the sun,' he said. The elevator arrived and Nazif stood back for Catherine to walk in. Then followed her. The doors slid shut. It was dark in the elevator. North Korea made sure they used just enough power.

'Not so good on the inside,' Nazif said, which he didn't need to, because they both knew that. 'You could drive them past,' Nazif said. 'If they insist, which they won't, we'll sort it out. Neither of them need to go up. They're here to instruct our people, so they don't have to go up. I don't think their employers would be happy to hear they were asking.'

Catherine nodded.

The doors opened.

'They've only just got here,' Catherine said.

'Exactly,' said Nazif. 'Take them out tomorrow. When the sun's out.'

'It's as much for their good as anyone's,' Catherine said.

'Exactly,' said Nazif.

The Macedonians had been in Pyongyang since the night before. They'd slept most of the day they said. The flight had been awful. They were having trouble getting used to their guides they said, pointing behind them to the table where all the guides sat. Catherine and Nazif smiled politely. They had a pleasant dinner. They asked all the questions that people ask when they first come to Pyongyang. That they asked when they didn't come to Pyongyang - from their houses, when they saw it on television. 'I hadn't really noticed,' Catherine said to the Germans. 'A building's a building.'

When Catherine and Nazif took the Macedonians to the karaoke competition and then to a disco, one of the Macedonians shouted in her ear above the music that it was all so strange. She smiled. 'It is what it is,' Nazif said. 'It's what you think.' Catherine and Nazif and Catherine and Nazif's guides walked the Macedonians and their guides to their room. At the door they asked about going up Ryugyong and Nazif explained the situation, and how they could see the hotel but not go inside, which disappointed them but they accepted it and said they looked forward to seeing the hotel up close. Closer because they were sure they could see it from the window of their room. 'The sun was shouting off it,' one of them said. 'Like it really thought it would reach the sky.' Everyone laughed and said good night. Catherine asked her guide if he could pick her up early the next day.

She was awake before the 7am workers' alarm. In the car on the way to the office, she read from papers she had brought home from work. Her guide looked out the window and sang along 
absently to the music which played on the car's radio. Nazif was there when they arrived. The Macedonians were on their way. He had spoken with an official and they could go as soon as the Macedonians arrived, before the meeting, so she had a reason to get them back.

Ryugyong was huge - 105 stories high. It had been started in 1987 and then stopped in 1992, from which time it had stood dormant, wasting, erased from official maps and photographs of Pyongyang. The Macedonians knew this and they stated it in the van, adding, 'Isn't that right?' To which Catherine smiled. 'Perhaps,' she said. 'I wouldn't know.' All the guides were in the van with them. As they turned the corner, the sun came out and the hotel gleamed, shone, shot the blue sky with a spear of white light. The Macedonians got their cameras out, the guides flinched and Catherine explained that she'd cleared it, they would take some appropriate photos and she would check those photos then an official would check her choice. It was all on her and Nazif, no one else. No one needed to worry.

'The Ryugyong,' she began, 'is based on the holy mountain on which Kim Jong-il was born. You can translate its name to "capital of willows" which is also an old name for this city.'

Back at the office the Macedonians were happy. The meeting went well. As they drank whiskey with Nazif, Catherine checked their photos with one of the government officials who worked at the office. They chose four of the photos and said the Macedonians could take these. Nazif gave them both a small statue of Ryugyong that had been made for visitors and they were driven to the airport with their guides by a driver.

When Nazif got back from walking the Macedonians to their car he asked Catherine to come into his office and they sat there for a while, relaxing, talking generally about what would need to be done next. For the aerial. Catherine brought out a handwritten spreadsheet and they looked at it rolled out on Nazif's desk. After they both knew what they needed to do next, Catherine went to leave. As she got to the door Nazif said, 'Did it look good?'

She nodded.

'Did it look very good?'

She smiled, 'Yes.'

'How many photos did they get?'

'Four.'

'Out of?'

'Probably twenty, thirty, I don't know.'

Nazif nodded. It belonged to them, him and Catherine and their guides, and the people who worked on it. The Macedonians didn't understand. Neither did the Polish painters, or the 
plumbers from Brazil. It was good that no one would see it.

The Macedonians had stood at the window of the restaurant the night before, as the dusk welted over Pyongyang, and complained. One of them framed the view in the rectangle he made with the right angles of his outstretched hands: thumb, forefinger, thumb, forefinger. They would hold the city in their heads he said. 'No regime can take that from us,' the other said.

'We can hold it in our hands,' he said, through the well of alcohol he'd drunk.

Nazif and Catherine looked out the window.

The first Macedonian brought down his hands and said, 'It's an empty city anyway.'

'It's what you think,' Nazif said.

A week later, an official came to Catherine's desk with a certificate. Everyone gathered round. He cleared his throat and explained the debt of gratitude they owed her for the work she had done on the marvellous hotel and how they wished her the best in her future work. 'Your work in Korea is complete,' he said with a broad kind smile. Catherine took the certificate and, looking at it, thanked everyone heartily. 'I have been very impressed with Korea,' she said. 'Thank you.' She put on her coat and she and her guide went to a car which was waiting for them in the carpark of the office block. Her cases were packed and in the trunk.

'You will like Beijing,' her guide said as they drove to the airport. 'It is extending an arm to imperialism but it has a fine Marxist tradition.'

'Thank you,' she said. 'I have enjoyed my time in Pyongyang greatly.'

'Yes,' said the guide. 'It is a fine city, but no foreigner can stay here forever.'

Catherine nodded. 'There aren't many people out today,' she said.

'No,' her guide replied. 'Not today.'

It was like a slow thaw. Or perhaps like tiny holes were being punched through her. Imperceptibly, while she slept. Beijing was fine. It lacked the comfort of enclosure but the structures were all there. The guidance was clear but people made it difficult. She would go to their desks to ask a question and they would be having a cigarette or standing at someone else's desk, talking. She could never find her interpreter and everyone left at five o'clock. In Beijing she felt her face set in a new way, her neutral position became a frown, she began to wear reading glasses. She applied for a transfer. 'Beijing and I,' she said, 'are not a good fit.' Her manager said lots of Western women found that.

The work in Taiwan was interesting and people worked harder there. She worked with several women from China and Iran but despite this she felt agitated constantly. She couldn't quite keep up, people would talk and she would talk but she felt like she was floating out to sea. 
'But why wouldn't we tie it to the shear wall?' she would say. 'The cost is minimal,' and the meeting would move on, as if she had said, 'Oh I agree.'

'Taiwan isn't really working,' she said over the phone to the human resources manager in the London office. 'Isn't there anything there?' 
Grand Lisboa 


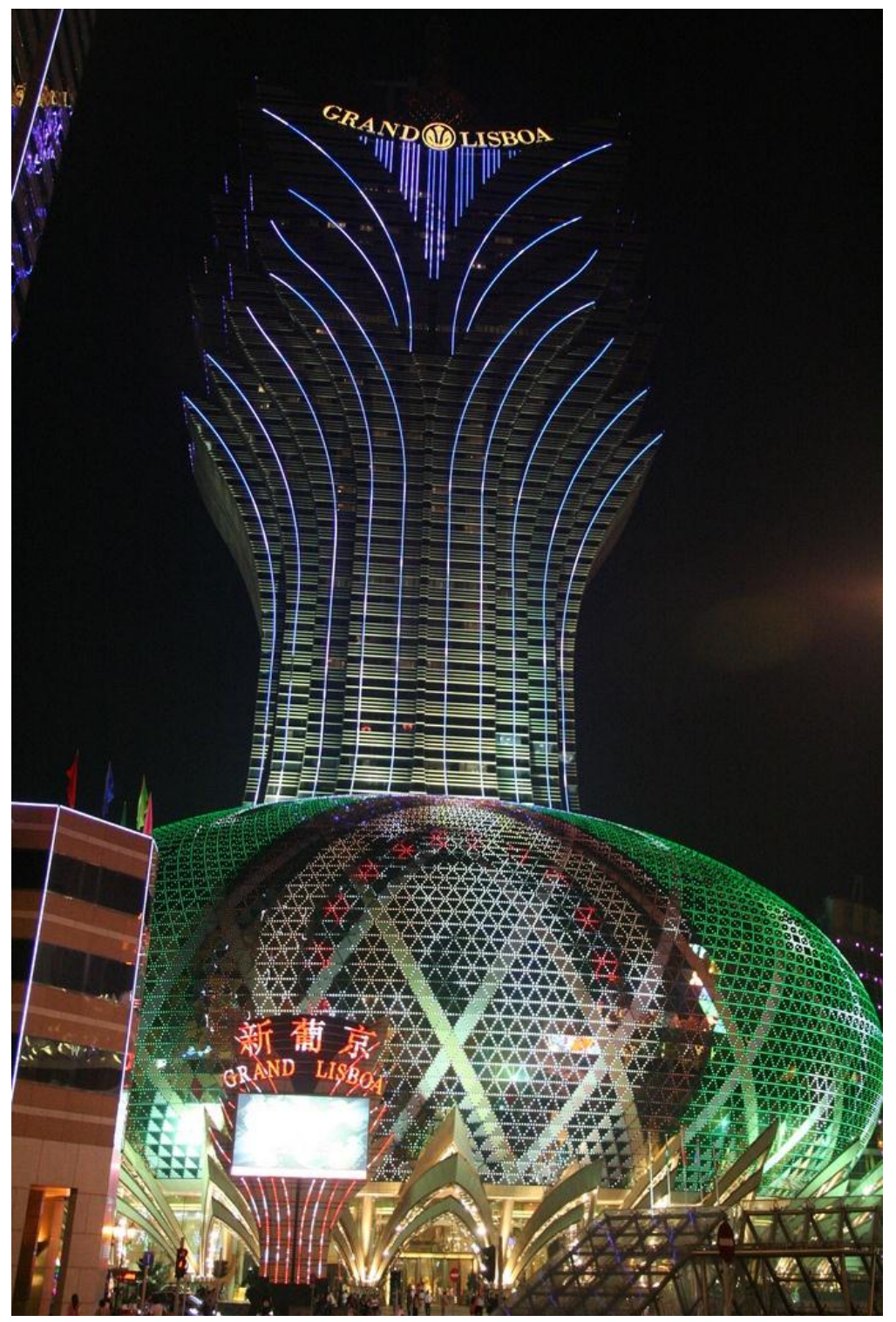


Biyu suggested it. She and Catherine were sitting at their computers. There was something wrong with the air-conditioning. It was freezing. Outside it was forty degrees, inside they'd wrapped the towels from their gym bags around their shoulders. Catherine had the entertainment section of the Apple Times over her bare legs. Everyone else had gone, but they had to collate some plans for a meeting the next day. They shouted file names and version at each other while they worked in shivering urgency.

'It'll be like this all the time in London,' Biyu said.

'No it won't,' Catherine said, typing with heavy strokes. 'It'll be summer won't it?'

'London's freezing,' Biyu said. 'All the time.'

'Have you lived there?'

Biyu shook her head. 'I've seen pictures.'

'Pictures of summer?'

'Pictures of snow.'

Catherine lifted her towel over her head like a hood. Biyu looked up from her computer and did the same. 'And grey,' she said. 'London is always grey.'

'What about the parks?' Catherine said.

Biyu shrugged. 'You should go on a holiday before you go, anyway.'

Catherine swivelled her chair to open a filing cabinet behind her.

'I should take you on a holiday.'

Catherine nodded.

'To Hainan.'

'I don't like beaches,' Catherine shook her hands to try and get some circulation back in fingers.

'Macau,' Biyu said assertively, as if it was decided. 'We should both go to Macau. For some gambling.'

Catherine rubbed her arms and looked out over Taipei. The sun was out and she imagined she could see the heat rising off the buildings beside them and off the cars below and the people. She imagined that all the close heat was rising right in front of their window while they sat behind it, freezing.

'Do you like gambling?' Biyu said.

'I'll be gone soon,' Catherine said.

'All the more reason to do it, then.' Biyu stood up and walked to the printer, she hopped slightly as she went, breathed into her cupped hands. 'London is freezing and grey. You'll need some colourful memories to hold you over.' 
The next morning the air-conditioning was fixed and the meeting was successful. Their manager thanked them for organising the files so promptly.

'It was freezing here last night,' Biyu said. 'I don't think I will ever get the feeling back in my hands.'

'Oh,' said their manager.

'It would be nice to have some time off,' said Biyu. 'To recuperate.'

Their manager smiled.

'From the cold. It really was very cold wasn't it Catherine.'

Catherine nodded, offhandedly, she was checking emails on her phone.

'Both of you?' their manager asked.

'I'd like to take Catherine to Macau,' Biyu said. 'For the weekend.'

'We are very sad to see you go,' their manager said to Catherine. 'We understand, but it would be nice if you had some good memories to take with you. Macau is an exciting destination.'

'She'll have so much cold when she gets to London,' Biyu said, and their manager nodded.

The company had a suite at the Grand Lisboa. It was the jewel in their corporate crown. When they pulled up outside the hotel, Catherine got low behind the taxi window so she could see it spread above them, 'I'm not quite sure how you did this,' she said.

Biyu smiled, 'But you're happy I did.'

'Yeah, I think I am. But how did you do it?'

'No one likes to look mean,' she said. 'And what's the first question you're going to be asked in London?’

'How did I like working in Taiwan?'

'And Catherine,' said Biyu as she paid the taxi driver and a concierge loaded their suitcases onto a trolley, 'how did you like working in Taiwan?'

Catherine was still looking up. She shielded her eyes from the weak glare. The large column-free elliptical sphere bulged like it had been dropped and out of it gasped the hotel, like some titanic spurt of concrete, and windows, and show.

'It's a lotus,' Biyu said. 'It's 228 metres high and it cantilevers over 20 metres on either side.' She lowered her voice. 'It's not the most elegant thing you'll see but it's pretty fucking impressive.'

Catherine nodded absently. 
In the foyer were huge glass cases and in the cases were huge ivory sculptures. Metres long, one had been fashioned into masses of figures: hundreds of tiny monkeys carrying a monkey king toward thousands of important looking people who carried scrolls and farm tools - some of the monkeys played musical instruments. Another was a sprawling castle set into willows and flowers. The floor of foyer was marble and lights hung from circular depressions in the high ceiling. For a moment, in the disorientation of the people and the golden glow of the lights and the lights reflected in the shine, Catherine was a monkey carrying a king to the palace. Shrunk small and sharp and brittle.

'Have you been here before?' Catherine asked Biyu as they sat on the couch in their suite, looking through the brochures that had been left on their table.

'Hm? Oh yeah, a couple of times. I won a competition in an office sweep. And then, the other time was with a woman from Iran. She was an architect.'

Catherine looked around the room and felt the couch cushion her. 'Thanks,' she said.

'We all know it hasn't been easy.'

'It's been fine,' Catherine said. 'It's me.'

'You've made it blatantly clear.'

Catherine felt the colour rise in her cheeks. 'I just don't feel like anyone's listening,' she said. 'Like no one hears what I'm saying.'

'Well we don't,' Biyu was looking through a menu for room service.

'But why?'

'You don't really belong,' said Biyu.

'In Taiwan?' Catherine said.

'Anywhere,' Biyu went to get the phone. 'In nature?'

'I don't like beaches,' Catherine said, searching, grasping.

'I know,' said Biyu. 'That's why we came here.' She was soft and round in the geometry of the window.

'It suits me better than in the West,' Catherine said.

'Then why are you going to London?' Biyu had the phone now.

'It should suit me better,' corrected Catherine. 'It should be better.'

'It doesn't seem to,' Biyu said.

'No,' Catherine said.

'Well, maybe London will be better.' She began to dial the numbers on the phone.

'Yeah,' Catherine said. 'Now that I've lived here.'

'Yeah,' said Biyu, lifting the receiver to her ear. 'Or the earth.' 
'What?' Catherine said.

But Biyu was already talking to the restaurant. She was soft and round and dark. In the white of the walls and the square of sky the window caught her in she was like a shadow, all her features were flattened to one brunette plane. The air-conditioning and the hum of the street below gulped up what she said as it left her mouth. Catherine was sure her words wouldn't make the phone which she rested on her chin. Half an hour later a plate of dim sum arrived. 'Almond cake,' Biyu said. 'Chicken cakes, cashew cookies, egg and cheese rolls.' She took the lid off the second platter, 'And shrimp.'

The afternoon dissolved into a peaceful roam from gift shop to pool to lobby, where they stood for a while in front of the polish, symmetry and internal flawlessness of the Star of Stanley Ho. It was lit from underneath and every facet of it twinkled as if it would break out of its ordinary circular case. Behind it a large gold lotus opened. It was the largest pillow-cut diamond in the world. That night they ate tortillas in the hotel's New York-style delicatessen, under a ceiling of blue and silver lights. They went to the Crazy Paris Show and then to bed.

The next morning they woke early and caught a taxi to Co-Tai a 5.2 kilometre strip of reclaimed land which joined two islands. They stood on the cobblestoned piazza and looked - at the Galaxy Macau, the Venetian Macao. They took a tour and saw the Tang Dynasty fortress and volcano which had been built for the Casino Babylon.

They saw the Casino Oceanus in the water cube which had been copied from Beijing. As the afternoon wore on and the sun got low they returned to Co-Tai and took a gondola ride through the Venetian canals. As they floated through the Byzantine façades and under the low, pentagonal arches of the foot bridges, Biyu said, 'You don't mind this water.' And Catherine shook her head. 'Because this water is run by us,' Biyu said. Catherine nodded and shifted so she could take a photo of Biyu with the street lights coming on behind her.

When they got back to Lisboa it was in full swing. The LED-integrated facade flashed and rippled. Lights swam and circled. Reds and pinks and blues and softer shades of blue bloomed and ran and sparkled and flickered and burst and exploded. Catherine and Biyu's faces were lit then dark in the wash of it all.

'It's great not to be working,' Biyu said.

'It's beautiful,' Catherine said. 'Thank you so much for bringing me here.'

'I think it might be quite like what you think heaven is,' Biyu said. 'Not a beach in sight,' she looked around, 'not a tree, not any water that wasn't put here.'

'And the ground's well below us,' said Catherine. 
Biyu nodded, 'Come on,' she said. 'We haven't gambled, yet.' And they made their way into the sphere and over the floating tunnel to the casino. 
A Basement Flat 


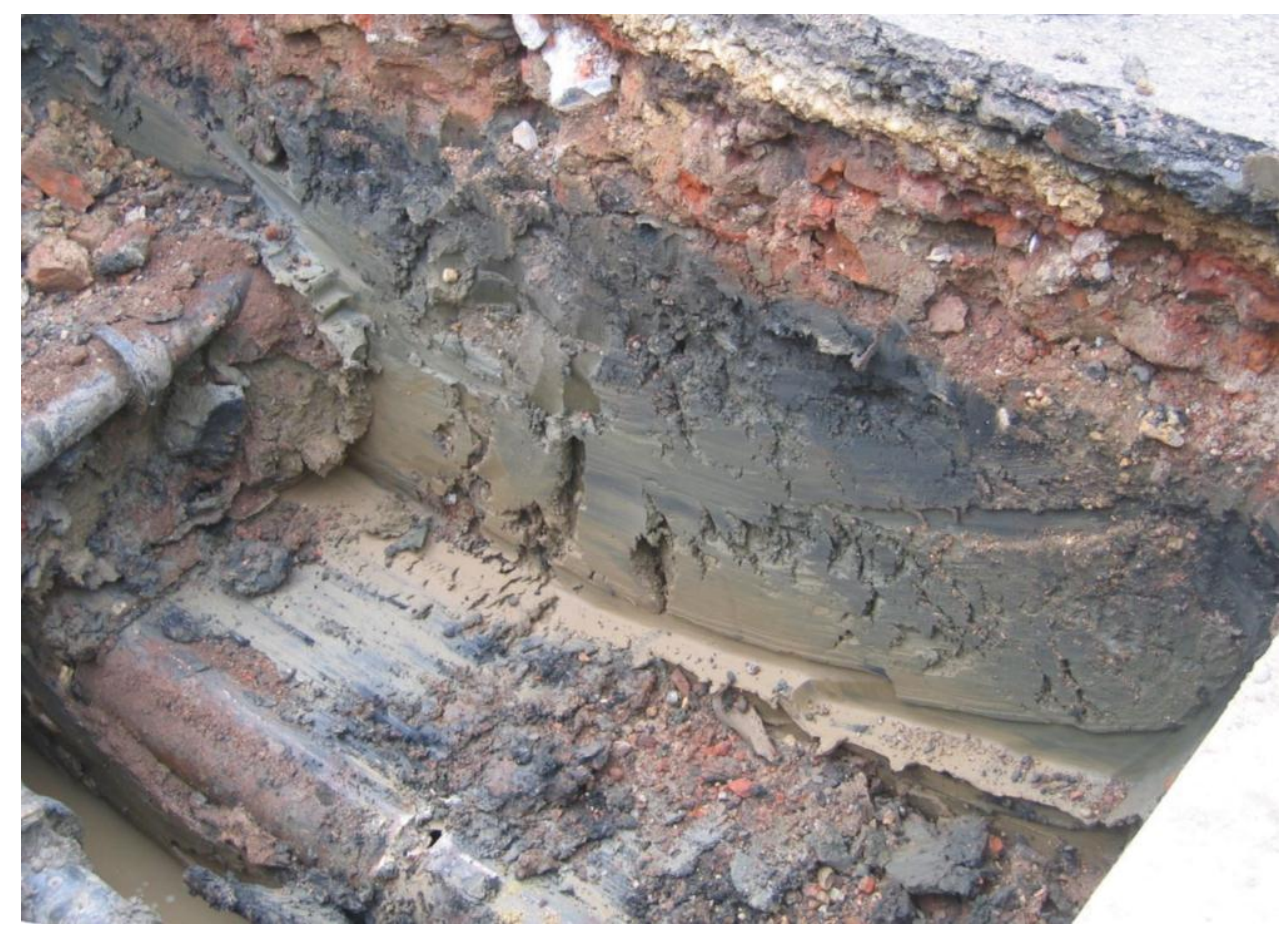


London was a basement flat and crying drunk. Showering in the morning, doing her hair.

London was mouthwash and meetings where she would present work which seemed good to her but pedestrian to everyone else in the office. A small lookout basement flat in London. Cold in winter, damp in summer. In amongst a city of bigger buildings, taller ones, chanting out in the skyline as she looked out from underground, inside rock and soil, clay and rock - including granite and limestone, marble, slate.

But probably not, probably just granite and not much of that, mainly soil - cohesive and granular, probably only clay - a small sample moulded and allowed to dry in the air, then broken, and a fragment pressed between thumb and forefinger. Thumb and finger pressing. A small amount of soil mixed with water to a very soft consistency in the palm of a hand. The back of the hand tapped gently. If the soil is silty, water rises quickly to its surface and it gives a shiny, glistening appearance. If the soil pat is then deformed by squeezing and, too, by stretching, the water flows back into it and leaves the surface with a dull appearance. Usually the greater the proportion of clay in the sample the slower the reaction to the test. The speed of the reaction is placed in the following categories: Rapid, Slow, None. London was people like her and people that reminded her of her. London was English being spoken almost everywhere she went. London was familiar and footpaths worn down that led to green lawns and brown waterways and a basement flat climbing out of clay and water. Kaolinite, montmorillonite-smectite, illite. At certain moisture contents, a soil which contains a significant proportion of clay can be deformed and remoulded in the hand without disintegration. When a moist soil sample can be manipulated, the soil will approach a non-plastic state, and begin to crumble. Just before this point is reached, a highly plastic clay can be rolled into a long thread which has sufficient strength to withstand its own weight. The thread toughness is classified Weak and Friable, Medium or Tough.

London was being in touch again, with her mother, her sister. Photos of Dominic and Honor's wedding. Polite congratulations, requests for a keepsake, the small porcelain horse. You know the one? It sat on the kitchen sill - but he can't find it now. Honor's love of horses and her birthday. The coarser particles fall out and the finest particles remain in suspension the longest. Sand settles in 30 to 60 seconds. Material of silt settles in 15 to 60 minutes. Clayey silt, 15 minutes to several hours, Sandy Clay: 30 seconds to several hours. Silty clay. Clay could take days. London was not working hard enough and time on her hands. Waiting. Silt is smooth in hands, rough on teeth. Tall buildings, stone bridges, a tunnel to France but still the basement flat. Structurally, for houses, the basement walls typically form the foundation. Water tries to run through it, the way it used to, before. Water flows around it. Dug out. Dug and dug and dug. 
Through clay and rock, mostly clay, some silt, chalky on your teeth, smooth in your fingers, but chalky, gritty, filing your teeth, wearing them down as you think, Silt? Clay, then — and a little silt and dug out, dug and dug and dug, and the water. Woosh. Trickle. Filling it up — the hole. The water. Filling the hole up and up and up. People jumped from bridges but they could just lie down. Eventually water would have its way. London was sleeping in on Sundays, not moving, waiting for the water to find its way again through clay, concrete. Listening, neck stiff, back sore, listening for the dribble, the wash, the flood. Praying that nothing was watertight. Then concrete. Concrete laid and then laid in floor, walls which fail in several ways, they overturn, slide forward, overload the ground which supports them, or break, but they don't $\mathrm{P}_{\mathrm{p}} \mathrm{W} \tan \varphi>3 \mathrm{~Pa}$. London was being human again.

London the muddle. A tangle of weekends. Misunderstandings. Choice. Fifteen different cafes, twelve different colours in all sizes. Day trips to Cambridge, sandflies, ducks in a lake. And slow walks. Times of absolute silence and calm. Perfect warmth and joy on a train, in a crush of shoppers walking down Oxford Street, anywhere she was in a crowd and above ground and looking up. London was a dream, burnt in, Dominic and Honor caught in a mechanical system of chains so fine they were like a spider's web and robotic, moving link by link, like muscle. So lucid, neither of them saw them when they climbed into bed, tired, aroused and Catherine looks down and she has the finest pair of nose pliers in her hand and, having caught them in her trap, William and Michael are there at her request, saying, 'Let them go. Catherine, don't be ridiculous,' and she says she won't fall for that again. And she feeds them and brings them things to amuse them and eventually they say, 'We'll stay,' so Catherine unchains them and they go back, to their friends, to the house and she is left with chains broken, bed filthy and the things she made to amuse them at her feet and walking around her in mechanical ways. Small dogs, yap, yap, flip. Larger dolls, eyes blinking and television. And William shakes his head and says, You just can't be relied on, and Michael speaks of the perfection of the tools and technology and their worthlessness in the hands of someone who cannot command them. And in the ensuing weeks they send her flowers and a pot plant. London was re-doing work, was stupid mistakes, was second-guessing every move she made. London was looking for jobs - every morning. London was closed doors in Asia, Russia, America. Until finally London became an opportunity in Berlin. Berlin was standing on the roof of a tall building, dreaming of emptying the ordered city of people, of time. Berlin was nightclubs and bars, a step into the world, phone numbers, a cell phone. But more than anything, Berlin was mediocrity, a reposition back into line, delivery of work that worked. A failure to give up in disgust. Berlin was an encouraging gesture made 
with wide-eyes, meant to humour her, when she found no peace in any of it. Berlin was looking fine on the outside. An easy smile and simple gait. 
Plattenbauten 


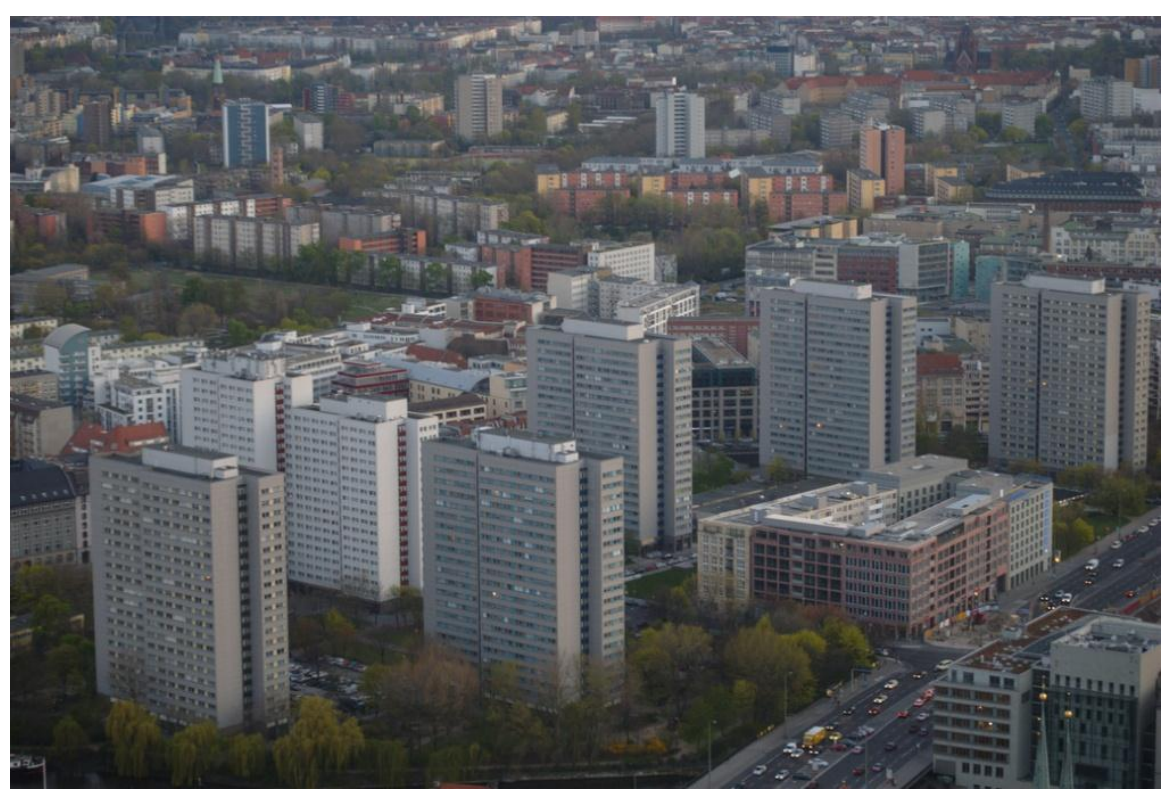


Joan Kelman was late.

Scott and I stood behind the reception desk looking at the computer screen. There was nothing else we could do and he was angry. It was four o'clock on a Friday and she was already fifteen minutes late.

'Maybe she won't turn up,' I said. Looking at the clusterfuck that was more and more likely every minute we weren't cutting and colouring Joan Kelman's hair.

Scott shook his head. She was always late.

'I could do Kate Delaney's foils before you cut her?' Scott shook his head again. It wouldn't work. I knew that, but sometimes it looked like Scott didn't want it to work. Like, by it not working, by us running round all night, hearts beating, arms aching, it would somehow punish Joan Kelman and she would never be late again - for anything.

The door opened and it wasn't her. The salon was getting loud, everything echoed off the wooden floors and walls. Danny dropped some tint bowls in the sink, Willo was stomping about in her big boots looking for her sectioning clips, Jodi shouted that she had them, 'Sorry,' the room hummed with smiles and staunchness and loud music. Bonnie strode to Willo's station, well ahead of the woman whose hair she'd just washed. She beat her there by a distance and was left standing with her hands on the chair, resting while the woman made her way. For that time the salon echoed loudly with her resting and it echoed with me and Scott standing uselessly at the reception desk.

'I could mix up her colour? In advance.' It was a stupid suggestion. Scott was so angry and then he said it, what they tell us to say, so we think higher of ourselves, so we make more money and in the fire of him standing there, waiting and waiting, like somehow it helped him feel worse about it, Scotty said it, and it still meant the nothing we all knew it meant, but he said it, and it sounded even more stupid in the saying than it did in our heads, 'She wouldn't do it to her dentist.'

'Maybe she would,' I said. 'Maybe she's like that. But if she did,' I said, 'they'd charge her for it.' They tell us to say that as well. So we feel like professionals. So we'll act like professionals - inflexibly.

Joan Kelman came in the door. She was in a flap and we both apologised to her and I took her coat and made her a coffee and Scotty washed her hair and cut it fast in a way that made her think he was taking all the time and care in the world and halfway through his fourfifteen arrived and he shouted, 'Hi, Yen.' And as I was taking Yen's coat, Scott came over and said, so no one could hear the energy in his voice, 'Joan's ready now, Isabel,' and it was beautiful and we were back and there was a chance once again that we wouldn't piss anyone off and that 
we would finish, eventually.

I swept the hair from around Joan Kelman. She looked down from her seat and said, 'He didn't take much off.'

'It looks great, though,' I said. I took one hand off the broom and ruffled her fringe. 'Doesn't it look great?'

She smiled. 'He's great,' she said, touching her nape where her dark blonde hair tapered neatly into her neck in perfectly disordered wisps.

Like God put them there, I thought.

I dried her hair off quickly, sectioned it up and started applying the foils. She continued to read the magazine, which was fine with me. Occasionally, she would comment on the pictures, 'Isn't she stunning?' 'Hasn't she put on weight?' 'What's he doing with her?' I knew all of the people she pointed to. This one was an All Black's wife, but I hadn't watched rugby for years. This one was a finalist in a TV show that was on while I was working. But I knew them. I also knew the score in the cricket. I can look interested when I'm not paying the tiniest bit of attention. I can be counting almost every single strand of hair on someone's heads but I can hear them and I can nod. I can watch what their faces do and I can do it and I can laugh when they joke, and sometimes I'm funny, too.

Joan Kelman looked stunning, so did Odin, so did Yen. They all looked stunning and at 9.30 they were all gone. Scotty let out a long sigh as he shut the door on the last of them. Willo started balancing up the till and I looked at my phone. 'What's the time in Berlin?' Scotty asked. I smiled at him. He thinks I have a lover. That's how much we listened to each other.

There'd been no reply when I'd called that morning. I'd checked the time difference. I checked it on a couple of different sites. I made it about $6 \mathrm{pm}$ on a Thursday but there was no reply. It was conceivable she was out. Maybe she had dinner with her friends on Thursdays. I had no idea how long it took her to get home from work. Perhaps she was working. She was important, I understood that much. Last time my parents and I had Skyped Catherine, her phone kept ringing and she would apologise but say she had to take it. She would bend to her phone, halving herself in the screen of my parent's computer. We could hear her talking softly and firmly in German, although, our father said, everything sounds firm in German. None of us spoke to each other, we just watched her - head bowed, often her hands held her eyes closed, like she needed to take herself somewhere else to speak, like she was making a dark little office to do her work in.

I was returning her call. She'd left a message. She'd just remembered our mother's birthday. I'd forgotten it completely and I had to work all day. Perhaps I could get her that new 
Jilly Cooper book? Catherine had said, perhaps I could bake a cake? I tried once more but I couldn't get through, so I had a shower and got ready for work. As I was leaving my father rang. Would I come round for dinner tomorrow, he asked. Would I see if Catherine was around? Did I think we could Skype her?

As the till spat up a printout and Jodi asked if anyone wanted a wine, I checked the time again. It was mid-morning now. I got my cigarettes out of my bag and took my phone outside. 'I'll do those in a minute,' I said to Bonnie, who was looking at the pile of Joan Kelman's foil I'd left in the sink. She was trying to clean some tint bowls and brushes, I knew it fucked her off. She'd probably whinge about it to Scotty and then Willo would find out and it would be annoying, but it seemed worth it now, I was gagging for a smoke and I might catch Catherine on her cell phone. It would give Bonnie something to do, something to talk about. I almost said that to her but I couldn't look at her screwed-up face for another second. Outside it was dark and cold. The salon was in a low building in an alley between tall buildings. I could hear people in the street beyond the buildings that boxed us in, every now and then one of them would shout out. I leaned against a wall so I was out of sight of the salon and lit a cigarette. I rang Catherine and she picked up. It was loud where she was and she had to talk louder than she normally did so I could hear her.

'That's 7 am here,' she said.

'Is it?' I said.

'It's twelve hours Isabel - and a day behind.'

'What time is it now?' I said.

'It's about 9.30 in the morning.'

'Where are you?' It sounded like a bar.

'At a meeting.'

'Is it a nice day?'

'Isabel, I'm in a meeting.'

'Oh sweet, sorry.'

We were both silent for a moment, I could hear the noise rising behind her, then it would subside. It was like waves on a beach. It didn't sound like a meeting.

'So what if we stay up later?' I said. 'Could we call you at 10? Or 11?'

'Call after dinner,' she said. I could tell she was talking to someone else, making hand signals to them, mouthing words.

'Okay,' I said. 'I'll tell them that.'

'Did you get the book?' she said. 
'I got her some shampoo.'

'Cool.'

‘Okay, well, how's work?’ I said.

'It's good. Busy. How about you?'

'Yeah, good. Have you got any holidays coming up?'

'Maybe after we finish this project. Maybe after that. I might have a break. Go to Stockholm. Something like that.'

'Nice.' I wasn't quite sure where Stockholm was.

'How's the flat?'

'Good, thanks, yeah. It's great.'

'Is it Friday night?' A siren had just sounded a couple of streets over.

'Yeah.'

'Oh well, I better let you get to it. Friday night in the big city.'

'Friday night,' I said.

'Righto,' she said, it sounded like she was stretching out to reach something. 'Love you. Love to Mum and Dad.'

'Love you,' I said, stubbing my cigarette out on the wall beside me. 'Have fun.'

I walked back into the salon. Everyone was sitting around, too tired to go home. The sink was still full of my foils. The tint bowls were clean. The only way Bonnie could have done it was to take all the foils out, do her cleaning then put all the foils back in. As I rinsed them out one by one, pressing them out on a towel laid flat, my mind wandered and rested on the day Dominic had brought Catherine home, which made me think about her now, in that meeting which didn't sound like a meeting. Maybe that's how it was in Germany. My father always called it 'Berlin' when he talked about it. I thought it made him sound much more savvy, like it was a pet name which showed he was familiar with it all. 'She's working on a big project in Berlin,' he would say and it sounded like he'd just got back. She was demolishing buildings. We'd talked for a long time in the early hours of one of my mornings. I'd just got home, she was in between things, or she was having a day off, or it was a public holiday or something. She was talkative, anyway. There were these huge buildings which people had lived in. They were centrally heated and safe and dry. Then the wall had come down and no one wanted to live in them anymore. 'No one,' Catherine had said.

'Why not,' I said.

'Because they want nicer houses now.'

'Are the apartments not nice?' I asked, my phone crooked in my shoulder, both my 
hands playing with a necklace I'd been wearing which was broken now.

'Not really.'

'Not, like, for anyone?'

'No. No one wants to live there.'

'Not even, like, artists?'

'No.'

'Wow. They must be really bad,' I said.

'Uh-huh.'

It felt like we were kids again, but not us, like we were living out some other kids' life. Talking into the night, in the dark, sharing secrets about boys. But it wasn't a secret, it was her job.

'They were like kitsets,' she said. 'They would make all the huge concrete walls and all the steel would be cut to measure and then they would ship them to the city and they would lay it all out and then they would pop them up.'

'Pop them up,' I said.

'Yeah.'

'Pop.'

'Yeah, that's why they're kind of easy to take down.'

'Pop down.' I couldn't fix my necklace, all the broken parts were too small and my fingers were sleepy and still drunk.

'Well, not quite that easy,' she sounded like she was warning me - against glibness, against being complacent. 'Someone else is making new houses out of the walls.'

'No way.'

'Yeah. That's why we have to be careful how we take them down. So they get all of the walls in one piece.'

I nodded.

'Yeah, so that's what I'm doing,' she said.

'Cool. How long do you do that for?'

'For ages, I think. There's heaps of them and each one needs kind of, you need to check out each one of them, cause they're all different. They're not different, they're, they've all been sort of, sat differently. They all sit in different places, you know, in relation to the wind or the road. Some of them have been sort of, um, blown about, or shaken a bit.'

'And that's why they need you.'

'Yeah. Ah?' 
'Cause you know about shaking, eh?'

'Oh, yeah. Yeah. I know about shaking.'

'Do you go out much?'

'Yeah. Sometimes. Have you just got home.'

'Yeah,' I said.

'Was it good out?'

It hadn't been. It had been a bit shit but I said, 'Okay,' because it was nice to talk to her, even if it was about buildings.

I've never been to Berlin but since I talked to her that night I've made up a little Berlin of my own and I walk her around in it. Sometimes I give her big hands, so big she can just take the buildings to pieces with them, without thinking too much, without doing sums, without cranes, but she's never really happy with that. Once I dreamed her up a huge dog who took the buildings to pieces in his mouth while she held him be on a long chain. The people who made the houses were waiting for the pieces and her $\operatorname{dog}$ passed them bit by bit with ease - the great concrete walls, the floors, the frames they sat on. Then I take her back in time, to when the buildings were wanted, to when they had to build more and more of them, when it felt like there would never be enough room for all the buildings they were going to build and I put her in the heart of it all. Pointing, in a hard hat. Holding a plan and pointing. There's a man beside her and he's looking to where she's pointing. This is how I play her in my little Berlin. She puts them up, then she takes them down. Neither one of her helping the other - she puts them up as tightly as she can and then she takes them down and splits them up so the one of her well back in the past has to search everywhere for bits that fit.

'Do you like it?' I said. The sun was starting to come up, we talked for hours that night.

'Yeah,' she said.

'Better than here?' I said.

'Different,' she said.

'The sun's coming up,' I said, moving to make a small split in the curtains to look out of. 'What can you see?' she said.

'The water's rough,' I said. 'Choppy. It's all blown up by the wind. It's going to be cold. The Sky Tower.' I looked and looked for anything else to tell her, 'What can you see?'

'Berlin,' she said.

'Can you see your apartments?' I said. 'What do they look like?'

'Empty,' she said. 'Open.' 
'So I guess they don't know they're coming down?' I said. And she laughed at me and I laughed at me, and we laughed.

I told them I'd be late, and I was. I blamed work but I'd been pissing about. They always forgot I only worked until three on a Saturday so it was an easy excuse to make. I'd got Bonnie to wrap the shampoo up, she's neat and careful. We all are, but she's a pedant. It looked lovely. I bought paper that had tiny Russian dolls on it and Bonnie had found some ribbon behind reception which she crafted into a series of bows.

'Ornate!' I said, enthusiastically. 'Or-right!' I thanked her and had every intention of going straight to mum and dad's but I just couldn't stomach it for a moment. It occurred to me that if it was mum's birthday then Catherine's wasn't too far away. I told myself it was prudent, considering my forgetting Diane's birthday, to get Catherine a gift while I remembered. I couldn't send her shampoo. She was so far away. I spent a couple of hours looking round the stores in High Street and then needed a coffee. In the end I found her a small white ceramic box which had the silhouette of a rabbit in black on its lid. There's a difference between concrete and ceramics but they're close enough.

Mum came to the door with the phone in her hand. 'Oh,' she said.

'Happy birthday,' I said and I handed her the gift and she said it was beautiful and we hugged.

'Did you get hold of Catherine?' my father said as I came into the room. He stood and hugged me.

'Yeah,' I said, sitting down. 'She said to call after dinner.'

'I'm going to order some takeaways,' Mum said. 'I was going to cook but your father said I shouldn't.'

'It's your birthday,' I said. 'Happy birthday.'

We ate Chinese takeaways my father and I went to pick up. He was doing some alterations up the front of the house and we talked about that and my work, how that was going, which was all right.

My father had bought a pavlova from the supermarket and when we finished our meal he brought it out and my mother cleared a space among the plastic containers and we sang her happy birthday and ate it.

'Oh,' my father said when he was halfway through his dessert. 'We should have waited for Catherine.'

'She won't mind,' I said. 'We can sing it again. I'll text her now shall I?' She replied quickly that she would be home in about ten minutes. 
We all went to dad's office and he turned on the computer. Then we called her. She was wearing a black polo neck but she still looked cold.

'Happy birthday,' she said, her eyes were looking at the corner of her screen, at the version of us that was there. It made her seem shifty.

'Cold there?' Dad said.

She looked at the camera, at us, 'Oh, yeah,' she said, pulling the collar.

'We've had a lovely night,' my Mum said.' You father made dessert.'

'Bought dessert.'

'Bought dessert,' she said. 'A pavlova.'

'Do you miss pav, Catherine,' Dad said.

'Oh, yeah,' Catherine said, she was looking down again now.

It went on like this for about twenty-five minutes. Our mother listed everyone she'd heard from this week and gave Catherine all the news. Then my father asked about how her work was going and she said it was all right and then he talked about how his work was going, which was good and then I talked a bit about my work, but we really only did that for Mum and Dad because we'd only talked last night.

'Okay,' said Dad. 'So, we'll let you go.'

'Okay,' said Catherine. 'So I might come home.'

'Sorry,' said Mum.

'To Auckland,' I might come back to Auckland. She was looking over her shoulder now, rubbing the back of her short hair. 'There's not much happening here.'

'Well, there's plenty happening here,' my father said. 'The rebuild'll be underway any day.'

'They're screaming out for engineers,' my mother said. 'They need engineers here. There's plenty of projects starting up. It's on the turn.'

'That development on the waterfront,' my father said, like he'd just thought of it. 'I heard that had an investor.'

'There's money,' Mum said. 'It's all coming out of the woodwork now.'

I was the only one looking at Catherine. My dad was looking at himself on the screen and my mother was trying to find an article in the local paper about a building project. Catherine was still looking away from us. I imagine she was looking out a window at the snow. Perhaps it was snowing. Perhaps she could see her apartments from there. Her top teeth gently held her bottom lip. It looked like she could see for miles. 
The Tallest Tower in

the World 


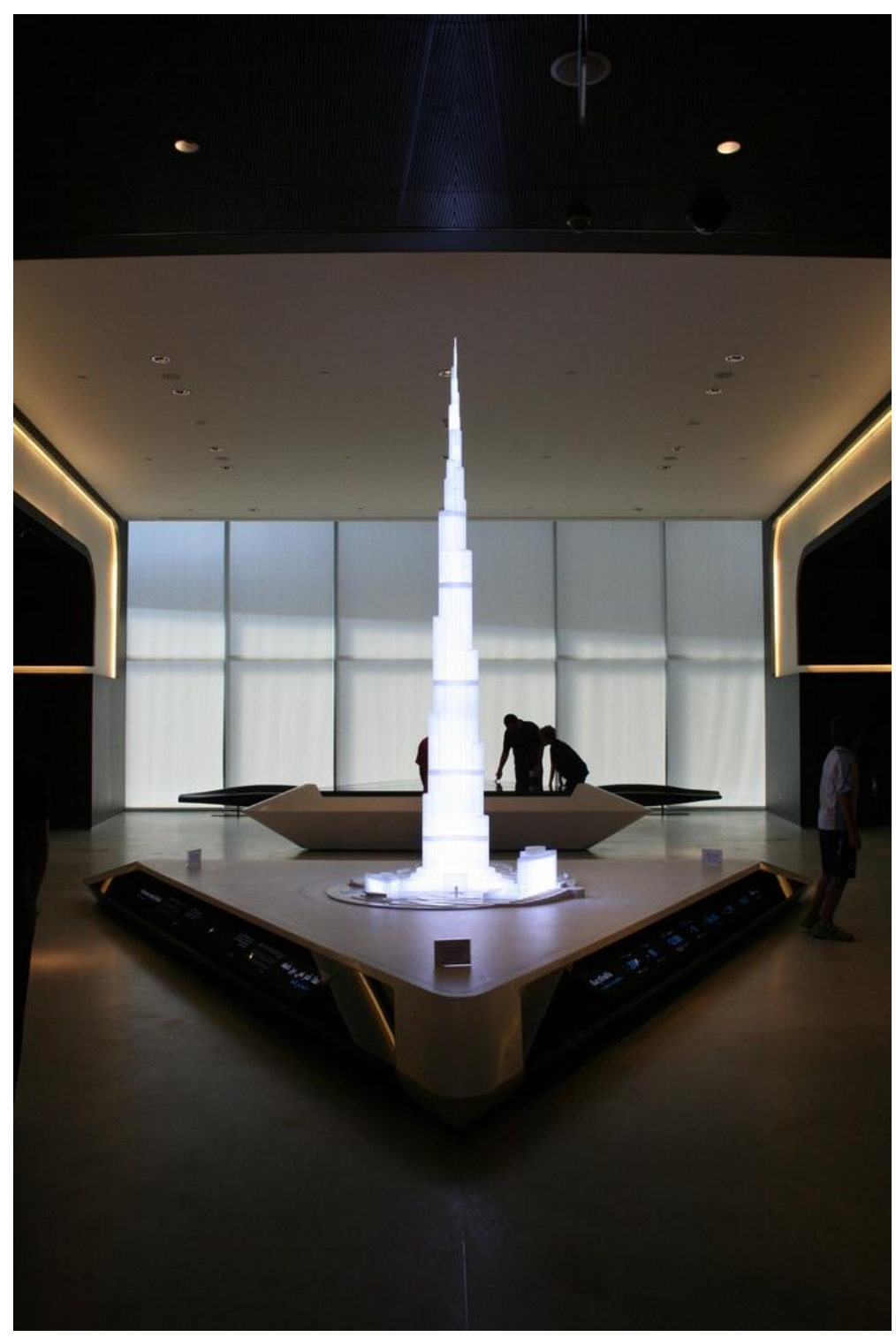


The buildings arrived at the desert. They cast shadows on each other and changed the way the sea wind travelled between them. Most of them were tall, but each one that arrived would change the conversation of height that was taking place in the corner of the desert they arrived at. Streets were made and they lined the streets. When a lake was dug and filled and stayed full all the buildings turned without moving to face the lake and soon everything fell into the day to day: oil, real estate, entrepôt. The special occasion was over and the effect of the latest arrivals on the sound of the shape of the buildings standing became less and less. The crowd of buildings adjusted, without missing a beat in the rhythm of their business, because now, they were a city. At the almost centre of this city, beside the mall and the fountain lake, was a space 104 kilometres square, which remained and remained empty. Because it was huge and completely empty this open land promised something that all the other buildings seemed waiting for.

There was still oil and there was still money in oil but there was also a government decision to diversify. A decision to diversify into something really sensational: water parks, theme parks, 3 hectares of parkland, 30, 000 homes, nine hotels, 19 residential buildings, the Dubai Mall and the lake and at the centre of the large-scale, mixed-use development a tower.

An email arrived from Dubai at the Chicago office of Skidmore, Owings and Merrill inviting them to enter a competition to make the tower for the centre of the centre of the world. It is cold in Chicago, raining. Architects gather round a computer while one of them Googles 'Dubai' and they see the desert and the other buildings and the space. One of them says, 'A Desert. A desert? What's in a desert?' They look at image after image of sand and brown and flat and heat. Then one of them says, 'There are no plants. There's nothing natural standing up there.' So they Google 'Dubai' and 'Plant' and they see a flower, ordinary except for six slim, stiff petals which extend from its plain lily shape. One of the architects starts sketching, then they all do, wandering from the computer toward their drawing boards, mumbling in pictures.

They meet three days later with pencilled lines on ripped out pages, to scratch and shuffle and battle. There is one which everyone starts moving toward, a rough small sketch of a three-lobed foot-print. In the weeks that followed more detailed drawings are rendered on computers. Engineers work beside architects, sketching over the top of their drawings in lead pencil and ball-point pen and as the submission date draws close Skidmore, Owings and Merrill send away fifteen plans, ten elevations and a three page report outlining a modular Y-shaped structure composed of three elements arranged around a central core which sets back along each of its three wings, tapering into a fine spire. 'While beautiful,' the report says, 'the regularity of the design will provide both a stable configuration and a good floor plate for residents.' The 
tower is 828 metres tall. 'This design,' the report reads, 'will return the Earth's tallest freestanding structure to the Middle East - where the Great Pyramid of Giza claimed this achievement for almost four millennia before being surpassed in 1311 by Lincoln Cathedral in England.'

High in the mountains of the Westland National Park in the South Island of New Zealand, hidden, they begin by moving mountains. It looked like coal mining. For months, isolated in the vast mountain range, they blasted overburden and filled the valleys with it but one day work stopped and the miners looked around to see they had left an area that was flat for kilometres. 'It must be 100 square kilometres,' they said as they took off their hard hats and wiped their brows and looked in a circle at what they'd made.

Helicopters landed on the huge, new plain, carrying people who dug borehole samples and went away again. Days went by, the miners played football on the wide, flat surface. Then the cranes were moved and the miners attached dynamic compaction tampers to them. For weeks the strange new valley shook and boomed as the cranes dropped the weights again and again, packing the ground tighter and the miners joked, 'This is going to make it hard to get anything out,' and laughed and dropped the weight one more time.

The people in helicopters returned with bore-hole samplers and the tampers on the cranes were replaced with pile drivers and began to dig 1.5 metre wide holes until they were 43 metres deep. As the holes were being dug the miners were shown how to tie reinforcing steel into 43 metre long barrels, 1.3 metres in diameter. None of them said anything. The barrels were fed one by one into the holes and concrete was poured into them until it filled the holes and drowned the barrels. For days it went on, one after the other after the other. Some of the men walked the perimeter of the piles on their way to lunch or dinner or at the end of the day and drew small versions of what it felt like it looked like onto bits of paper and into their food. It was like a flower. An alpine daisy with three petals and they would say to each other softly, 'Are we building?'

One day another concrete pourer arrived and they were shown how to make formwork and they began to lay the shape for what would be the northern raft. 3.7 metres deep and it was a boat, bow, stern, starboard side. Meanwhile, other men made giant placement test cubes 3.7 metres in each direction into which they poured the $50 \mathrm{MPa}$ raft mix which incorporated $40 \%$ fly ash and had a water/cement ratio of 0.34 . Engineers, who seemed to have come from nowhere, walked round the test cubes verifying the placement procedure and monitoring the concrete temperature rise. 
The men, who started as miners, were sure now they were builders. They worked in groups and the groups were given instructions for one task at a time, isolated from all other tasks. There was some movement in the living quarters so the living groups reflected the working groups. All breaks and working hours were staggered. Some of them had built houses, garages and when they saw the distance between the piles and the depth of the piles they looked up into the low clouds that sat over the mountains and whistled. The men who had built nothing but were practical men tried not to be curious but when the reinforcement for the northern raft was laid, at $300 \mathrm{~mm}$ spacing and arranged so that every $10^{\text {th }}$ bar in each direction was omitted to create what their supervisors called pour enhancement strips and when the northern raft was poured, and when it took 24 hours to pour even they realised whatever it was, was huge. Their pay cheques kept coming in and although they talked casually with each other, none of them asked anybody who might know what was going on and as their guards came down and they talked more and to more people it became clearer that no one knew all of what was going on.

In the end there were four pile-supported rafts, three petal-shaped and a fourth which made the central core. There were drinks. Someone in a suit gave a speech about the highest aspirations and there was a toast and the next day when the men arrived at work, as if it had all appeared while they slept, there were signs and TV cameras and everyone was saying it, 'After the earthquake and after the recession and even while Wellington was still not completely rebuilt - here in the Alps, in the midst of the most beautiful place in the world, they were building another Burj, exactly the same as the other Burj, people would come from everywhere to see and stay and shop in the Alpine Burj. This was how confident New Zealand was. No one had challenged the Burj, and they weren't challenging the Burj but they were matching it, which was to say, conquering it.'

When the cameras went and the Prime Minister, it was dark and the men ate their dinner in the quiet and when they arrived at work the next day they were taught to build up. The walls would be formed using a self-climbing framework system. The ends of the petals were called wings now and would have round nose columns, and would be constructed using circular steels forms, while the floor slabs were poured on panel formwork. The wall reinforcement would be prefabricated on the ground in eight metre sections. As they watched and learned three primary tower cranes were located adjacent to the central core. Each crane contained high-speed, highcapacity construction hoists which would transport workers and materials to the required heights.

Large concrete walls began to take up room in the horizon. Wall after wall, boxes of space were enclosed. The shadow of the tower slid its way up the hillside, wrapping up the 
stepped shoulders the rearrangement of earth had left. As if in sympathy the tower stepped in at each floor, higher and higher. When the men asked their supervisors how tall it was going to be, their supervisors shrugged and said, 'Tall'. Some men would say to themselves at the end of each floor, 'I'll stay for one more floor.' They had to arch their necks now, to see it.

At 509 metres the tower raised a floor above the top of the tallest neighbouring mountain, it was like coming out from inside. The wind, blown up by the mountain range, hit the form work for the walls and the men as they tried to place the concrete. The men swore and complained loudly to their supervisors who were as dirty and blown around as they were.

Everyone was shouting. The heavy cages on the cranes swung and a large piece of wood blew off the building. Three men left in the night, walking out of the mountains with nothing but the clothes they wore. There was sway in the floor, more than they'd anticipated - progress slowed.

Catherine watched them making progress slowly from outside her office beside the tower and laughed. 'You can see the sway from here,' she laughed as the other engineers looked up in contained horror. 'Fuck,' she said, 'what a cluster-fuck,' and she finished her coffee and got back to her long calculating work: playing small wire frames of the tower, simplified sisters and daughters, making them unhappy. Overloading the wings, overloading one of the wings, twisting them, eroding their feet, breaking a single bolt on an upper floor, setting them on fire. 'Be monsters,' she would say and there were monsters. She would go to meetings with printouts and A3 pages with single lines drawn across them. Sure of herself, angry at everything, more qualified than anyone and for a while she tried teaching because no one would give her a job engineering in New Zealand. During her last classroom placement, her tutor came to her and told he she didn't relate well. 'To the children?' she asked. 'To anyone,' her tutor said.

The sway would be fine once the walls were on; they just needed to get the walls on. She laughed again and drank some more coffee. A couple of storeys ago, they'd made her go to a job interview for the job she was doing. After the job interview they asked her into an office and the project manager explained again the sensitive nature of the project and the need for team-work. She told him she didn't care about the team, she cared about the tower. He looked at a file open on his desk and told her, that on assessment, she was over-qualified for one part of her job and under-qualified for the rest of her job. Then the floor started blowing around and wood and steel started flying off it and they asked if she could stay on. She was meaner from then. It was hard to stay positive, so she didn't. It looked dark. She did everything they asked and it still wasn't enough. Nobody noticed how good she was, and they always fought with her.

She built the tower up on her computer screen and then blew at it from all the directions that the wind came from. She went to a meeting and told them they were going to have to build 
a model and test it in a wind tunnel. 'It wasn't designed for here,' she said. They didn't like that. 'It'll be fine once you get the walls on.' They didn't like it at all. 'It was an idiot plan.' She unrolled the A3 printout she'd brought to the meeting and showed them the prevailing wind and suggested the wall parallel to the wind should be built first and she suggested strapping down the form work more heavily and tying the men to the superstructure and giving them Valium. No one laughed but the site manager said it sounded better and they could try it that afternoon.

An hour after the meeting the site manager and the project manager came to her desk, they were both wearing high visibility vests and hard hats, she looked at them and said, 'Fuck. No.' They handed her vest and hard hat to her. 'Really?' she said, putting the vest on, 'You can't work this out for yourselves?' She logged out of her computer and rolled up the printout again. They walked across the barren plain toward the crane. The site manager and the project manager talked and she walked behind them, insolent. They got into the cage and the crane lifted them up. It was quiet at first, then they came out over the top of the shelter of the mountains. The cage landed on the floor slab and they were the only people up there. She unrolled the printout and held it on the floor as it flapped and flew around. She pointed this way and that way and the two men nodded and then she walked them round the floor showing them the places they could harness the men onto. It was going to be slow but they had no choice. Then the two men asked questions and it became clear they still couldn't see. She repeated herself again. She could hear herself talking plainly. She could show them, she said, when they got back to the office, on another printout, on the computer. The men looked at her, none of them spoke. The project manager nodded and she rolled the plans up and as the crane took them down in the cage she looked down.

When they got back to the office no one asked her to show them on another printout. The project manager asked if she could send an electronic copy of the printout to another engineer. She looked at her screen and wound the scroll wheel of her mouse angrily as he spoke. 'Thanks,' he said, and walked away. 'Fucking idiot,' she said as he left the room. She had to work with such fucking idiots. She'd been in Beijing, Taiwan, Berlin, she'd been working on big things - stadiums, bridges, mines - what had they been doing here? She hadn't wanted to come back to New Zealand, not ever. But she had, like a fucking idiot, with her references and her work history and her heavy optimism. Her parents had met her at the airport - they hugged her. Her father lifted her cases off the carousel. She should have turned around then, ran if she had to, left her father standing there with her cases. As soon as they stepped outside the airport she knew it was too late.

Her father drove them back along a motorway which passed under a narrow pedestrian 
bridge she'd worked on her first year out of university. She hated it. London had been bad but it was unbearable here and no one would employ her. She had totally forgotten how much it was awful in New Zealand. She wanted to go to Scandinavia, they were building a dam in Iceland, people got sick of hearing about it, or Pyongyang, she would love to go back to Korea. People didn't want to hear her telling them what was wrong here, especially not at job interviews, her father had said so. She shouldn't do it. But, she said, she was being honest and people knew. 'Who would employ anyone who didn't want to get out of here?' she said, holding her hands out to show him: this room, this city, this terrible country. Then there was teachers' college and the weeks of sitting after teachers' college and then like a light at the end of a tunnel the tower.

She was watching daytime television in the living room of her parents' house. It was hot. Her parents were at work, her father delivering books, her mother working as a receptionist at a dental surgery. Her cell phone rang. She said 'Fuck,' standing half-heartedly and lifted things around her to find her phone without moving her eyes from the television. The phone stopped ringing and she forgot about it and ate some more from the bag of potato chips beside her and thought about masturbating. When her father came home, he said, 'Hello.' She said, 'Hello.' Then he went to put his papers and his dinner down on the kitchen bench but her phone was in the way, 'You've got a message,' he said, and brought her the phone which she took without looking up from the television and dialled without looking up and listened. The voice sounded professional. She adjusted herself on the couch. They wanted to talk to her about work engineering work. They couldn't talk about it over the phone, perhaps they could meet her.

They met her in a Mr Bun on the edge of an old quarry in Mt Wellington that had been turned into a new suburb. There was a lake. They talked at length about the job, how they couldn't give her many details about the job due to the nature of the job. She could tell it was part of the craziness that was everywhere since the earthquake; a special insanity of hope and badly thought-out action, of government subsidies and a mass of unemployed, waiting, willing digging holes, filling them in again. She could tell this was that, probably plenty of other engineers had said no. Probably the engineers that had said yes, thought they were the priests in it, the saviours, that this would be their life's work. Probably, if they had got this far, asking her, it was going ahead, their stupid secret plan. They bought her a coffee and asked if she had any questions. She asked a few, none of which they could answer. Then they asked if she would consider moving away from Auckland to work. She swallowed the last mouthful of her coffee. 'That's all I've been saying,' she said. 'All this time, I just want to get out of Auckland.'

They flew her to Queenstown with some of the other engineers. As they came through the doors of the arrival gate she saw a man holding a white board with the developer's name on 
it in black pen - there were about five other men beside him standing around their luggage, talking and checking their phones. She followed the driver and the other men into the ice, night air and to a white van in the car park. They drove in the dark, the men talked all the way. She looked out the window, answering the few questions directed to her and asked a couple of her own to be polite. At Te Anau the van pulled into a small airport and they carried their luggage to two helicopters. It was darker than she remembered it could get. Some of the men dozed on the helicopter, she looked out the window and watched their reflections bouncing back at them. The helicopter landed and they were taken to their rooms in one of the three storey blocks which had been built to house the workers just above the building site. She turned off the lights and looked out the window, trying to imagine the possibilities that lay there in the darkness which gave no hint of shape or form and was, instead, complete on its own.

She woke slightly disorientated to her cell phone alarm. She showered, dressed and ate her breakfast with the curtains drawn, all the time calling into her head, from the pictures that had come with the plans she'd been sent, exactly how it would look. Finally, she set to leave for the site office. She opened the door looking at the floor, then she looked up. It wasn't Iceland. A barren plain opened up for kilometres in front of her, hemmed in at all sides by mountains, the closest of which were cavernous shades of grey and fell to the ground, cutting the sky in half. She turned away from it all to put the small key in the lock and heard the hammer inside fall with force above its weight. She walked along the open corridor and down three flights of stairs to where she saw some of the men she recognised from the night before and walked with them through a throng of contractors and machinery milling about.

She hated it almost more than she'd hated not working in Auckland, but she would finish the tower. There was no one else. She looked round her office, there was no one. She sent an email telling the other engineer he could pick up an electronic version of the printout here, she sent him a link. He wrote back asking which printout she was talking about. She scowled and walked to his desk and explained. He looked blankly, so she explained again, being more specific and finally he said, 'Oh yeah, yeah sorry.' She said he would be, but it fell flat with him just saying, 'Okay, cool, thanks.'

A group of them ate their lunch on the porch of the site office. The whole work site broke for lunch at the same time now. They looked up at the construction workers eating their lunch on the lower levels of the tower, like they were fruit, someone said. 'Oranges,' said someone else. 'Or something that's orange and blue on top,' she said. The engineer she had given the printout to said, 'Yeah, right. Yeah,' and took a large bite out of a red apple. Snow 
White, she thought, but she didn't say it, she looked at the tower, it was huge. It stood much stiller now that the walls were on, the sway was imperceptible, like she said it would be. She shook it again in her mind.

Things went on and on without much change, the tower stepped in and climbed higher, one floor at a time then they fell behind. One of the project managers from the city brought a Gantt chart and pointed out exactly why they would have to work overtime. Surely not her, she said, what with the over-qualified, under-qualified thing. They didn't listen to anything she said so what was the point of her working any harder, wasn't that pointless, surely she could just keep finishing at five and having the weekends off. No one agreed except the people that worked directly with her. Everyone started working late.

Each office was divided into shifts that would overlap in the early afternoon to hand over. The jobs were all restructured so that two people would work on one job, all day and then as they fell further and further behind, all night. She didn't like it, no one worked the way she did, well, everyone worked the way she did, just not as well. Out of everything she hated handing over worst. She would get to work at about eleven at night and someone would explain step by step what they had been doing, she would ask questions which she hoped would make them think she'd understood but instead made them squint their eyes and interrupt her. Then they would go and she would trawl through what they'd done and go back through their notes and back though their numbers until she found her work from the night before and she'd delete what they'd done and start again. Even doing this she got just as much done as anyone else. At 1 am she would boil the jug and take a cup of instant coffee out to the porch. Construction on the tower didn't stop now, either, the welders worked under flood lights, in small pockets. Concrete poured all night and all day. Eventually the sun would come up and she would have another cup of coffee and watch it come up, fighting its way through the wind and the sky. It was nearly 740 metres high, they would be putting the spire on it in the next couple of months.

Two weeks into overtime she hit a problem, she couldn't get a joint on one of the middle floors to stop twisting. She changed numbers in the equation, first systematically, then randomly, trying to make it work. She went back in her workings, she went forward. It'd happened before, if she could see the joint, stand next to it, walk around it, place her hand over it. She looked at her watch. Another shift of welders would be starting in ten minutes. She grabbed her hard hat and her vest and pulled on her safety boots. So here we go, she thought as the crowded cage left the ground.

She climbed down from the top floor in the group of men who had come for the next shift. The crowd dwindled the lower they climbed until she was by herself, chanting out a single 
tinging beat on the steel stairs. She looked at herself as if she was on the porch of the site office, a tiny figure occasionally appearing at the windows of the tower further and further below the arc welders shouting out suddenly in brightness. The moon giving her shape, a small black figure, a shadow sinking into the belly of the enormous tower. She looked at her watch. There was no rush; she couldn't go back until the welding shift was over. She laughed to herself and climbed down the steel stairs until she reached the hundred and thirteenth floor and went to the joint she couldn't model on her computer and knelt so she could touch it. She had never felt the men above her before, it was as if she was submerged and they pulled her up, like helium, like birds stuck in her hair. Standing from the joint, she leaned against an outer column and felt all the fine lines of steel deep inside it that gave the concrete tensile strength. It was the wrong bolt. It needed replacing. She bent to it again, then stood and leaned on the column once more. She looked out over the darkness and imagined a fire so hot it would fix her to the column, the steel, kill everyone else but keep her here and everywhere always - in the past saving children, right at the very end of time. Burn and burn until she was melted to the permanence of it, the pieces that had always been: mountain, rock, tower, and at the very end. Somewhere there would be a building left that still stood alone in the darkness under a red sky - ash floating, and that's where she could be, her face still broken and her body remade over and over - tiny babies: Catherines coming out of Katherines coming out of Katies and Kittys and Cats. Kathys and Cathys and Katherines all about and around - until she got it right. Suckled by animals - rats, possums, anything else that survived, gnawing away at the afterbirth. A place held by some fiery order. But she was here now and cool, gently loosening her grip on the column. Looking for lightening in the sky. Nothing would ever surprise her again, not waste, not power, not failure. Not hope. 